\title{
FROM DISPARITY TO PARITY: \\ UNDERSTANDING THE BARRIERS TO INCLUSION OF PERSONS WITH VISUAL DISABILITIES IN THE DIGITAL REVOLUTION OF UGANDA
}

\section{DISSERTATION}

to obtain

the degree of doctor at the University of Twente, on the authority of the rector magnificus, prof.dr. H. Brinksma, on account of the decision of the graduation committee, to be publicly defended on Thursday $5^{\text {th }}$ of March 2015 at 12.45 hours

by

Abdul Busuulwa born on the $26^{\text {th }}$ of March, 1970

in Namagunga, Uganda 
This thesis is approved by:

Promotor: Prof.dr. J.C. Lovett

Co-Promotor: Dr.ir. E.C.J. van Oost 
Members of the Committee:

\begin{tabular}{|c|c|c|}
\hline Chair/ Secretary: & Prof.dr.ir. A.J. Mouthaan & University of Twente \\
\hline Promotor: & Prof.dr. J.C. Lovett & University of Twente \\
\hline Co-promotor & Dr. ir. E.C.J. van Oost & University of Twente \\
\hline Member: & Prof.dr. S. Kuhlmann & University of Twente \\
\hline Member: & Prof.dr. N.E.J. Oudshoorn & University of Twente \\
\hline Member: & Prof.dr. M.E. de Bruijn & Leiden University \\
\hline Member: & Prof.dr. V.A.J. Frissen & Erasmus University \\
\hline Member: & Dr. B. Jæger & Roskilde University, Denmark \\
\hline Member: & Dr. J.S. Clancy & University of Twente \\
\hline
\end{tabular}

Colofon

(C) 2015 Abdul Busuulwa, University of Twente, Faculty BMS / CSTM

No part of this publication may be reproduced, stored in a retrieval system, or transmitted, in any form or by any means, electronic, mechanical, photocopying, recording or otherwise, without prior written permission of the author.

Print: Ipskamp Drukkers, Enschede

ISBN: 978-90-365-3847-3

DOI: $10.3990 / 1.9789036538473$ 



\section{Contents}

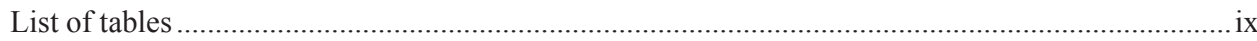

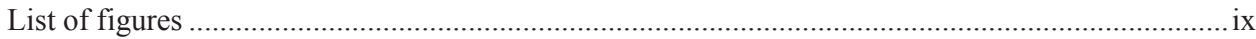

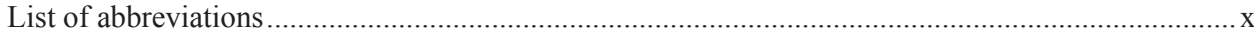

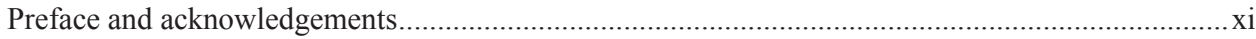

\section{Chapter 1 Introduction}

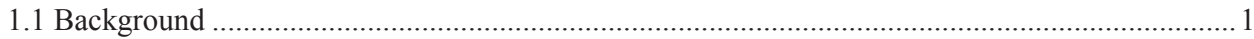

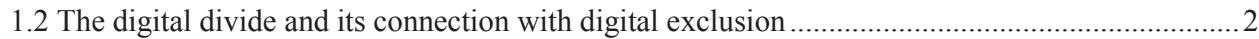

1.3 Technologies responsible for digital revolution and exclusion ..................................................... 4

1.4 The history of the digital revolution in Uganda ......................................................................

1.5 Models of disability and restriction to the use of ICTs ................................................................ 10

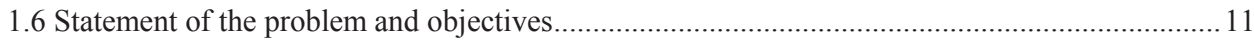

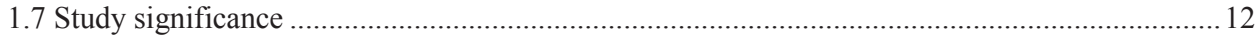

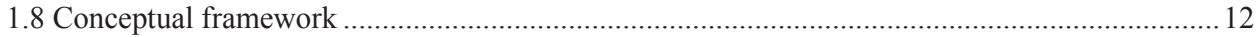

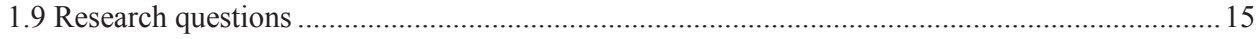

1.9.1 What are the barriers to the adoption of screen readers and screen magnifiers in Uganda?... 15

1.9.2 How does the cumulative and recursive model of successive kinds of access to digital technologies contribute towards understanding the constraints in digital technology inclusion for PWVDs in Uganda?.

1.9.3 How has the universal access policy in Uganda ensured access to ICTs for persons with

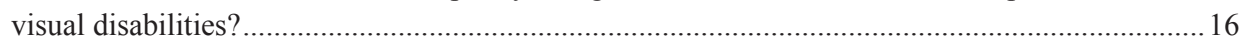

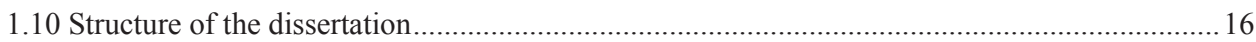

\section{Chapter 2 Literature review}

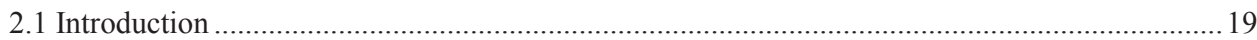

2.2 Technological barriers to the inclusion of PWVDs in the digital revolution ................................ 19

2.3 The human factors affecting digital inclusion of PWVDs in any given community...................21

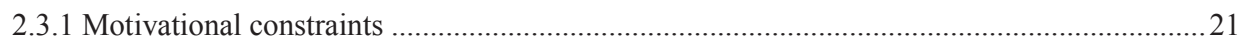

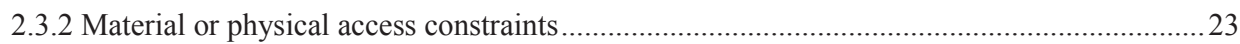

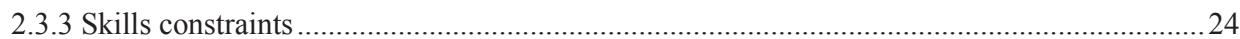

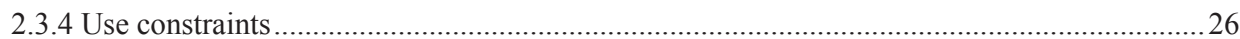

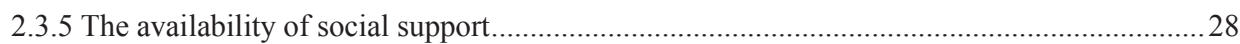

2.4 How demographic factors contribute to digital exclusion..........................................................2 29

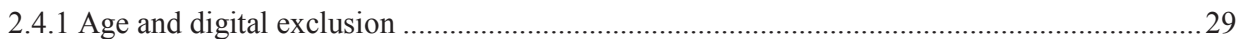




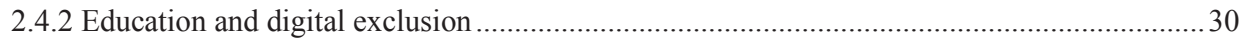

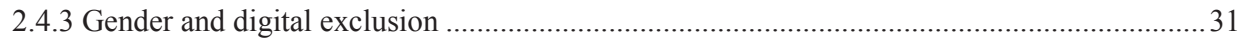

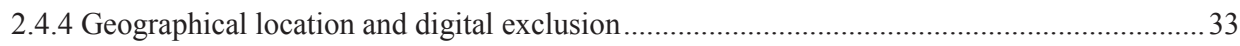

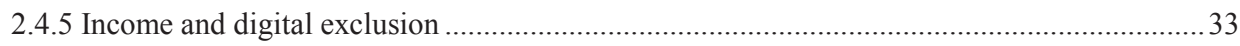

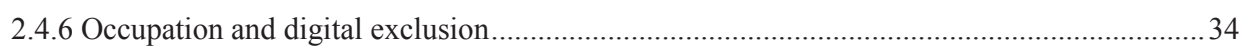

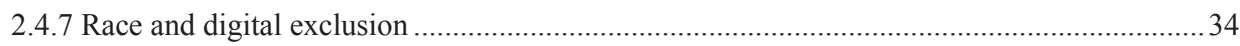

2.5 Existing gaps in universal access policies relating to the digital inclusion of PWVDs ................36

2.5.1 Universal access policy interventions in developed and developing countries .......................36

2.5.2 Universal access policy interventions for persons with visual disabilities ............................ 40

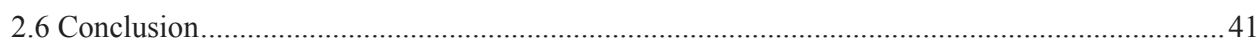

\section{Chapter 3 Methodology}

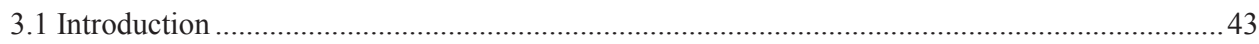

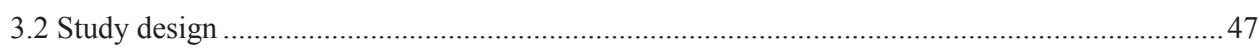

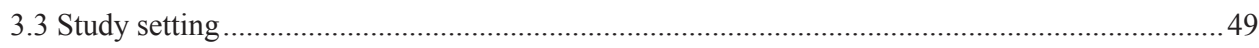

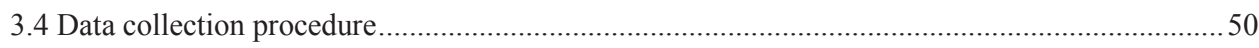

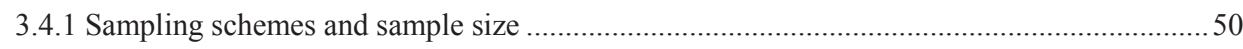

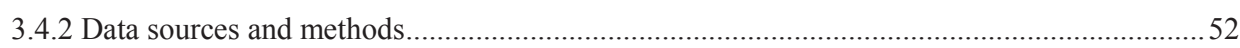

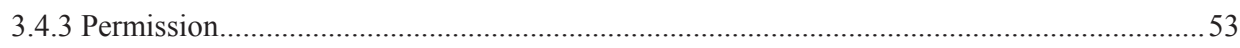

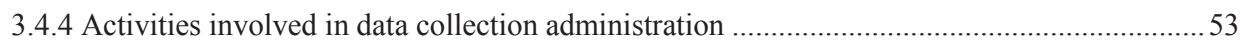

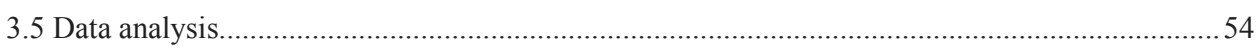

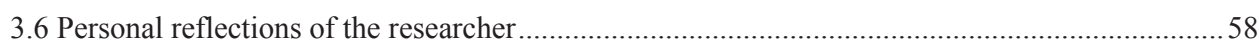

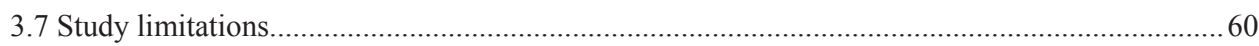

\section{Chapter 4 Barriers to the adaptation of screen readers and screen magnifiers by persons with visual disabilities in Uganda}

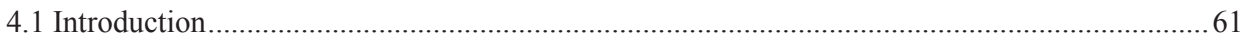

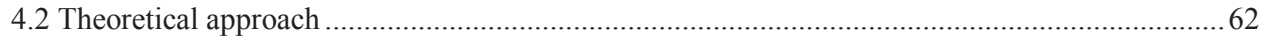

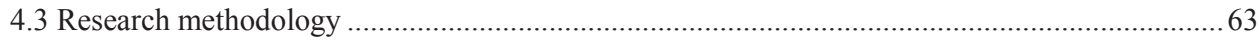

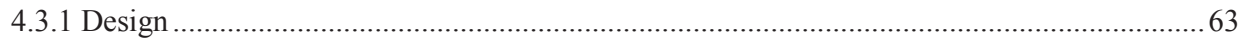

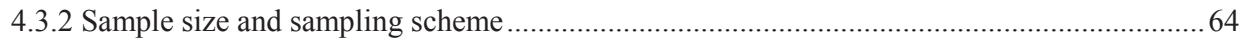

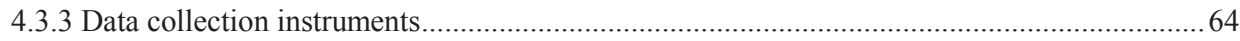

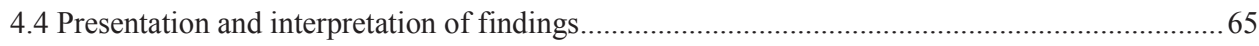

4.4.1 How innovation attributes affect the adoption of screen readers and screen magnifiers among persons with visual disabilities in Uganda...... 
4.4.2 How type of innovation-decisions would affect the diffusion of screen readers and screen magnifiers among PWVDs in Uganda

4.4.3 The effect of communication channels on the adoption of screen readers and screen magnifiers by PWVDs in Uganda.

4.4.4 How nature of social system may affect adoption of screen readers and screen magnifiers by Ugandans with visual disabilities

4.4.5 The role of ICT service providers in the diffusion of assistive technologies among Ugandans with visual disabilities .76

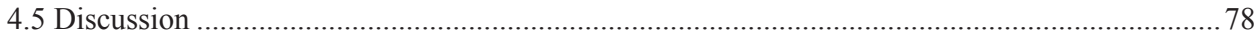

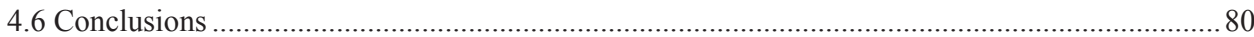

\section{Chapter 5 The human constraints towards digital inclusion for PWVDs in Uganda}

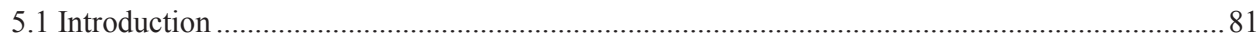

5.2 The cumulative and recursive model of successive kinds of access to digital technologies ........ 82

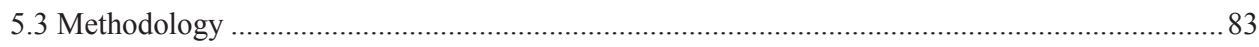

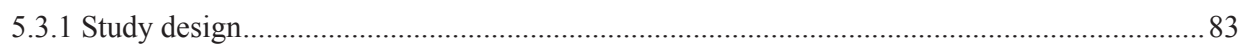

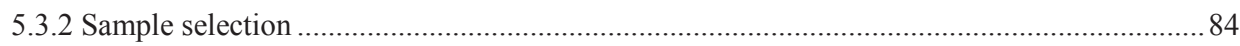

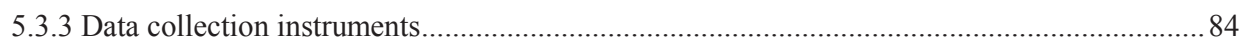

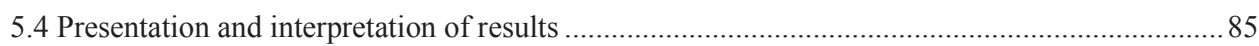

5.4.1 Motivational constraints PWVDs find in access to ICTs in Uganda ......................................85

5.4.2 Physical constraints towards access of ICTs by PWVDs in Uganda......................................92

5.4.3 Digital skills constraints of PWVDs in Uganda ................................................................... 95

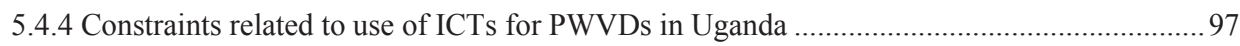

5.4.5 Importance of access to social support for persons with visual disabilities.......................... 100

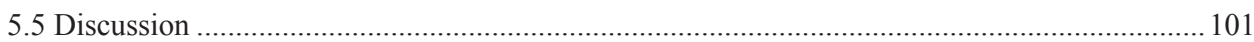

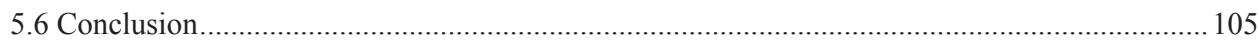

Chapter 6 The contribution of policy to digital inclusion of persons with visual disabilities in Uganda

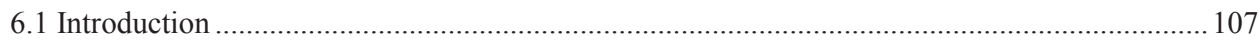

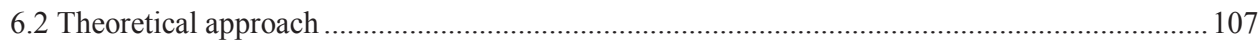

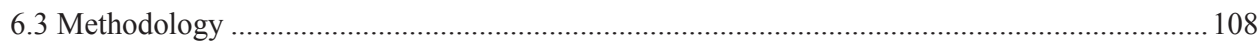

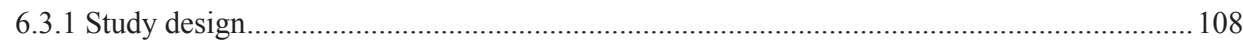

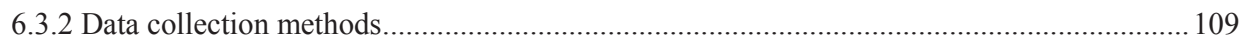

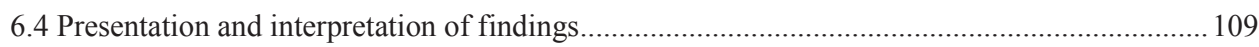

6.4.1 How the principles of affordability and availability of universal access cater for the digital needs of persons with visual disabilities in Uganda 
6.4.2 How lack of accessibility in universal access affects the digital inclusion of persons with visual disabilities in Uganda

6.4.3 The qualities of the new digital media and their effects on how PWVDs benefit from universal access in Uganda

6.4.4 Discussion

6.6 Conclusions

\section{Chapter 7 Conclusions and recommendations}

7.1 Introduction 125

7.2 Conclusions

7.2.1 Conclusions on the adoption of screen readers and screen magnifiers by PWVDs in Uganda

7.2.2 Conclusions on the human constraints for PWVDs in accessing ICTs

7.2.3 Conclusions on the Universal Access Policy to the digital inclusion of PWVDs in Uganda130

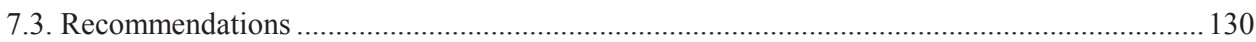

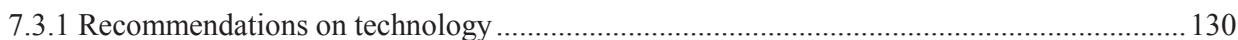

7.3.2 Recommendations to alleviate human and policy barriers to the digital inclusion of PWVDs

7.3.4 Recommendations for further research

List of references

Summary in Dutch

About the author 149

Appendix 1: Questionnaire for respondents with visual disabilities

Appendix 2: Interview guide for ICT service providers.

Appendix 3: Letter for Abdul

Appendix 4: Survey questionnaire for respondents with visual disabilities 163

Appendix 5: Interview protocol for respondents conversant with ICTs 165

Appendix 6: Interview guide for knowledge experts 170 


\section{List of tables}

Table 1.1: Growth in Ugandan ICT infrastructures between 1996 and 2003

Table 3.1: $\quad$ Presenting the nine characteristics of Mixed Methods Studies 44

Table 4.1: Commonly used assistive technologies for computers 66

Table 4.2: Commonly used assistive technologies for mobile phones 66

Table 4.3: $\quad$ Prices of some common assistive technologies $\quad 67$

Table 4.4: $\quad$ Time since respondents adopted assistive technologies $\quad 71$

Table 4.5: $\quad$ Frequency distribution for ICT usage in terms of age 74

Table 4.6: Frequency distribution for usage of assistive technologies in terms of $\begin{array}{ll}\text { level of education } & 74\end{array}$

Table 4.7: $\quad$ Showing the different sources of assistive technologies $\quad 77$

Table 5.1: Likert scale scores for CSE and computer training types for respondents $\quad 87$

Table 5.2: $\quad$ Likert scale scores for ISE and internet training types for respondents $\quad 88$

Table 5.3: Cross tabulation of CSE and time spent after computer training 89

Table 5.4: Cross tabulation of ISE and time spent after computer training 90

Table 5.5: Places where respondents accessed computers and the Internet 92

Table 5.6: Cross-tab of age and access to ICTs 93

Table 5.7: Cross-tab of occupation and access to ICT 93

Table 5.8: Cross-tab of level of education and access to ICT 94

Table 5.9: Cross-tab of income and access to ICT 95

Table 5.10: $\quad$ Years when respondents began using the different ICTs 97

Table 5.11: Sources of ICT skills for respondents 101

Table 6.1: ICT related achievements of the first phase of the RCDF 111

\section{List of figures}

Figure 1.1: Framework of factors affecting use of ICTs by persons with visual disabilities 13

$\begin{array}{lll}\text { Figure 3.1: } & \text { Presenting the overall design for the Study } & 48\end{array}$

Figure 3.2: $\quad$ Sampling design for this research $\quad 50$

Figure 4.1: Variables determining the rate of adoption of innovations (Rogers, 2003) 63

Figure 5.1: Connections between the four components of the access model 82 


\title{
List of abbreviations
}

\author{
APRM African Peer Review Mechanism \\ CRPD Convention on the Rights of Persons with Disabilities \\ DPO Disabled People's Organisation \\ EDGE Enhanced Data rates for GSM Evolution \\ GPRS General Packet Radio Service \\ GSM Groupe Speciale Mobile \\ IBM International Business Machines \\ ICTs Information and Communication Technologies \\ ITU International Telephone Union \\ LDC Least Developed Country \\ MMR Mixed Methods Research \\ NGO Non-Governmental Organisation \\ NITA-U National Information Technology Authority - Uganda \\ NTIA National Telecommunications and Information Administration \\ PWDs Persons with Disabilities \\ PWVDs Persons with Visual Disabilities \\ RCDF Rural Communications Development Fund \\ RCDP Rural Communications Development Policy \\ SMS Short Message Service \\ UCC Uganda Communications Commission \\ UMTS Universal Mobile Telecommunications System \\ UNAB Uganda National Association of the Blind \\ UNHS Uganda National Household Survey \\ VSAT Very Small Aperture Terminal \\ WHO World Health Organisation \\ WSIS World Summit on the Information Society
}




\section{Preface and acknowledgements}

My journey to this $\mathrm{PhD}$ on understanding the barriers to digital inclusion of Persons with Visual Disabilities in Uganda started off at the time when I was undertaking a Bachelor of Arts with Mass Communication degree, where technology was a key determinant of my performance. It was a requirement for all the students of Mass Communication to use a manual typewriter and tape recorder when doing course assignments. We were also supposed to learn how to use computers, but I personally missed that opportunity because of lacking a text-to-speech software (screen reader) that could enable me perform the input and output functions of this technology effectively. In other words, lacking a screen reader made it impossible to use the keyboard and read what would be displayed on the screen.

After the Bachelors I worked briefly as a freelance journalist with two newspapers but the technology challenge, mixed up with negative attitude from potential employers, prevented me from confirming this as my employment career. Due to the inability to use a computer and the Internet, I could neither be given a full-time job with any media house nor progress to the level of an editor where I would do most of my work in one place and not perpetually run around in the news-reporting role I was doing as a freelance journalist. About five years later I got an opportunity to learn using a computer under the tutelage of a Canadian instructor who was invited to the country by Uganda National Association of the Blind (UNAB). This was a rare opportunity to appreciate what a screen reader would add to my capability to use ICTs as a Person with Visual Disability. By then I was a Development Worker, and this computer training gave me tremendous improvement in my job performance through writing and submitting reports on time, developing my own workplans and reading any literature I obtained from anywhere in soft copy.

When I decided to do a masters in Management Studies from the Uganda Management Institute, the aim was initially to strengthen my foothold in social development work. But I found myself engaging in a field research as part of the management course, which took me to investigating the factors that were responsible for the job performance of Employees with Disabilities in Uganda. Of these Information and Communication Technology came out quite strongly as one of the factors responsible for good performance, and employees with visual disabilities expressed lack of this as a big challenge in their employment careers. This finding increased my passion for finding out more about how lack of ICTs became a barrier in people's employment. A few years later I attended the Africa Forum for the Blind in Nairobi, whose theme was an inclusive community. That's when I realized that ICTs were the most important barrier persons with visual disabilities had to overcome in order to improve their prospects for inclusion in the community both as learners in school and workers in organisations. I made some preliminary discussions with people, which revealed that the high costs of acquiring screen readers was the biggest hindrance to enabling persons with visual disabilities use them wherever and whenever they wanted so. But none of them talked about the cost of screen magnifiers, which meant that such technologies were either difficult to use or there was overwhelming ignorance in the country about their existence.

I was finally lucky to apply for and win a scholarship with the International Fellowship Program of Ford Foundation with which I secured admission to the Centre for Sustainable Technology and Management (CSTM) of University of Twente. While here, in order to enrich my scholarly understanding of how lack of ICTs became a barrier in the life of a person with visual disability I got exposed to several concepts that would explain the need for ICTs to be accessible. Two of these 
include Universal Design and Assistive technology. I particularly looked at the technology barriers that Persons with Visual Disabilities would face in the use of ICTs, which were actually more than simply the cost of screen readers and screen magnifiers. Later I extended the research into other barriers like policy and personal factors preventing the use of ICTs by PWVDs. These give a more holistic picture to the factors responsible for the exclusion of Persons with Visual Disabilities from the world of digital technology.

In all this I wish to acknowledge the support from my family, particularly my brother Ali Lwanga and my sister Ashar Nakawuma, who were always ready to look after my home whenever I was away in the Netherlands pursuing my doctoral studies. I also wish to extend my sincere thanks to my wives, Tausi Nagawa and Joweriya Hood, and my children, Abdulswabur Busuulwa and Usrah Nansereko, who had to endure my frequent absence from home as a result of fieldwork and study trips to the Netherlands that usually ran into several weeks and months.

Thanks also go to my main promoter, Professor Jon Lovett, and the co-promoter, dr. Ellen van Oost, who encouraged me to undertake this research even amid several financial and theoretical challenges. Both were always there to give me the professional guidance I needed to carry on with this dissertation. In the same vain I wish to acknowledge the support I got from one senior lecturer at Kyambogo University, Dr. Ali Ayub Baguwemu, who really assisted me a lot in understanding the theoretical options I could take for my research; and to peer review my work so I did not veer off the correct path.

Throughout the years, several staffs at CSTM also gave me invaluable support without which studying in the Netherlands would have been pretty hard. This support entailed even the most basic personal help like taking me for shopping at grocery stores, booking for accommodation I would find easy to navigate to and from as a person with visual disability on daily basis, giving me the initial guidance to several places around the university, and to identify for me journal articles and books, especially whenever I lacked the appropriate online registration to the university library while in Uganda. Of special mention in this regard include Annemiek van Breugel, Ada Krooshoop and Barbera van Dalm-Grobben.

Finally, let me acknowledge the vital support I got from my research assistants - John Miiro and Aisha Namirembe - who were always ready to undertake any assignment I brought to their attention without considering how much or when I would pay them. Their support was most important during fieldwork, where they recorded for me data on questionnaires and took field notes that I found quite useful in my subsequent analysis in the research. John was even a technical expert who usually entered my quantitative data into SPSS and did the relevant analysis to enable me come out with the right interpretations and conclusions in my research. 


\section{Chapter 1 Introduction}

\subsection{Background}

Information and communication technologies (ICTs) have revolutionized the way humans communicate with each other. ICTs particularly offer enormous opportunities to Persons with Disabilities (PWDs), as they provide them with ways of communicating that might be otherwise denied in traditional communication methods. But if ICTs are not designed for PWDs, then it can become a barrier. For PWDs in developing countries this barrier is twofold as it includes, apart from design, all the disadvantages inherent in the developing world, such as difficulty of gaining good internet access. Because PWDs constitute a complex and heterogeneous group, this dissertation explores the nature of opportunities and barriers for Persons with Visual Disabilities (PWVDs) using ICTs in Uganda.

The current trend is such that more everyday commercial and public services, which were once conducted through face-to-face interactions, are getting transferred online. In most cases registering a student for school, filing taxes, applying for social benefits, banking, and performing numerous other tasks requires use of the Internet (Jaeger, 2012). Another remarkable trend is that when there are physical and virtual equivalents, the online versions often offer lower prices, greater selection, home delivery, and other conveniences (Jaeger, 2012). These trends underline that full ICT access for PWDs will become more and more crucial for their equal societal participation.

These developments must have been a strong reason behind the commitment of the World Summit on the Information Society (WSIS) to turn the digital divide into a digital opportunity for all, particularly for those who risk being left behind and being further marginalized. The WSIS was held in two phases of December 2003 and November 2005 in Geneva and Tunis respectively, following a recognition of the fundamental role information and communication technologies (ICTs) can play in promoting economic growth, social development and cohesion, as well as a sense of cultural identity (ITU \& UNCTAD, 2007). There was also the realization that ICTs can help create new jobs, while transforming firms and streamlining work practices. But even before that there were several other initiatives aimed at bridging the global digital divide, such as the Info Dev programme of the World Bank, which had been launched in 1996, aimed at financing small-scale projects designed to implement ICTs as part of broader development efforts; the United Nations eight Millennium Development Goals proposed in 2000, one of which was about making "available the benefits of new technologies - especially information and communication technologies" (Epstein, Nisbet \& Gillespie, 2011); and the establishment of the Digital Opportunity Task Force (DOT force) by the G8 leaders at the 2000 Kyushu-Okinawa Summit, which was aimed at integrating efforts to bridge the digital divide into a broader international approach (Report of the Digital Opportunity Task Force, May 2001).

All the above efforts were couched in technological determinism, which assumes that access to, and use of, ICTs is a panacea for some of the development problems plaguing countries and communities around the world. Examples of the solutions which digital technology would offer include increased productivity, improved decision-making, better policy-making, decentralization, reduced costs, 
increased revenues, integrated services, and more political participation (Helbig, Gil-Garcia \& Ferro, 2009).

However, technology is not a neutral artifact in society (Barzilai-Nahon, 2006). Rather it should be comprehended and explicated within a given context. It is part of daily politics and social life, and as such it should be approached as a social and behavioral phenomenon. Therefore, without delving into the practicalities of implementing the WSIS commitment, turning the digital divide into a digital opportunity requires contextualizing the efforts.

\subsection{The digital divide and its connection with digital exclusion}

The term 'digital divide' means different things to different people. Firstly, it defines the gap separating those individuals who have access to new forms of information technologies from those who do not (Gunkel, 2003; Dewan \& Riggins, 2005; NTIA, 1999). This results in a gap between information 'haves' and information 'have-nots'. This understanding of the digital divide had its origins in the United States in the mid-1990s and was widely used by bureaucrats, legislators, activists, and scholars (Helbig, Gil-Garcia \& Ferro, 2009). According to Barzilai-Nahon (2006), policy makers may gravitate towards single factors such as access to ICTs because they are convenient and easy to measure, and the measures can subsequently be used to influence public opinion since lay people can relate to them.

The second definition depicts a multidimensional phenomenon, taking into account more factors than just the binary classification of the digital divide. For instance, Norris (2001: p. 1), argues that the digital divide is a multidimensional phenomenon encompassing three distinct aspects: the global divide (referring to the disparity of Internet access between industrialised and developing societies); the social divide (concerning the gap between information rich and poor in each nation); and the democratic divide (signifying those who do, and those who do not, use the panoply of digital resources to engage, mobilise and participate in public life). This is alluded to by the OECD (2001), Dewan \& Riggins (2005), DiMaggio \& Hargittai (2001) and Hargittai (2002) who refer to first order effects (inequality in access to ICTs) and second order effects (the inequality in the ability to use ICTs among those who already have access) of the digital divide.

The third definition by Wei et al. (2011) is an improvement of the second. They present a three-stage illustration of the digital divide, the first being the digital access divide (the inequality of access to ICTs) proceeded by the digital capability divide (the inequality of capability to exploit ICTs) and finally the outcome divide (the inequality of outcomes, say learning and productivity, of exploiting ICTs). This definition of the digital divide is more to do with exacerbating already existing political, economic and social inequalities in society rather than the simple dichotomy of technology haves and have-nots.

In Europe, the term used to mean digital divide is e-inclusion (Helbig, Gil-Garcia \& Ferro, 2009), and it was one of the three strategic pillars of the i2 2010 plan - a plan for society with overarching goals of growth, employment, and quality of life. At that time the European strategy was to ensure that the benefits of the information society can be enjoyed by everyone, including people who are disadvantaged due to limited resources or education, age, disability, ethnicity, gender, and living in less favored areas. For third world nations, particularly in Sub-Saharan Africa, the digital divide is one component of a larger problem of information poverty, which in turn encompasses the lack of 
access to emerging ICTs, information infrastructure in general, skills to manipulate and use information, and basic educational and cultural barriers (Gebremichael \& Jackson, 2006). This is worsened by problems such as governmental censorship and control, lack of established information policies, and information illiteracy.

All the above definitions point to the digital divide as a complex and convoluted phenomenon to understand and it requires lots of effort to eliminate. Indeed the digital divide is far from being resolved and two strong and opposing views exist to explain this. One is that the digital divide simply reinforces long-standing social inequalities that have their roots in poverty and low expectations, and there is no necessity for policy intervention to achieve equal distribution of digital technologies. Scholars who agree with this view argue that the divide will go away on its own as more and more people continue adopting ICTs. For example, Compaine (2000) contends that: "The early adopters pay higher per unit costs that reflect lower production volumes of manufactured products - such as Personal Computers - or start-up costs of services, such as Internet access via cable system. But as production builds, unit costs decline, product costs decline and manufacturers are able to lower prices." Indeed the diffusion of ICTs in most developed countries has reached near universal access following the provision of free computers, Internet connections and training in ICTs at libraries, schools, cyber cafes and community telecentres. Even web-enabled mobile devices are more affordable.

The other view is that the digital divide is more permanent and will continue growing if nothing is done to stop it. Martin (2003), for example, after reanalysing data in the fifth NTIA report "A Nation Online: How Americans are Expanding their Use of the Internet", predicted that the digital divide could easily persist for a generation or longer. He premised his prediction on a polemic argument that the rapid increases in the use of computers and the Internet in the U.S. in the late 1990s occurred amid a robust increase in wealth and income, and amid a strong political commitment to address inequalities in computer access. Therefore, any dissipation in the political will or economic boom would result in only modest increases in the proportion of poorer households with computers or Internet access. As if to vindicate this second scholarly position even further, Hsieh, Rai \& Keil (2008) gave the following statistics: the OECD had ranked the U.S. 4th worldwide in 2001 in high speed Internet penetration but it slipped to $12^{\text {th }}$ position in 2006 . A similar ranking by the International telecommunication Union (ITU) showed the U.S. slipping from the $13^{\text {th }}$ position in 2004 to $16^{\text {th }}$ in 2005.

In whichever way the digital divide is defined, at the heart of it are ICTs, whose composition is also not universally agreed upon. The ICTs most studies on the digital divide refer to include personal computers and the Internet. However, the term ICTs more accurately refers to an updating of the conventional 'information technology' to encompass the rapid convergence of technologies such as computers, telecommunications and broadcasting technologies, as well as stressing the communication and networking capacity of modern-day information technologies. Thus ICT is best seen as an umbrella term for a range of technological applications, such as computer hardware and software, digital broadcast technologies, telecommunications technologies such as mobile phones, as well as electronic information resources such as the world wide web and CD-ROMs (Selwyn, 2004).

Many studies on the digital divide (say OECD, 2001; Norris, 2001) have used demographic and socioeconomic factors as indicators of the disparities in access to and use of ICTs. Thus, the people most likely to be on the wrong side of the digital divide are those with low incomes, ethnic minorities, those living in rural areas, the illiterate, the unemployed, Persons with Disabilities (PWDs), the 
elderly and women. But by far PWDs present the most complex relationship to the digital divide. On one hand they are commonly regarded as having the most to gain from ICTs (computers and the Internet). For example according to Kaye (2000), those who have difficulties leaving their homes can $\log$ in and order groceries, shop for appliances, research health questions, participate in online discussions, and catch up with friends or make new ones. On the other hand, the presence of disability is often a direct cause of exclusion of individuals from using ICTs because PWDs harbor all the other conditions mentioned.

For purposes of specificity, this dissertation aspires to contribute to the elimination of the digital divide through a simpler term of "digital exclusion" used by Macdonald \& Clayton (2012). In this regard, digital exclusion refers to a lack of access to and use of information and communication technology resources. The dissertation also examines the barriers to digital inclusion of a single disability (persons with visual disabilities). This is so because there is no single solution for curing digital exclusion of PWDs as a heterogeneous group. For example, a web-enabled device with a touch screen may seem like a miracle to a user with a hearing impairment and a nightmare to a user with a visual impairment (Jaeger, 2012). Equally so, people with a hearing impairment would require visual captioning while those with a visual impairment would need audio descriptions of the visual content, if both must achieve full enjoyment of digital television.

Visual impairment means that the visual acuity (sharpness of vision) of a person is 20/200 or worse, or his/her visual field (the total area in which perception is possible while looking straight ahead) is less than 20 degrees in the best eye after correction (Vanderheiden \& Vanderheiden, 1991). The World Health Organization (WHO) estimates that about 284 million people are visually impaired worldwide, out of whom 39 million are completely blind and 245 have low vision (WHO Visual Impairment and Blindness, 2012). In addition, approximately $90 \%$ of people with visual impairment live in developing countries (WHO, 2012).

This dissertation prefers using 'visual disability' to 'visual impairment' because the former is what describes restriction. Not all people who are labeled as visually impaired actually carry the disability of being totally blind or having very low vision.

\subsection{Technologies responsible for digital revolution and exclusion}

What is considered responsible for the digital revolution around the world are computers, mobile phones and the Internet that evolved into powerful communication and information tools of today. On a general note, these technologies started off as complex office machinery or sophisticated gadgets targeted at a few special consumers but were later adopted by the general public at a faster rate than had been anticipated. That massive diffusion is what again contributed to exclusion of some people. This section provides a concise overview of the main development of these technologies.

As for computers, their early use was limited to complex calculations and repetitive data handling tasks.. Rogers \& Malhotra (2000) argued that computers could have developed in a quite different way had four of its pioneers (Vannevar Bush, J.C.R. Licklider, Robert W. Taylor and Douglas C. Engelbart) not articulated a vision that entailed computers as communication devices. This shift is of particular importance for understanding the computers role in the digital revolution and the exclusion dynamics. The first computer pioneer Vannevar Bush not only contributed to developing machines for complex calculations (e.g. the differential analyzer in the 1930s), in 1945 he also developed 
conceptually a computing device called the 'memex'. The memex can be seen as a conceptual blueprint for a desktop computer: "Bush's thinking dealt with the symbiosis between humans and computers. His memex machine would access and store vast knowledge for use by human beings in order for them to cope with an information overload" (Rogers \& Malhotra 2000, p.11).

The second visionary pioneer, J.C.R. Licklider was originally an acoustical psychologist. Licklider had a revolutionary vision of networked computers communicating with each other. He developed the notion of time-sharing. Rogers \& Mahotra (2000, p.11) mention that a strong initial opposition by the leaders of the computer industry: "They felt that computer technology was too valuable to waste on communication." From the early 1960s Licklider developed a future vision where the interaction between humans and computers stood central. He saw a future "in which computers would help citizens" and would free humans from "clerical and mechanical tasks" so they could devote their time to "innovative and creative thinking" (Rogers \& Malhotra 2000, p. 11) Licklider's vision on the 'mancomputer symbiosis' was supported and implemented by Robert W. Taylor, the third pioneer who introduced the visual display. Taylor started his career as a research manager at NASA in 1962, where he funded research on interactive computing and computer applications related to communication. To Taylor, the computer's visual display was the most important part of a computer. The function of the rest of the electronic equipment was to deliver what appeared on the computer's screen. Taylor and Licklider wrote together in 1968 a seminal article on the computer as communication device, in which they stated: "In a few years, man will be able to communicate more effectively through a machine than face to face" (quoted in Rogers \& Malhotra 2000, p.10).

The fourth and last visionary is Dr. Douglas C. Engelbart. His ideas were similar to Lickliders, as he too believed that computers should perform as a powerful auxiliary to human communication. Engelbart argued "that computers could manipulate human language and that individuals could use computers as communication tools to extend their human abilities" (Rogers \& Malhotra 2000, p.14). Perhaps the most important contribution to the computer communication of Engelbart was his design of a new computer interface technology, the computer mouse. This device could be controlled by one hand. By moving the mouse the user was able to direct a computer cursor and by clicking one of the three buttons command could be communicated to the computer.

To conclude, these four visionaries have developed in the 1960s the conceptual and material building blocks for the further development of the computer as a communication device, where humancomputer interaction would become central.

To gain insight into the broader societal diffusion of computers, a shift towards the role of computer producers is needed. The role of IBM (International Business Machines) has been crucial in the early period. IBM was in the 1930s and 1940s a big player in the field of mechanical business machines. The company started to manufacture computers for universities and business customers in the 1950s, and it went on to dominate the global computer market for the next three decades (Hovitz, 2003). An important reason for this dominance was IBM's strategy of selling and leasing its computing hardware and software as an integrated package. This dominance was broken when the U.S. Federal Trade Commission, in 1969, accused IBM of being anti-competitive by discouraging its customers from going to other suppliers for enhancing their computer hardware and software (Hovitz 2003) When IBM agreed to let its customers buy software from other companies, implied that they had to release details of how their hardware worked so that non-IBM programmers could write runnable software. This established a precedent for 'open standards' in computer design and enabled off-theshelf software to emerge as a commercially viable product (Hovitz, 2003). Soon other companies such 
as Apple, Atari and Commodore started and began to design and build personal computers and sell them already assembled.

The release of MS-Dos in 1980 and the reverse-engineering of IBM's Basic Input and Output System (BIOS) by Compaq and Phoenix Technologies Ltd., enabled other computer manufacturers to build relatively cheap clones. This dynamics led to the development of personal computers that became affordable for an average consumer. The diffusion of personal computers grew exponentially with 615 million computers in the whole world by end of 2002, up from 120 million in 1990 (UN Millennium Project, 2005).

For the Internet, its prototype was implemented in 1969 as ARPANET, originally built as a defense and research network. Although ARPANET allowed participants in a communication system to interact across large distances at minimal cost, it was restricted to the community of ARPA-funded computer scientists who had developed it (Rogers \& Malhotra, 2000). However, ARPANet was only one among the 'network of networks' that soon became known as the Internet. Braman (2012) argued that also the French CYCLADES was of particular importance for Internet design, as well as a number of other technical innovations such as the commercial packet switching standard developed in the mid-1970s by data networking groups in Canada, the US, UK and France, and the first Internet search engine, Archie, which was developed at McGill University in Montreal in 1990.

The first International Conference on Computer Communication was held in Washington DC in October 1972 (Rogers \& Malhotra, 2000) but the widespread use of the Internet only started after the creation of the World Wide Web in 1989 by Tim Berners-Lee, a British researcher at the CERN Laboratory in Geneva. In 1993 two computer science students, Marc Andreessen and Eric Bina, at the University of Illinois developed the first graphical interface, Mosaic, that made the Web much easier to use. Mosaic was the forerunner to Netscape, a commercially available browser that made the Internet more accessible to the user with the point and click of a computer mouse. Gradually, millions of homepages were created on the Web, containing an unmatched information resource that attracted large numbers of people. Following this popularization of the World Wide Web, the Internet population surged from about 3 million worldwide users in 1994 to more than 400 million in late2000 (Norris, 2001). Nowadays, late 2014, almost 3000 million users worldwide have internet access (www.internetworldstats.com).

Turning to mobile telephony, today the mobile phone is a portable device that simultaneously surfs the web, stores digital media, works as a computer, stores and plays audio and video, takes digital pictures, works as a phone, provides navigation, and performs many other functions (Jaeger, 2012). This functionality was unpredictable three decades ago.

According to Morris (2006), the first mobile phone networks evolved from the technologies used in specialist mobile phone radio systems, such as train cab and taxi radios, and the closed networks used by emergency and police services and similar military systems. The first public network open to subscribing customers rather than restricted to a dedicated group of private users, was the Autoradiopuhelin (ARP, or car radio phone) network in Finland. This was successfully launched in 1971 by the Finnish state telephone company and peaked in 1986 at around 35,000 subscribers.

The first cellular telephones were first offered to American consumers in 1983 (Rogers, 2003). The early adopters were primarily male executives whose companies provided them with phones as an office perk (Rogers, 2003). At that time, a cellular phone cost about $\$ 3,000$ and was a large 
rectangular object about the size of a brick. The companies that introduced mobile phone services in the United States were Motorola and AT\&T. European networks for mobile phones were opened in 1985 in the UK (Vodafone), Italy, Spain and France. Germany had already introduced its own system in 1981. In Japan, a limited car-based mobile phone service was introduced in 1979 by Nippon Telegraph \& Telephone the Japanese not-yet privatized telecommunications monopoly, but wider roll-out was held back until 1984. Japan introduced in 1991 a new Total Access Communication System (TACS) (Morris, 2006). This and all the other systems mentioned above were cellular-based, analog networks, so-called first-generation $(1 \mathrm{G})$ mobile phone networks.

The development of the second-generation (2G) networks began in 1982 when the Groupe Speciale Mobile (GSM) project was initiated by the European Telecommunications Standards Institute (ETSI), to standardize a next-generation mobile phone technology (Morris, 2006). The European Commission endorsed the GSM standard in 1984. GSM reflected according to (Morris 2006, p.4) "a deliberate social as well as economic goal: that of enabling seamless communications for an increasingly mobile phone world as part of the wider project to create a unified Europe." The new politics of deregulation was an important factor in the emergence of new mobile phone networks rivaling the monopoly of traditional telecommunications providers.

Soon the quality of mobile phone services improved, the price of a cellular phone dropped steeply (to $\$ 200$ or less), and the product became so small that it could fit into a shirt pocket (Rogers, 2003). Cell phones became a fashion statement, with Nokia, the Finnish company, first capitalizing on this new perception of mobile telephony. Colour and shape became increasingly important features of mobile phones, adding to the responsibility for their rapid diffusion. By 2004 there were 152 million mobile phone users in the U.S. alone and 1 billion users worldwide (Ling, Hwang \& Salvendy, 2007). Rice \& Katz (2003: p. 601) also provided some useful statistics on the diffusion of mobile phone. They pointed out that by 2003 approximately $95 \%$ of all nations had mobile phone networks, and the majority of the world's countries had more mobile phone subscribers than fixed landline ones. In addition, many households in both the developed and developing world only had mobile phone service. In some cases well-to-do people in the U.S. were the ones forgoing their landline services and keeping only mobile; yet in the developing world the poorest population segments were often the earliest adopter of mobile telephone.

In the first years of the 21th century, the development of the third-generation (3G) mobile phone networks enabled mobile phones to link to the Internet "by introducing fully packetized mobile phone networks" (Morris 2006: p.5). 3G technologies include GPRS (General Packet Radio Service), UMTS (Universal Mobile Telecommunications System) and EDGE (Enhanced Data rates for GSM Evolution). Packetization allowed to unify the mobile phone networks with IP (Internet Protocol)based data networks. 3G phone users have direct access to the Internet with the Internet content formatted appropriately for the small screen of the phone. The $3 \mathrm{G}$ network brought mobile phones into the realm of the Digital Divide.

\subsection{The history of the digital revolution in Uganda}

The first global Digital Access Index (DAI), covering a total of 178 economies, ranked Uganda in the lowest category - low access economies - including countries that were the poorest in the world and most of them were Least Developed Countries (LDCs) (ITU Telecommunication Development 
Bureau, 2003). The DAI was built around four fundamental factors - infrastructure, affordability, knowledge and quality - that impact a country's ability to access ICTs.

Computers were introduced to Uganda in 1967 by Uganda Computer Services, an organization set up to provide data processing services to government and public sector organizations operating at that time (Kasusse, 2005). This meant academics, students and other professionals were not part of the arrangement to entrench computer literacy in the country.

Nowadays the variety of computer users in Uganda includes both large organizations and individuals. Computer training schools have mushroomed in towns, while universities and certain schools also have added computer training elements to their curricula (Kasusse, 2005). However, access to computers by 2005 was at just $3.5 \%$ in urban homes, and only $0.4 \%$ in the rural areas where the majority of Ugandans live. The national overall penetration was $0.7 \%$, giving an estimate of 182,000 computers for 26 million Ugandans at that time (Tusubira et al., 2005).

In regard to the Internet, Uganda was one of the first countries in sub-Saharan Africa to obtain a full Internet connection. The private company, Info Mail was the first provider, establishing a VSAT (Very Small Aperture Terminal)-based service via an Intersputnik satellite to MSN in the United States in 1995 (Kasusse, 2005). This Internet Service Provider (ISP) later merged with another one, Starcom, a venture of US-based Starlight Communications whose VSAT link connected via Norway. The new company came to be called InfoCom, providing two redundant international links with a total of 1024 Kbps international bandwidth. By April 2001 the Uganda Communications Commission (UCC) had licensed 14 other ISPs.

Although Internet use has not been appreciated by many sectors (both public and private) as a strategic unit of economic transformation (Information Technology Policy for Uganda, 2010), it is slowly catching on as a medium of communication, business transaction and source of news. According to International Telecom Union, as cited by Internet World Stats (www. internetworldstats.com), Uganda had 40,000 Internet users in 2000 that raised to 500,000 in 2006 and $3,200,000$ as of June 2010 . This last number is $9,6 \%$ of the total Ugandan population of 33,3 million.

For e-governance, the government of Uganda is still the biggest consumer of IT services and user of related equipment. Major initiatives being implemented by government in this regard include: Integrated Financial Management System, Integrated Human Resource Management System, Local Government Information and Communication System, Uganda Revenue Authority Countrywide Network, e-tax Payment, Electronic Funds Transfer System, Community Information System, Integrated Personnel Payroll System and Land Information Management System. However besides email capability and web sites, most of these services do not allow for public interaction and thus limits the involvement of Ugandans in producing web content.

On the side of e-health, Uganda is a beneficiary of telemedicine through a programme known as HealthNet. This is a computer-based telecommunication system sponsored by SATELLIFE, a U.S.based charitable organization dedicated to connecting health professionals around the world (Gebremichael \& Jackson, 2006). But HealthNet is operational in only a few health centres, for example Mulago and Mengo Hospitals, yet there would be compelling justification for its expansion. For example, Uganda belongs to the Sub-Saharan Africa region, which is riddled with multiple medical problems, such as a large number of its people living with HIV/AIDS, high infantile mortality 
due to malaria, acute shortage of medical personnel (fewer than 10 doctors per 100,000 people on average), and the few available medical services are concentrated in cities.

As for e-learning, Uganda is hooked into the African Virtual University, a system for teaching at a distance (Kasusse, 2005). This is backed up by school net, an electronic-based teaching facility used by Makerere University. But if e-learning is to take shape in the country, school net should be enabled to trickle down to other tertiary institutions and lower schools in the Ugandan education hierarchy. In addition, more facilities similar to school net can be established to cater for existing gaps in elearning.

Turning to mobile telephony, the first mobile phone operator in Uganda was Celtel Uganda Ltd., which commenced its work in 1995 with a nation-wide coverage. However, this was not classified as a national operator until July 2001. Instead, two other telecom companies formed a duopoly carrying the title of national operators, designed to give incentives to private investors in the telecommunication sector. One of these was Uganda Telecom Limited (UTL) formed from taking over the telecommunication services of the former government-owned Uganda Posts and Telecommunications Corporation in 1996, and the other was the Mobile Telephone Network (MTN) from South Africa licensed to operate in Uganda in 1998.

The spread of mobile phones has created also a synergy with the spread of private FM radio stations. With more than 200 operational stations in Uganda, radio provided near total national coverage in local languages (Tusubira et al., 2005). Whereas radio used to be a passive tool for development information dissemination, it has now become an interactive public discussion forum through the popular phone-in programmes ranging from political debates to other topical issues in health, agriculture, education and the environment.

Table 1.1 provides an overview of the development of Ugandan ICT infrastructures. What is interesting to note is the differences in growth rate between fixed and mobile phones. In the period 1999-2003, the number of fixed lines was rather stable whereas the mobile subscribers has grown by a almost a factor 10 .

Table 1.1: Growth in Ugandan ICT Infrastructures between 1996 and 2003

\begin{tabular}{|l|l|l|l|l|l|l|}
\hline SERVICES PROVIDED & $\begin{array}{l}\text { Dec } \\
\mathbf{1 9 9 6}\end{array}$ & $\begin{array}{l}\text { Oct } \\
\mathbf{1 9 9 8}\end{array}$ & $\begin{array}{l}\text { Dec } \\
\mathbf{1 9 9 9}\end{array}$ & $\begin{array}{l}\text { July } \\
\mathbf{2 0 0 1}\end{array}$ & $\begin{array}{l}\text { July } \\
\mathbf{2 0 0 2}\end{array}$ & $\begin{array}{l}\text { June } \\
\mathbf{2 0 0 3}\end{array}$ \\
\hline Fixed lines connected & 45,145 & 56,196 & 58,261 & 56,148 & 54,976 & 60,995 \\
\hline Mobile Subscribers & 3,000 & 12,000 & 72,602 & 276,034 & 393,310 & 621,082 \\
\hline National Telephone Operators & 1 & 2 & 2 & 2 & 2 & 2 \\
\hline Mobile Cellular Operators & 1 & 2 & 2 & 3 & 3 & 3 \\
\hline Internet/Email subscribers & 504 & 1,308 & 4,248 & 5,999 & 6,600 & 7,024 \\
\hline International Data Gateways & 2 & 3 & 7 & 8 & 8 & 8 \\
\hline Internet Service Providers & 2 & 3 & 9 & 11 & 17 & 17 \\
\hline
\end{tabular}

Source: Uganda Communications Commission, 2003

According to Tusubira et al. (2005), the growth of the mobile telephone sector in Uganda in this period can be attributed to a number of factors:

- The provision of fixed line telephony services which, for many years, was riddled with inefficiency, unreliability and poor customer service. 
- Use of the pre-paid model that provides the freedom to make calls (and spend money) according to need.

- The ease of getting a telephone connection, and the resulting mobility.

The period between 2003 and 2006 was particularly significant with a multitude of governance initiatives for stimulating national ICT development. The government of Uganda drew up a National ICT Policy Framework, formed a parliamentary sessional committee on ICT, and established a Ministry in charge of coordinating, harmonizing and spearheading the development of ICTs in the country (APRM - National Commission for Uganda, 2008). Also economic measures were introduced such as the introduction of zero import duty on computers and their accessories in 2004. The Uganda Communications Commission (UCC) also stimulated rural ICT development by setting up a Rural Communications Development Fund (RCDF) that subsidized the installation of Internet Points-ofPresence to facilitate local Internet access and reduce usage cost. They also initiated more than 54 ICT training centres countrywide and installation of public payphones in selected sub-counties across the country.

In the period 2006 to 2010 had a new surge in ownership of mobile phone, it raised from $17 \%$ of the Ugandan inhabitants in 2006 to 46\% in 2010 (Uganda National Household Surveys (UNHS) 2005/06 and 2009/10). The dismantling of the duopoly of UTL and MTN in the communications sector in 2006 was an important trigger of this growth as this implied that three more telecom companies were licensed to be active on the mobile phone market.

To conclude, the Ugandan government actively undertook various ICT policies measures aiming to transforming Uganda into a digital country. Unfortunately, PWDs hardly featured anywhere in all these efforts. Therefore this study sought to focus on PWVDs, who were considered most susceptible to digital exclusion among PWDs, to find a solution to this irregularity.

\subsection{Models of disability and restriction to the use of ICTs}

There are three models of disability - the medical, social and integrated - that can be used to understand the restriction of use of ICTs by PWDs (Smart, 2009). The medical model takes disability to be pathology, disorder or deformity that is located within an individual. In this model disability can be classified, quantified, measured, and standardized. Thus many medical diagnoses include an evaluative rating using 'normality' as the standard of the severity of disability or degree of impairment. This has had far-reaching effects on the design and distribution of ICTs, where assistive technologies are encouraged only as correction to an individual's impairment to a state of normal functionality, just like the so-called normal people. The medical model stemmed from the work of an American theorist, Talcott Parsons, and his discussion of sickness and sickness-related behavior in 1951. For Parsons the normal state of being in western 'developed' societies is 'in good health'. Therefore sickness, impairment and disability are deviations from normality (Barnes, 2005; Woodin, 2012). Seen in this perspective, the medical approach to disability accords an unfair privilege to medical personnel and rehabilitation professionals to prescribe what is right for persons with disabilities.

The social model of disability, which was developed by PWDs themselves in reaction to the medical model, simply shifted the location of disability from individuals to society. Persons with disabilities thus averred that it is not individual limitations, of whatever kind, that are the cause of the problem, 
but society's failure to provide appropriate services and adequately ensure that the needs of disabled people are fully taken into account in its social organization (Oliver, 1990). Consequently, persons with disabilities experience this failure as discrimination entrenched throughout society.

The integrative model, owing to the complex and multivariate nature of disability, seems closest to what can appropriately represent the demands of all PWDs (including those with visual disabilities) in terms of technology. The integrative model is an attempt to bring together the positive aspects of the medical and social models. For instance, the combined successes of medicine, medical technology and pharmacology have greatly enhanced (and saved) the lives of many PWDs (Smart, 2009). On the other hand, the social model was quite instrumental in enabling PWDs to identify a political strategy towards removing disabling barriers from society. Furthermore, the social model of disability helped PWDs to understand that society, rather than themselves, was at fault. This enabled them to become empowered and mobilize, organize and work for equal citizenship (Shakespeare \& Watson, 2002). Using the lens of an integrative model therefore, it would be safer to say people are disabled by social barriers (social model) as well as by their bodies (medical model); rather than understanding disability solely on either of the two perspectives.

A new and emerging integrative model of disability has its clearest representation in the International Classification of Functioning, Disability and Health (ICF) by the World Health Organization (2001), which suggests that a disabled person's ability and extent to which he/she participates in any activity is influenced by three interrelated factors: the individual's impairment, the environment with which he/she interacts and his/her personal factors such as determination to succeed, self-esteem, motivation to work, etc.

\subsection{Statement of the problem and objectives}

Studies covering the digital divide would offer one of the best opportunities for understanding the digital inclusion or exclusion of PWVDs. However, many (for example Kaye, 2000; NTIA, 2000; Dobransky \& Hargittai, 2006; Guo, Bricout \& Huang, 2005; Kim \& Doh, 2006; Vicente \& Lopez, 2010) either stop at making comparisons between PWDs and non-disabled populations, or they simply include disability among other disadvantages related to age, education, income and race. The likely outcome from this non-disaggregation of PWDs into smaller and more specific groups is a gap in understanding their digital technology needs. In other words, the studies that have been pointed out here tended to subsumed Persons with Visual Disabilities (PWVDs) in the general rubric of PWDs, thereby failing to articulate their unique challenges in using ICTs.

The picture is not so different in Uganda. Here, apart from a few studies done on the general situation of PWDs, there is a general lack of understanding of the needs of PWVDs specifically in relation to ICTs. This excludes majority of them from the digital revolution of the country through the high cost of assistive technologies, lack of appropriate digital content, the challenge of learning new applications and technologies, and the general lack of knowledge about and appreciation of the potential usefulness of assistive technologies (Uganda Communications Commission, 2011). In addition, the laws and policies that constitute the Information Technology Policy framework of Uganda refer to PWDs in general terms, failing to explicitly articulate the specific needs of Persons with Visual Disabilities. 
Finally, so far there is no known study in Uganda that has been undertaken to understand the personal benefits and challenges PWVDs may find while participating in the digital economy. Lack of knowledge in this area is likely to lead either to PWVDs missing out on the socio-economic opportunities directly linked to using ICTs or to having no clear avenues for sorting out personal challenges related to the use of Information and Communication Technologies.

The overall objective of the study was to examine the barriers to digital inclusion of Persons with Visual Disabilities in Uganda.

Specific objectives are:

1. To investigate the technological barriers to the digital inclusion of PWVDs in Uganda.

2. To establish person factors affecting digital inclusion of PWVDs in Uganda.

3. To elucidate existing gaps in the Ugandan Universal Access policy relating to the digital inclusion needs of PWVDs.

\subsection{Study significance}

This research was conceived at a time when Uganda was undergoing a massive digital revolution characterized by the enactment of several laws and policies on the use of ICTs. This study is therefore intended to fill the knowledge gaps identified in order to inform government, civil society organizations and the business community on the appropriate measures for including PWVDs in the opportunities from the nascent digital revolution.

The academic significance of this study is a demonstration that the different types of disability need to be identified as specifically as possible when considering their technological needs; hence the singling out of Persons with Visual Disabilities in the dissertation. The current practice favours bundling PWDs together as if their needs are the same. Furthermore, this study aims to make a modest contribution to understanding the accessibility needs of PWVDs in relation to ICTs. This is so through emphasizing that PWVDs constitute a group of end-users of ICTs who are different from other disabilities and they should always be identified as such when considering their accessibility needs.

\subsection{Conceptual framework}

The conceptual framework that guided the current study was adapted from the International Classification of Functioning, Disability and Health (ICF) (World Health Organisation, 2001). The ICF model views disability as a functional limitation a person with an impairment (health condition) encounters when he/she interacts with contextual barriers (environmental obstacles and personal factors). The ability and the extent to which the person with visual impairment accesses and uses ICTs depends on the magnitude of those factors and their impact on the individual's ability to carry out activities related to use of ICTs. These factors affect each other in a two-way direction as the arrows in the figure below indicate. Figure 1.1 illustrates the ICF model. 
Figure 1.1: Framework of factors affecting use of ICTs by persons with visual disabilities

Indepedent variable

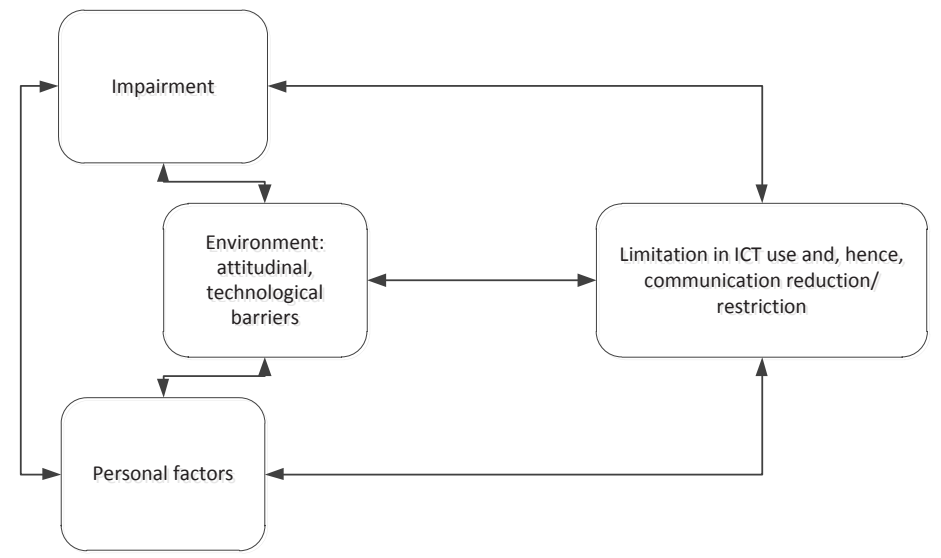

Adopted from the World Health Organisation, 2001

From the above model, disability is contributed to and manifested at three levels of functioning:

a) Body Level (impairment). This is a problem in body function or alteration in body structure - health condition. It is a specific decrement in body function and structure, often identified as a symptom or sign of health condition. Impairment in a body part (limb, organ, structure or system) is caused by disease, injury or disorder and it leads to a functional limitation in the affected part. Examples of impairments include paralysis, blindness, deafness or a combination of two or more of the above. The impaired part of the body has minimal or no capacity to carry out the functions for which it was created.

b) Person Level (activity limitations). Because of impairment the individual experiences activity limitations or considerable difficulties in carrying out activities that are related to the affected body part. For example a person with a visual impairment has little or no capacity for carrying out activities related to seeing. At the personal level there are other person related factors that may influence a person's inability to carry out activities of living. Such factors include negative self-image, low self-confidence, low level of self-efficacy, motivation and other personal factors. These can influence how much a person participates in society.

c) Societal Level (participation restrictions). At the societal level the person may experience participation restrictions in social activities - for example playing, employment, meeting, attending school etc. that is to say, s/he experiences problems with involvement in social activities and on the basis of that $\mathrm{s} /$ he may experience discrimination in employment or transportation. Further barriers within the physical and social environment may hinder activity participation by a person with disability. For example, the person may be excluded from such an activity as a meeting because s/he cannot reach the venue that is located in a place that is inaccessible by the person.

According to the ICF model disability is $\mathrm{A}+\mathrm{B}+\mathrm{C}$, i.e. impairments, activity limitations, and participation restrictions, respectively. It refers to difficulties encountered in any or all three areas of functioning. The ICF model contains a classification of environmental factors describing the world in which people with different levels of functioning must live and act. These factors can be either 
facilitators or barriers. Environmental factors include: products and technology; the natural and built environment; support and relationships; attitudes; services, systems and policies.

A person's environment has a huge impact on the experience and extent of disability. Inaccessible environments create disability by creating barriers to participation and inclusion. An example of a negative impact of the environment is a blind person using a computer without a screen reader.

Deriving from the above conceptual framework, this study identified three levels of restriction impairment, personal and societal - which were found likely to be barriers to the inclusion of PWVDs in the digital revolution of Uganda. Restriction at the impairment level centres on use enablers, which this study refers to as assistive technologies. Restriction at the personal level takes into account the personal characteristics of PWVDs that may prevent them from accessing ICTs. At the societal level the study is concerned with government laws and policies as well as international instruments, which may hinder access and use of ICTs by PWVDs. Each of the three levels of restriction are analyzed in this study from a specific theoretical framework, aiming at highlighting the core dynamics at each level. Below each framework will be concisely introduced. A further elaboration is given in each of the respective chapters.

At the impairment level, Rogers (2003) theory on 'Diffusion of Innovations' will be applied to gain insight into the diffusion of assistive technologies (screen readers and screen magnifiers) among PWVDs. This theory asserts that an innovation is communicated through certain channels over time among members of a social system (Rogers, 2003). The Diffusion of Innovations theory sets out five factors that are perceived to affect the rate of adoption of an innovation:

1. The perceived attributes of the innovation - relative advantage, compatibility, complexity, triability, and observability - which Rogers (2003) argues explain most of the variance in the rate of adoption of innovations, from 49 to $87 \%$. How Ugandans with visual disabilities perceive these attributes can be a barrier or enhancement to the adoption of certain ICTs.

2. The type of innovation decision. This was about whether the uptake of ICTs depended on individual decisions or some authority in the form of organizations, which would also affect the rate of adoption of ICTs.

3. The nature of communication channels diffusing the innovation. Here, attention was focused on whether the mass media (newspapers, radio or television) were involved in disseminating information about ICTs, or PWVDs relied on interpersonal communication.

4. The nature of the social system in which the innovation is diffusing. In this case it is Ugandans with visual disabilities. Here the degree of interconnectedness among members, any norms that bind them together, and a semblance of structure that can facilitate information dissemination regarding where and how to find specific ICTs, was considered.

5. The extent of change agents' promotion efforts in diffusing the innovation. Here the question was whether there were institutions committed to promoting the use of ICTs in Uganda or everything had been left to market forces.

At the personal level this study will use the cumulative and recursive model of successive kinds of access to digital technologies by Jan van Dijk (2005) to investigate four types of constraints towards access to ICTs by PWVDs. This model asserts that four successive and accumulative types of access motivation, material, digital skills and usage - mark the steps to be taken by individual users in the total process of appropriation of digital technology (Van Dijk, 2005):

1. Motivation is the starting point of access, where people who do not have digital technology should actually be persuaded to want it. 
2. Material access. After acquiring the motivation to get access, the next challenge for new users of ICT is to act on it by either purchasing a computer and Internet connection themselves, or they may use those of others.

3. Skills access, which brings in the necessity for knowledge to manage the hardware and software acquired at the material level of access.

4. Use access, which is concerned with the actual time someone uses the technology; and the number and diversity of usage applications.

In the course of this study, social support was found as an additional important access constraint but mediating across all the above four types of access. For instance, PWVDs start gaining from social support at the level of motivation to use ICTs, then to physically obtain the ICTs, acquire the skills to use ICTs and finally to make effective use of the ICTs. The ICF model (Figure 1.1) also hints at the relevance of social support as part of environmental factors.

At the societal level this study will use the critical disability theory to contest the role of both the medical and social models of disability in shaping policy on the digital inclusion of PWVDs. Critical disability theory states that politics and power are the key issues, rather than disability simply being a lack of the application of cures to health problems (Pothier \& Devlin, 2006). One dominant policy in the access and use of ICTs over time has been that of universal access, and this is the concept placed at the centre of this study. The research wanted to examine whether universal access as a policy gives PWVDs all they need to use ICTs.

\subsection{Research questions}

Based on the problem statement that was developed in this chapter, the general overarching research question of this study is:

\section{What are the barriers to digital inclusion of Persons with Visual Disabilities in Uganda?}

As has been outlined in this chapter, the concept of disability is complex and multi-layered. In consequence the overarching research question is broken down into three main sub-questions that reflect the three layers of restriction: impairment, personal and societal. The first sub-question deals with barriers to adoption of technology in the form of screen readers and screen magnifiers. The second sub-question explores the human dimension of access to digital technology. The third subquestion elucidates the role of policy, focusing on universal access. These three sub questions are dealt with sequentially in Chapters 4,5 and 6 . The sub questions are further broken down into questions that are tractable to analysis as presented below:

\subsubsection{What are the barriers to the adoption of screen readers and screen magnifiers in Uganda?}

- How do attributes of screen readers and screen magnifiers affect their adoption by PWVDs in Uganda?

- How does type of innovation-decisions affect adoption of screen readers and screen magnifiers by PWVDs in Uganda? 
- How do communication channels hinder or enhance the diffusion of screen readers and screen magnifiers in Uganda?

- What barriers does the nature of the social system impose on the rate of adoption of screen readers and screen magnifiers among PWVDs in Uganda?

- What contributions have ICT service providers made towards the adoption of screen readers and screen magnifiers by PWVDs in Uganda?

\subsubsection{How does the cumulative and recursive model of successive kinds of access to digital technologies contribute towards understanding the constraints in digital technology inclusion for PWVDs in Uganda?}

- What are the motivational constraints PWVDs find in access to ICTs in Uganda?

- What are the physical access constraints to ICTs for PWVDs in Uganda?

- What are the constraints to acquiring digital skills by PWVDs in Uganda?

- What are the constraints relating to use of ICTs by PWVDs in Uganda?

- What is the importance of social support in furthering access to ICTs for persons with visual disabilities?

\subsubsection{How has the universal access policy in Uganda ensured access to ICTs for persons with visual disabilities?}

- How do the principles of affordability and availability in Universal Access cater for the digital needs of persons with visual disabilities in Uganda?

- How has lack of accessibility in universal access affected the digital inclusion of Persons with Visual Disabilities in Uganda?

- How do qualities of the new digital media affect how Persons with Visual Disabilities benefit from universal access in Uganda?

\subsection{Structure of the dissertation}

The dissertation consists of seven chapters including this introductory one. The introductory chapter begins with giving the various definitions of the digital divide and tries to determine the one suitable for this research. It then goes on to trace the digital divide from how some key technologies have evolved over time, leading to what is now referred to as the digital divide. As the research was done in Uganda, it was also found vital that the chapter gives a snapshot of the history of how the digital revolution took shape in the country. Another key section of this chapter is the problem statement, which defines the problem to be tackled by the dissertation. The problem statement is immediately followed by an overall goal that is broken down into three objectives. These are further transformed into three main questions. Then a conceptual framework is given, which explains the theories upon which the study was based; hence the Diffusion of Innovations theory, the cumulative and recursive model of successive kinds of access to digital technologies, and the critical disability theory. Finally, the chapter ends with an outline of the structure of the whole dissertation as laid out in this section.

Chapter 2 is a literature review on two key approaches to digital inequality. It also compares the policies aimed at solving digital inequality in the developed world with those meant for the developing world. Since the main focus of this dissertation is in a developing country, a comparison 
would be relevant for finding effective solutions to the problem. The chapter concludes by identifying the gaps in knowledge that are addressed in the research chapters, 4, 5 and 6. The gaps in knowledge are addressed for each of the levels of restriction. For the technology level there is no clear evidence for how PWVDs access the appropriate types of screen readers and screen magnifiers they can use on computers and mobile phones. For the human level the clearest gap is the role of social support in enabling PWVDs to access ICTs. For the policy level the gap is that the knowledge that is available does not address the needs of PWVDs.

Chapter 3 describes the overall methodology of the dissertation. This has both quantitative and qualitative aspects of research, and these are largely of an exploratory nature. There is surprisingly little known about the barriers to diffusion and uptake of ICT by the visually disabled population in Uganda. In consequence, the research needed to start by gathering basic data using inductive approaches of interviews, questionnaires, observations and documentary analysis. Quantitative data obtained from the questionnaires was then used to test hypotheses derived from the theoretical literature surrounding the diffusion of innovations and the recursive model of access.

Based on the three layers of restriction, the dissertation then continues with three research chapters that present the original empirical work conducted for the dissertation. Chapter 4 explores the impairment aspect of restriction, zeroing in on adoption of screen readers and screen magnifiers as key assistive technologies necessary in the use of new ICTs by Persons with Visual Disabilities.

Chapter 5 tackles the personal factor aspects of restriction - motivation, material, skills and use which were found as key constraints in the access and use of digital technologies. Lack of social support was also identified as a major constraint in the access and use of ICTs for PWVDs, especially as it relates to acquiring the motivation and skills necessary for using ICTs as well as the material access of ICTs themselves.

Chapter 6 explores restrictions brought about by gaps in the laws and policies of the country. The chapter contends that such gaps emanate from the complex definition of disability influenced by both the medical and social models of disability. The policies fail to meet the needs of PWVDs because they only mention disability in general terms, without dealing with the special needs of this particular group. This highlights the heterogeneous nature of disability and the need for policy makers to be aware of the specific requirements of each sub-group of PWDs.

The dissertation ends with Chapter 7, which has the main conclusions and recommendations of the research. These cover all the major issues explored in the three empirical chapters and explain how the original research conducted for the dissertation answers the research questions. Recognizing that disability is a broad concept, anything not fully covered by this dissertation was left for research undertakings in the future, and clear recommendations were given to this effect. 


\section{Chapter 2 Literature review}

\subsection{Introduction}

This chapter briefly reviews the theoretical literature used to underpin this study. It also reviews existing work on digital inequality as a basis for understanding the barriers to digital inclusion of Persons with Visual Disabilities (PWVDs), and how such barriers can be mitigated using solutions of a technological, human and policy nature.

The essence of this review is to make a broader examination of the barriers to digital inclusion beyond what could result from the dichotomous classification of the digital divide, which is traditionally premised on technology 'haves' and 'have nots'. Supporting a broader view of digital inequality, Jung et al. (2001: p. 507) observed that "When a technology becomes a resource for attaining or maintaining higher status in society, as computer-based technologies have increasingly become, unequal access to such technology becomes more than a question of ownership. The question of unequal access must address whether there is an ability to maximize the utility of the technology for pursuit of various goals." For example, an individual can own a computer with an Internet connection but not know how to utilize it as a way of getting (or keeping) a high-tech job. Similarly, there are more things a high speed broadband Internet connection would enable someone to do, say video streaming or sharing photographs with friends, than a slow dial-up connection.

For PWVDs specifically, the above examples mean that efforts to diffuse the technologies that enable their access to the benefits of ICTs may not be successful if the capabilities of the target group are not also simultaneously raised. This is a perspective expanded upon in Section 2.3.3 of this chapter. Furthermore, policies are vital in enabling the citizens of any given community to access and use ICTs, which view is expanded upon in Section 2.5.

The chapter concludes with identifying gaps in knowledge that form the basis of the research in this dissertation. These range from technological to human and policy factors that should take into account PWVDs as a distinctive group of users of ICTs.

\subsection{Technological barriers to the inclusion of PWVDs in the digital revolution}

As pointed out in Chapter 1, PWVDs were singled out as one of the groups of persons with disabilities having greater vulnerability in terms of digital technology uptake. Visual disabilities generate special hardware and software demands, which make technological barriers significantly different from barriers other users of ICTs might experience.

As far back as 1998, the National Council on Disability (NCD) carried out a study in which it recognized the barriers people with sensory disabilities (including those with visual disabilities) face in using computerized multimedia technology and recommended actions that would reduce or 
eliminate them (National Council on Disability, 1998). As advances in computer and telecommunications technology made it possible to combine high-quality computerized video, audio, text and images into attractive and compelling multimedia presentations, people with sensory disabilities faced a troubling, uncertain future in which opportunities for employment, education and recreation were greatly diminished as a direct result of new technology. The NCD study found out lack of knowledge and awareness among multimedia companies and the market they serve concerning access issues; the costs involved in developing access solutions; and technological challenges as the barriers preventing people with sensory disabilities from achieving full and equal access to multimedia products.

For PWVDs specifically, the lack of awareness barrier consists in software developers being unaware of accessibility issues so they can build them into their products. For cost, accessibility comprises additional features to be built in software products for a small number of users, yet the final products must be sold at a reasonable price on the general consumer market. The technological challenges come from the shift from text-based systems to the Graphical User Interface (GUI), where keystroke commands (appropriate for a user with visual disability) were replaced with use of a mouse or other pointing device to manipulate visual representations of objects in the form of icons.

As a compromise for addressing the barriers discussed above, Universal Design was considered most appropriate. Universal Design is "the design of products, environments, and communication to be used by the widest number of people, to the greatest extent possible, without the need for adaptation or specialized design" (Liem, Swierenga \& Gheerawo, 2010; Loy \& Batiste, 2008).

Universal Design operates on the following seven principles:

- Equitable use - aimed at maximizing the usefulness of design for everyone, identical whenever possible and equivalent when not, so that it avoids segregating or stigmatizing any users;

- Flexibility in use - values design that accommodates a wide range of individual preferences and abilities;

- Simple and intuitive use - seeks to create ease of understanding for users regardless of their experience, knowledge and language;

- Perceptible information - ensuring that design allows information to be communicated effectively to the user regardless of ambient conditions or the user's sensory abilities;

- Tolerance for error - seeks to minimize hazards and the negative consequences of accidental or unintended actions;

- Low physical effort - ensuring that interaction with the environment can occur efficiently and comfortably and with minimal fatigue;

- Size and space for approach and use - aimed at maximizing approach, reach and manipulation capabilities of users irrespective of their size, posture and mobility.

With proper application, the above principles can go a long way in ameliorating the barriers faced by PWVDs. This is because Universal Design encapsulates two basic strategies: firstly to make product features easier to use, and secondly to allow for redundancy (making products with more than one mode of interaction) (Tobias, 2003).

Loy \& Batiste (2008) noted that many product manufacturers have begun to integrate Universal Design principles into the newest available technologies. Indeed this is true for Nokia's large screen 
displays with help menus which make seeing and understanding the display simpler; and tactile feedback which lets a user know each time a key is pressed (Centre for Universal Design, 2008). Likewise, the Windows operating system has accessibility features such as Microsoft Narrator, Microsoft Magnifier and keyboard shortcuts, which are useful for PWVDs (Microsoft TechNet, 2012). However, there are challenges around ensuring that ICTs comply with the principles of Universal Design. For example, Microsoft TechNet states that the Microsoft Narrator and Magnifier are temporary solutions not intended to replace text-to-speech or enlargement utilities available from other software companies. This is a clear admission that the utilities in windows meant for PWVDs are of inferior quality.

As demonstrated by the above pitfalls with basic ICTs, universal design appears not to be a panacea for the accessibility challenges faced by PWVDs. Soderstrom \& Ytterhus (2010) argue that the complexity of a digitalized environment and the differences in how people access and use ICT may represent an unsolvable problem for the goal of universal design. This then brings in the concept of Assistive Technology. An assistive technology device is "any item, piece of equipment, or product system, whether acquired commercially, modified, or customized, that is used to increase, maintain or improve functional capabilities of individuals with disabilities" (Ballabio \& Whitehouse, 1999; National Council on Disability, 2004). Some examples of assistive technologies include: speech input and synthesized speech output, screen readers and screen magnifiers, standardized keyboards and keyboard layouts with landmarks, visual, acoustics and tactile feedback and alert signals, smart cards that provide a preferred user interface and output, and audio recorded information

The main goal of visual assistive technologies for computers and mobile phones is "to provide the best possible sight enhancement or sight substitution mechanism" (Soderstrom \& Ytterhus 2010: p.305). For people with low vision that goal is about magnifying the screen display to facilitate visual digital tasks such as reading text, selecting menus, responding to system prompts and navigating between different parts of web sites. For the totally blind this involves providing non-visual alternatives for visual tasks through translating the visual interface into either tactile or auditory output, or a combination of both .

\subsection{The human factors affecting digital inclusion of PWVDs in any given community}

The cumulative and recursive model of successive kinds of access to digital technologies as developed by Van Dijk (2005) gives adequate contribution to understanding the constraints human beings would find in digital technology inclusion. This model describes four successive and cumulative types of access - motivation, material, digital skills and usage - that mark "the steps to be taken by individual users in the total process of appropriation of digital technology" (Van Dijk, 2005).

\subsubsection{Motivational constraints}

In the access model, motivation is the first phase of access to the new digital technologies, and it is considered a preliminary condition of all other phases (Van Dijk, 2005). Whereas potential users are motivated to adopt, acquire, learn and use such ICTs as computers, mobile phones and the Internet under normal circumstances, there are people who show no interest in taking any of these steps in favour of digital technologies. A number of studies have found various reasons for this. Crump \& McIlroy (2003) reported that majority of non-users of a New Zealand project said they were not 
interested in using the computer room housing the Fugisu hub project, and there reasons included: "too shy", "no friends to go with", "I would visit with women only/men only/own ethnic group", "no time", "room not open when I am free", "no computer skills" and "worried about computers".

Lenhart et al. (2003) gave reasons for non-use of Internet following three categories of people including:

- Net Evaders - those who exploit workarounds that allow them to use the Internet (sending and receiving e-mails and doing online information searches) by proxy through family members;

- Net dropouts - those who were once Internet users but stopped due to technical problems such as broken computers or problems with their Internet service providers;

- The truly disconnected - those who have no direct or indirect experience with the Internet.

Likewise, Wyatt (2003) described four categories of Internet non-users including:

- Resisters (who have never used the Internet because they do not want to);

- Rejecters (who have stopped using the Internet voluntarily because they find it boring, expensive or they have other perfect sources of information and communication);

- The socially and technically excluded (have never had access to ICT); and

- Those who have been expelled (have stopped using the Internet involuntarily due to the cost involved or have left the institution where access was possible).

All the above categories of non-users point to digital exclusion, which is either deliberate or inevitable but bearing serious ramifications for communication and information dissemination using the new media.

There are also mental and psychological factors that may hinder motivational access. Most prominent is a feeling of technophobia, which is a fear of technology in general, and distrust in its beneficial effects (Van Dijk, 2006). Thus someone may resist using ICT just because of fearing its consequences. Anxiety and self-efficacy are the factors relevant here. These are part of the Social Cognitive Theory by Albert Bandura (1989), which asserts that behavior, cognition and personal factors, and environmental influences all operate as interactive determinants which influence each other bidirectional. More specifically, self-efficacy refers to a person's belief in his/her capability to perform certain behaviours, and this affects choices about which behaviors to undertake, the effort and persistence exerted in the face of obstacles to the performance of those behaviours, and ultimately the mastery of those behaviours (Compeau \& Higgins, 1995).

Several scholars have associated these with computer and the Internet with a resultant coinage of such phrases as computer anxiety, computer self-efficacy or Internet self-efficacy. A meta-analysis carried out by Chua, Chen \& Wong (1999) summarised the nature of computer anxiety as follows:

a) Computer anxiety is a fear for computers when using the computer, or when considering the possibility of computer use;

b) Computer anxiety is a kind of 'state anxiety' which can be changed;

c) Computer anxiety is a complex psychological construct; it cannot be described from a single perspective;

d) Computer anxiety causes computer use avoidance.

Computer self-efficacy, on the other hand, refers to individual confidence in one's capability to use a computer and may help determine ease of skill acquisition (Smith, 2001). In relation to internet self- 
efficacy, people who have little confidence in their ability to use the Internet, who are dissatisfied with their internet skills or who are uncomfortable using the Internet may be said to have weak selfefficacy beliefs (Eastin \& LaRose, 2000).

All the above present psychological barriers to the use of ICTs, and are relevant for understanding the barriers to the digital inclusion of any population segment. However, it is not clear whether there are additional considerations for PWVDs to overcome the mental and psychological barriers to acquiring and using ICTs.

\subsubsection{Material or physical access constraints}

Having overcome motivational constraints, the next phase is getting access to the different ICTs. This is what is termed as the material or physical access in the access model. In fact public opinion, public policy and all kinds of research are strongly preoccupied with this second level of access (Van Dijk, 2000; 2005). The most prominent studies in this regard are the NTIA reports of 1995, 1998, 1999 and 2000, which espoused the notion that disparities in access to personal computers, telephone and the Internet were causing a digital divide among various population segments of the U.S.

DiMaggio \& Hargittai (2001), in their five critical dimensions of digital inequality, pointed out variation in technical means, which they said meant discrepancies in hardware, software and connectivity. They went ahead to posit that inferior technical apparatus (slow connections, older software, and old hardware) reduces the benefits users can gain from the Internet directly and indirectly. When it comes to connectivity, a constraint is discernible around the level of bandwidth available to Internet users. An increase in bandwidth makes access to web sites with sophisticated graphics, streaming audio or video possible, and the display of Java applications (DiMaggio \& Hargittai, 2001). On the contrary, users with slow connections are simply unable to access certain sites.

Bowe (2007) made the differences in slow versus high speed Internet more relevant to the social group under study by giving several benefits persons with disabilities would gain from broadband (high-speed, always-on connectivity that facilitates the convergence of voice, video and data). Since this dissertation is focused on PWVDs, only those aspects relating to that particular group will be reviewed. Thus, broadband fosters effective communication by enabling conversion of text to audio so that it can be navigated by someone with a vision disability; expands opportunities for employment through VoIP, assistive technology devices and other technological advances that broadband supports; enables telemedicine, which makes it possible for the delivery of healthcare remotely through video conferencing, to be enjoyed by PWVDs at home; and enables e-learning through advanced communication technologies with guidance from live instructors.

But PWVDs cannot enjoy the above benefits fully without access to the web. This secondary challenge has been tackled with several interface design guidelines for web developers to make web pages accessible for users with various disabilities. Some common examples include: Research-Based Web Design and Usability Guidelines, and Web Content Accessibility Guidelines (WCAG 2.0). The Research-Based Web Design and Usability Guidelines are basically aimed at improving the design and usability of information-oriented web sites; and they cover accessibility, hardware and software requirements, page layout, navigation, scrolling, links, text appearance, lists, Widgets, graphics, content organization and so on (Leavitt \& Shneiderman, 2006). On the other hand, the Web content Accessibility Guidelines 2.0 cover a wide range of recommendations based on four principles perceivable, operable, understandable and robust - which lay the foundation for accessing the web by 
all people regardless of sensory, physical or cognitive abilities (Caldwell, Cooper, Reid \& Vanderheiden, 2008). However, the challenge with all the interface design guidelines is that they are voluntary, and therefore their implementation is hard when the development of web sites is largely in private hands. Consequently, Waddell (1999) observed that many web pages are inaccessible either by hiding text within images, frames, applets or animated gifs; or render the text unintelligently in table, columnar, or PDF formats. Even on-line forms can become inaccessible when designed to prevent keyboard navigation and input. No disability suffers from these design deficiencies more than visual disability, because they hamper interoperability between assistive technologies and web browsers.

\subsubsection{Skills constraints}

Unlike the traditional media (radio, television and newspapers), new digital media require a minimum level of active engagement and the possibility of interactions, transactions, and interpersonal communication is offered (Van Deursen \& Van Dijk, 2011). Thus the use of digital media requires a rather complex set of digital skills. Clearly, this is an obvious indicator of inequality, in that possession or non-possession of digital skills makes the difference between users and non-users.

Mark Warschauer (2003: pp. 111-119) described four types of literacy required for the attainment of digital skills:

- Computer literacy - the basic forms of computer operation (turning on a computer, opening a folder and saving a file);

- Information literacy - the skills and understandings involved in using ICT to locate, evaluate, and use information;

- Multimedia literacy - the ability to combine text, backgrounds, photos, graphics, audio and video in a single document.

- Computer-mediated communication literacy - the interpretative and writing skills necessary to communicate effectively via online media such as e-mail, web-based bulletin boards, etc.

The above literacy types are heavily weighted towards the operational skills required for using a computer and the Internet; but meaningful use of the latter has to be based on new skills, such as "purposeful searching strategies, assessment of source credibility or construction of meaningful frames for interpretation”. (Bomfadelli, 2002).

According to Steyaert (2002) and Van Dijk (2005), there were three general types of skills applicable to both computers and the Internet. Steyaert mentions instrumental skills (the ability to handle the basic functionality of the hardware and/or software involved in the technology), structural skills (the ability to handle the new formats in which information is communicated) and strategic skills (the attitude to use information as a basis for decision making, involving an attitude to look for information before taking action, to continuously scan the information environment for relevant items, to translate information into consequences and implement necessary or possible actions). Van Dijk (2005), on the other hand, made a slight modification of the three types of skills given by Steyaert. These included operational skills (the skills to operate computers and network hardware and software), information skills (the skills to search, select and process information in computer and network sources) and strategic skills (the capacities to use these sources as the means for specific goals and for the general goal of improving one's position in society). Furthermore, Van Dijk breaks down information skills into two subcategories of formal information skills (the ability to understand and to handle the formal characteristics of a computer and a computer network - the Internet - such as file structures, menu structures, and hyperlinks); and substantial information skills (the ability to find, select, process, and evaluate information in specific sources of computers and networks according to specific questions and needs). 
This "proliferation" of types of digital skills is boiled down by Van Deursen \& Van Dijk (2011) into what appears to be the most advanced categorization of digital skills. They state that use of the Internet requires both medium and content related skills. They broke down these two types of Internet skills into four subcategories as follows:

- Operational skills - a set of basic skills needed for using Internet technology;

- Formal skills - navigation and orientation skills relating to the hypermedia structure of the Internet;

- Information skills - the actions via which users try to fulfil their information needs; and

- Strategic skills - the capacity to use the Internet as a means of reaching particular goals and for the general goal of improving one's position in society.

DiMaggio \& Bonikowski (2008), with the exception of operational skills, gave further elaboration on the importance of the other three skills by showing that new Internet users must:

1. Understand graphic conventions prevalent in web design (e.g. the difference between a list and a drop-down menu) and learn the cues that make it easy for experienced users to tell one from the other;

2. Acquire a mental map of the Internet as a "space" across which one can "navigate," and master the instrumentalities (e.g., hyperlinks, URLs, search engines) through which one can do so;

3. Learn the basics of online searches (e.g., generating queries that are neither too broad nor too narrow, using Boolean operators to refine a search);

4. Acquire information about the uses and reputations of major web sites;

5. Develop skill in distinguishing between trustworthy information sources and amateurish or misleading sites; and

6. Master the pragmatics of online communicative competence (e.g. knowing when it is appropriate to contact a stranger or participate in an online forum, the appropriate formality of address, appropriate message length and content, and use of abbreviations and emoticons).

Certainly all the above groupings of digital skills show signs of digital constraints for the most disadvantaged social groups. Formal training, often restricted to operational skills, is the utmost intervention in alleviating such a constraint; but attitudinal change, accumulation of social capital and experience would be required in overcoming information and strategic skills deficiencies. These require more complex approaches, which are rare to find by disadvantaged groups.

We can also rely on the three-user typology - the athletes, laid-backs and the needy - by Ferro, Helbig \& Gil-Garcia (2011) to understand that even acquiring digital skills through formal training may not be so straightforward. Using the analogy of climbing a staircase to define digital skills acquisition, Ferro, Helbig \& Gil-Garcia (2011) show that the "athletes" will climb stairs mainly because they enjoy exercising and being fit. The "laid-back" have the physical ability to climb the stairs but they are reluctant to do so. In other words, they have the necessary intellectual capacity to acquire ICT skills on their own but lack sufficient incentives. For the "needy", regardless of their willingness to climb the stairs, they do not have the capacity to take the first step, and need external help. That is, even if they may be willing to use ICTs in their daily lives, they lack the basic skills and cultural background to win the initial inertia for starting to use it in meaningful ways. This user typology shows that people require different interventions for digital skills acquisition. For example the athletes (technophiles) do not need any kind of external incentives because they enjoy using the technology and value the costs they put in to gain its benefits. The laid-back will require both 
incentives (sensitisation) and coercive means (making computer use compulsory in schools and the workplace) to acquire ICT skills; because they simply want to stick to basics. The needy will be most in need of external help - training and material support - to overcome the first step towards acquiring ICT skills.

In the case of PWVDs, the capabilities they need raised before they can take advantage of digital technologies are not necessarily obvious. The correlations between capability and other forms of deprivation are well explored following Sen's classic and extensive work in this area (Sen, 1999). For example Sen says "If our attention is shifted from an exclusive concentration on income poverty to the more inclusive idea of capability deprivation we can better understand the poverty of human lives and freedoms in terms of a different informational base" (Sen, 1999: p. 20).

\subsubsection{Use constraints}

It is now well known that providing technology access and creating conditions for its initial usage is only the first step and does not guarantee continued intention to use ICTs (Hsieh et al., 2008). This is true for e-mail, e-banking, the world wide web, etc. Benefits from ICTs occur through sustained use, which makes examining the constraints around continued use vital. Available literature shows that these include the experience of users, types of use patterns and the autonomy users have over the technology.

Based on the length of time a person has used the Internet (i.e. experience) and the frequency with which he or she logs on from home, Howard, Rainie \& Jones (2001) developed a typology with four broad categories of Internet users:

1. Netizens. This category had gone online for more than three years and had done so from home every day. They had incorporated the Internet into their work and home lives, were relatively comfortable spending money online, used the Internet to help manage their finances, used email to enhance their social relationships, and were the most avid participants on most web activities on an average day.

2. Utilitarians. These had also gone online for more than three years and from home every day. However, compared to netizens, members of this group were less intent in their use of the Internet, expressed less appreciation for what the Internet contributed to their lives, were less likely to spend their money online, and were less active in accessing the web's content.

3. Experimenters. These had gone online for two to three years or about one year and had done so from home every day. They had ventured beyond the fun activities that Internet novices enjoy, and were interested in using the Internet as an information retrieval utility.

4. Newcomers. They had gone online for one year or less than that. They were just learning their way around. But even without a great deal of experience, they enjoyed many of the fun aspects of the Internet at levels similar to the overall average of the Internet population -playing games, browsing for fun, participating in chat rooms, getting information about hobbies, and listening to and downloading music.

Though the frequency with which someone goes online from home may not have brought out any marked differences in Internet use, the above typology shows that time spent online is vital for understanding the types and volume of activities a person can do on the Internet. This means policy- 
makers who are interested in combating digital inequality should not stop at ensuring access to Internet facilities, but extend to their continued use as well.

Following a pattern similar to the above typology, Lenhart \& Horrigan (2003) carried out a study that categorized Internet users in the United States on a continuum of experienced users (with broadband connectivity and uninterrupted dial-up connectivity), Intermittent Users, Net Dropouts, Net Evaders, and the Truly Unconnected. Although the last four categories (from Intermittent Users to the Truly Unconnected) were labelled as non-Internet users, only the Truly Unconnected would actually merit that labelling. The rest were simply other diversities of users because intermittent users were just on and off the net for extended spells of time; the Net Dropouts had experience of using the net and were likely to return to it if prevailing negative conditions would dissipate; and Net Evaders knew the value of the net and had thus chosen to be second-hand users of it.

Nonetheless, the four groups exhibiting less than full utilization of the Internet give reasons to which scholars interested in examining user-constraints should pay serious attention. According to Lenhart \& Horrigan (2003), these include: not having the time to use the Internet; not finding much of use online; have workplace or family care demands; could no longer get to the locations (school, friend's place or public library) where they used to go online; have technology problems (loss or breakdown of computers, and loss of Internet connectivity); fears of addiction to the Internet, online crime, and pornography; the Internet being too hard to use, too confusing and too information laden; and the cost of an online connection becoming too expensive. The Truly Unconnected pointed out one other unique reason - that very few or none of the people they knew went online - which makes isolation a trait preventing social networks that would encourage them to build Internet use into their daily lives. Majority of the four groups expressing these reasons for not fully utilizing the Internet were women, low income earners, the less educated, and seniors. This brings us back to socio-economic factors as important causes of digital inequality, suggesting that these circumstances need to be changed, or taken into consideration in the design of Internet accessibility, before people can universally use ICTs effectively.

User-constraints can also be examined via types of use patterns. Here, Hargittai (2008) observed that "Baseline Internet use statistics do not distinguish among those who go online for no more than checking sports scores or TV schedules and those who use the medium for learning new skills, finding deals and job opportunities, participating in political discussions, interacting with government institutions, and informing themselves about health matters. Yet such differentiated uses can have significant implications for how ICT uses may relate to life outcomes." She goes on to say that certain types of Internet use can result in increased human capital, financial capital, social capital, and cultural capital, while other types of use may out rightly disadvantage the uninformed. This implies that specific use patterns of the Internet can enhance or impede one's life chances, which is certainly an area of use constraint worth paying attention to.

Autonomy of use as a constraint was identified by DiMaggio \& Hargittai (2001) as one of the five broad forms of digital inequality. This refers to the autonomy which people feel different locations can permit them to connect to the Internet. For example, users may constrain their online activities if they feel that their actions are monitored by workplace Internet tracking software or they may experience low autonomy at the library if they must complete all their activities within a limited time frame (Hassani, 2006; DiMaggio \& Hargittai, 2001). 
But even if formal time or use regulations are absent at public places, users may be concerned about the privacy of their activities online - especially if activities involve personal information that could remain on public computers after a session is over (Hassani, 2006). For persons with disabilities, including those with visual disabilities, many who rely on ICTs located in public spaces like libraries, community centres and schools face transportation and other barriers to getting to and into these spaces (Stienstra, Watzke \& Birch, 2007). The other barriers include lack of privacy, lack of appropriate support to facilitate the use of ICTs and identity problems associated with assistive technologies and disability.

The above catalogue of problems seems to suggest that home is the best option for using ICTs because it allows Internet users the greatest ease of access as well as the greatest freedom of use, due to the absence of regulation coupled with high levels of privacy. For PWVDs who rely on alternative assistive technology, customized home access remains the most realistic option for getting online (Watling, 2011). However, home use of ICTs is often curtailed by affordability. In addition, Balka (1997), drawing on anecdotal evidence in Canada, found that when women and children share computer equipment in the home, in the interest of ensuring that their children gain wide exposure to computer equipment, the women often place their computing needs - even when they are related to paid employment - after those of their children. Home based Internet access may therefore not prove effective in giving women who are parents, access to the Internet.

The original definition of "autonomy of use" did not take into account mobile telephony. However, as Campbell (2007) found out, acceptability for use of mobile phones in public places is dependent on cultures to varying degrees. A major finding of his study was that settings involving more collective levels of involvement (movie theatres and classrooms) would be regarded as less acceptable locations for talking on a mobile phone than settings that support more individualized levels of focus (buses, grocery stores and sidewalks). Intolerance against voice calling in a cross-section of cultures is an obvious pointer towards private settings as the most appropriate for using mobile phones for this particular purpose. Talking on a phone in a public place forces bystanders into the discomfort of eavesdropping, which is possibly not the case if one restricts use to mobile Internet, SMS or voicemail.

\subsubsection{The availability of social support}

Availability of social support was identified as one of the five broad forms of digital inequality by DiMaggio \& Hargittai (2001); the rest including inequality in technical apparatus, autonomy of use, skill and variation in the use of digital technologies.

DiMaggio \& Hargittai (2001) and DiMaggio et al. (2004) made a strong argument for social support by suggesting exploration of the distribution and impact of three kinds of support including:

- Formal technical assistance from persons employed to provide it (for example, office staff in workplaces, customer support staff in businesses, librarians, and teachers);

- Technical assistance from friends and family members to whom the user can turn when he or she encounters problems; and

- Emotional reinforcement from friends and family, in the form of both commiserations when things go wrong and positive interest in sharing discoveries when things go right.

Warschauer (2003) extends the discussion on social support through the notion of social capital. In relation to ICTs, he argues that social capital is important in gaining access to computers and the Internet, which involves making decisions whether or not to buy a computer, how to set it up, what 
kind of software to get, how to install it, how to obtain and set up internet access, and finally how to use the computer, software and the Internet. Most people rely on their social networks - friends, neighbours, colleagues and family members - to offer support in all this. The visual bias of most ICTs makes the availability of social support a vital ingredient in the use of the new digital technologies by PWVDs. This could be from siblings who can assist in fixing some simple Internet problems or neighbours who are also discovering the latest options for using ICTs, which may allow for more opportunities of knowledge sharing than in a situation of isolation from any knowledgeable networks. This is in line with a concept known as the 'warm expert'. The warm expert is an Internet/computer technology expert in the professional sense, or simply in a relative sense, compared with the less knowledgeable other (Bakardjieva, 2005). The two features of the warm expert are that he or she possesses knowledge and skills gained in the world of technology and, at the same time, are immediately accessible in the user's life world as a fellow man/woman. The warm expert mediates between the technological universal and the concrete situation, needs and background of the novice user with whom he is in a close personal relationship.

\subsection{How demographic factors contribute to digital exclusion}

Analysing demographic factors (age, disability, education, gender, income disparities, geographical location, occupation and race) can give further understanding of the barriers to digital inclusion of PWVDs. Several write-ups on the digital divide allude to disparities in these factors as indicators of digital technology haves and have-nots. Indeed the first report of the National Telecommunications and Information Administration (NTIA, 1995) was the earliest to bring to light these as indicators of digital exclusion of some population segments in rural and urban America. All the other reports in the 'Falling through the Net' series and many other studies elsewhere, carried the same socio-economic characteristics as indicators of the differences in access to digital technologies. This section of the chapter takes a brief look at each of them to examine their relevance in understanding the digital exclusion of Persons with Visual Disabilities.

\subsubsection{Age and digital exclusion}

There seems to be consensus among researchers that while the uptake of ICTs among citizens in the EU and the U.S. is increasing, older persons are much less likely to be online or have broadband access than younger people and that this divide will continue for the foreseeable future (Morris, Goodman \& Brading, 2007). Sourbati (2009) quotes several statistics corroborating this assertion, including the Oxford Internet Survey (OxIS, 2004), which had it that $31 \%$ of UK residents aged between 65 and 74 had accessed the Internet in 2004 and just 1 in 5 aged 75 vs. $60 \%$ of the national population. According to the U.S. Census (2004), 38\% of people aged 65 were going online in 2003, compared with $75.9 \%$ of all Americans at that time. Again she reported that the Eurostat survey (2004) showed just over 10\% of Europeans aged 65 or over accessing the Internet in 2004.

The reasons advanced for the above low statistics include lack of interest, feeling too old, fear of technology compounded by rapid hardware and software development, lack of ICT skills and experience, age-related functional restrictions, and the cost of acquiring and maintaining computers and Internet connection (Morris, Goodman \& Brading, 2007). Seniors are also more likely than any other age group to be living with some kind of disability, which could hinder their capacity to get to a computer training center or read the small type on many Web sites (Fox, 2004). Sourbati (2009) clarifies the reasons related to disability, saying that a decline in vision, slowing of movement and arthritis-related physical dexterity make it difficult to use technological artifacts designed for younger, 
able-bodied users. Declines in perceptual and cognitive abilities can also impede their ability to learn to use new ICTs.

Despite the grim realities highlighted above, there is evidence that both younger and older persons are equally interested in ICTs. Morris, Goodman \& Brading (2007) note that services such as e-mail, Internet banking, online shopping, general interest web sites, discussion lists and creative computer applications can facilitate the learning and socialization of older persons as well as helping them to preserve their independence. Similarly, the NTIA reports (NTIA 1995 and 1998) recognised that the young were most likely to use electronic services to find jobs, housing, or other services. Howard, Rainie \& Jones (2001) add that young Americans were likely to have used the Internet by the year 2000 for fun communication via instant messages or chat rooms, and then to have gone to the web to browse for fun, to have done school work-related research, to have downloaded music or getting information about movies, books and other leisure activities, and to have performed convenience activities online such as banking and arranging travel.

The implication of all this is that efforts geared at tackling digital exclusion emanating from age differentials should focus on a phenomenon which is likely to change with time. For example, as Internet users in their 50s get older and retire, they are unlikely to give up their wired ways and therefore will transform the wired senior stereotype (Fox, 2004). Only the challenges that associate old age with disability may persist, because these require more intervention than those that aim at mitigating aging effects. There may also be need to address the situation where many seniors in the U.S. who are still offline actually live far removed from the Internet, know few people who use email or surf the Web, and cannot imagine why they would spend money and time learning how to use a computer (Fox, 2004).

The predictably close association of age and disability has often led policy-makers to design projects that cater for both. One good example is the Telematics for Integration of Disabled and Elderly people initiative (TIDE), which is a user-driven research programme focusing on socially useful information and communication technology applications (Ballabio \& Whitehouse, 1999). Among the many technologies created or further developed by the TIDE initiative have included training, educational and vocational applications, developments in home systems and remote services, tools and services enabling greater mobility and orientation, systems and methods to restore and enhance hearing, speech, communication, cognitive and motor impairments, and the tools to support the selection and use of assistive technologies. Justification for the TIDE initiative is threefold: the increasing number of elderly people in the European Union - 1 in 4 by 2020, an equally increasing number of Europeans with disabilities, and advanced medical treatments which are reducing mortality rates for individuals with developmental or degenerative diseases and those involved in fatal accidents.

\subsubsection{Education and digital exclusion}

Education seems to have the most explicit relationship with digital exclusion because ICTs are characteristically knowledge intensive. For example, using the Internet constitutes action, interaction and transaction. Thus people who are less educated find themselves increasingly getting excluded from all the benefits the Internet now has to offer, ranging from economic opportunities such as privileged access to jobs, health opportunities such as better diets or improved exercise habits, or political opportunities such as online services and participation (Van Deursen \& Van Dijk, 2010).

But even long before the ubiquity of the nascent media technologies, Tichenor, Donohue \& Olien (1970), using their knowledge gap hypothesis, found out that education was a powerful correlate of 
acquisition of knowledge about public affairs and science from mass media. Thus, increased formal education indicates an expanded and more differentiated life space, including a greater number of reference groups, more interest in science and other public issues, more accumulated knowledge of these topics, and more extensive exposure to mass media content in these areas.

Extending research into the theoretical and empirical authenticity of the knowledge gap hypothesis, Bonfadelli (2002) found five underlying factors or processes responsible for the emergence of knowledge gaps as follows:

1. Communication Skills. Better educated people are better able to manage communication in general and to use and interpret specific media information than less educated people.

2. Prior knowledge. Better educated people possess more general knowledge on a broader range of public affairs topics than the less educated.

3. Relevant social contacts. Better educated people are integrated in broader social and/or local networks that function as additional interpersonal information resources.

4. Selective use, acceptance and storage of information. Education correlates strongly with a general pattern concerning the civil duty of active information seeking.

5. Structure of the media system. Modern media systems are differentiated insofar as most public affairs information is distributed by the print media.

The above factors or processes responsible for the emergence of knowledge gaps imply that policies geared at combating digital exclusion should, as a matter of necessity, concentrate on reducing educational disparities. This is even more important for population segments whose exclusion from mainstream education is very high, such as Persons with Visual Disabilities.

\subsubsection{Gender and digital exclusion}

From the literature reviewed on this topic, there appears to be no evidence suggesting that gender is a direct cause of digital exclusion among persons with disabilities. But gender roles are socially constructed through institutions such as family, media, religion, education, and are pervasive in daily routines (Kennedy, Wellman \& Klement, 2003). As a result, these roles frame actions and shape behaviours. In a way, these breed social inequality that extends to the everyday use of new digital media technologies.

Arguing in a similar vein, Cooper (2006) said that "roots of the digital divide are embedded in social developmental differences between boys and girls, societal stereotypes of what is appropriate for the two genders and gender-specific attributional patterns". These factors are intertwined to create the expectation that computers are the province of boys and men, not girls and women. Such expectations are reinforced by others in the social environment and exacerbated by the social context in which computing is typically learned and performed. The social context, Cooper argues, stems from the male-oriented software (featuring sports, war-like, and space competitions) which increase the performance of boys but lower that of girls, hence raising computer anxiety levels for the latter gender.

As if to confirm the above assertion, Wasserman \& Richmond-Abbott (2005) reported that in the early stages of home computer use, the new technology was popularly portrayed as a male domain. However, women were more likely than men to use computers at work, but purposely for routine office activities such as word processing and spreadsheet work. Also, given their emotive role in family matters, today women are more likely than men to use email messages to maintain longdistance social network ties with friends and relatives. The same scholars, Wasserman \& Richmond- 
Abbott (2005), argue that being at work full time, especially in professional and administrative work, gives men greater access to the web, as well as to technical experts who can effectively advise them on its use - a resource that women who are usually at home lack.

According to Bimber (2000), the gap between men and women using the Internet is accentuated by socio-economic and a combination of underlying gender-specific phenomena biased towards men. Reasons for such phenomena may include the fact that there has been commercial success in maleoriented pornography on the internet, online sexual harassment that echoes behavior in maledominated workplaces, and the gender inequality in the professions and industries producing technologies of the Internet.

Indeed gender harassment on the Internet is particularly rife, impacting women more negatively than men in both asynchronous (say listservs and usenet newsgroups) and synchronous (Internet Relay Chat and Multi-User Dimensions) modes of computer mediated communication. A study by Susan Herring (1999) in which she carried out a comparison of two extended interactions on the Internet, one on an asynchronous discussion list and the other on an Internet Relay Chat channel, showed that male participants advanced views that were demeaning to women, then women responded by resisting the demeaning characterizations, and finally the men insulted and blamed the women as the cause of the discord (Herring, 1999). Consequently, the constant harassment of women forced them to either comply with the male norms or they simply fell silent. The harassment involved repeated episodes of men exhibiting intentions to annoy, alarm or verbally abuse women. Another form of harassment was for male participants, who were often in privileged positions to control discussions, to either kick their female colleagues off the channel (electronically break their connections) in the case of the Internet Relay Chat channel or use intimidating language in the case of the discussion list.

Other circumstances where women are often on the losing end are those where sharing is the most viable option for using ICTs. For instance, Balka (1997) gave a number of factors that constrain women's use of publicly accessible computer networking facilities. These include time pressures (women enjoy considerably less leisure time than men throughout the life cycle), lack of willingness to compete with others (often young, male teenagers) for access to network facilities, and inability to obtain adequate assistance from (frequently male) staff members who are responsible for maintaining the facilities.

A more recent study carried out in seventeen countries across Africa revealed that women who have fewer opportunities for personal contact as a result of being housewives, doing unpaid work or generally earning less than their male counterparts, seem particularly disadvantaged by the high cost of communication (Gillwald, Milek \& Stork, 2010). This directly relates to their inability to pay monthly subscriptions for mobile phones and Internet services.

All the literature reviewed in this sub-section is clear on the fact that policies aimed at mitigating gender-based digital exclusion should address such issues as poverty, software design, and providing better opportunities for access to Information and Communication Technologies. In other words, ridding society of the exclusion anomaly requires designing software that is either gender-neutral or which caters for the interests of the two genders differently, providing access points for digital technologies where both genders are most comfortable (say at home), and working towards reducing poverty disparities between men and women. 


\subsubsection{Geographical location and digital exclusion}

Digital exclusion emanating from geographical location was first highlighted in the mid-1990s in the U.S. when the National Telecommunications and Information Administration (NTIA) sought to examine trends in telephone subscription, as well as usage and ownership of PCs and modems in the rural and urban America. Thus the variance in penetration of these three ICTs was an important input for policy development in the nascent Information Age (NTIA, 1995).

Whereas several characteristics were considered in the survey, poverty seemed to stand out as the underlying factor for the preponderance of new technology 'have-nots' in rural America. For instance, the rural poor were the lowest in terms of computer penetration overall $(4.5 \%)$. Furthermore, Native Americans (American Indians, Aleuts, and Eskimos) in rural areas had the lowest telephone penetration (75.5\%) compared to whites in urban areas with the highest (96.2\%); rural Blacks had the lowest computer rates (6.4\%); and households composed of Asian/Pacific Islanders who owned computers $(26.7 \%)$ and Native Americans in rural areas had the least modem penetration.

The rural urban differential continued to be high even during the broadband era, with broadband connections at home remaining less prevalent in rural America $(24.7 \%)$ than in urban areas $(40.4 \%)$ (NTIA, 2004). Here the reason was the cost of deploying cable modems and Digital Subscriber Line services (the two technologies by which broadband connection is most possible in the U.S.) becoming very expensive as population density went low in rural areas. As a result, either such services were unavailable in some rural areas or a good number of people in rural settings could not afford them.

Outside the U.S., the gap between rural and urban access to ICTs comes out quite prominently in SubSaharan Africa with capital cities in this region serving as centres of economic, political and educational activities. Thus, these cities traditionally maintain the highest concentration of ICT development and implementation, including the largest number of telephone lines, television sets and radios (Gebremichael \& Jackson, 2005). For example, in 2001 there were about 150 tele-centres with Internet access in Ghana, 90\% of which located in Accra (Fuchs \& Horak, 2008). This means urban residents of Sub-Saharan Africa get the opportunity to adopt various forms of the modern information technologies more readily than those in rural communities

As a matter of policy, poverty seems to be the most urgent issue to tackle by those interested in reducing geographical digital exclusion. Furthermore, since affordability of networked technologies relies heavily on the number of subscribers, attention should also be paid to finding alternatives to high population density as a reducer of telephone and Internet costs. Already, the U.S. gives subsidies to rural populations, which are characteristically low in density, to enable them use telephones and the Internet at affordable rates.

\subsubsection{Income and digital exclusion}

Income, of course, is directly related to the ability to own a computer (Cooper, 2006). Likewise, family income is a strong indicator of whether a person uses a computer or the Internet. Individuals who live in high-income households are more likely to be computer and Internet users than those who live in low-income households. (NTIA, 2002).

The above point is illustrated even more vividly by the NTIA report of 1998, where rural households earning between $\$ 5,000$ - $\$ 10,000$ accounted for the lowest penetration rate for PCs $(7.9 \%)$ and on-line access $(2.3 \%)$. This contrasted sharply with households earning more than $\$ 75,000$ in urban areas, whose PC ownership rates stood at $76 \%$ and on-line access rates at $50.3 \%$. 
When digital inequality is blamed on disparities in income, PWVDs are at an obvious disadvantage. It is widely known that poverty and disability are deeply interrelated in a vicious circle (Vicente and Lopez, 2010). A disability often results in poverty, and conversely, living in poverty increases the likelihood of acquiring a disability.

\subsubsection{Occupation and digital exclusion}

Digital exclusion based on occupation is largely dependent on other demographic variables such as gender and education. For example, using several national surveys of adults between 1983 and 2002, Losh (2004) found out that educational gender differences steered women and men toward different job specialties. In turn, occupational type was directly linked to information technology use. Losh gave the example of research, science or technology workers (more often male) who routinely employed digital searches, diagnostics, analyses, simulations or syntheses; while any other professionals were female pink-collar workers (i.e. service providers in hotels, schools, medical offices, or service agencies) who probably spent much time working first hand with students, patients or clients and comparatively had less time remaining for online exploration, analysis, or communication. Another example was of managerial workers (often male) who would find e-mail useful and Internet access enhancing their job performance; while clerical workers (usually female) who also often had access to computers, but not e-mail or Internet.

Another interesting twist in the occupational causes of digital exclusion may stem purely from the non-use of the technology. For instance, in some occupations in some industries, workers who can use the Internet effectively may perform better than those who cannot, and they will therefore have privileged access to desirable jobs, be rewarded more generously for their performance, or both (DiMaggio \& Bonikowski, 2008). Earlier studies support this assertion; say Krueger (1993), whose findings from three micro data sets were such that workers who used computers at work earned 10 $15 \%$ higher pay than those who did not. But we must take this particular finding with caution, because the data Krueger relied on to come to this conclusion was gathered at a time (the 1980s) when there was tremendous spread of computer use in the U.S. and demand for computer literate workers expanded faster than the supply of the same.

A more robust argument in favour of ICTs as an employment factor was given by Freeman (2002), who contended that since computerization, particularly the Internet, allows workers to work at home more easily, the effect of the new technologies on hours worked could be more important over the long run than the effect of those technologies on wages.

The discussion in this subsection serves to show that new digital technologies are crucial in improving one's chances for employability. In addition, certain occupations can improve people's chances for access and use of digital technologies. Therefore, individuals with few or no chances of being in employment, say PWVDs, would most likely miss out on this technology, which should be an alert point for policy-makers to consider while providing avenues for accessing ICTs instead of simply assuming that people would get this from the organisations where they go to work. More so, providing avenues for people to train in digital skills is something policy-makers can no longer ignore.

\subsubsection{Race and digital exclusion}

It is in the United States where race has been identified as a source of digital inequality. As such, the NTIA report of 2002 showed that differences in computer and Internet use across the broad race 
categories in the U.S. still persisted. In each survey, whites and Asian American and Pacific Islanders have had higher rates of both computer and Internet use than Blacks and Hispanics (NTIA, 2002). One small explanation for this is in language disparities, where $14.1 \%$ of Hispanics who lived in households with Spanish as the only language spoken used the Internet compared to $37.6 \%$ of Hispanics who lived in households where Spanish was not the only language spoken (NTIA, 2002). This is hardly surprising given the assumption that English is the second language spoken by Hispanics. Furthermore, English is generally considered to be the first global language because of its current dominant role as a lingua franca in international communications (Warschauer, 2003). This stands true for global economic, political and social exchange. Even on the Internet English maintains a strong position over other languages because of the historical fact that this was already the de facto global language at the time the Internet was created, and remains so today (Warschauer, 2003).

Beyond the above explanation based on language disparities, it is quite inconclusive that race per se can be a predictor of disparities in access to and/or use of ICTs. Rather, before race carries some value in that regard, there must be other demographic factors brought into context. In the U.S. for example, the wealthy, educated, young and white are more likely to have a home computer and use the Internet at home than people who are poor, less educated, older, African-American and Latino (Mossberger et al., 2006). Further statistics from the same scholars show that African-Americans residing in areas of concentrated poverty were $83 \%$ less likely to have a home computer than African-Americans residing in a middle-class community. This is a stark vindication that poverty rather than race provides a better explanation of the variance between users and non-users of digital technologies.

Even when Hoffman \& Novak (1998) set out to investigate the difference between whites and African-Americans in the U.S. with respect to computer access (a primary prerequisite for Internet access and web use), they could not do so without invoking other demographic variables such as income and education. For instance, although they found out that whites were significantly more likely than African-Americans to have a computer at home (44.2\% vs. $29.0 \%)$, and a similar pattern reoccurred for having access to a PC at work (38.5\% for whites vs. $33.8 \%$ for African-Americans). When analysed together with income, increasing levels of income corresponded with an increased likelihood of owning a home computer regardless of race.

Combining race with education, Hoffman \& Novak (1998) again came to the conclusion that increasing levels of education corresponded to an increased likelihood of work computer access regardless of race. Similarly, there was a general pattern that higher education levels corresponded to higher probabilities of owning a home computer.

In another investigation, Hoffman, Novak \& Schlosser (2000) reached a more concrete conclusion involving both whites and African-Americans, but again with income and education in context. They reported that within both racial groups, Web users were most likely to be among the wealthiest individuals (those with incomes above the median of $\$ 40,000$ ), while the segment with no Internet access was the most likely to be composed of individuals with the lowest incomes (less than $\$ 40,000$ ). The same holds true for education. The Web user segment was most likely to consist of individuals with some college education, or who had completed college, while the segment with no access was most likely to be composed of those with a high school education or less. All these effects were more pronounced for African Americans than whites, and these effects appear to persist over time.

The last bit of those statistics was most informative, showing that the digital divide in terms of web use was more severe among African Americans than whites. All the same, curbing digital inequality 
should not be based on race differences because no race is starkly averse to access and use of digital technologies unless other demographic variables are brought into the picture.

To sum up, the discussion in all the subsections of this section reveals strong correlates between digital exclusion and the traditional social stratifications. The disadvantages brought about by old age, limited education, gender, low-income status, joblessness, geographical location and race have only been extended to the digital world. However, PWDs, including the visually disabled, tend to bear the brunt of socio-economic problems more than ordinary users of ICTs. Statistics in the U.S. show that disability is associated with being older, less educated, and living in a lower income household (Fox, 2011). These statistical patterns reported by the Pew American Life Project were consistent with findings of the American Community Survey, the Current Population Survey and the U.S. Census. Some $27 \%$ of American adults living with disabilities were significantly less likely than adults without a disability to go online (54\% vs. $81 \%$ ) (Zickuhr \& Smith, 2012). The situation was not so different a decade earlier, where the NTIA report of 2000 quoted a survey done in 1999 that people who had a disability were only half as likely to live in homes with Internet access as those without any disability. Also, while just below $25 \%$ of people without a disability had never used a personal computer, close to $60 \%$ of people with at least one disability had never used a computer. A trend comparable to the above was reported in the European Union. Using data from the eUser project (2005), Vicente \& Lopez (2010) found out that persons with disabilities had about half of the rate of Internet use of those without disability (35\% vs. $61 \%)$. This was because the disabled community was largely poorer than the general population.

\subsection{Existing gaps in universal access policies relating to the digital inclusion of PWVDs}

\subsubsection{Universal access policy interventions in developed and developing countries}

The term 'universal access' is usually traced from the United States Communications Act of 1934 covering telephone, telegraph and radio services. This Act sought to ensure 'adequate facilities at reasonable charges,' especially in rural areas and prevent discrimination on the basis of race, color, religion, national origin or sex (Shneiderman, 1999; Compaine, 2000). The Act's universal-service doctrine required the Federal Communications Commission to "make available, so far as possible to all the people of the United States ... a rapid, efficient, nation-wide, and world-wide wire and radio communication service with adequate facilities at reasonable charges ..." (National Council on Disability, 2006). This was the foundation for making telecommunications services affordable and available for all; because people living in high-density urban areas were charged more by the phone companies in order to subsidise subscribers in low-density suburban and rural areas.

Most West European Governments, after World War II, decided to enforce a monopolistic universal service telecommunications system since the telephone was only accessible and affordable to the rich and urban elite (Burgelman, 2000). Contrary to the U.S. therefore, affordability of a telephone, and probably its availability in the European context, was confined to business people.

It should be stated that PWVDs did not also get any direct benefit from the Universal Service Doctrine because their concerns could only be granted within a larger package for PWDs, such as reducing the reach to a telephone to three kilometres from a habitation (the definition of the 
International Telephone Union). The only group that obtained noticeable benefit from the Universal Service Doctrine early in the implementation of the U.S. Communications Act were people with hearing disabilities; because of the nationwide deployment of telecommunications relay services, hearing-aid compatibility, TTYs (teletypewriters), and Ring Signalers. It was only much later, when the accessibility standards under Section 255 of the U.S. Telecommunications Act of 1996 instructed that telecommunication products be made with accessible features such as adjustable fonts, distinct buttons, ridges or elevated marks on keys, and vibrating ringers (Jeager, 2006), that PWVDs got any specific benefit from the Universal Service Doctrine.

Today universal access has evolved to include provision of computer and Internet services, and the U.S. now boasts of a National Information Infrastructure (NII) that is more than telecommunication services per se, which is capable of enabling users all over the country to exchange data, video, music, information and anything else they could think of, in real time. Universal access is also applicable to all countries around the world; although this takes different forms in developed and developing countries. In developed countries it means household access for all as the first option, yet in developing countries access in public buildings, community centres, and commercial telecentres and internet cafes is the only achievable option in the short to medium term (Van Dijk, 2005). Furthermore, unlike developed countries, many developing countries are blighted by autocratic governments that are bent on deliberately hindering the diffusion of the Internet and other ICTs by reducing interest of potential users by either creating fear in them of government action or curbing good web content. Milner (2003) gave eight ways through which governments do this, including:

- Use of firewalls (proxy servers to scan email for "offensive" or prohibited content and to review all web traffic by checking URLs against a constantly updated blacklist);

- Forcing ISPs to install Routers capable of blocking offending IP addresses and even filtering content;

- Using software to filter all email and web traffic;

- Internet policing;

- Coercion through self-regulatory measures for ISPs;

- Restricted access by compelling all users to register with governments ISPs;

- Setting high access prices; and

- Developing a national Intranet that is solely controlled by government and which limits all contact with the global web.

The above government controls point to more problems in developing countries than mere lack of the means to cater for equitable access to information. However, a model that could be used to turn around a bleak digital situation for any given population is given by Tongia (2006), with four components including:

- People must know what can be done with ICTs (awareness);

- ICTs must be offered within reasonable proximity (availability);

- Consider the ability to use ICTs (accessibility in terms of literacy, language and interfaces);

- All usage of ICTs together should, ideally, be only a small percentage of one's income preferably under $10 \%$ maximum (affordability) - taking into account the total cost of ownership of hardware, software, connectivity and education.

In the same vein, Fuchs \& Horak (2008) discuss six strategies for bringing developing countries and their populations to par with developed countries. These are described and analysed below for their feasibility: 
1. Attracting foreign capital will increase wealth for all and access in developing countries. The argument is that liberalizing telecom and Internet sectors in developing countries will attract investment from large international corporations, which will result in economic growth that benefits all and lowers Internet and phone prices due to competition. Although this would make a good economic argument, it cannot ensure access to ICTs for all because investors from western countries come to the third world to seek opportunities for capital accumulation and not necessarily ensuring affordability of telephone and Internet services.

2. By entering into markets and competition, developing countries will be able to leapfrog directly into information societies. According to Davison, Vogel \& Harris (2000), technology leapfrogging means the implementation of a new and up-to-date technology in an application area in which at least the previous version of that technology has not been deployed. In developed economies, newer versions of technology are often used to upgrade older versions, but this is not possible in developing economies where older versions of technology are still prevalent. For example, the diffusion of broadband connectivity has been possible and faster in western countries (through Digital Subscriber Lines and cable modems) due to fixed telephone wirelines, which had been built over a long time. However, wireless technology offers a slim chance of ensuring broadband connection, only that it is likely to be expensive for majority of third world populations, and may not be in tandem with market liberalization. In addition, mobile devices are such that users find them difficult to produce information, except in a one-to-one mode (voice or data as SMS), making them consumers of information at best (Tongia, 2006). Even third-generation (3G) cellular systems, which would provide a relevant solution for combining data and voice, tend to be costly because carriers, who are often private, charge highly so as to recoup their investments in the shortest time possible.

Davison, Vogel \& Harris (2000) give a further argument against technology leapfrogging in developing countries: that successful use of Information Technology requires much more than mere installation and application of systematized knowledge. It also requires the application of implied knowledge regarding the organization and management of the technology and its application to the contextual environment in which it is to be used. Implied knowledge often represents experience with the deployment of previous technologies accumulated over time, which is probably not in abundance in many developing countries.

3. A 'wait and see' approach will reduced costs as market and technological development will cheapen access. This is in line with Compaine's (2000) approach to digital inequality; but as Fuchs \& Horak (2008) argue, the 'wait and see' strategy cannot solve the problem of digital inequality for third world countries because they are systematically excluded from wealth and technological progress.

4. Technologies for the developing countries. The argument here is for transporting old computers from rich to poor countries as means for solving the global digital divide. This is unfair because it transforms the third world into a dumping ground for electronic waste, just as it has been for other forms of waste and used clothes. Furthermore, the global digital divide will continue since the two worlds will be advancing at different paces technologically.

5. The developing world does not need technology. The argument here centers around catering for basic problems like poverty, health issues and illiteracy in developing countries; not ICTs that could be considered a luxury. But Fuchs \& Horak (2008) argue that access to ICTs is as 
fundamental a human right as any other, and denying it to a person or community is a blatant violation.

6. An integrated strategy combining the global redistribution of wealth, educational and health programmes, and digital literacy programmes; public and free access to computers and the Internet, Open Source technologies, and computers for the third world. This last strategy offers a combination of all the five strategies discussed above, reflecting the interconnectedness of technology access, social factors, uneven development, human rights and global capitalism. In so doing, the combined strategy for bringing developing countries and their populations to par with developed countries brings out a realization that digital exclusion is actually not a technological problem but an economic, social and political issue. Within the combined strategy the most viable component is Open Source Software or free software for third world users of ICTs. As Fuchs \& Horak (2008) put it, Open Source Software offers four kinds of freedom for the user: i) the freedom to run the programme for any purpose; ii) the freedom to study how the programme works and adapt it to specific needs; iii) the freedom to redistribute copies of the programme so that someone can help his neighbour; and iv) the freedom to improve the programme, and release these improvements to the public, so that the whole community benefits. Open Source Software is freely available on the Internet and constitutes an alternative model of production that questions proprietary production models. The most successful examples of Open Source Software include the Linux Operating system and an Internet browser known as Mozilla Firefox.

Despite their elaboration, none of the above strategies appears to offer a specific solution to the digital exclusion of such disadvantaged groups in LDCs as Persons with Visual Disabilities. This is so because the exclusion of PWVDs from ICTs goes beyond educational and economic considerations, touching instead on technology developers who do not consider assistive technology as a major priority. This then calls for examining whether the many policies advanced at the zenith of digital divide deliberations in the U.S. could be the ones to provide a better answer. Carveth \& Kretchmer (2002) grouped these into four clusters: marketplace interventions, philanthropy or community action, government action and private/public partnerships.

The marketplace intervention to the digital divide suggested fixing the problem by allowing the basic laws of demand and supply to be the primary engines for change. Here the market would fulfil consumers' evolving needs while government restricted itself to nurturing fair competition and funding basic research. Proponents of this solution advocated patience on the part of policy makers; thereby letting the market fulfil consumers' evolving needs, instead of rushing to create expensive and unwarranted new federal programmes (Carveth \& Kretchmer, 2002). This approach fits with the Diffusion of Innovations theory which recognizes the fact that most innovations spread slowly among adopters - starting from innovators to early adopters, the early majority, late majority and finally to the laggards. The free market proponents thus claim that the digital divide is not a question of 'haves and have-nots' but of 'have-nows and have-laters' because the prices of acquiring and using ICTs will keep on dropping as more and more people adopt them.

One example of philanthropic or community action was when Bill Gates, the Chairperson of Microsoft corporation, in direct response to the NTIA report of 1995, launched his campaign in 1996 to provide Internet access in America's public libraries. For Gates, the problem of the digital divide was of access to computers and the Internet, and training on how to use these tools effectively (Stevenson, 2007). Subsequently, by 2004 the Bill and Melinda Gates Foundation had installed 47,200 Internet-ready computers in almost 11,000 libraries across the U.S. and trained approximately 
62,000 library workers for this new initiative. Other examples of philanthropic or community action were 3Com Corporation, which donated $\$ 1$ million in networking equipment and consulting services to ten U.S. cities to help minorities and low-income families to access the Internet, and the Verizon Foundation which established an online resource centre to assist schools and libraries to apply for the federal "e-rate" programme and offered $\$ 500,000$ in workforce development grants to communities in Illinois and Indiana (Carveth \& Kretchmer, 2002).

Government action - at the federal, state and local levels - involved direct funding, and regulatory and tax policy for direct funding at the federal level, and the U.S. Department of Education allocated over $\$ 135$ million in grants to train 400,000 teachers to use ICTs more effectively in the classroom. In addition, the 'Kids 2000' Programme provided an average of 10 computers to each of the 2,300 boys' and girls' clubs in America together with Internet access and instructors to show the youths how to utilise the technology (Carveth \& Kretchmer, 2002).

An example of combatting the digital divide through public-private partnership was the Schools and Libraries Universal Service Fund. This funding programme allowed primary and secondary schools and libraries to receive basic and advanced telecommunications services at discounts ranging from 20 to $90 \%$ below commercially available rates. At the state level, one renowned example was the governor of Maine who pledged to provide every seventh-grader with a free laptop that he/she would keep after graduation. For local level action against the digital divide, one example was the Free Internet TV Initiative in LaGrange, cited in Hsieh et al. (2008). In April 2000 the LaGrange city government devised a three-way contract with the cable company (Chater Communications) and an Internet service provider (Worldgate Communications) to use the excess bandwidth of the communication infrastructure to provide an Internet TV service to every household at no additional cost. Thus, residents were able to receive Internet service without paying anything beyond the basic cable fee of $\$ 8.70$ per month. The Internet TV used a television-based Internet access device. Subscribers received a free wireless keyboard and digital set-top-box, which connected the cable, and users could browse the Internet via their TVs at the rate of 158 Kbits per second. In addition, they enjoyed unlimited access, a free e-mail service, $5 \mathrm{MB}$ of web space and a technical support hotline available seven days a week.

From what has been presented in this subsection, the policy options given by Carveth \& Kretchmer (2002) were those used in correcting the digital divide in the United States, and they thought the same would be applicable to combating the digital divide in Western Europe. Those options also seem more applicable to the situation in Sub-Saharan Africa than the six strategies discussed by Fuchs \& Horak (2008). In the context of universal access, the four different policy options by Carveth \& Kretchmer (2002) are quite practical in tackling issues of access to both computers and the Internet, and they seem to give appropriate interventions in terms of digital skills as well. However, neither of the two sets of strategy options for combating the digital divide (in both the developing countries and Western Europe) seem to take into account the unique challenges PWVDs find in the use of ICTs. This is the focus of the next subsection.

\subsubsection{Universal access policy interventions for persons with visual disabilities}

The previous section revealed remarkable differences in the efforts towards achieving universal access in developed countries and developing countries. However, the challenges of PWVDs in relation to access and use of digital technologies in the two situations are surprisingly similar. For instance, there is consensus that assistive technologies are expensive, which limits access to the right 
hardware and software solutions for people with various disabilities. The only exception is that some developed countries have devised ways of giving assistive technologies to their visually disabled citizens free of charge or at subsidized rates. For example in Norway, every county houses an assistive technology center which provides assistive technologies, free of charge, to people whose ability to function in everyday life is considerably and persistently reduced (Soderstrom \& Ytterhus, 2010). The common assistive technologies available at the centers include standard computer devices, ICT tools and equipment for handling computer and communication aids. In the U.S., a number of states work towards Assistive Technology projects implementing tax incentives such as removing state Sales Tax on many devices and pieces of equipment (National Council On Disability, 2000). A model is offered by the 2000 Missouri SCPE law, which provides for the distribution of affordable specialized equipment such as screen readers, screen magnification devices, speech recognition technology and adaptive keyboards to facilitate Internet access and e-mail by people with varying disabilities.

In terms of digital skills, since PWVDs use accessible technology, the training appropriate for them is hard to procure. Access technology requires specialist support, which is seldom available from local computer stores or independent retailers (Watling, 2011). Even where training packages are offered, usually on CD ROMs accompanying screen reader or screen magnifier programmes, much time can be spent in orientation rather than applying knowledge to practice.

In terms of use, solutions which focus on increased community-based access, for example in libraries, coffee shops and pubs, fail to take into account the diversity of ways in which PWDs make use of alternative assistive technologies (Watling, 2011). Here users are assumed to have the mobility to sit at a standard height workbench or table, use a standard computer keyboard or mouse and work with default monitor and system display settings.

Finally, technical assistance would be paramount in the use of ICTs for PWVDs. However, both faceto-face support and telephone assistance are overly expensive (Watling, 2011), and they often fail to take into account the degree of individual personalization required. The alternative would have been social support; but the benefit PWVDs can get from this is also minimal, hampered by the scarcity of information about accessibility in ICTs. Repeatedly, lack of information, professional training, and local support services have been identified as key barriers to the rollout of accessible technology (Tobious, 2003). This is hardly the case for mainstream information and electronic technology products, whose presence is announced everywhere in advertising, ubiquitous retail establishments, and through observing and communicating with other consumers.

\subsection{Conclusion}

The literature reviewed in this chapter has given a broad view of digital exclusion, which starts from the technology itself, then to the humans who should make the decision to use or not use the technology and finally to the policies of various countries that should determine the type of usage their citizens would put technology to. Since PWVDs are at the core of the entire dissertation, it is interesting how they fit into this three dimensional equation of exclusion.

Indeed the literature review left a number of gaps in knowledge that could only be bridged by conducting field research. First, there was surprisingly little information on the use of ICTs by PWVDs, which is because research on persons with disabilities tends to lag behind that involving the 
general population. For instance, it would be quite unusual for a conventional researcher to consider investigating the adoption of screen readers and screen magnifiers because these serve a small marginalized group of people. This is even worse in countries classified as developing where, until recently, Internet access in areas such as Sub-Saharan Africa has been bad for everyone. Only in the past few years has the use of ICTs become a part of everyday life with the advent of increased mobile Internet coverage through the availability of $3 \mathrm{G}$ networks and improved undersea cable Internet links. Therefore, a paucity of academic work on this topic would be expected. A major gap in knowledge is thus simple basic information on what type, and how ICTs are used by PWVDs; so that putting in place a plan of diffusing them would alleviate digital exclusion of this social group in Uganda. This gap in knowledge is researched in Chapter 4.

Flowing on from the above lack of basic information on the use of ICTs by PWVDs, there is a major gap in knowledge surrounding the human dimension of restriction expressed as barriers that prevent PWVDs from becoming digitally included in society. In other words, it is not clear what motivational, material, skills and use factors affect Ugandans with visual disabilities when they try to become part of the digital world. So far the literature reviewed in this chapter has shown that demographic factors including age, education, gender, geographical location, income, occupation and race are predictors of the differences between haves and have-nots in terms of the possession of Information and Communication Technologies. However, these do not clearly demonstrate where persons with disabilities (PWVDs inclusive) fall in such categorisations; because they are capable of identifying with the disadvantages emanating from any of these factors. This gap is addressed in Chapter 5.

On a similar note, the literature reviewed in this chapter has shown that the policy environment around the world is not well informed about the way laws and policies can be formulated to effectively address the digital needs of PWVDs. This chapter, for instance, revealed marked differences between how developed and developing countries have handled issues of access and use of ICTs for the general population. The same has even pervaded the approaches for addressing access to the new digital media for Persons with disabilities apart from the cost of assistive technologies that remains high across all countries; and the tendency towards standardization rather than specialization in the provision of digital skills across a wide spectrum of ICT users. An attempt to address this gap in knowledge is covered in Chapter 6. 


\section{Chapter 3 Methodology}

\subsection{Introduction}

This chapter presents the philosophy underpinning this research and its methodological framework as a whole. The philosophy followed was born from an acknowledgement by Johnson \& Onwuegbuzie (2004: p. 15) that "today's research world is becoming increasingly interdisciplinary, complex and dynamic; therefore, many researchers need to complement one method with another, and all researchers need a solid understanding of multiple methods used by other scholars to facilitate communication, to promote collaboration, and to provide superior research." As an example elaborating their acknowledgement, the two authors go on to suggest that qualitative researchers should be free to use quantitative methods, and quantitative researchers should be free to use qualitative methods.

Indeed the claims that qualitative research uses words while quantitative research uses numbers are overly simplistic (Brannen, 2007: p. 175). Further, a claim that qualitative studies focus on meanings while quantitative research is concerned with behavior is not fully supported since both may be concerned with people's views and actions.

The acknowledgement by Johnson \& Onwuegbuzie (2004) discussed earlier fits well with the pragmatism philosophy, which takes an explicitly value-oriented approach to research. It applies the logic of moving back and forth between induction and deduction (abduction), subjectivity and objectivity (intersubjectivity), and context and generality (transferability) in its inquiry. Of the many uses pragmatism can offer, Johnson \& Onwuegbuzie (2004: p. 17) said it offers a practical and outcome-oriented method of inquiry that is based on action and leads, iteratively, to further action and the elimination of doubt.

Putting pragmatism into the real perspective of this research, it can safely be said this dissertation is anchored in understanding the interaction between PWVDs, technology and society, which required using various methods and techniques to uncover more than what previous researchers had achieved on the same subject within the ambit of the digital divide. Previous researchers investigated PWDs in general terms (without acknowledging existing differences amongst them; yet this dissertation argues that any generalization of people around the access to and use of ICTs tends to blur their technological requirements. The resultant effect is for some people not getting the benefits of most technological advancements at the same time with the rest of society. For PWVDs in particular, they often get the benefits of ICTs after relevant modifications have been made to those technologies. This simply means they will miss the benefits accruing from some new technologies altogether if modifications to them are forgotten or ignored.

The methodological framework suiting the demands of the above philosophical assumptions was found to be a Mixed Methods Research (MMR) approach. By definition, MMR refers to the class of research where the researcher mixes or combines quantitative and qualitative research techniques, methods, approaches, concepts or language into a single study (Johnson \& Onwuegbuzie, 2004: p. 
17). Furthermore, the mixed method approach is premised on the idea that the use of quantitative and qualitative approaches in combination provides a better understanding of research problems than either approach alone (Creswell \& Plano Clark, 2007). This better understanding results because mix methods offer strengths that offset the weaknesses of separately applied quantitative and qualitative research methods.

One major weakness of quantitative approaches is that measurement typically detaches information from its original ecological "real world" context (Castro et al., 2010). The limitations of qualitative approaches, on the other hand, would include difficulties in the reliable integration of information across observations or cases; and difficulties in assessing links and associations that occur between observations, cases, or constructs (Castro et al., 2010). Also, qualitative research methods often lack well-defined prescriptive procedures; thus limiting the capacity for drawing definitive conclusions an important aspect of scientific research. In addition, purely qualitative studies (say phenomenology, ethnography, grounded theory or case study research) have been challenged for their small or unrepresentative samples, and thus their limited capacity to produce generalizable findings.

Conversely, choosing a mixed methods research approach would again imply drawing on the strengths of both quantitative and qualitative approaches. According to Castro et al. (2010: p. 342), those of quantitative approaches which MMR would draw on include: a) accurate operationalization and measurement of a specific construct; b) the capacity to conduct group comparisons; c) the capacity to examine the strength of association between variables of interest; and d) the capacity for model specification and the testing of research hypotheses. On the other hand, the strengths of qualitative approaches include: a) the capacity for generating reach detailed accounts of human experiences (emotions, beliefs and behaviours); and b) narrative accounts that are examined within the original contexts in which observations occur.

But choosing an MMR approach did not take just garnering the strengths of both quantitative and qualitative methods and offsetting their weaknesses. For instance, Bryman (2008) gave three other reasons for using mixed methods, which were found relevant to this research:

- Completeness - to bring together a more comprehensive account of the area of enquiry;

- Explanation - to use qualitative methods to explain some of the data generated through quantitative methods; and

- Credibility - to enhance the integrity of findings.

Table 3.1: Presenting the nine characteristics of Mixed Methods Studies

\begin{tabular}{|l|l|}
\hline Number & Characteristic \\
\hline 1. & Methodological eclecticism \\
\hline 2. & Paradigm pluralism \\
\hline 3. & Iterative, cyclical approach to research \\
\hline 4. & Set of basic (signature) research designs and analytical processes \\
\hline 5. & Focus on the research problem in determining the methods employed in any given study \\
\hline 6. & Emphasis on continua rather than a set of dichotomies \\
\hline 7. & $\begin{array}{l}\text { Emphasis on diversity at all levels of the research enterprise } \\
\text { community" }\end{array}$ \\
\hline 8. & Reliance on visual representation (figures and diagrams) and a common notational system \\
\hline 9. &
\end{tabular}


Tapping maximum benefit from all the above reasons demanded wide readership on MMR, followed by a meticulous application of whatever was found relevant to this research. One useful guide was a journal article by Teddlie \& Tashakkori (2012), which gave nine common core characteristics of mixed methods studies as summarised in Table 3.1.

As presented in the Table 3.1, the term methodological eclecticism means that practitioners of mixed method research can select and creatively integrate the most appropriate techniques from a wide variety of qualitative, quantitative and mixed strategies in order to thoroughly investigate the phenomena of interest (Teddlie \& Tashakkori, 2012: p. 776). This was the real impetus towards choosing the MMR approach for this research. However, Yanchar \& Williams (2006) cautioned that "it is important to recognize that the adoption of a method will implicitly commit researchers who use it to certain kinds of assumption-based outcomes that both reveal and conceal (or obscure) phenomena in particular ways and that bring with them certain affordances and limitations." Indeed there are limitations the researcher found in applying MMR, and these will be declared in an appropriate section of this chapter.

The second characteristic of MMR presented in Table 3.1 is paradigm pluralism, which is a belief that a variety of paradigms may serve as the underlying philosophy for the use of mixed methods (Teddlie \& Tashakkori, 2012: p. 779). The present research oscillates between pragmatism and critical theory, which broadly combine to offer the best approach for answering the questions of this research.

The third characteristic of MMR is the iterative, cyclical approach to research. To elaborate on this, Teddlie \& Tashakkori (2012: p. 781) contended that "MMR is characterized by a cycle of research, which includes both deductive and inductive logic in the same study or program of study". The two authors go on to argue that research may start at any point in the cycle -- from theories or abstract generalizations or from observations or other data points. Morgan (2007) suggested a third type of logic relevant to MMR, known as abduction, where a researcher moves back and forth between induction and deduction (first converting observations into theories and then assessing those theories through action). This research attempted to apply a cyclical approach to research by using theories (say the Diffusion of Innovations theory) in its inquiry while relying on observations and other data points to arrive at certain conclusions.

The fourth characteristic of MMR is a set of basic "signature" research designs and analytical processes. Teddlie \& Tashakkori (2012) give several examples of the signature processes, such as parallel mixed designs, conversion mixed designs, and sequential mixed designs. Indeed the next section of this chapter attempts discussing several research designs in a bid to logically arrive to the one most appropriate for this particular research.

The fifth characteristic, as presented in Table 3.1, is focusing on the research problem in determining the methods employed in any given study. Creswell and Tashakkori (2007) argue that a strong mixed methods study starts with a strong mixed methods research question or objective. This means the methods to be used in a mixed study are better implied right at the problem level. Although this particular research did not follow that logic, it is important to show the various options the two authors suggested for formulating, stating and exploring MMR questions; hence:

1. Write separate quantitative and qualitative questions, followed by an explicit mixed methods question. 
2. Write an overarching mixed (hybrid, integrated) research question, later broken down into separate quantitative and qualitative sub questions to answer in each strand or phase of the study.

3. Write research questions for each phase of a study as the study evolves.

The sixth characteristic of MMR is about emphasis on continua rather than a set of dichotomies. This simply means that rather than using dichotomies of positivism vs. constructivism; quantitative vs. qualitative; and probabilistic vs. non-probabilistic, mixed methods studies should be placed on continua that include all the mentioned aspects as part of a mixed approach. As exemplified in the empirical chapters of this research, it is possible to use numbers and at the same time involve interpretation; or use narrative data but involve some kind of counting.

The seventh characteristic is emphasis on diversity at all levels of the research. This is further emphasis on doing research on a continuum rather than sticking to either a qualitative or quantitative approach even where it may not serve the purpose of a study. Diversity also means that mixed methods are used with the hope of obtaining divergent pictures of the same phenomenon; and ideally the divergent findings would be compared and contrasted. Comparison of results obtained from different methods is one of the motivations for the current research.

The eighth characteristic is a tendency toward balance and compromise that is implicit within the "third methodological community". Mixed Methods Research is the third methodological community being referred to here, and according to Johnson \& Onwuegbuzie (2004: p. 18), it is a movement that moves past the recent paradigm wars by offering a logical and practical alternative. Philosophically, mixed research makes use of the pragmatic method and system of philosophy. Its logic of inquiry includes the use of induction (or discovery of patterns), deduction (testing of theories and hypotheses), and abduction (uncovering and relying on the best of a set of explanations for understanding one's results).

The ninth and final characteristic of MMR is reliance on visual representation (figures and diagrams) and a common notational system. The diagrams use geometric shapes (boxes and ovals) to illustrate the steps in the research process (say data collection, data analysis) and arrows made with solid lines (4) to show the progression through these steps (Creswell \& Plano Clark, 2007). The illustrative nature of this approach makes figures (tables, matrices, charts, graphs and Venn diagrams) also inevitable. Finally, a common notational system has been adopted by several scholars to convey the complexity of mixed methods designs and perhaps to distinguish MMR from the traditional (qualitative and quantitative) research approaches. An example of a notational system common with MMR is given by Creswell \& Plano Clark (2007), where a shorthand "quan" and "qual" is used to illustrate the equal stature of the two methods (i.e., both abbreviations have the same number of letters and same format). For example, QUAN + QUAL indicates that both the quantitative and qualitative methods were used concurrently during the research, and both had equal emphasis; QUAL 4 quan indicates that the methods were used in a sequence, with the qualitative methods being used before the quantitative methods and the former emphasized in the study; and QUAN (qual) indicates that the qualitative methods are embedded within a quantitative design. 


\subsection{Study design}

As already mentioned, this study used a mixed method research design. According to Leech \& Onwuegbuzie (2009), MMR represents research that involves collecting, analysing and interpreting quantitative and qualitative data in a single study or in a series of studies that investigate the same underlying phenomenon. However, this definition is too general to pin point the exact design used in this research because, just like quantitative and qualitative approaches, MMR has several research designs to choose from. Zeroing down on the most appropriate design therefore required scanning through several typologies found in the mixed methods literature. According to Teddlie \& Tashakkori (2006), typologies provide a variety of paths, or ideal design types, that may be chosen to accomplish the goals of a study. Teddlie \& Tashakkori (2006) listed seven criteria that various authors have used to create mixed methods design typologies. These include: 1) number of methodological approaches used, 2) number of strands or phases, 3) type of implementation process, 4) stage of integration of approaches, 5) priority of methodological approach, 6) functions of the research study and 7) theoretical perspective. Bryman (2006: p. 98) was in agreement with five of the seven criteria mentioned by Teddlie \& Tashakkori, remaining silent on priority of methodological approach and theoretical perspective.

The earliest known typology was by Greene, Caracelli \& Graham (1989), which had five dimensions based on functions of the research study and seven design characteristics. The five dimensions included:

1. Triangulation (seeks convergence, corroboration, correspondence of results from the different methods),

2. Complementarity (seeks elaboration, enhancement, illustration and clarification of the results from one method with the results from the other method),

3. Development (seeks to use the results from one method to help develop or inform the other method),

4. Initiation (seeks the discovery of paradox and contradiction, new perspectives of frameworks, the recasting of questions or results from one method with questions or results from the other method), and

5. Expansion (seeks to extend the breadth and range of inquiry by using different methods for different inquiry components).

A typology by Teddlie \& Tashakkori (2006) had four different families of mixed methods designs sequential, concurrent, conversion, and fully integrated designs. There is also a typology by Creswell \& Plano Clark (2007), which has four design types based on weighting, timing and the level of mixing. These include: 1) the triangulated design - to obtain different but complementary data; 2) the embedded design - in which one data set provides a supportive secondary role; 3) the two-phase explanatory design - which builds or explains quantitative results; and 4) the exploratory design which is also two-phased but led by the qualitative aspect. There were many more typologies to draw from but as observed by Collins \& O'Cathain (2009), these cannot address sufficiently the wide range of mixed methods designs implemented in various fields. In some cases they delineate only minimally the information required by the researcher, or give inconsistent information, or present overly complex information. 
However, the researcher for the present study found a typology by Leech and Onwuegbuzie (2009) as having the closest semblance to what would represent his practical arrangements in the field. For this typology, determining any particular design would take into account three dimensions basing on:

a) whether the level of mixing in the research would be partial or full;

b) whether or not the quantitative and qualitative phases of the research would occur at approximately the same point in time (concurrent versus sequential); and

c) Whether both quantitative and qualitative phases of the research would have approximately equal emphasis (equal status versus dominant status) with respect to addressing the research question(s).

To put it more succinctly, this study followed a fully mixed concurrent equal status design, which involved mixing qualitative and quantitative research within one or more or across four components research objective, type of data and operations, type of analysis, and type of inference (Leech \& Onwuigbuzie, 2009). In this design, the quantitative and qualitative phases are mixed concurrently at one or more stages or across the components. Both elements are given approximately equal weight.

Figure 3.1 Presenting the overall design for the study

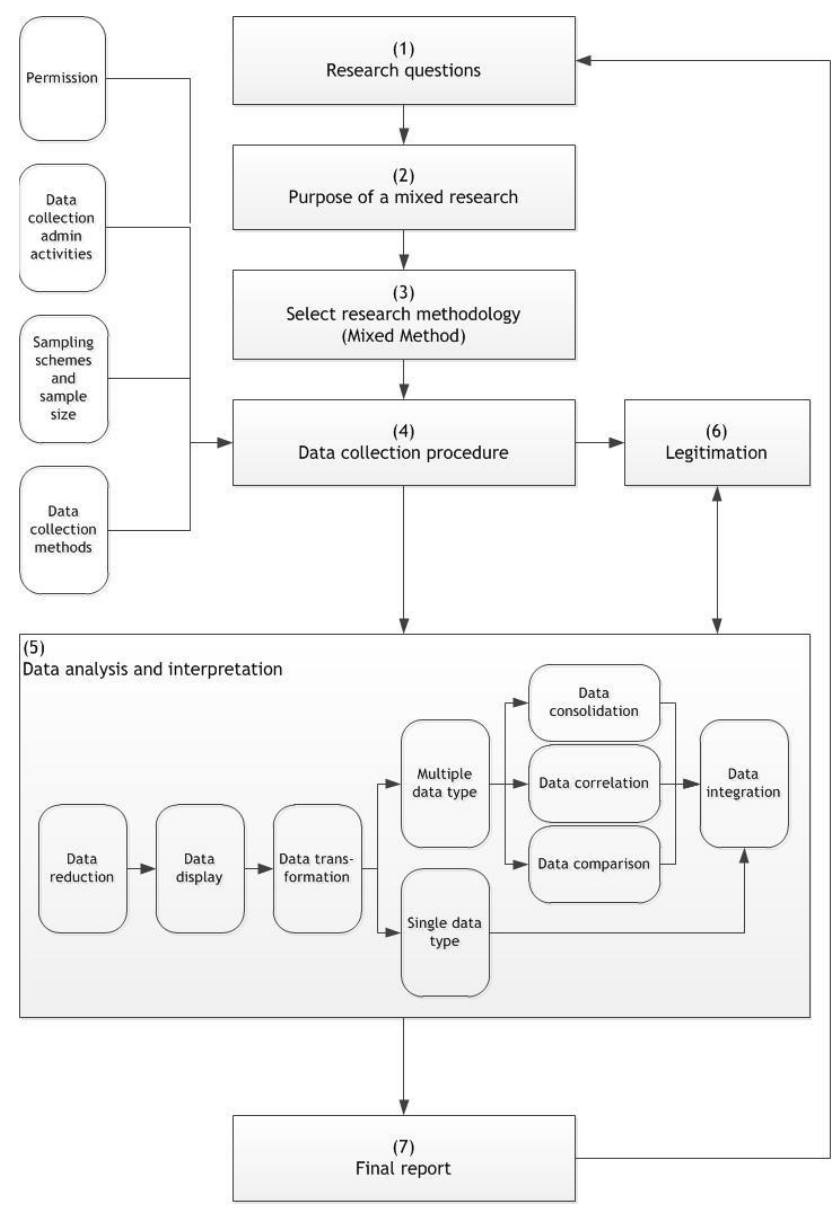


To give a practical explanation of the design in relation to this particular research, it can be revealed there were two fieldwork undertakings (done in 2010 and 2011) involving a quantitative survey and a qualitative study for each. The surveys were conducted on respondents with visual disabilities in Uganda to establish their level of orientation to ICTs (especially computers, mobile phones and the Internet). The surveys also captured demographic factors of respondents for purposes of analysing the data that was subsequently collected.

The qualitative studies were phenomenological, conducted to confirm or explain certain data from the surveys. For example, the first qualitative study was aimed at tapping into the experiences of respondents to explain the barriers against the adoption of assistive technologies (screen readers and screen magnifiers) in Uganda. The second qualitative study involved respondents who were fairly skilled in using all the three ICTs under focus (computers, mobile phones and the Internet), and the aim was obtaining an in-depth understanding of the personal constraints of PWVDs towards access to ICTs in Uganda. An additional qualitative study was conducted, as part of the second fieldwork, to find out the policy gaps towards access and use of ICTs by PWVDs in light of the universal access policy. The necessity for this additional study was the literature review in Chapter 2, which revealed several policy strategies or options that had been used to combat the digital divide in various countries (or blocks of countries), and the same would be used to determine the type of access to ICTs for Persons with Visual Disabilities.

\subsection{Study setting}

This research was carried out in Uganda which, according to the Digital Access Index (DAI), was ranked as one of the low access economies around the world. This means Uganda is one of the countries known as LDCs. The DAI measures the overall ability of individuals in a country to access and use ICTs (ITU Telecommunication Development Bureau, 2003: p. 7), which is in terms of infrastructure, affordability, knowledge, quality and actual usage.

In terms of geographical location, Uganda is one of the five countries that make up the East African Community. Its total surface area is 241,039 square kilometres. It is bordered by South Sudan to the north, Kenya to the east, Tanzania to the south, Rwanda to the southwest and the Democratic Republic of Congo to the west. Uganda lies between $1500-2000 \mathrm{~m}$ above sea level along the equator between latitudes $4^{\circ} 12^{\prime}$ to the north and $1^{\circ} 9^{\prime}$ to the south and between longitudes $29^{\circ} 34^{\prime}$ to the east and $35^{\circ} 0^{\prime}$ to the west. The Uganda National Household Survey (UNHS) of 2009/10 estimated the population of Uganda at 30.7 million. $49 \%$ of this was male and $51 \%$ female.

Uganda was chosen for this research because it is one of the few countries on the African continent with good laws and policies for Persons with Disabilities. However, these contrast sharply with the lack of provisions for the same people in relation to ICTs. To start with the laws and policies for PWDs, the constitution of the Republic of Uganda (1995) carries a specific provision (article 35) stating that PWDs have a right to respect and human dignity. This is backed up with several laws with provisions on disability, such as the Local Government Act (1997), Parliamentary Elections Act (2005), Persons with Disabilities Act (2006) and the Equal Opportunities Commission Act (2007). However, Uganda has no comprehensive legislation catering for the use of ICTs by PWDs. The Communications Act (1997) and the National Information Technology Authority - Uganda Act (2009) only refer to disability as part of special interest groups in general. 
Sites for this research were selected from six districts covering the four regions of Uganda. Thus Mbarara was selected from the west, Kampala and Mukono from the central, Iganga and Soroti from the east, and Gulu from the north. However, sites were also determined from districts with known concentrations of PWVDs around the country. These included five secondary schools and two public universities and one Primary Teachers' College - all having special units for students with visual disabilities, and several organisations where PWVDs worked from.

\subsection{Data collection procedure}

Collecting data takes a number of phases that make up the data collection step in research. According to Creswell and Plano Clark (2007), these phases include the sampling procedures, permissions, types of information collected, forms for recording the data, and the activities involved in administering the data collection. Below is a similar sequence of the phases followed in this particular research.

\subsubsection{Sampling schemes and sample size}

The sampling scheme denotes the explicit strategies used to select units of analysis (people, groups, settings and events), whereas sample size indicates the number of units selected for the study (Collins, Onwuegbuzie \& Jiao, 2007: p. 271; Collins \& O'Cathain, 2009). In MMR, the researcher has to make sampling scheme and sample size considerations for both the qualitative and quantitative phases of the study. For the studies in this particular dissertation, people and settings were the crucial elements in the sampling procedure. In so doing, varying sample sizes and schemes were employed to gather as much data as would answer the research questions. Teddlie \& Yu (2007: p. 77) said the sampling strategies for MMR involve the selection of units or cases for a research study using both probability sampling (to increase external validity) and purposive sampling strategies (to increase transferability).

Figure 3.2: Sampling design for this research

\section{PHASE 1}

Time orientation

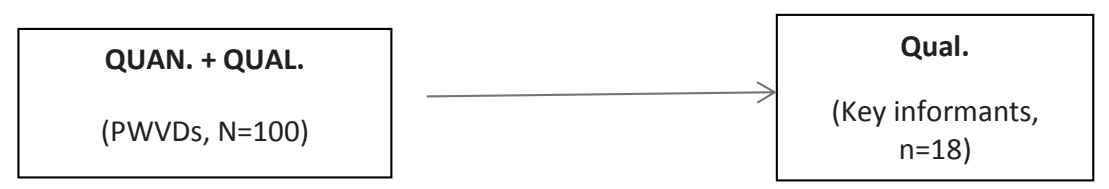

PHASE 2

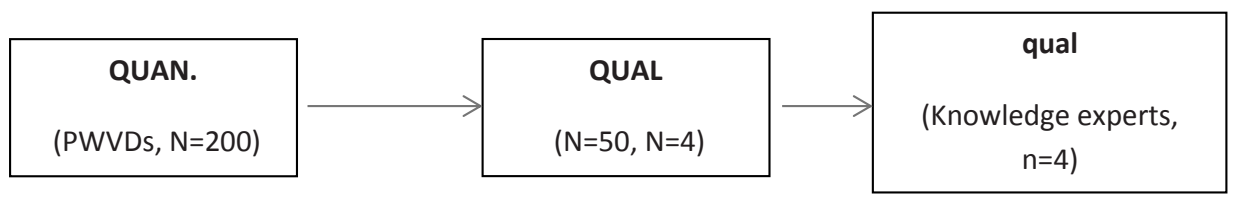

Notation: "qual" stands for qualitative, "quan" stands for quantitative, "+" stands for concurrent, " $\rightarrow$ " stands for sequential, capital letters denote high priority or weight, and lower case letters denote lower priority or weight. 
Regarding studies in this particular dissertation, the sites from which respondents and key informants were selected included learning institutions (universities, secondary schools and a primary teachers college) plus organizations where both types of people were employed. However, defining a specific population from which to select a random sample was hard due to the scanty information about users of ICTs in Uganda who are visually disabled. What brought about the information scarcity was PWVDs constituting just part of a bigger group of PWDs who are not properly disaggregated due to the multiplicity of definitions of disability. For example, the UNHS (2009/10) put the number of PWDs at $16 \%$ of Uganda's population basing on people's abilities rather than physical characteristics (UNHS 2009/10: p. 139). On the contrary, the UNHS (2005/06) put the number of PWDs at $7 \%$ of the population basing on physical characteristics (UNHS 2005/06: p. 130).

A further complication for this study, deriving from the literature review, was demanding PWVDs with a high likelihood for using ICTs as respondents. This meant having some education, income and engagement in some employment. There were no clear records of PWVDs with such characteristics in Uganda; so only non-random sampling was feasible. Figure 3.2 illustrates the sampling schemes used in this research.

To explain the above figure, for the first survey the sample size was $\mathrm{N}=100$, and both the convenience and chain sampling schemes were used for selecting the respondents. The convenience sampling scheme involves drawing samples that are both easily accessible and willing to participate in a study (Teddlie \& Yu, 2007: p. 77). For this specific study, the cost of accessing the sampling units (who included PWVDs with a high likelihood of using ICTs) was the driving factor for selecting this sampling scheme; because they had to be identified from various secondary schools, universities and places of work around the country. For chain (or snowball) sampling, this is an approach for locating information-rich key informants or critical cases (Patton, 1990: p. 177). The process begins by asking well-situated people who know a lot about a given phenomenon, who will then direct a researcher to others to talk to. As the number of new information-rich people to talk to accumulates, the chain grows bigger and bigger. For this particular study, it was often the teachers, who were themselves part of the sample, that acted as the beginners of the chains by leading the researcher to the several students with visual disabilities in their respective schools.

The sample for the second survey was $\mathrm{N}=200$, again selected through a combination of convenience and chain sampling schemes. However, the sample for the second survey was different in two other ways besides size. One is that the second survey covered more places around the country than the first; and its respondents were subjected to questions quite different from those of the first survey.

For the two qualitative studies, again various sampling schemes were used to select the respondents. The sample for the first qualitative study did not change from that of the survey; but an addition of 18 key informants (ICT service providers) were selected using criterion sampling to complement the survey data. The logic of criterion sampling is to review and study all cases that meet some predetermined criterion of importance (Patton, 1990: p. 176). In this case the selection criterion was for service providers (managers of internet cafes, customer relations personnel at mobile phone companies, ICT trainers and importers of various ICT products) to demonstrate serving clients with visual disabilities at some point in the course of their work.

The sample for the second qualitative study was $\mathrm{N}=50$, and again the criterion sampling scheme was used to select them from the 200 respondents that had taken part in the survey. The criterion for 
selecting the 50 respondents was capability of using all the three ICTs under focus (computers, mobile phones and the Internet). This meant excluding all the respondents who were not users of the Internet.

As part of the second phase of fieldwork, another qualitative inquiry involving a sample of $\mathrm{N}=4$ was carried out. These were knowledge experts selected using the expert sampling scheme. In this scheme the researcher is looking for individuals who have particular expertise that is most likely to be able to advance the researcher's interests and potentially open new doors (Palys, 2008). In this particular study, the role of knowledge experts was to discuss the gaps in the Ugandan laws and policies on the distribution and use of ICTs in relation to Persons with Visual Disabilities.

\subsubsection{Data sources and methods}

According to Verschuren \& Doorewaard (2005), two types of information are important in any research project - data and knowledge - which can be gathered from five sources: people (as respondents, informants or knowledge experts), the media (radio, television and newspapers), reality, documents and literature. Naturally, extracting data and/or knowledge from the five sources requires various methods including interview, questionnaire, gathering observational data, using measuring instruments, content analysis, and search methods. Right from the outset, using measuring instruments was considered an irrelevant method for this study since it fits more with natural sciences rather than a social science. Content analysis was also not used because there was no need for analyzing a large quantity of existing texts or other media-content for determining the presence and meaning of certain words or concepts. Rather, any concepts that the researcher found in the course of undertaking this research actually emerged purely from data he personally collected through various other methods interviews, questionnaires, field notes, documentary analysis and Internet search.

This research was set out to answer three broad questions, each of which requiring several data and knowledge sources as well as data-collection methods. These are explained below:

1) What are the barriers to the adoption of screen readers and screen magnifiers in Uganda?

Three data sources (PWVDs, ICT service providers and the new digital media) were found relevant for this question. The data-collection methods included a semi-structured questionnaire for respondents with visual disabilities (Appendix 1), a key informant interview guide (Appendix 2) and the Internet search method. the semi-structured questionnaire was administered to 100 respondents and it was made up of four sections - the first containing 7 questions asking for personal bio data, the next two having questions (13 each) related to use of computers and mobile phones, and the last section having 6 questions related to the Internet. An Internet search was also carried out to find more corroborating information for some answers given in the semi-structured questionnaire. The key informant interview guide had 18 questions that were administered to a sample of 18 ICT service providers identified during the fieldwork. The researcher identified these in the vicinity of or at the sites where respondents with visual disabilities resided.

2) How does the cumulative and recursive model of successive kinds of access to digital technologies contribute towards understanding the constraints in digital technology inclusion for PWVDs in Uganda?

The data source for this question was respondents with visual disabilities. A closed questionnaire (Appendix 4), an interview protocol (Appendix 5) and field notes were used to collect the required data. The closed questionnaire was administered to 200 respondents in form of a survey. It had two 
sections - the first (with 8 questions) capturing personal bio data and the second (with 9 questions) for capturing data relating to the experience of respondents with ICTs. The Interview protocol had four sections - the first three capturing data relating to experience of respondents in the three ICTs under focus (computers, mobile phones and the Internet); and the last section had two questions administered on a Likert scale. It is worth noting that study assistants who administered this interview protocol were also asked to record any peculiar information at the interview sites, which would form additional field notes to be used during data analysis.

3) How has the universal access policy in Uganda ensured access to ICTs for persons with visual disabilities?

Knowledge experts (officials in government regulatory agencies for ICTs), literature and policy documents were the data sources for this question. An interview guide for knowledge experts (Appendix 6) and document review were the two methods used to collect the required data. The interview guide, administered to the knowledge experts, had 14 questions. The document review was an exercise done in complement to the interview guide, where government laws and policies related to ICTs, some international instruments relating to ICTs and PWVDs, and documents (books and articles) with examples of how ICTs are made available to PWVDs were read for purposes of getting more corroborating information to the data obtained through interviews with the knowledge experts.

\subsubsection{Permission}

In as far as permission was concerned, two requirements were fulfilled. First was obtaining a letter from the key research supervisor (see Appendix 3) to be used in introductions to the various institutions from which data would be collected. The letter stated the purpose of the research, which was academic advancement, and it requested for permission to access all the co-operation obtainable from the officials in charge of those institutions. Many of these were head teachers of secondary schools and officers in charge of disability affairs at the two public universities and the primary teachers college as well as managers of organizations where potential respondents worked.

Second was a cover letter or introduction section on questionnaires and interview guides (see Appendices 1 and 2), which the researcher designed to explain the purpose of the research and ask for the consent of prospective respondents and key informants to take part in the research. A specific commitment was undertaken in this letter or section to keep the participation of individuals confidential and anonymous. Thus nobody was coerced into participating in this research.

\subsubsection{Activities involved in data collection administration}

As guided by Creswell \& Plano Clark (2007), a helpful way to conceptualize data collection in MMR is to consider data collection as occurring concurrently or sequentially. In this case it was concurrent; hence both qualitative and quantitative data were largely gathered at the same time and at the same sites. But two concerns had to be addressed before gathering data. One of these was whether the same or different individuals would be selected for the quantitative and qualitative strands of the study. The same individuals were selected, as much as possible, to take part in both the quantitative and qualitative strands of this particular study. However, in the first fieldwork it was found necessary to seek the opinions of service providers in order to corroborate the findings from respondents with visual disabilities. Even for the second fieldwork it was necessary to find out the perspectives of knowledge experts on the implementation of laws and policies regarding ICTs; hence their inclusion as a distinctive sample. The second concern was about whether or not the sample sizes for the two strands of research would be the same. As already illustrated in Section 3.3.1 above, the samples for 
qualitative studies were largely smaller than for the quantitative studies. This is because the qualitative studies played complementary rather than comparison roles to the surveys.

After developing the data-collection instruments (questionnaire and the interview guides), a pretesting exercise was conducted on some of the would-be study respondents. This brought out a number of flaws such as vagueness in some questions and addition of more questions, which were corrected before going to the field.

Following the pre-testing exercise and the correction of flaws on the data-collection instruments, the researcher identified two research assistants and trained them to assist in the fieldwork. These had to learn probing techniques in case of conducting interviews, and to tick or fill in questionnaires appropriately. The research assistants were also very useful in observing actions that could be entered in the field notes as part of the data-collection process. Training was therefore necessary for the research assistants because the topics of study were new to them. Further, they had to be taken through some of the key concepts regarding ICTs so they are able to make correct inferences from comments made by respondents before recording them down.

The activity of data-collection itself involved three sub-tasks. First was seeking the consent of respondents as to whether or not they would participate in the study. After agreeing to this the next step was taking the respondents through a set of questions requiring ticking or filling in short answers (in the case of survey questionnaires) or asking questions to which lengthy answers were recorded on interview schedules (in case of interviews). Field notes were also written down, which were not necessarily following the questionnaire or interview patterns, but were in any case relevant for the studies being conducted at any one given time. Photographs were also taken, just in case they could illustrate certain field events.

Finally, at the end of each day in the field the research team carried out reviews of the work done so far and made all necessary corrections on any questionnaire or interview script before embarking on the next day's work. Errors of a grammatical nature would be corrected immediately; but factual errors were always corrected after going back to specific respondents for clarification.

\subsection{Data analysis}

As stated by Creswell \& Plano Clark (2007), the type of data analysis varies depending on the type of mixed methods design used. This particular research used a concurrent mixed methods design, where the quantitative and qualitative data analyses are kept separate. From that understanding, the researcher found it most convenient to follow the five steps given by Creswell \& Plano Clark (2007), which they argued researchers usually go through when analysing both qualitative and quantitative data. These steps include:

i) Preparing the data for analysis - involving converting the raw data into a form useful for data analysis. For the quantitative aspect of research, this means scoring the data by assigning numeric values to each response, cleaning data entry errors from the database, and creating special variables needed for analysis, such as recoding items on instruments with inverted scores or computing new variables that comprise multiple items that form scales. This particular task was required in two empirical chapters (Chapter 4 and 5) and it was completed using SPSS with the help of a data-entry expert. Preparing qualitative data means organizing the document or visual data for review or transcribing text from interviews and observations 
into a word-processing file for analysis. In this particular situation, the sort of data preparation engaged in by the researcher was manually typing out interview transcripts and notes from field observations into word-processing files using a computer.

ii) Exploring the data - involves examining the quantitative data with an eye to developing broad trends and the shape of the distribution; or reading through the qualitative data, making memos, and developing a preliminary understanding of the database. In this particular situation, exploring data involved conducting a descriptive analysis on the quantitative data to establish the variance of responses to determine the general trend in the data. Descriptive statistics were generated for all major variables in the study, especially the independent and dependent variables. For qualitative data it entailed undertaking a general review of all data gathered, followed by recording initial thoughts by writing short memos in the margins of interview transcripts and field notes. The initial thoughts were later used in forming broad themes.

iii) Analysing the data - this consists of examining the database to address the research questions or hypotheses for both quantitative and qualitative analysis. Analysis also means organizing and interrogating data in ways that allow researchers to see patterns, identify themes, discover relationships, develop explanations, make interpretations, mount critiques, or generate theories (Leech \& Onwuegbuzie, 2007: p. 563). It often involves synthesis, evaluation, interpretation, categorization, hypothesizing, comparison, and pattern finding. For quantitative research, the researcher uses the appropriate statistical test to address the questions or hypotheses. In two of the three empirical chapters of this dissertation where quantitative data were collected, several relations were established between the dependent variables (access and use of various ICTs by PWVDs) versus independent variables (age, education level, gender, income, location and occupation). Specific to Chapter 4, degree of blindness was also examined as an independent variable; because it was considered vital in understanding the adoption of screen readers and screen magnifiers by Ugandans with visual disabilities. Another unique set of variables was in Chapter 5, generated from data collected on a Likert Scale in regard to Computer Self-Efficacy and Internet Self-Efficacy. These included the dependent variables (confidence levels of respondents with visual disabilities) and the independent variables (type of computer and Internet training; plus time spent after training in computers and Internet). Findings from these would indicate whether or not Computer SelfEfficacy and Internet Self-Efficacy were appropriate for gauging the motivation of PWVDs towards access and use of the two ICTs. Qualitative analysis involves coding the data (the process of grouping evidence and labelling ideas so that they reflect increasingly broader perspectives), dividing the text into small units (phrases, sentences and paragraphs), and assigning a label to each unit. The label can come from the exact words of the respondents, a term composed by the researcher, or a concept in the social or human sciences. Leech \& Onwuegbuzie (2007) refers to this as the method of constant comparison analysis, which was used particularly in chapters four and five to analyse qualitative data collected through interviews and a semi-structured questionnaire. For chapter six, the interviews were few and there was no need for this method; save for identifying specific data to be quoted to answer a specific question within the study. However, it is worth adding that everything was done manually as the researcher never had access to any of the modern statistical software packages which could simplify the process of qualitative data analysis. 
iv) Representing the analysis - in quantitative research this involves representing the findings in statements summarizing the statistical results, or tables reporting results related to descriptive or inferential questions. Researchers can also use figures - bar charts, line graphs, or pie charts - to present quantitative results in a visual form. For presenting the qualitative results, this may involve a discussion of the evidence for the themes or categories; the presentation of figures that depict the physical setting of the study; or frameworks, models, or theories. When discussing the evidence for a theme or category, writing strategies for providing this evidence include conveying subthemes or subcategories, citing specific quotes, using different sources of data to cite multiple items of evidence, and providing multiple perspectives from individuals in a study to show the divergent views (Creswell \& Plano Clark, 2007). A researcher may also represent his findings through visual aids such as figures, maps, or tables that present the different themes.

Since this dissertation used an MMR approach, with the exception of bar charts, line graphs and pie charts, the rest of the above presentation methods were used in relation to both quantitative and qualitative data in the three empirical chapters. For example, a multiplicity of perspectives was given in Chapter 4 when conveying the experiences of ICT service providers; and when presenting the challenges that respondents gave in connection with using the different ICTs. Furthermore, quotations and tables were widely used as methods for presenting results throughout the empirical chapters.

v) Validating the data. Issues of validity were given adequate attention in all the three empirical chapters of this dissertation. This was one of the requirements for ensuring the quality of both quantitative and qualitative data and results. But before delving deeper into the specifics of how validity was dealt with in this particular research, it is worth mentioning that scholars grounded in MMR have come up with a unique terminology regarding this subject, which differs from that of the traditional quantitative and qualitative approaches. For example, Onwuegbuzie \& Johnson (2006) recommend that validity in mixed research be termed as legitimation in order to use a bilingual nomenclature that can be used by both quantitative and qualitative researchers. They further argue that legitimation in MMR should be seen as a continuous process rather than as a fixed attribute of a specific research study. On the other hand, Tashakkori \& Teddlie (2008) suggested using the term 'inference quality' as an umbrella term for evaluating the quality of conclusions that are made on the basis of the findings in a mixed methods study. Again according to Tashakkori \& Teddlie, inference quality is a combination of design quality, which refers to the degree to which the investigators have utilized the most appropriate procedures for answering the research question(s), and implemented them effectively; and interpretive rigour, which is the degree to which credible interpretations have been made on the basis of obtained results.

In their subsequent typology (Onwuegbuzie \& Johnson, 2006: p. 57), the two researchers included the following nine different types of mixed methods legitimation: sample integration (the extent to which the relationship between the quantitative and qualitative sampling designs yields quality metainferences), inside-outside legitimation (the extent to which the researcher accurately presents and appropriately utilizes the insider's view and the observer's view for purposes such as description and explanation), weakness minimization(the extent to which the weakness from one approach is compensated by the strengths from the other approach), sequential legitimation (the extent to which one has minimized the potential problem wherein the meta-inferences could be affected by reversing the sequence of the quantitative and qualitative phases), conversion (the extent to which the quantitising or qualitising yields quality meta-inferences), paradigmatic mixing (the extent to which 
the researcher's epistemological, ontological, axiological, methodological and rhetorical beliefs that underlie the quantitative and qualitative approaches are successfully combined or blended into a usable package), commensurability (the extent to which the meta-inferences made reflect a mixed worldview based on the cognitive process of Gestalt switching and integration), multiple validities (the extent to which addressing legitimation of the quantitative and qualitative components of the study result from the use of quantitative, qualitative, and mixed validity types, yielding high quality meta-inferences), and political legitimation (the extent to which the consumers of mixed methods research value the meta-inferences stemming from both the quantitative and qualitative findings).

Five of the above nine legitimation types were addressed directly by this research. For instance, sample integration legitimation was followed in as far as the samples for the qualitative components of the research were drawn from those of the quantitative components; thus enabling the drawing of conclusions that can aid population transferability. However, the quantitative samples were nonrandom, which could hinder generalization.

Another was insider-outsider legitimation, referring to the degree to which a researcher accurately presents and utilizes the insider's view and the observer's view (Onwuegbuzie \& Johnson, 2006: p. 58). To obtain an insider's view (or emic viewpoint), the researcher used member checking - where some of the study participants were invited to review the scripts written out of the interviews done with them. To obtain a justified observer's view (or etic viewpoint), the researcher used a lecturer from Kyambogo university who was well versed with disability research to peer review and comment on his work.

The third legitimation type taken into consideration was weakness minimization. This was ensured through the study design, where the concurrent study design was used as much as possible. This meant doing both quantitative and qualitative studies concurrently at each phase of the research, where the qualitative approach was always meant to give further explanation of the data collected using the quantitative approach.

The fourth legitimation type under consideration was conversion. This was limited to quantitisation of qualitative data, done through frequency counts in addition to narrative descriptions, and computation of percentages when reporting certain results. However, the researcher was aware of the counting pitfalls explained by Sandelowski (2001: pp. 235-238) and tried to avoid them. These include verbal counting (when researchers imply numbers without actually giving any), over counting (including representational and analytic overcounting), misleading counting (using percentages to describe small samples), and contextual counting (where researchers offer no other information about a participant or event except numbers or in which they draw unsubstantiated inferences from numbers).

The last type of legitimation catered for in this research is paradigmatic mixing. This can be accessed from the fact that this research used pragmatism as its philosophical underpinning (see Section 3.1). The pragmatism approach may combine deductive and inductive thinking, as the researcher mixes both qualitative and quantitative data (Creswell \& Plano Clark, 2007). As it were, multiple methods of data collection informed the problems under study.

The remaining four legitimation types not commented on here, including sequential legitimation, commensurability, multiple validity, and political legitimation, were either not directly applicable to this research or the researcher lacked the competences to cater for them in his own legitimation assessment. 
On the side of inference quality, which was even practically applicable to this research, Tashakkori \& Teddlie (2008) gave four basic standards for quality of research design and its implementation:

- Design suitability - was the method of study appropriate for answering the research question(s)?

- Design adequacy/fidelity - were the components of the design (say sampling and data collection) implemented adequately?

- Within design consistency - Did the components of the design fit together in a seamless and cohesive manner?

- Analytic adequacy - Are the data analysis techniques appropriate and adequate for answering the research questions?

In order to assess interpretive rigor and improve the quality of inferences, Tashakkori \& Tedlie (2008) again give the following five criteria or standards which a researcher has to meet:

- Interpretive consistency - does each conclusion closely follow the findings? Also, do multiple conclusions based on the same results agree with each other?

- Theoretical Consistency - Is each inference (explanation for the results or for relationships) consistent with current theories in the academic field and/or with empirical finding of other studies?

- Interpretive Agreement - Would other scholars reach the same conclusions on the basis of the results from the study?

- Interpretive Distinctiveness - Is each conclusion distinctively different from other plausible conclusions regarding the same results?

- Integrative Efficacy - This is the degree to which inferences made in each strand of a mixed methods study are effectively integrated into a theoretically consistent meta-inference.

\subsection{Personal reflections of the researcher}

The person who undertook this research has a visual disability (totally blind), which brought him quite close to the people about whom he was researching. This was both an automatic introducer of bias into the whole research process, which would probably compromise objectivity. But it can also be argued that the researcher's visual disability was an opportunity by which to analyse the lived experiences of the respondents, albeit with some level of bias, to answer the research problem more accurately. Although researchers would easily fall for the first of these two scenarios, Mantzoukas (2005: p. 279) argued that "bias is not by definition counterproductive for research studies, and that biased studies do not necessarily constitute invalid research." This is so because, for instance, preconceptions enable identification of issues or situations since they enable researchers to be alert to themes in common with the broader human experience (Ahern, 1999). On the other hand, as a requirement of academic rigour, the researcher has to minimize bias so as to attain valid results.

Faced with the predicament as being explained here, the researcher had to make a decision whether to declare the potential areas of bias right from the outset of the research and a solution is found early enough or he simply waits and see how the process unfolds and would deal with biasing situations as they came along. The researcher took the second option, which meant constantly checking his own influence on the research process so he could report on the various events and situations in the study as fairly as possible. 
According to Ahern (1999: p. 407), “...in many forms of qualitative research, it is expected that researchers will make sincere efforts to put aside their values in order to more accurately describe respondents' life experiences. The means by which researchers endeavor not to allow their assumptions to shape the data collection process and the persistent effort not to impose their own understanding and constructions on the data are known as bracketing." In so doing, it was found useful to use some of the ten tips given by Ahern (1999) to achieve this in data collection and analysis. Thus:

1. Identifying some of the interests that, as a researcher, you might take for granted in undertaking a specific research. According to Ahern, these could include such issues as obtaining a degree or advancing in one's academic career. For this particular research project, the researcher clearly stated in the letter of introduction attached to the questionnaires that collecting such data was in partial fulfilment of the requirements for obtaining a Ph.D. so respondents had no qualms as to why data was being collected from them. Secondly, it was easy for respondents to associate the researcher with a higher socio-economic status because he was known to live and work in the city. Effort was taken to ensure this does not become a hindrance in getting the right data. This was through interviewing the respondents personally and the research assistants were only assigned complementary roles. Also, no respondent was paid money to participate in the research, unless where it was found important to reimburse his/her transport fair.

2. Clarify your personal value systems and acknowledge areas in which you know you are subjective. These are issues to which you need to keep referring back when analyzing your data (Ahern, 1999: p. 407). Being a person with a visual disability would certainly make the researcher have bias on some aspects of the research. For instance, he had a fairly good understanding of the challenges and benefits associated with using screen readers. This was quite helpful in analyzing data from the respondents, especially because the researcher could make constant reference to his own experience as an end-user of ICTs. But again this did not stand in the way of collecting data.

3. Describe possible areas of potential role conflict. For this research, the researcher took care not to report findings that would look like accusations for non-action by government and other providers of ICTs in Uganda. Instead, the report was written in such a way that it would serve as an eye-opener to the issues, say accessibility of ICTs that had hitherto not been given adequate attention in the country.

4. Identify gatekeepers' interests and consider the extent to which they are disposed favorably towards the project. The gatekeepers for this particular project included heads of learning institutions where PWVDs studied, organizations employing workers with visual disabilities and government departments charged with distributing and regulating the use of ICTs in Uganda. In order to prevent role conflict, the researcher always explained the purpose for doing this research (see Section 3.3.2.) so he is not perceived as a fault finder or pursuing any other negative motive.

5. Recognize feelings that could indicate a lack of neutrality (Ahern, 1999: p. 408). This is another angle deserving some reflection. The fact that the researcher shared some affinities with the respondents on whom he conducted an investigation, it necessitated creating a candid interaction between the researcher and the researched; hence the former disclosed his own limitations as an enduser of ICTs. This was vital in putting the respondents at ease to disclose as much information as possible about their abilities or ignorance in regard to using computers, mobile phones and the Internet. This was hugely important in understanding the intricacies surrounding the interaction of PWVDs and digital technologies in an LDC like Uganda. 


\subsection{Study limitations}

Johnson \& Onwuegbuzie (2004) and Yoshikawa et al. (2008) listed a number of general weaknesses found in MMR, some of which became evident in this research as follows:

1. Balancing respondent/informant burdens. "A long, structured, closed-ended survey, or hundreds of questionnaire items to fill out, page after page, can be a burden for many" (Yoshikawa et al., 2008). Johnson \& Onwuegbuzie add that if two or more approaches (both qualitative and quantitative) are expected to be used concurrently, this may require a research team. Indeed this was a direct experience in this particular study, where at some point a long questionnaire with four sections, which had to be completed by both respondents and research assistants, which proved quite cumbersome.

2. Managing time and resources. Mixed methods research requires partnering with others who have complementary expertise, which often turns out to be rather expensive and time-consuming. These two limiting factors were also expressed by Johnson \& Onwuegbuzie (2004: p. 21). This was true with data-collection and data-analysis in this research; but the researcher offset it by taking charge of the qualitative interviews, because of his relatively good skills in qualitative methods, while he hired assistants to collect quantitative data and enter it into SPSS for analysis.

3. The relatively recent history of mixed methods as an independent research approach, probably formally existing for not more than twenty years by the time the current study commenced, makes it seem more complex than both the qualitative and quantitative approaches applied separately. Indeed deciding whether or not to use this approach took the researcher for this dissertation a lot of time reading various suggestions and counter-suggestions on the different components of the study. For instance, it was hard deciding the stage of research at which mixing would take place. Tashakkori \& Creswell (2007) discussed four perspectives that describe where mixing would take place. these include a methods perspective, where scholars view mixed methods as focused on the process and outcomes of using both qualitative and quantitative methods and types of data; a methodology perspective, where mixed methods is a distinct methodology that integrates aspects of the process of research, such as worldview, questions, methods, and inferences or conclusions; a paradigm perspective, in which researchers discuss an overarching worldview or several worldviews that provide a philosophical foundation for mixed methods research; and the practice perspective, where scholars view MMR as a means or set of procedures to use as they conduct their research designs, whether these are survey research, ethnography or others. The perspective taken in this particular dissertation is a combination of both the methods and practice perspectives. 


\section{Chapter 4 Barriers to the adoption of screen readers and screen magnifiers by persons with visual disabilities in Uganda}

\subsection{Introduction}

This chapter focuses on the research question 'what are the barriers of adoption of screen readers and screen magnifiers in Uganda?' A study of this nature has never been done before; thus there is virtually no knowledge regarding the extent to which Persons with Visual Disabilities (PWVDs) use screen readers and screen magnifiers in Uganda. It should be clarified right from the outset that unlike in some developed countries where such technologies are given to PWVDs either completely free of charge or at subsidized prices, the same technologies in a developing country like Uganda are either rare to find or their existence is totally unknown to those that are supposed to make use of them. This is probably so because screen readers and screen magnifiers are categorized as specialized technologies. More so, Uganda is largely an importer and not a manufacturer of ICTs; so the origination and development of screen readers and screen magnifiers is done elsewhere.

As shown in the literature reviewed in Chapter 2, this comes on the backdrop that as the information revolution catches on, screen readers and screen magnifiers should offer the most viable assistive technology solutions by which PWVDs (the totally blind and those with low vision) can use ICTs (computers and mobile phones) effectively. Furthermore, it is by the same technologies that PWVDs are distinguishable from other disabilities in regard to accessing digital content on the World Wide Web, use e-mail and interact with any other forms of the Internet.

Finding out the barriers to the adoption of screen readers and screen magnifiers within the community of PWVDs in Uganda was aimed at understanding the limitations in using ICTs as part of their execution of education, employment, and everyday tasks that are increasingly becoming dependent on ICTs, and then come up with recommendations for improvement. The theoretical approach adopted is that of Rogers (2003) in which he explores the reasons for diffusion and uptake of innovations.

Besides these introductory remarks, this chapter proceeds with an overview of the theoretical approach used in the study, followed by describing the methodological approach involving a combination of qualitative and quantitative methods of research applied on 100 respondents with Visual Disabilities and 18 information-rich participants (providers of various ICT services). The section next to that is where the results are presented in the context of the theoretical framework adopted; and then a detailed discussion of the results is carried out. Finally, policy orientated conclusions are drawn. 


\subsection{Theoretical approach}

The study applied the Diffusion of Innovations theory by Everet M. Rogers to understand the barriers of adoption of screen readers and screen magnifiers in Uganda. This theory asserts that an innovation is communicated through certain channels over time among members of a social system (Rogers, 2003). What qualifies screen readers and screen magnifiers as innovations is their ability to enable PWVDs to use computers and mobile phones. Screen readers are most suited to people who are totally blind and screen magnifiers benefit those with low vision. By extension, it is worth reiterating that the two assistive technologies are also instrumental in enabling PWVDs access the World Wide Web if web sites are designed following accessibility principles. In the context of the digital divide therefore, their adoption or non-adoption is one step towards or away from the inclusion of PWVDs in the digital transformation of any given community.

The user's adoption of a screen reader or screen magnifier was considered vital in this study as a starting point for understanding the limitations PWVDs experience in using ICTs. Rogers (2003) Diffusion of Innovations theory sets out five factors that are perceived to affect the rate of adoption of an innovation, including:

1. The perceived attributes of the innovation - relative advantage, compatibility, complexity, trialability, and observability - which Rogers argues explain most of the variance in the rate of adoption of innovations, from 49 to $87 \%$. Depending on how PWVDs perceive these attributes can be vital in determining whether they are a barrier or enhancement to the adoption of screen readers and screen magnifiers.

2. The type of innovation decision. This was about whether the uptake of screen readers and screen magnifiers in Uganda depended on individual decisions or some authority in form of organizations, which would also affect the rate of adoption.

3. The nature of communication channels diffusing the innovation. Here, attention was on whether the mass media (newspapers, radio or television) was involved in disseminating information about screen readers and screen magnifiers, or interpersonal communication was what PWVDs relied on. Either of these has impact on the rate of adoption of an innovation. This takes into account how people are exposed to new messages regarding the existence and usage of such technologies.

4. The nature of the social system in which the innovation is diffusing. In this case it was PWVDs in Uganda. Here the degree of interconnectedness among members, any norms that bind them together, and a semblance of structure which can facilitate information dissemination regarding where and how to find screen readers and screen magnifiers is what was considered.

5. The extent of change agents' promotion efforts in diffusing the innovation. Here the question was whether there were institutions committed to promoting the use of screen readers and screen magnifiers in the country or everything had been left to market forces. Here the assumption was that, since the country was increasingly becoming an information society, various ICT service providers had done all it takes to ensure that PWVDs were included in the new developments. This framework is illustrated in Figure 4.1. 
Figure 4.1: Variables determining the rate of adoption of innovations (Rogers, 2003)

\section{Variables determining the rate of adoption}

\section{Dependent variable that is explained}

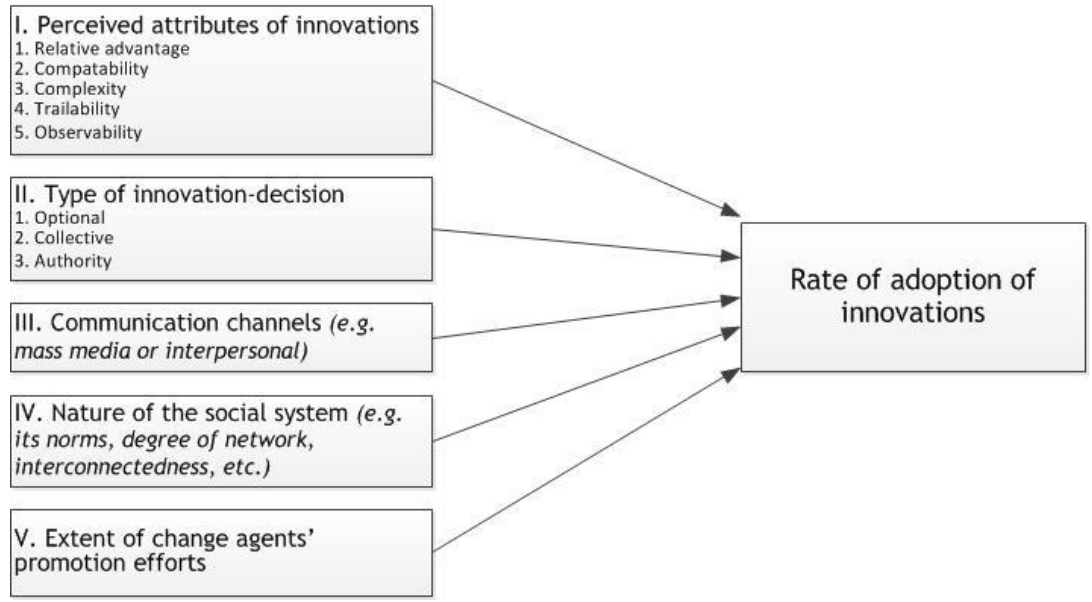

Based on the five variables in the above model by Rogers, the general research question for this chapter can be elaborated into the following five sub-questions:

- How do attributes of screen readers and screen magnifiers affect their adoption by Persons with Visual Disabilities in Uganda?

- How does type of innovation-decisions affect adoption of screen readers and screen magnifiers by Persons with Visual Disabilities in Uganda?

- How do communication channels hinder or enhance the diffusion of screen readers and screen magnifiers in Uganda?

- What barriers does the nature of the social system impose on the adoption of screen readers and screen magnifiers among PWVDs in Uganda?

- What contributions have ICT service providers made towards the adoption of screen readers and screen magnifiers by Persons with Visual Disabilities in Uganda?

\subsection{Research methodology}

\subsubsection{Design}

As already mentioned in Chapter 3, both qualitative and quantitative approaches were used to answer the research questions. Awareness of the extreme complexity of many development problems and the information needed to find solutions has led to constructive cross-fertilization of tools and more integrated methodologies to build on the complementarities between different methods (Desai \& Potter, 2009).

The qualitative approach the study employed was descriptive phenomenology. According to Groenewald (2004), a researcher applying phenomenology is concerned with the lived experiences of the people involved, or who were involved, with the issue that is being researched. In this case the study was specifically targeted on PWVDs who had the experiences of using screen readers and 
screen magnifiers. Service providers whose work had ICTs as a critical component were also involved in the study through the same approach.

For the quantitative methodology, the study used the survey approach to capture the demographic characteristics of respondents such as age, sex, level of education, degree of blindness, occupation and location. These characteristics would then assist in grouping and comparing the responses obtained on the various issues under study. In other words, the survey would help in explaining the conditions pertaining to the respondents and enrich the findings from the qualitative study.

\subsubsection{Sample size and sampling scheme}

The sample for this study was respondents with visual disabilities - $\mathrm{N}=100$, and ICT service providers - $\mathrm{N}=18$. The scheme used to select both the respondents and service providers was criterion sampling. The criteria used on respondents entailed level of education - everyone was between Uganda Certificate of Education and Post-Graduate level; and having a regular occupation - either as student or engaged in formal employment. Justification for this is given by Rogers (2003), who argues that "individuals seldom expose themselves to messages about an innovation unless they first feel a need for the innovation, and that, even if individuals are exposed to innovation messages, such exposure will have little effect unless the innovation is perceived as relevant to the individual's needs and is consistent with the individuals attitudes and beliefs." In light of this, including people not engaged in any occupation was considered unrealistic as these would have few or no prospects for using ICTs.

Using the above criteria, 45 respondents were selected from two secondary schools, 6 from a Primary Teachers' College, 34 from two universities and 15 from various organisations where they worked. Respondents were also grouped in terms of age categories, where the majority (71) was between 15 and 24 years old, 19 between 25 and 34 years, 9 between 35 and 44 years and only 1 in the age bracket of 45 - 54 years. Gender was also considered, with 63 respondents being male, and 37 female.

It was also thought location would have some impact on the adoption of screen readers and screen magnifiers; thus respondents were drawn from three districts of Uganda (Kampala representing urban areas; Iganga and Soroti for rural areas). In this regard, 58 were from rural areas (35 from Soroti and 23 from Iganga) and 42 from the urban areas of Kampala.

Finally, the adoption of screen readers and screen magnifiers was related to the degree of blindness of the respondents. Thus 49 had low vision, 41 were totally blind and 10 had functional vision.

The criterion used to select the 18 service providers was that they had to have served some clients with visual disabilities in the course of their work. In that regard, managers of Internet cafes, trainers in ICTs, personnel at mobile phone companies and importers of various ICT products were selected for interviews. This assisted in getting insights into their roles regarding the diffusion of screen readers and screen magnifiers among PWVDs in Uganda. Only three (two from Iganga and one from Soroti) met the pre-set criterion, and fifteen were selected from Kampala. However, many service providers (importers of various ICT products and mobile phone companies) chosen from Kampala were operating countrywide; hence their views could have a general application.

\subsubsection{Data collection instruments}

This study used the following data collection methods depending on appropriateness to sources:

(a) A semi-structured questionnaire (see appendix 1). This was used in collecting data from the 100 respondents with visual disabilities. It was arranged in four sections, with Section a) targeted to personal bio data, sections b) and c) to the experience of respondents about the different screen 
readers and screen magnifiers usable on computers and mobile phones, and section d) was focused on experience with the Internet.

(b) An interview guide (see appendix 2). This was used to collect data from selected service providers to understand whether or not they contributed to the diffusion of screen readers and screen magnifiers among PWVDs in Uganda. This was in respect of them being managers of Internet cafes, personnel at telephone companies, ICT trainers, and distributors of various ICT products.

(c) Internet Search Method. This was done on a limited scale to reinforce some of the data collected through interviews and questionnaires. For instance, respondents had cited affordability as a major barrier in their use of assistive technologies, and an Internet search confirmed that proprietary screen readers and screen magnifiers were indeed very expensive compared with the cost of computers and mobile phones.

(d) Field Notes. These were taken basing on what was observed at the various sites where data was collected using the other instruments. The intention was collecting that data not anticipated in the interviews and survey questionnaires but nonetheless important during the analysis phase of the study.

\subsection{Presentation and interpretation of findings}

This section presents the study findings in accordance with the objective it was set out to achieve. The objective was to find out the factors affecting the adoption of screen readers and screen magnifiers among PWVDs in Uganda, out of which five thematic areas were derived following the research questions. Results from 100 respondents with visual disabilities and 18 ICT service providers were analysed and presented.

\subsubsection{How innovation attributes affect the adoption of screen readers and screen magnifiers among persons with visual disabilities in Uganda}

Rogers (2003) lists five attributes - relative advantage, compatibility, complexity, trialability and observability - which generally affect the rate of adoption of an innovation. Rogers further explains that these need not be objectively classified by experts or change agents, but just the way they are perceived by individuals will affect the rate of adoption of an innovation.

Before explaining how innovation attributes affected the adoption of screen readers and screen magnifiers for PWVDs in Uganda, it is worth defining what screen readers and screen magnifiers are. According to an assistive technologies news web site (www.axistive.com), a screen reader is "a software application that identifies and interprets what is being displayed on the computer screen, and this information is presented to blind people as speech or through a Braille display". The same web site defines a screen magnifier as "software that interfaces with a computer's graphical output to give enlarged screen content". More than ten types of screen readers and screen magnifiers exist around the world, and these are grouped in accordance with their categories that include proprietary (third party software products a user buys from a shop and installs on the computer or mobile phone), freeware (downloadable from specific web sites free of charge following certain instructions), Open Source Software (which, under the General Public License, gives users the freedom to be run for any purpose, be it to study and/or modify, and redistribute copies of it without having to pay royalties to previous developers (Wheeler, 2007), and integrated (built in the computer or mobile phone operating system). 
In line with Section 2.2, this research chose to refer to screen readers and screen magnifiers with a collective term of assistive technologies. As an original contribution by this research, it was found out that type of assistive technology is an indicator of quality. For example those that are integrated within the operating systems (such as Voice Over and Zoom) only offer basic accessibility, and proprietary assistive technologies (Magic and Mobile Speak) are better alternatives for extensive use by PWVDs, especially with computers and mobile phones used in educational or professional situations (Rempel, 2012). Open Source Software and freeware lie somewhere in between the other two, but fall more on the side of integrated assistive technologies. A detailed list of various types of assistive technologies is given in Tables 4.1 and 4.2.

Table 4.1: Commonly used assistive technologies for computers

\begin{tabular}{|l|l|l|l|}
\hline $\begin{array}{l}\text { Type of assistive } \\
\text { technology }\end{array}$ & Screen reader & Screen magnifier & $\begin{array}{l}\text { Operating system } \\
\text { compatible with }\end{array}$ \\
\hline Proprietary & JAWS For Windows & Magic & Windows \\
\hline Proprietary & Window-Eyes & ZoomText & Windows \\
\hline Proprietary & SuperNova & LunarPlus & Windows \\
\hline Open Source & NVDA & & Windows \\
\hline Open Source & Gnopernicus Screen Reader & Gnopernicus Magnifier & Linux \\
\hline Freeware & Thunder Speech Reader & Lightning & Windows \\
\hline Integrated & VoiceOver & Zoom & MacOS \\
\hline Integrated & Windows Narrator & Windows Magnifier & Windows \\
\hline
\end{tabular}

Source: researcher's own compilation using Internet search.

As mobile phones nowadays perform more functions associated with computers than just making and receiving calls, some software developers have come up with screen readers and screen magnifiers that can work with such products as well. Table 4.2 presents some examples of such assistive technologies that are widely used around the world.

Table 4.2: Commonly used assistive technologies for mobile phones

\begin{tabular}{|l|l|l|l|}
\hline $\begin{array}{l}\text { Type of assistive } \\
\text { technology }\end{array}$ & Screen reader & Screen magnifier & $\begin{array}{l}\text { Operating system } \\
\text { compatible with }\end{array}$ \\
\hline Proprietary & Mobile Speak & Mobile Magnifier & Symbian \\
\hline Proprietary & Talks & ZOOMS & Symbian \\
\hline Proprietary & Smart Hal & $\begin{array}{l}\text { Magnifier for windows mobile } \\
\text { phones }\end{array}$ & Windows \\
\hline Open Source & Spiel & & Android \\
\hline Freeware & Nokia Screen Reader & Nokia large displays & Symbian \\
\hline Integrated & VoiceOver & Zoom & iOS \\
\hline Integrated & Oratio & & Blackberry \\
\hline
\end{tabular}

Source: researcher's own compilation using internet search.

It is worth noting that whether used on computers or mobile phones, screen readers and screen magnifiers can be programmed to work in combination to increase accessibility for especially people with low vision. For example, Mobile magnifier can work in conjunction with mobile speak - and ZOOMS can be used with TALKS - to provide both screen magnification and speech output (Huffman \& Burton, 2007). Also, Zoom and Voice Over can work simultaneously on the Mac; but Windows Narrator offers no more than repeating the keys pressed when used in combination with Windows Magnifier (Rempel, 2012). Furthermore, the latest generations of touch screen phones come 
with gesture-based screen readers such as Voice Over and Spiel, which allow users with visual disabilities to hear descriptions of functions on their phones through touch and also allow them to drag and tap to control their activities. Finally, it is also noteworthy reiterating here that speech output, particularly beneficial for the totally blind, can also be enhanced with refreshable braille displays. Refreshable braille displays are devices that rely on piezo-electric braille cells (tactile braille cells made of materials that respond to electric current by changing their dimensions) to produce one line of letters and words (Candela, 2006).

Now we turn to explaining how each of the five innovation attributes as given by Rogers (2003) affected the adoption of screen readers and screen magnifiers among PWVDs in Uganda.

\section{Relative advantage}

Rogers argues that the greater the perceived relative advantage of an innovation, the more rapid its adoption is likely to be. Innovation scholars tend to subdivide this into three aspects: economic profitability, social prestige or self-esteem, and personal control (Rogers, 2003; Robinson, 2008). There is a way adoption of screen readers and screen magnifiers relates to economic profitability and personal control, as will be explained below, but not so much with social prestige since these are secondary innovations only supposed to improve the accessibility of computers, mobile phones and the Internet. However, a recent study carried out on 11 visually impaired young Norwegians found that there was a strong association between assistive technologies and identity. Some visually impaired people, whenever possible, would reject assistive technologies (screen magnifiers) in order to fit in with ordinary young people; yet others who are totally blind would accept assistive technologies (screen readers) as the only means to participate effectively in online discussions (Soderstrom \& Ytterhus, 2010). But that was in the context of a developed country where access to ICTs is very high.

Regarding economic profitability, Rogers (2003) posits that the initial cost of an innovation may affect its rate of adoption, and he gives the example of Palm Pilots which many consumers in the United States took on in the late 1990s due to their relatively low price. Assistive technologies that work effectively for most PWVDs are tenable at a price which is usually higher than a computer bought from a mainstream retailer. A screen reader or screen magnifier costs many hundreds of pounds plus additional costs of upgrading from time to time; therefore out of reach for many who are unemployed or live on fixed incomes such as pensions or unemployment benefits (Bird \& Plumpton, 2008; Watling, 2011). This has profound effects on their adoption.

Table 4.3: Prices of some common assistive technologies

\begin{tabular}{|l|l|l|}
\hline Assistive technology & Company & Price in USD \\
\hline JAWS For Windows & Freedom Scientific & 1,095 \\
\hline Window-Eyes & GW Micro & 895 \\
\hline ZoomText & AI Squared & 499 \\
\hline Mobile Speak & Code Factory & 275 \\
\hline
\end{tabular}

Source: Researcher's own compilation from company web sites.

Results of the fieldwork conducted for this study revealed that high set-up costs were cited as a challenge by 54 out of 55 respondents who did not use assistive technologies on computers, and 31 of 86 who did not use them on mobile phones. Another challenge is that the screen readers for mobile phones that were found in use at the time of this study (Mobile Speak and Talks) could only be installed on the Symbian operating system. This meant that the costs for both the screen reader and 
mobile phone were beyond the reach of most respondents. Indeed, as presented in Table 4.3, a quick Internet search revealed the following prices for some common assistive technology products.

Concerning personal control, Robinson (2008) explains that this is about how people get results in their lives. The more people have control the more certain they become of getting what they want with a minimum of disruption, delay, danger, doubt and uncertainty. This is certainly in tandem with all assistive technologies, screen readers and screen magnifiers inclusive, as they are designed to reduce dependence and increase independence of the user.

As expressed by various respondents in this study, screen readers and screen magnifiers helped them to write flawless documents (letters and course assignments), carry out proper filing, do calculations and data management, and some were even able to select music from lists. Respondents also said they reduced mistakes in text messaging, calling wrong numbers, and increased their confidence in carrying out money transactions via SMS. In terms of Internet access, respondents were able to search for literature, download music, and read/listen to news online.

\section{Compatibility}

Rogers defines compatibility this as "the degree to which an innovation is perceived as being consistent with the values, past experiences, and needs of potential adopters." Adoption of an incompatible innovation often requires prior adoption of a new value system, which is relatively a slow process. An example of an incompatible innovation is the use of contraceptives in countries where religious beliefs discourage use of family planning as in certain Moslem and Catholic nations (Rogers, 2003).

In this study, compatibility was found to have little effect on the adoption of assistive technologies. For example, whereas respondents who were totally blind relied on Braille or sighted readers to read most of the literature they needed, and they used typewriters to produce write-ups for the benefit of others who were not blind, few expressed resistance to new technologies. Only two said they were comfortable writing out their work with typewriters and four said computers were expensive, especially if one had to hire the services of others. The rest found digital technologies opening up more opportunities for them to communicate with the sighted world and to access documents more easily, especially if available in soft copy.

Approaching compatibility from another angle, it can be argued that the degree of cultural homogeneity of a country's population affects the rate of adoption of certain innovations because it increases the degree of structural equivalence between transmitters and potential adopters (Wejnert, 2002). Although culture was not part of this study, it is known that Uganda does not have a homogeneous culture and PWVDs actually belong to different ethnic groups. However, PWVDs tend to have strong collaboration around blindness issues, and therefore nobody would simply reject a message regarding new technologies on grounds of culture. We can also learn from Strang \& Meyer (1993: p. 488) who argued that "when adoption is socially meaningful (as in the case of screen readers and screen magnifiers for PWVDs), it is common to think of actors as making different choices cognitively available to each other, developing shared understandings, and exploring the consequences of innovation through each other's experience."

\section{Complexity}

Complexity is defined by Rogers (2003) as "the degree to which an innovation is perceived as relatively difficult to understand and use". In this study, it was obvious that adoption of most ICTs 
involved acquiring some new skills learned at different paces depending on various factors including one's ability to learn and the subsequent necessity for using such skills. Being a Person with Visual Disability makes learning digital skills even harder because using assistive technologies requires specialist support that is seldom available from local computer stores or independent retailers (Watling, 2011). This is so because screen readers are mostly suited to work with keyboard rather than mouse commands requiring a user to learn several keystrokes pertaining to both the mainstream computer applications and the screen readers themselves. Screen magnifiers are even more complex with several settings (moreover shrouded in arcane technical details) that a user must always go through in order to maximize benefit. These are not suited to a novice computer user, especially with vision loss. For example, Windows Magnifier provides three viewable modes - Full Screen (magnifying the entire viewable area), Lens (magnifying and tracking the area surrounding the mouse pointer), and Docked (increasing a stationary portion of the viewable area of the screen) - which are entirely up to the user (Rempel, 2012). All other screen magnifiers have similar customization options. Besides, the user is left to magnify the viewable area severally, say from 1 to 16 times for Windows Magnifier, and from 1 to 25 times for Zoom. There are even other magnification features demanding additional configuration, such as tracking the various elements of a screen, which include text insertion point (tracking the cursor as someone types), mouse pointer, and keyboard focus. Font Smoothing is another option, which reduces pixilation in the appearance of text; yet another option is color inversion, where users can choose and adjust the colour schemes available in various screen magnifiers to their individual preferences, say black and white, color low resolution, color high resolution, and inverted color.

Screen magnifiers for mobile phones pose yet another challenge. As the magnification level increases, the amount of information that will fit in the magnified window decreases. This applies to all magnifying products; and higher levels of magnification make mobile phone users lose orientation since there is such a small amount of text on the screen at a time (Huffman \& Burton, 2007).

Finally, the effective use of the Internet by PWVDs also requires the aid of screen readers and screen magnifiers; but this depends heavily on how web sites are designed. Some examples where the two assistive technologies may not work properly include: where edit boxes and buttons on forms are not labelled; where text is embedded in images; where there are no clear and descriptive headings; where there are no alternative texts for images. Furthermore, the Captcha, a security feature consisting of distorted letters and numbers that users are supposed to read and type before they register for a new service or send an e-mail, is a barrier faced by screen reader users (Vicente \& Lopez, 2010). Audio Captchas should be the perfect alternative for this; but very few web sites have them for PWVDs.

Findings of this study showed that when respondents were asked why they did not use computer or the Internet, 34 and 28 respectively gave reasons of not being trained or lacking assistive technologies. Even those who had received computer training said they found challenges in picking up the screen reader enunciations; hence slowing the learning process.

Some respondents who made use of assistive technologies even mentioned several challenges they experienced before obtaining them, which can be of further help in understanding the complexity associated with ICTs among PWVDs in Uganda. Many said they always required assistance from the sighted when using ICTs (20 for computer, 6 for the Internet and 5 for mobile phones). Others said they were totally unable to use ICTs (14 for computer and 1 for mobile phone) prior to getting assistive technologies. Other challenges mentioned were: producing work with lots of mistakes, and experiencing lots of eye-strain when reading what was on the screen. 
Other challenges, particularly relating to the complexity of screen readers, were reported by service providers. These included:

- Clients with visual disabilities often went to them with phones on which they had installed screen readers wrongly.

- ICT Service providers said they wasted a lot of time on training the blind how to use JAWS.

- Many blind trainees were unable to comprehend what JAWS said.

One fact observed from the field confirmed the negative effects of complexity on the adoption of assistive technologies. Nearly all students in the two secondary schools visited could not use computers available in their resource centres, which state of affairs was attributed to lack of specialists who could teach the blind students how to use ICTs. Secondly, the research team found several copies of SuperNova (screen reader) lying uninstalled on the computers.

\section{Trialability}

Trialability is the degree to which an innovation can be experimented with on a limited basis (Rogers, 2003). Trying out an innovation is one way for an individual to give meaning to the innovation and to find out how it works under one's own conditions. A more rapid rate of adoption is possible via this option, especially for products riddled with uncertainty.

This study found out several ways in which screen readers and screen magnifiers can be tried out to reduce uncertainties before deciding to buy full licenses. First was through free downloads of demonstration versions from some web sites such as: www.freedomscientific.com/ and www. nuance.com/zooms. The former would give a potential user 40 minutes of use before the screen reader would stop and require rebooting the computer, and the latter would give ten minutes. Such trial versions usually work for a limited time span of about thirty days, which is all the same adequate for a potential user to think out a decision to adopt the technology by purchasing a full license or reject it altogether. However, rebooting the computer or mobile phone is rather disruptive and can put off potential adopters.

Another example of trialability was found in a Hi-tech project of Uganda National Association of the Blind (UNAB). Set up in 2001, this project pioneered the training of PWVDs in computer and screen readers. However, as revealed by a training officer interviewed for this study, the contribution of this project to the diffusion of screen readers was hampered by lack of follow-ups on the trainees passed out to ascertain whether they went on to train others or even continued using the skills acquired on their own. The officer said over 80 blind people had attended the special course by the time of this study. However, only 28 respondents mentioned receiving training from a blindness institution.

\section{Observability}

Rogers (2003) argues that the easier it is for individuals to see the results of an innovation, then the more likely they are to adopt it. Visible results lower uncertainty and also stimulate peer discussion of a new idea, as friends and neighbours of an adopter often request information about it. The familiarity with the outcomes of an innovation may, however, depend on the connectedness of potential adopters in a network (Wejnert, 2002).

For PWVDs, observing how others use screen readers and screen magnifiers would be difficult, especially because these are used by a specific type of people as secondary technologies when using computers and mobile phones. Perhaps this explains why 34 of the 51 respondents who could not use computer; and 28 of the 68 who could not use the Internet, blamed it on lack of training. but it is even 
well known that consumer innovations such as home computers are relatively low in observability and thus diffuse more slowly (Rogers, 2003).

To sum up, it may be hard to assign a specific percentage of how each of the five innovation-attributes contributed to the adoption of screen readers and screen magnifiers by PWVDs in Uganda. However, complexity seems to stand out as one attribute that slowed down or totally hindered the adoption of assistive technologies because of the several challenges associated with their configuration and learning how to use them.

\subsubsection{How type of innovation-decisions would affect the diffusion of screen readers and screen magnifiers among PWVDs in Uganda}

The Diffusion of Innovations theory lists three major types of innovation-decisions. These include optional, where the choice to adopt an innovation is made by an individual independent of the decision by other members of a system; collective, where the choice to adopt an innovation is made by consensus among the members of a system; and authority, where a few individuals possessing power, high social status, or technical expertise in a system make the choice to adopt an innovation (Rogers, 2003). Each of these decisions will have an influence on the rate of adoption of an innovation, and subsequently its process of diffusion. For instance, people wielding authority may cause an innovation to be adopted at first; yet if the innovation-decision is optional individuals may be slow to adopt. Likewise, a collective decision would quicken adoption in a closed community such as an organization, or cause members to gang up against an unpopular innovation.

Taking the assumption that using ICTs largely yields benefits for individuals, it was easy to imagine that the rate of adoption for assistive technologies in Uganda was better enhanced through optionalinnovation-decisions. This was the nub of the problem. An individual's decision about an innovation is not an instantaneous act but a process that occurs over time and it consists of a series of different actions (Rogers, 2003).

In this study, in order to prove that the decision to adopt assistive technologies was a process that occurred over time, respondents who indicated using screen readers and screen magnifiers were asked for how long they had been using them. The results are summarized in Table 4.4.

Table 4.4: Time since respondents adopted assistive technologies. $N=45$. The 8 people who have adopted assistive technologies for mobile phones are a subset of those who have adopted the technologies for computers

\begin{tabular}{|l|l|l|}
\hline $\begin{array}{l}\text { Time taken } \\
\text { after adoption }\end{array}$ & $\begin{array}{l}\text { Assistive technologies } \\
\text { for computers }\end{array}$ & $\begin{array}{l}\text { Assistive technologies } \\
\text { for mobile phones }\end{array}$ \\
\hline Less than 1 year & 15 & 4 \\
\hline $1-3$ years & 20 & 4 \\
\hline $4-6$ years & 6 & 0 \\
\hline 7 years \& above & 4 & 0 \\
\hline Total & 45 & 8 \\
\hline
\end{tabular}

Source: Primary data

The results in Table 4.4 shed some light on the rate at which PWVDs in Uganda were adopting screen readers and screen magnifiers; hence the table shows that majority of the respondents who used assistive technologies ( 35 for computers and 8 for mobile phones) had adopted them for not more than 
three years. This was in tandem with the Diffusion of Innovations theory, which provides that adoption of any given innovation is slow and increases with time (Rogers, 2003).

In this study, knowing where to buy or request for assistive technologies from, installing it correctly, and eventually learning how to use it took a long series of actions many would prefer not to engage in. Indeed 54 out of the 55 respondents who did not use assistive technologies on computers, and 31 out of the 86 who did not use them on mobile phones, gave the reason that it was expensive. But that was rather contradictory to the fact that cheaper options existed for obtaining assistive technologies, including Via Open Source Software, freeware or simply buying computers with assistive technologies already integrated into their operating systems (see Tables 4.1 and 4.2 for examples). Another cheap option was given by an official from a Non-Governmental Organization (NGO) known as Sight Savers International - Uganda, who revealed that his organization had distributed 65 free copies of SuperNova to various educational institutions around the country (including those where many of the respondents had been selected from), and he backed up his claim with a distribution list showing five or ten copies of the software package sent to each of the institutions.

It was also discovered that two respondents, secondary school students, made their own effort to learn and use ICTs without necessarily relying on assistive technologies. One of them joined the mainstream computer classes in the Cyber School, thereby learning to use the computer and Internet on her own. Other students with visual disabilities in the same school, despite having a fully-furnished resource centre, did not know how to use the two ICTs. The other student (from another secondary school), unable to get help from a sighted reader, saved a play, Romeo and Juliet, on the memory card of his mobile phone so he could listen to it several times as a way of revising for his Literature assignments.

Other findings revealed that despite the high cost of JAWS For Windows, this screen reader registered the largest number of users among the respondents (38 out of 45) who reported using assistive technologies on computers. Only 3 had SuperNova, 1 had Thunder Speech Reader, 1 had ZoomText, 1 had Magic and 1 had a Refreshable Braille display. Only 8 out of the 94 respondents with mobile phones used screen readers ( 4 had Talks and 4 had Mobile Speak). This shows how optionalinnovation decisions can slow down the rate of adoption for certain innovations. It should also be noted here that ZoomText and Magic (screen magnifiers ) registered one user each; yet findings show that 49 respondents had low vision, and Magic comes in the same CD package with JAWS For Windows.

The adoption of SuperNova was again affected by trusting that authorities in the host institutions would ensure its use by the students. Rogers (2003) argues that problems of implementation are usually more serious when the adopter is an organization rather than an individual. In an organizational setting, a number of individuals are usually involved in the innovation decision process and the implementers are often a different set of people from the decision-makers. Also, the organizational structure that gives stability and continuity to an organization may resist the implementation of the innovation. Indeed the scenario described above is exactly what was reported in this study. Some of the institutions which had been given computers and copies of SuperNova by Sight Savers International - Uganda ended up diverting the computers to other purposes and did not train students with visual disabilities. Furthermore, students with visual disabilities in the two secondary schools and three tertiary institutions visited had been largely left out of learning computer and the Internet, yet this was a given for their sighted counterparts. This certainly had an impact on their ability to use assistive technologies as well. What this reveals is that both optional and authority 
innovation-decisions have been a barrier to the adoption of screen readers and screen magnifiers in Uganda, and efforts should be directed towards collective innovation-decisions instead. This study has also shown elsewhere how training in the use of assistive technologies can be difficult; hence placing a specialist in ICTs in each institution with a sizable number of students with visual disabilities could go a long way in alleviating the problem of low adoption rates. Collective training can also be given by the UNAB Hi-Tech project for professionals with visual disabilities who have left school so as to enhance their employability.

\subsubsection{The effect of communication channels on the adoption of screen readers and screen magnifiers by PWVDs in Uganda}

Diffusion scholars are agreed that adoption of innovations does not always follow a linear progression and neither does it rely on a single communication channel. Sometimes it is the interpersonal influence within a social system or external influence through the mass media or cosmopolitan actions aiding the adoption of innovations (Valente, 1996).

As for this study, most respondents seemed to have benefited from interpersonal communication and the cosmopolitan nature of where they came from. There was hardly any evidence that mass media channels (radio, television and newspapers) were involved in disseminating information regarding assistive technologies; yet these are usually the most rapid and efficient means of informing potential adopters about the existence of an innovation, to create awareness (Rogers, 2003). Awareness, persuasion and making correct decisions are important stages in the innovation-adoption process. Persons with Visual Disabilities were supposed to know where to procure screen readers and screen magnifiers from and how to use them. For example, when respondents using mobile phones were asked where they first got information about assistive technologies from, 49 said they were not aware of such technologies. For those who had got the information, 21 computer users and 4 mobile phone users said they learnt about screen readers from friends; and only 5 ( 3 using computers and 2 using mobile phones) claimed getting information about screen readers from the media. Indeed the absence of the mass media in the diffusion of assistive technologies was reflected in the fact that screen magnifiers were not used widely among respondents; yet 49 of them had low vision and would benefit from using such assistive technologies.

Perhaps the marked non-involvement of the mass media in the promotion of screen readers and screen magnifiers can be explained by the fact that these are technologies for a small consumer market and not the mainstream (O'Brien, 2005). These are adaptive technologies for users with visual disabilities; yet in Uganda this group is just part of $7 \%$ of the population who are categorized as persons with disabilities (UNHS, 2005/06), and of which just a tiny minority actually uses ICTs.

\subsubsection{How nature of social system may affect adoption of screen readers and screen magnifiers by Ugandans with visual disabilities}

What qualifies PWVDs in Uganda as belonging to some kind of common social system is vision loss, and by extension the likely challenges they face in using ICTs. Even then, this is not a homogeneous group because some are totally blind, others have functional vision and yet others are with low vision. This group also varies in terms of age, gender, level of education, location and occupation. Age, level of education and occupation are part of the characteristics of adopter categories. Rogers (2003: pp. 287-292) grouped the characteristics of adopter categories under three headings - socio-economic status, personality values and communication behavior - and these fall under the first heading. 
From the results of this study it can be assumed that all the above variables had an influence, whether negative or positive, on the rate of adoption of assistive technologies. For instance, only $37.5 \%$ of the respondents who used assistive technologies on mobile phones and about $25 \%$ of those who used the computers were female. In terms of location, fewer respondents from rural areas (17 and 3) than urban areas (28 and 5) had used assistive technologies on computers and mobile phones respectively.

For occupation, 18 respondents who registered as workers and 27 students used assistive technologies on computers; while 5 students and 3 workers used them on mobile phones.

In terms of age, majority of the respondents (71) were between $15-24$ years, followed by 19 between 25 - 34 years, then 9 between 35 - 44 years and only 1 respondent was in the age bracket of 45 - 54 years. As presented in Table 4.5, most of the respondents identified as users of assistive technologies fell in the age bracket of $15-24$ years. Although this would favour a conclusion that adoption of assistive technologies was higher among young PWVDs, this is rather misleading because even the majority of non-users of assistive technologies (48 respondents) were in the same age bracket.

Table 4.5: Frequency distribution for ICT usage in terms of age. $N=45$. The 8 people who have adopted assistive technologies for mobile phones are a subset of the adopters of technologies for computers.

\begin{tabular}{|l|l|l|}
\hline Age category & $\begin{array}{l}\text { Assistive technologies } \\
\text { for computers }\end{array}$ & $\begin{array}{l}\text { Assistive technologies } \\
\text { for mobile phones }\end{array}$ \\
\hline $15-24$ years & 23 & 4 \\
\hline $25-34$ years & 16 & 3 \\
\hline $35-44$ years & 5 & 1 \\
\hline $45-54$ years & 1 & 0 \\
\hline Total & 45 & 8 \\
\hline
\end{tabular}

Source: Primary data.

Relating adoption of assistive technologies to education, findings show that the greater the education level of respondents the more they used assistive technologies. This pattern is shown in Table 4.6.

Table 4.6: Frequency distribution for usage of assistive technologies in terms of level of education. $N=45$. The 8 people who have adopted assistive technologies for mobile phones are a subset of those who have adopted the assistive technologies for computers.

\begin{tabular}{|l|l|l|}
\hline Level of education & $\begin{array}{l}\text { Assistive technologies } \\
\text { for computers }\end{array}$ & $\begin{array}{l}\text { Assistive technologies } \\
\text { for mobile phones }\end{array}$ \\
\hline Post-graduate & 3 & 0 \\
\hline Degree & 27 & 4 \\
\hline Diploma & 2 & 0 \\
\hline Grade 3 Certificate & 1 & 1 \\
\hline UACE & 3 & 0 \\
\hline UCE & 9 & 3 \\
\hline Totals & 45 & 8 \\
\hline
\end{tabular}

Source: Primary data.

Degree of blindness was also considered as a variable while examining the adoption of assistive technologies. In this case the study assumed it was possible for people with low vision to struggle with enlargement utilities (Microsoft magnifier and colour contrast schemes) built in computer operating systems; while those with functional vision or the totally blind would solely rely on 
proprietary screen readers to use computers and mobile phones. Furthermore, someone with low vision could easily learn using a computer from a friend; yet a totally blind person would most likely require special training. Contrary to those assumptions, only 2 respondents out of the 49 who registered as having low vision said they used screen magnifiers. The remaining 43 respondents who registered as users of assistive technologies said they used screen readers.

With the exception of 'degree of blindness' and age, all the above variables (education, gender, location and occupation) can be used to classify the respondents into different adopter categories, which may subsequently explain the rate of adoption for screen readers and screen magnifiers by PWVDs in Uganda. Conversely, the diffusion of screen readers and screen magnifiers among PWVDs can be enhanced basing on the above variables. For instance, females would need more information about assistive technologies than males; those with less education would need more diffusion messages directed to them than those with more education; and finally it can be inferred from the above results that PWVDs in some form of occupation can afford the cost of procuring assistive technologies than others not in employment. But it is not clear from the results whether more diffusion messages should be directed to the old than the young or vice versa.

Another way to examine the adoption of assistive technologies is through networks, norms and social trust. Many scholars have studied how all these may be useful as vehicles for co-ordination and cooperation in social systems. They call this social capital (Coleman, 1988; Putnam, 1995). Coleman endeavored to demonstrate how the presence of social capital in the family and/or community aids the formation of human capital (accounting for dropouts in American high schools); while Putnam was concerned that the decline in civic engagement in the American society was due to dwindling social capital among various communities and individuals.

Applying the same concept to PWVDs in Uganda, it was found that most respondents considered themselves members of the Uganda National Association of the Blind (UNAB). In this case membership was derived more from personal feelings than formal registration; because people regarded themselves as members only by virtue of being visually disabled and belonging either to the national or district branch executives.

The respondents who regarded themselves as members of UNAB mentioned a list of values and practices which bound them together. These are summarized below:

- UNAB gives us assistance to attend celebrations to mark the International White Cane day and the International Day of the Disabled, which fall on $15^{\text {th }}$ October and $3^{\text {rd }}$ December respectively;

- UNAB provides our schools with scholastic materials - Perkins Braillers and Braille paper on a regular basis;

- We attend meetings, workshops and trainings organized by UNAB;

- UNAB organizes sports tournaments each year, which bring together blind students from several primary schools around the country;

- UNAB is recognized as an advocacy organization for the blind nationally and internationally.

But coordinating Ugandans with Visual Disabilities under UNAB remains difficult because those that identify themselves as its members are scattered all over the country with no recognized form of communication. Using its structure for diffusing any innovation, including assistive technologies, could therefore affect the rate of its adoption. It was, for instance, found out that UNAB only reaches blind people who are members of its district branches and some students in schools, which leaves out 
the bulk of other blind people who are either out of school or do not belong to the district branches. It is also important to add that UNAB does not have branches in all the districts of Uganda, narrowing its membership even further.

The only way to have a fair understanding of the adoption of an innovation in a structure like that of UNAB is by using the strength of weak ties hypothesis by Mark Granovetter. This is about relations between groups and segments of social structure not easily defined in terms of primary groups (Granovetter, 1973). This hypothesis can be explained through some arbitrarily selected individual whom Granovetter called Ego. Ego will have a collection of close friends, most of whom are in touch with one another (a densely knit clump of social structure). Ego will also have a collection of acquaintances, few of whom know one another. Each of these acquaintances, however, is likely to have close friends in his own right and therefore to be enmeshed in a closely knit clump of social structure, but one different from Ego's. The weak tie between Ego and his acquaintance, therefore, becomes not merely a trivial acquaintance tie but rather a crucial bridge between the two densely knit clumps of close friends. The assertion ends thus: these clumps would not, in fact, be connected to one another at all were it not for the existence of weak ties (Granovetter, 1983). In light of this hypothesis, there is anecdotal evidence of some weak ties existing among the respondents of this study. For instance, a secondary school student who used Thunder Speech Reader, the only one to do so among all respondents, disclosed that the chairperson of UNAB was the friend who had given him information about it. It is noteworthy that there was no direct connection between the UNAB chairperson and the school. Another example was given by some two respondents who had trained for computer and the JAWS screen reader from Kenya using financial support of an NGO (Uganda Joint Christian Council) not conventionally associated with such sponsorships. Finally, it was the expectation of the UNAB Hi-Tech project, as explained by the officer interviewed, that its trainees would go and train others after their training. However, the only problem with all these examples is that evidence of those who had got support elsewhere never brought it to bear on people within their close ties. As a conclusion for this section therefore, the nature of social structure was more of a hindrance than enhancement to the adoption of assistive technologies. This was so because no deliberate effort had been taken, by the time of this study, to enable all PWVDs to acquire such technologies. Even the UNAB Hi-Tech project did not offer its special training free of charge, which made affordability a big factor in its uptake.

\subsubsection{The role of ICT service providers in the diffusion of assistive technologies among Ugandans with visual disabilities}

Rogers (2003) argues that change agents would not be needed in the diffusion of innovations if there were no social and technical chasms between the change agency and the client system. Indeed the innovations on which this study focused bear some sort of specialty; hence they require specific promotion efforts to get them adopted by the intended users. For instance, in case computers or mobile phones had the appropriate assistive technologies (screen reader or screen magnifier) built into their operating systems, one would expect a retailer to advise a customer with visual disability on its appropriateness to his/her needs. Likewise, those charged with managing Internet cafes would be able to run the assistive technologies for their clients with visual disabilities; hence facilitating eventual adoption. Deriving from that explanation, the various service providers (importers of ICT products, customer-relations personnel at telephone companies, managers of Internet cafes and trainers in ICT) selected for the study were asked whether they had ever made any deliberate considerations towards enabling PWVDs to interact with ICTs.

The importers of ICTs (computers and assistive technologies) said the following: 
- We customize for blind people some of the hardware and software products we supply as part of our after-sale service.

- Offer some software donations to deserving blind people free of charge.

The views of personnel at telephone companies and mobile phone retailers were overlapping, and they were summarized together in the following bullets:

- We introduced phones that have large screen displays and talk through menus.

- We have imported mobile phone models that favour blind people, such as Nokia 2300,6230, 1280 , etc.

- We provide Bluetooth hands-free which enables them (the blind) to answer calls easily.

- We have made Interactive Voice Response (IVR) a permanent feature on our network.

The managers of Internet cafes and ICT trainers said:

- Have tried teaching my colleagues how they should handle the blind such that they get the right attention.

- Plan to introduce support services like speech software for the blind.

Deducing from the above perspectives, although service providers could be construed as caring about the needs of clients with visual disabilities, sometimes they lacked the requisite knowledge to offer the best support. A good example is from ICT trainers visited, who were not from secondary schools and tertiary institutions. These showed appreciation for some sort of special software requirements for blind people to use computers effectively. However, they kept referring to voice recognition software, which is instead suitable for people with severe motor difficulties who cannot use the keyboard. Also, providing Bluetooth hands-free features on phones so that people can answer calls easily, a claim made by personnel at telephone companies and mobile phone retailers, does little or nothing to alleviate the challenges experienced by PWVDs. This would instead be more appropriate for people who have difficulties using their hands.

Table 4.7: Showing the different sources of assistive technologies. $N=45$. The 8 people who have adopted assistive technologies for mobile phones are a subset of those who have adopted the technologies for computers.

\begin{tabular}{|l|l|l|}
\hline $\begin{array}{l}\text { Source of Assistive } \\
\text { Technologies }\end{array}$ & $\begin{array}{l}\text { Frequencies for computer- } \\
\text { based assistive technologies }\end{array}$ & $\begin{array}{l}\text { Frequencies for phone-based } \\
\text { assistive technologies }\end{array}$ \\
\hline Got it from where I work/study & 15 & 1 \\
\hline Bought from a licensed dealer & 8 & 6 \\
\hline Was given by a donor agency & 9 & 1 \\
\hline $\begin{array}{l}\text { Got it from a blindness } \\
\text { institution }\end{array}$ & 6 & -- \\
\hline Downloaded it from Internet & 1 & - \\
\hline Got it from a friend & 3 & -- \\
\hline-- & 3 & -- \\
\hline Total & 45 & -- \\
\hline
\end{tabular}

Source: Primary data.

As for managers of Internet cafes, none of them had computers installed with assistive technologies. This makes ordinary service providers non-contributors to the adoption of screen readers and screen magnifiers. This was confirmed further by asking the respondents where they obtained assistive 
technologies from; and they mentioned friends, blindness institutions, organisations where they worked or studied, donor agencies and licensed distributors (see Table 4.7).

\subsection{Discussion}

This study has attempted to explore the barriers to the adoption of screen readers and screen magnifiers by PWVDs in Uganda, using the variables determining the rate of adoption of innovations as given by Rogers (2003: p. 12). From the strict definition of an innovation as given by Rogers (2003), which is an idea, practice, or object that is perceived as new by an individual or other unit of adoption, this study considered screen readers and screen magnifiers as innovation. Therefore, such factors as innovation attributes, type of innovation-decisions, communication channels, nature of social system, and the role of change agents, were found applicable as barriers suitable for investigation in this inquiry.

From the results, it is clear that the adoption of screen readers and screen magnifiers was still low among PWVDs in Uganda, with only 45 and 8 respondents out of 100 using such technologies on computers and mobile phones respectively. This had a direct relationship with the low use of ICTs because only four respondents reported using computers without the aid of assistive technologies. However, 86 respondents reported using mobile phones without assistive technologies, which reveals a weak relationship between the two technologies. But the number that reported using the Internet (32 respondents with visual disabilities) was far below that for assistive technologies, which meant lack of screen readers and screen magnifiers was simply an additional problem to the complications PWVDs find with the Internet. The major problem for PWVDs is the poor design of web sites, the solution of which cannot be found without government intervention. Deriving from this scenario, it can be asserted that PWVDs in Uganda have been forced into some kind of structural exclusion from which extrication will be very hard in the foreseeable future.

On another note, there was overwhelming ignorance among respondents about cheaper means of obtaining assistive technologies. For example, none of them reported trying out the many screen magnifiers that either came on the same programme CDs with screen readers (say Magic with JAWS For Windows) or those that were built in the operating systems of computers (such as Zoom for Mac OS). Also, ZOOMS (the screen magnifier from Nuance Communications) is now bundled with TALKS as part of the Premium Edition; and Mobile Magnifier (from Code Factory) was bundled with the 3.0 version of Mobile Speak (Huffman \& Burton, 2007). Another option for obtaining assistive technologies cheaply would have been via Open Source Software; but again no respondent, according to the findings of this study, had adopted this type of assistive technologies (NVDA). However, it is important to reiterate that both integrated and Open Source Software has limitations in performing certain tasks such as web browsing and reading of documents.

Another challenge was the lack of government support in the provision of assistive technologies. The organisations that respondents said had given them screen readers and screen magnifiers were NGOs like Sight Savers International - Uganda and UNAB, which could discontinue the distribution of such assistive technologies at any time sighting resource constraints or change of priorities. Perhaps government should consider offering grants to deserving Ugandans to acquire screen readers and screen magnifiers, especially in the rural areas where majority of the respondents (58 out of 100) came from. 
One further challenge which affected adoption of screen readers and screen magnifiers was the insufficient training in ICTs for PWVDs in the country. Training was available only at the UNAB HiTech Project and was restricted to those who could afford paying for it. The situation could be improved tremendously if there were other institutions around the country offering similar trainings. However, as observed in all the institutions visited, the overall diffusion of ICTs in the country was still undermined by the inadequate supply of computers, with user to machine ratio sometimes going as high as 1-10. Moreover, many of the computers were old and they broke down from time to time.

Actual usage of ICTs in Uganda was reduced even further by the following challenges:

- Lack or inadequate power supply, especially in rural areas;

- Poor Internet connectivity in many areas;

- High usage costs for Internet and mobile phones;

- Inadequate training for most users of computers and the Internet; and

- All available telecommunications devices were in foreign languages that were not easily understood by the majority of the population.

Finally, the Diffusion of Innovations theory may not fully explain how to overcome the low adoption of screen readers and screen magnifiers. Unlike the mainstream consumer market where a critical mass would force prices of given products to fall, hence accelerating the rate of adoption, the market for assistive technologies will always be small with cost remaining consistently high (O'Brien, 2005). However, Seelman (2005) discussed some alternative ways change agents have explored to stimulate acceptance of assistive technologies, and these relate to technology transformation and social dimensions of assistive technologies. It is perhaps worth reflecting on some of them. These include the following:

1. Encourage crossovers from assistive technology to universal design. This acts as reaction to the stigma attached to disability or the medical appearance of some assistive technology products. In relation to this study, if someone buys an Apple computer, a screen reader (Voiceover) and screen magnifier (Zoom) are features already built into the operating system at no additional cost (Blubaugh, 2011).

2. Use of standards. Over time, national and international standards associations such as ISO (International Organisation for Standardization) and ANSI (American National Standards Institute) have issued standards for the built environment, many of which have been referred to in codes with enforcement power (Seelman, 2005). Likewise, The World Wide Web Consortium (W3C) develops and maintains the protocols used on the Web to insure interoperability to promote universal access. Uganda uses the W3C standards for its web sites, which is a good starting point for ensuring use of the Internet among PWVDs.

3. Government incentives and mandates such as technical codes, antidiscrimination legislation, direct and indirect reimbursements of devices by health and social service systems, tax credits and benefits to individuals with disabilities, parents and businesses that accommodate or employ persons with disabilities. As an example, section 508 of the U.S. Rehabilitation Act of 1973 (as amended in 1998) requires federal agencies to ensure that the electronic and information technologies they develop, procure, maintain or use allows federal employees with disabilities to have access and use of information and data that is comparable to what federal employees without disabilities get, unless an undue burden would be imposed on the agency. Likewise, third party reimbursements in Japan and many European countries are incentives that have caused an upward surge in markets for certain assistive technologies. In the case of Uganda, there was an incentive of zero import duties on computers and related accessories introduced in 2004. 
However, this had no impact on the prices of screen readers and screen magnifiers because it did not cover software licenses.

\subsection{Conclusions}

Findings of the study bring out a clear conclusion that assistive technologies are vital for the digital inclusion of PWVDs. For instance, over fifty percent of the 100 respondents could not use computers, which they blamed on lack of screen readers. Also, 68 percent could not use the Internet, which again shows that lack of assistive technologies has a negative impact on the capability of PWVDs to use ICTs. However, 94 respondents could use mobile phones with or without assistive technologies, which make this conclusion a little confusing. The only explanation for this apparent contradiction is that mobile phones are used for many simple tasks besides or apart from computer-related functions. Nonetheless, the simplicity in operating most mobile phones, at least according to the findings of this study, is a good point from which to start enabling PWVDs gain access to digital technologies. This is not far-fetched if one considers the statistics in Chapter 1 of this dissertation that show rapid diffusion of mobile telephony around the world.

If adoption of assistive technologies is to be encouraged among PWVDs in Uganda, more efforts should be directed towards females and rural areas. Females are perceived to suffer double discrimination, both as women and PWVDs; and rural areas benefit less from cosmopolitan channels of communication that are known to bring in new ideas.

It is clear from the findings that degree of blindness had little influence on adoption of assistive technologies by PWVDs in Uganda. For instance, only two respondents used screen magnifiers (Magic and Zoom Text) on computers, and none used them on a mobile phone. This comes on a backdrop of 49 respondents registering as low vision people. However, no clear reason was given for this anomaly. Either it was due to ignorance about the existence of several screen magnifier options or it was because of the hardship of setting up such technologies for maximum output.

The reason for many respondents not using screen readers and screen magnifiers was not necessarily affordability. Rather it was what Rogers (2003) termed as the KAP (Knowledge, Attitude and Practice) gap. For instance, many respondents did not know where to procure such technologies from, let alone knowing the several other options for obtaining integrated, open source or freeware technologies. Only one service provider, a computer trainer from one University, mentioned colour contrasts (available within the Windows operating system) as an option for enabling someone with low vision to use a computer.

Absence of the conventional media (newspapers, radio and television) from the promotion of ICTs for PWVDs in Uganda could have had a bigger effect on the adoption of assistive technologies than other factors investigated. This conclusion comes from the fact that only five respondents acknowledged obtaining information about screen readers and screen magnifiers from such media channels; yet those media are better placed to provide information for awareness, training opportunities and attitudechange to vast numbers in a Low Developed Country (LDC) like Uganda. The status quo denies many PWVDs the opportunity to benefit from interpersonal relations available in some organisations and schools. 


\section{Chapter 5 The human constraints towards digital inclusion for PWVDs in Uganda}

\subsection{Introduction}

This chapter addresses the research question: 'How does the cumulative and recursive model of successive kinds of access to digital technologies contribute towards understanding the constraints in digital technology inclusion for PWVDs in Uganda?' A field study was conducted with a total of 200 respondents, and the main finding was that three out of the four types of access (material, skills and use) as stated in the model by Jan van Dijk (2005) help to clarify some major constraints responsible for the low uptake of digital technologies by PWVDs in Uganda. Motivational access was the only one that did not manifest any unique constraints attributable to PWVDs directly; yet this would have been a good extension of the factors the ICF model identifies - negative self-image, low selfconfidence and low levels of self-efficacy - which may hinder a person from carrying out activities of daily living.

Unlike the dichotomous classification of technology haves and have-nots found in the conventional digital divide rhetoric, this study used the expanded view of access. Clement and Shade (1998) were the first scholars to explore this elaborate kind of access to digital technologies, illustrating it in a model they referred to as the Access Rainbow. This model had seven layers of access explained as follows: carriage facilities (the facilities that store, serve or carry information), devices (the actual physical devices that people operate), software tools (the programmes that run the devices and make connections to services), content/services (the actual information and communications services people find useful), service providers (the organizations that provide network access to users), literacy/social facilitation (the skills people need to take full advantage of information/communications facilities, together with the training and facilitation to acquire these skills), and governance (how decisions are made concerning the development and operation of the infrastructure).

On the other hand, De Haan (2004) introduced a multifaceted theoretical model in which Internet access is dependent on the user's motivation, possession, digital skills and use pattern. These four facets have a hierarchical relationship - possession builds on motivation, digital skills build on possession and use builds on skills (De Haan, 2004: p. 84). The model offers a better understanding of the causes and consequences of digital inequality in the information society, unlike the binary concept of access vs. non-access or use vs. non-use of ICTs found in the concept of the digital divide.

This chapter is structured as follows. It begins with these introductory remarks, then a brief review of the cumulative and recursive model of successive kinds of access to digital technologies and how it is used to answer the specific research questions associated with the human dimension of restriction outlined in Chapter 1. This is followed by explaining the research methods, then presentation of results and finally a discussion and conclusion. 


\subsection{The cumulative and recursive model of successive kinds of access to digital technologies}

The access model developed by Jan van Dijk (2005) was used in this investigation as a framework to ascertain the digital constraints faced by PWVDs in Uganda. It asserts that four successive and cumulative types of access - motivation, material, digital skills and usage - mark the steps to be taken by individual users in the total process of appropriation of digital technology (Van Dijk, 2005).

Motivation is the starting point of access, where some of the people who do not have digital technology should actually be persuaded to want it. This is a motivational problem explained by socio-cultural or mental/psychological factors (Van Dijk, 2006). Socio-cultural factors of motivation are hinged on income and education status, where the Internet may not have appeal for people with low income or low education. The mental or psychological factors relate to computer anxiety (a feeling of discomfort, stress, or fear experienced when confronting computers) and technophobia (fear of technology in general and distrust in its beneficial effects). As laid out here, these are serious constraints capable of limiting access to digital technology by PWVDs. This is because digital technology is associated with highly technical competences for which someone must take a great deal of effort to acquire.

The second strand in this model is the material or physical access to digital technologies. After acquiring the motivation to get access, the challenge for new users of ICT is to act on it by either purchasing a computer and Internet connection themselves, or may use those of others (Van Dijk, 2005). This may be done privately at home, work or school, with family and friends, or in public places such as cyber cafes and community telecentres. The present study considers mobile phones as well, which can be accessed in similar ways. Material access brings out two peculiar constraints for PWVDs. First is affordability of computers or mobile phones as well as Internet connection; second is the ability to move to the places where there is shared access for the ICTs being referred to.

Figure 5.1: Connections between the four components of the access model. Derived from Van Dijk (2005).

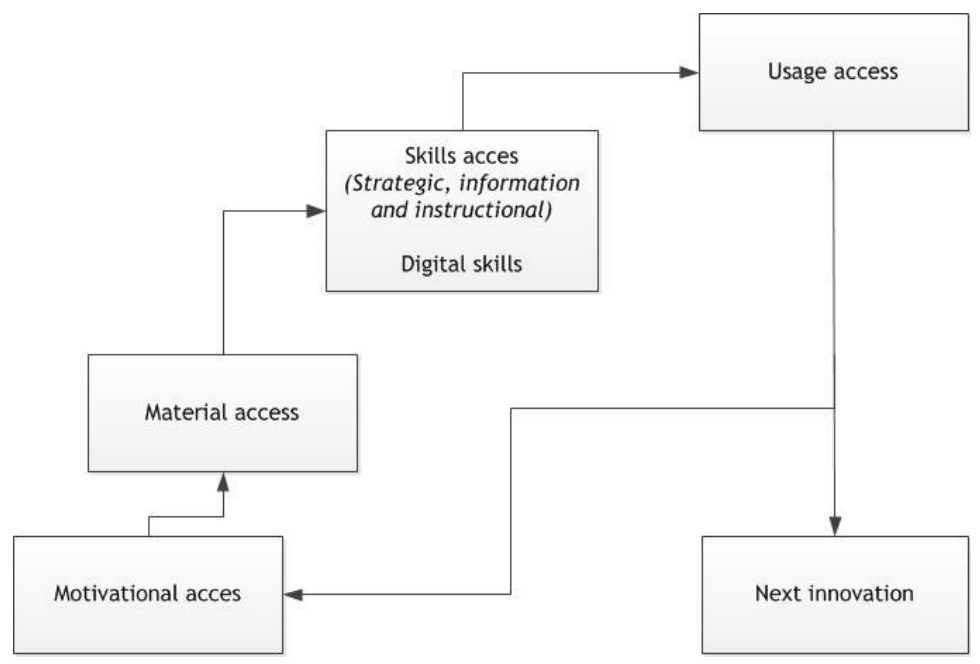


The third strand is skills access, which brings in the necessity for knowledge to manage the hardware and software acquired at the material level of access. This is an area of great constraint because both computers and the Internet usually require formal training to be used effectively. As mobile computing becomes more popular by the day, proper training will also soon be required to maximize the benefits users can derive from them.

The fourth and last strand in the model is the use access. Van Dijk (2006) argues that having motivation, physical access and skills to apply digital media are necessary but not sufficient conditions of actual use. In so doing, to understand the constraints associated with use access requires examining the actual time someone uses the technology; and the number and diversity of usage applications. It has also been argued that broadband or narrowband connection determines the type of Internet usage. Connections between the four strands of the model are represented in Figure 5.1.

Whereas the above model stopped at the above four levels of access, the present study seeks to add a fifth strand (access to social support), which mediates between all the above four. So far several scholars within the realm of Digital Divide research have alluded to the importance of social support, such as DiMaggio \& Hargittai (2001), Warschauer (2003) and Van Dijk (2005). However, these do not bring it out as part of the access model. DiMaggio \& Hargittai recognize it among the inequalities in the use of ICT, Warschauer alludes to social support through another concept known as social capital, and van Dijk refers to it as part of skills access.

Other scholars, such as Anandarajan, Igbaria \& Anakwe (2002) and Frank, Zhao \& Borman (2004) examined social pressure as a major factor determining the diffusion of computer use among 143 organizational workers in Nigeria and teachers in six schools respectively. If we take social pressure into account, the two studies present further evidence of how social support is important in the acquisition and use of ICT.

Based on the above model and the addition of social support, this chapter explores five sub-questions:

1. What are the motivational constraints PWVDs find in access to ICTs in Uganda?

2. What are the physical access constraints to ICTs for PWVDs in Uganda?

3. What are the constraints to acquiring digital skills by PWVDs in Uganda?

4. What are the constraints relating to use of ICTs by PWVDs in Uganda?

5. What is the importance of social support in furthering access to ICTs for PWVDs?

\subsection{Methodology}

\subsubsection{Study design}

Answering the questions in this chapter is part of the second phase of the research project, which necessitated using mixed methods research involving both qualitative and quantitative approaches.

For the quantitative approach, a survey involving 200 respondents drawn from the four regions of Uganda (central, east, north and west) was undertaken. This survey was conducted separately from the one undertaken for the research presented in Chapter 4. The set of respondents was also predominately different with just about 10 percent appearing in both surveys. Six independent variables (age, education level, gender, income, location and occupation) were considered in selecting the respondents. Barzilai-Nahon (2006) refers to these as monotonically indicators/measures, which are common in studies on the digital divide - say Losh (2004), DiMaggio et al. (2004) and Hoffman 
et al. (2000). Monotopical measures of the digital divide typically identify one or a few variables that influence a dependent variable, which in turn reflects one aspect of the divide, such as awareness, access, attitudes, or application (Barzilai-Nahon, 2006: p. 270). Each of these may serve as a gauge of the gap. In this particular study access to ICTs was the aspect of the digital divide considered.

The qualitative approach was a follow-up of the quantitative survey, using fifty respondents who were selected from the 200 to be engaged in further interaction. The aim was to gain a deeper understanding of the factors responsible for the low uptake of ICTs among Ugandan PWVDs and how these would be overcome.

\subsubsection{Sample selection}

For the survey, the researcher used convenience sampling; and the primary sampling units (users and non-users of various ICTs) were voluntarily selected from various districts (Gulu, Iganga, Kampala, Mbarara, Mukono and Soroti) in the four regions of Uganda in an attempt to reflect the national character of the country. However, six variables (including age, education level, gender, income, location and occupation) were considered. Details of the respondents in regard to the six variables were as follows:

- Location shows 55\% of the respondents from rural areas and $45 \%$ from urban areas.

- Gender shows 64 (32 percent) respondents as female and 136 (68 percent) as male.

- For age, 140 respondents were between 15 - 24 years, followed by 35 between 25 - 34 years, then 16 between 35 - 44 years, 8 between $45-54$ years and only one respondent was 55 years + . The age related bias is due to two reasons. Firstly, the majority of the respondents were students, as the sampling was undertaken largely in schools and other educational institutions. Secondly, the older people were drawn from the institutions where people were working, where there were few respondents available.

- With respect to level of education, most respondents (59) were undergraduate students at two universities, others were pursuing Uganda certificate of education and Uganda Advanced Certificate of Education (54 and 33 respondents respectively). 30 respondents were degree holders, diploma holders were 13, 5 had Post-graduate qualifications, and 5 were teachers with Grade III certificates. Only 1 respondent had a certificate in secretarial studies.

- In terms of occupation six categories emerged including 142 students, 10 in senior management, 11 programme/project officers, 22 teachers, 5 support staff and 10 with no occupation.

- In terms of income, respondents were in six categories depending on their approximate monthly earnings of between 100,000 and 500,000 Uganda Shillings, 600,000 and 1,000,000, 1,100,000 and $1,500,000,1,600,000$ and 2,000,000. However, a sizable number never belonged to any of the above categories - either because their incomes were below 100,000 Shillings or they earned nothing at all. Income was chosen as one of the areas of analysis as it is one of the factors that can determine affordability of ICTs.

For the qualitative study Criterion Sampling was used to select the respondents. In this case the criterion for selection was capability to use the three ICTs (computer, mobile phone and the Internet) under study; hence dropping non-users at this stage.

\subsubsection{Data collection instruments}

For this empirical research part three data collection instruments were developed.

1. Survey Questionnaire: This was a semi-structured questionnaire made up of two sections (see appendix 4). Section (A) had ten questions largely aimed at collecting personal biodata of the 200 respondents; and section (b) had nine questions aimed at collecting data on the experience of 
respondents in regard to ICTs. Answers from the latter section determined the respondents who would be selected for further interaction in the study; hence separating those who were conversant in using ICTs from those who were not.

2. Interview Protocol was used for Respondents conversant with ICTs (see Appendix 5). Following the survey interviews were conducted with fifty respondents (selected from the 200) who had been found to possess the highest level of experience in ICTs. In this study, highest experience meant having the capability to use all the three ICTs under focus, without necessarily testing specific competences. The purpose was to get more insights into the restrictions from digital inclusion for Persons with Visual Disabilities. A detailed interview protocol was drawn for this purpose, which comprised four sections. Each of the first three sections (A, B, and C) was aimed at collecting data regarding a particular technology(personal computer, mobile phone or the Internet), giving detailed experiences of the respondents. Section (D) had two questions, one with twenty sub-questions and the other with ten, which were arranged on a Likert scale. The aim was testing the confidence of respondents against two of the three ICTs which they had picked on earlier as experienced in. This was termed as Computer Self-Efficacy (CSE) and Internet SelfEfficacy (ISE) respectively. It was not possible to apply the same Likert scale questions to mobile phones because of the confusion surrounding their multiple functions as digital technologies. The Likert scale was used to assess the degree of confidence of respondents in performing various tasks, and the components of CSE were grouped into four sets - the first for general knowledge on using the computer; second for computer terminology; third for advanced skills in computer; and finally for troubleshooting computer problems. for Internet, the components of ISE were grouped into three sets - knowledge on using the Internet; Internet terminology; and advanced skills in Internet. Based on the ratings given by Smith (2001), the respondents answered the twenty CSE and 10 ISE questions on a five-point Likert scale ( 5 = totally confident, $4=$ moderately confident, $3=$ do not know, $2=$ not confident, and $1=$ not at all confident). The average scores obtained by ranking all the 50 respondents, and grouping them as explained, were again compared with the types of training through which respondents had learnt computer and Internet use; and the time respondents had taken after training in computer and the Internet. The final scores would then determine the confidence levels of respondents; hence giving hints on whether or not proper training and time taken using computer and the Internet were motivators towards using ICTs by Persons with Visual Disabilities.

3. Field Notes, were taken simultaneously with interviews at the various sites where the field research was conducted to collect more data regarding the situation of PWVDs and ICTs in Uganda. This means they were used to collect that data not anticipated in the survey and interviews.

\subsection{Presentation and interpretation of results}

\subsubsection{Motivational constraints PWVDs find in access to ICTs in Uganda}

In the access model, motivation denotes the first phase of access to the new digital technologies and it is considered a preliminary condition of all other phases (Van Dijk, 2005). Whereas potential users are motivated to adopt, acquire, learn and use ICTs under normal circumstances, there are people who show no interest in taking any of these steps in favour of digital technologies. Section 2.3.1 gives several reasons for non-use of ICTs; although these do not show specific relationship to Persons with Visual Disabilities. 
Unlike previous studies which focused on computers and the Internet, the current one included mobile telephony as well. Three arguments were considered for this:

- Mobile phones are multifunctional - acting as ordinary telephones as well as performing many computer and Internet-based functions;

- Many services, say money transfers, property advertisement and dissemination of messages intended for the public, are being provided via SMS; and

- The same providers of mobile telephone services are providers of mobile Internet, which is a cheaper and easier way of Internet connection in Uganda.

Indeed the results show that inclusion of mobile telephony in this study was worthwhile; because all the 200 survey respondents were found to be regular users of mobile phones. this was much higher than for the other two ICTs under focus, where computers registered 124 users and the Internet only 50. The reasons that respondents gave for not using both computers and the Internet included lack of access to computers (67), lack of training (27) and lack of Internet connection at the institutions of work/study (24). Other respondents (27) sighted lack of assistive technologies and 5 simply said they did not know how to use the two ICTs without giving reasons. This meant that rather than low motivation, non-use of ICTs could be blamed on lack of physical access to the relevant digital technologies.

For mobile phones, the findings (from interviews) showed that no respondent expressed formal training as a requirement for starting to use them. However, only 11 respondents could use mobile Internet, which was a sign that training would remain a vital requirement for use of mobile phones with an Internet capability. Another interesting finding captured through field notes was that most of the mobile phones respondents used were not installed with assistive technologies; but this had little or no impact on how they used them.

As shown in the literature review, mental and psychological factors were found responsible for the low motivation towards use of ICTs. This study therefore investigated whether or not such factors were prevalent among PWVDs in Uganda. Indeed a few of the respondents surveyed said they initially had a fear of working on a computer thinking it could read one's mind and compromise his or her life. But it would be erroneous to conclude that fear was the ultimate reason for the 62 and 75 percent of the respondents found not to use computers and the Internet respectively; because about 95 percent of them were found to study or work in institutions with computers, and to some extent with Internet connection (see Table 5.5 showing the occupations of respondents). This means mental and psychological factors may not be ruled out completely as causes of low motivation towards use of ICTs.

Further investigation into the reasons for the low motivation of PWVDs towards use of ICTs was carried out through CSE and ISE of the 50 respondents who were interviewed after the survey. To do this properly, the confidence levels of respondents in using computers and the internet were measured by assigning them Likert scale questions - twenty for CSE and ten for ISE, the results of which were compared with the type of training each respondent had used to learn computer and the Internet respectively. For better management of results, average scores were obtained for all components in each of the four sub-sections (in the case of CSE) and the three sub-sections (in the case of ISE) as explained in the methodology section. Two hypotheses were used for this purpose. 
Hypothesis 1:

Computer Self Efficacy (CSE) is positively related to type of training in computer use. The results are presented in Table 5.1.

Table 5.1: Likert scale scores for CSE and computer training types for respondents

\begin{tabular}{|c|c|c|c|c|c|}
\hline \multirow{2}{*}{\multicolumn{2}{|c|}{ Type of Score }} & \multicolumn{3}{|c|}{ Computer training } & \multirow{2}{*}{$\begin{array}{l}\text { Total } \\
1(2 \%)\end{array}$} \\
\hline & & \multirow{2}{*}{$\begin{array}{l}\text { Formal } \\
1(2 \%)\end{array}$} & & & \\
\hline General & Not confident & & $\begin{array}{l}\text { Informal } \\
0\end{array}$ & $\begin{array}{l}\text { Self } \\
0\end{array}$ & \\
\hline knowledge & Do not know & $1(2 \%)$ & $1(2 \%)$ & $1(2 \%)$ & $3(6 \%)$ \\
\hline on using a & Moderately confident & $10(20 \%)$ & $5(10 \%)$ & 0 & $15(30 \%)$ \\
\hline computer & Totally confident & $23(46 \%)$ & $7(14 \%)$ & $1(2 \%)$ & $31(62 \%)$ \\
\hline \multicolumn{2}{|l|}{ Total } & $35(70 \%)$ & $13(26 \%)$ & $2(4 \%)$ & $50(100 \%)$ \\
\hline \multirow{4}{*}{$\begin{array}{l}\text { Computer } \\
\text { terminology }\end{array}$} & Not confident & $3(6 \%)$ & $2(4 \%)$ & 0 & $5(10 \%)$ \\
\hline & Do not know & $4(8 \%)$ & 0 & $1(2 \%)$ & $5(10 \%)$ \\
\hline & Moderately confident & $15(30 \%)$ & $5(10 \%)$ & 0 & $20(40 \%)$ \\
\hline & Totally confident & $13(26 \%)$ & $6(12 \%)$ & $1(2 \%)$ & $20(40 \%)$ \\
\hline \multicolumn{2}{|l|}{ Total } & $35(70 \%)$ & $13(26 \%)$ & $2(4 \%)$ & $50(100 \%)$ \\
\hline \multirow{4}{*}{$\begin{array}{l}\text { Advanced } \\
\text { skills in } \\
\text { computer }\end{array}$} & Not confident & 0 & $1(2 \%)$ & $1(2 \%)$ & $2(4 \%)$ \\
\hline & Do not know & $5(10 \%)$ & 0 & 0 & $5(10 \%)$ \\
\hline & Moderately confident & $8(16 \%)$ & $5(10 \%)$ & 0 & $13(26 \%)$ \\
\hline & Totally confident & $22(44 \%)$ & $7(14 \%)$ & $1(2 \%)$ & $30(60 \%)$ \\
\hline \multicolumn{2}{|l|}{ Total } & $35(70 \%)$ & $13(26 \%)$ & $2(4 \%)$ & $50(100 \%)$ \\
\hline \multirow{4}{*}{$\begin{array}{l}\text { Trouble } \\
\text { shooting } \\
\text { problems }\end{array}$} & Not confident & $3(6 \%)$ & $1(2 \%)$ & $1(2 \%)$ & $5(10 \%)$ \\
\hline & Do not know & $6(12 \%)$ & $2(4 \%)$ & 0 & $8(16 \%)$ \\
\hline & Moderately confident & $15(30 \%)$ & $5(10 \%)$ & $1(2 \%)$ & $21(42 \%)$ \\
\hline & Totally confident & $11(22 \%)$ & $5(10 \%)$ & 0 & $16(32 \%)$ \\
\hline \multicolumn{2}{|l|}{ Total } & $35(70 \%)$ & $13(26 \%)$ & $2(4 \%)$ & $50(100 \%)$ \\
\hline
\end{tabular}

Source: primary data.

From Table 5.1, it is shown that $70 \%$ of the respondents learnt using computers through formal training, $26 \%$ of them undertook informal training (were helped by friends and colleagues) and $4 \%$ learnt using computers through self-training. When cross tabulation was done between the four areas of CSE and the three types of training, it was found out that the respondents who were totally confident in general knowledge of computer use registered the highest score of 31(62\%). 23(46\%) of these had learnt using computer through formal training; 7 (14\%) had learnt through informal training and $1(2 \%)$ had learnt through self-training. Regarding computer terminology, respondents who were totally confident and those who were moderately confident registered the same score of 20 as highest. To break down those that were totally confident, the table shows that $13(26 \%)$ were formally trained in using computer, $6(12 \%)$ had learnt through informal training and $1(2 \%)$ had learnt through selftraining. Regarding advanced skills in computer, respondents who were totally confident again registered the highest score of 30. To break this down, 22 (44\%) had learnt using computers through formal training, $7(14 \%)$ had learnt through informal training and $1(2 \%)$ had learnt through selftraining. The final score was about troubleshooting computer problems; and the highest score of 21 was for respondents who were moderately confident. This was 5 points below that of respondents who were totally confident. As a breakdown of those that were moderately confident, $15(30 \%)$ had learnt using computers through formal training, $5(10 \%)$ had learnt through informal training and $1(2 \%)$ had learnt through self-training. These scores largely prove the hypothesis that CSE is positively related to 
the type of computer training respondents receive. In other words, the more respondents got exposed to formal training in computer the more they gained confidence in its use.

Hypothesis 2:

\section{Internet Self Efficacy (ISE) is positively related to type of training in Internet use.}

Table 5.2 presents the results of this hypothesis elaborately, showing that $16 \%$ of the respondents undertook formal internet training, while $58 \%$ of them undertook informal internet training, $6 \%$ of them said they learnt Internet through self-training and $20 \%$ used a combination of two or all the three types of training. When cross tabulation was done between the three areas of ISE and the four types of training through which respondents had learnt using the Internet, it was found out that for knowledge in using Internet, the respondents who were moderately confident registered the highest score of 18 . To break this down, 4 (8\%) had learnt Internet through formal training, 10 had learnt through informal training, $2(4 \%)$ had learnt through self-training and $2(4 \%)$ had learnt through a combination of training methods. For Internet terminology, again respondents who were moderately confident registered the highest score of 22. To break this down, 2 (4\%) had learnt Internet through formal training, $16(32 \%)$ had learnt through informal training and $4(8 \%)$ had learnt through a combination of training methods. For advanced skills in Internet, again respondents who were moderately confident registered the highest score of 20 . To break this down, $2(4 \%)$ had learnt Internet through formal training, $15(30 \%)$ had learnt through informal training, $2(4 \%)$ had learnt through self-training and $1(2 \%)$ had learnt through a combination of training methods. From these results, there are consistently low scores registered in all the three areas scored for confidence in regards to formal training. This nullifies the hypothesis that ISE is positively related to the type of Internet training respondents received. In other words, it is possible that respondents got few opportunities for formal training in Internet; but then their confidence levels in its use were relatively high.

Table 5.2: Likert scale scores for ISE and internet training types for respondents

\begin{tabular}{|c|c|c|c|c|c|c|}
\hline \multicolumn{2}{|l|}{ Type of Score } & \multicolumn{4}{|c|}{ Internet training } & \multirow{3}{*}{$\begin{array}{l}\text { Total } \\
1(2 \%) \\
\end{array}$} \\
\hline & & \multirow{2}{*}{$\begin{array}{l}\text { Formal } \\
0\end{array}$} & \multirow{2}{*}{$\begin{array}{l}\text { Informal } \\
1(2 \%)\end{array}$} & \multirow{2}{*}{$\begin{array}{l}\text { Self } \\
0\end{array}$} & \multirow{2}{*}{$\begin{array}{l}\text { Other } \\
0\end{array}$} & \\
\hline Knowledge on & Not at all confident & & & & & \\
\hline using internet & Not confident & $2(4 \%)$ & $5(10 \%)$ & $1(2 \%)$ & $2(4 \%)$ & $10(20 \%)$ \\
\hline & Do not know & $2(4 \%)$ & $3(6 \%)$ & 0 & $2(4 \%)$ & $7(14 \%)$ \\
\hline & Moderately confident & $4(8 \%)$ & $10(20 \%)$ & $2(4 \%)$ & $2(4 \%)$ & $18(36 \%)$ \\
\hline & Totally confident & 0 & $10(20 \%)$ & 0 & $4(8 \%)$ & $14(28 \%)$ \\
\hline \multicolumn{2}{|l|}{ Total } & $8(16 \%)$ & $29(58 \%)$ & $3(6 \%)$ & $10(20 \%)$ & $50(100 \%)$ \\
\hline \multirow{5}{*}{$\begin{array}{l}\text { Internet } \\
\text { terminology }\end{array}$} & Not at all confident & $2(4 \%)$ & $1(2 \%)$ & 0 & $1(2 \%)$ & $4(8 \%)$ \\
\hline & Not confident & $2(4 \%)$ & $2(4 \%)$ & $1(2 \%)$ & $1(2 \%)$ & $6(12 \%)$ \\
\hline & Do not know & $2(4 \%)$ & $7(14 \%)$ & $1(2 \%)$ & $4(8 \%)$ & $14(28 \%)$ \\
\hline & Moderately confident & $2(4 \%)$ & $16(32 \%)$ & 0 & $4(8 \%)$ & $22(44 \%)$ \\
\hline & Totally confident & 0 & $3(6 \%)$ & $1(2 \%)$ & 0 & $4(8 \%)$ \\
\hline \multicolumn{2}{|l|}{ Total } & $8(16 \%)$ & $29(58 \%)$ & $3(6 \%)$ & $10(20 \%)$ & $50(100 \%)$ \\
\hline \multirow{5}{*}{$\begin{array}{l}\text { Advanced } \\
\text { skills in } \\
\text { internet }\end{array}$} & Not at all confident & $2(4 \%)$ & $3(6 \%)$ & $1(2 \%)$ & 0 & $6(12 \%)$ \\
\hline & Not confident & $2(4 \%)$ & $2(4 \%)$ & 0 & $4(8 \%)$ & $18(16 \%)$ \\
\hline & Do not know & $1(2 \%)$ & $8(16 \%)$ & 0 & $4(8 \%)$ & $13(26 \%)$ \\
\hline & Moderately confident & $2(4 \%)$ & $15(30 \%)$ & $2(4 \%)$ & $1(2 \%)$ & $20(40 \%)$ \\
\hline & Totally confident & $1(2 \%)$ & $1(2 \%)$ & 0 & $1(2 \%)$ & $3(6 \%)$ \\
\hline \multicolumn{2}{|l|}{ Total } & $8(16 \%)$ & $29(58 \%)$ & $3(6 \%)$ & $10(20 \%)$ & $50(100 \%)$ \\
\hline
\end{tabular}

Source: primary data. 
Not wishing to conclude with CSE and ISE vis-à-vis type of training alone as indicators of motivation towards use of ICTs, the researcher thought it appropriate to also test out the CSE and ISE Likert scale scores with the time respondents had spent after training in computer and Internet use. This is premised on the argument that most people will perfect their skill with practice; hence improving the confidence levels of respondents in using the two ICTs.

Hypothesis 3:

Computer Self Efficacy (CSE) is positively related to time spent after training in computer use.

From Table 5.3, 24\% of the respondents had spent less than a year after training in computer use, 50\% had spent between 1 and 3 years, 12\% had taken 4-6 years and 14\% of them had completed training in computer use over 7 years earlier. As before, these were cross-tabulated with Likert scale scores based on general knowledge of using the computer, computer terminology, advanced skills in computer use, and troubleshooting computer problems.

Table 5.3: Cross tabulation of CSE and time spent after computer training

\begin{tabular}{|c|c|c|c|c|c|c|}
\hline \multirow{2}{*}{\multicolumn{2}{|c|}{ Type of Score }} & \multicolumn{4}{|c|}{ Time spent } & \multirow{3}{*}{\begin{tabular}{|l} 
Total \\
$1(2 \%)$
\end{tabular}} \\
\hline & & \multirow{2}{*}{$\begin{array}{l}<1 \text { year } \\
0\end{array}$} & \multirow{2}{*}{$\begin{array}{l}1-3 \text { years } \\
1(2 \%)\end{array}$} & \multirow{2}{*}{$\begin{array}{l}4-6 \text { years } \\
0\end{array}$} & \multirow{2}{*}{$\begin{array}{l}>7 \text { years } \\
0\end{array}$} & \\
\hline General & Not confident & & & & & \\
\hline knowledge of & Do not know & 0 & 0 & $2(4 \%)$ & $1(2 \%)$ & $3(6 \%)$ \\
\hline using a & Moderately confident & $3(6 \%)$ & $8(16 \%)$ & $2(4 \%)$ & $2(4 \%)$ & $15(30 \%)$ \\
\hline computer & Totally confident & $9(18 \%)$ & $16(32 \%)$ & $2(4 \%)$ & $4(8 \%)$ & $31(62 \%)$ \\
\hline \multicolumn{2}{|l|}{ Total } & $12(24 \%)$ & $25(50 \%)$ & $6(12 \%)$ & $7(14 \%)$ & $50(100 \%)$ \\
\hline \multirow{4}{*}{$\begin{array}{l}\text { Computer } \\
\text { terminology }\end{array}$} & Not confident & 0 & $3(6 \%)$ & $2(4 \%)$ & 0 & $5(10 \%)$ \\
\hline & Do not know & $1(2 \%)$ & $2(4 \%)$ & $1(2 \%)$ & $1(2 \%)$ & $5(10 \%)$ \\
\hline & Moderately confident & $5(10 \%)$ & $11(22 \%)$ & $1(2 \%)$ & $3(6 \%)$ & $20(40 \%)$ \\
\hline & Totally confident & $6(12 \%)$ & $9(18 \%)$ & $2(4 \%)$ & $3(6 \%)$ & $20(40 \%)$ \\
\hline \multicolumn{2}{|l|}{ Total } & $12(24 \%)$ & $25(50 \%)$ & $6(12 \%)$ & $7(14 \%)$ & $50(100 \%)$ \\
\hline \multirow{4}{*}{$\begin{array}{l}\text { Advanced } \\
\text { skills in } \\
\text { computer }\end{array}$} & Not confident & 0 & 0 & $1(2 \%)$ & $1(2 \%)$ & $2(4 \%)$ \\
\hline & Do not know & $1(2 \%)$ & $1(2 \%)$ & $2(4 \%)$ & $1(2 \%)$ & $5(10 \%)$ \\
\hline & Moderately confident & $2(4 \%)$ & $8(16 \%)$ & $1(2 \%)$ & $2(4 \%)$ & $13(26 \%)$ \\
\hline & Totally confident & $9(18 \%))$ & $16(32 \%)$ & $2(4 \%)$ & $3(6 \%)$ & $30(60 \%)$ \\
\hline \multicolumn{2}{|l|}{ Total } & $12(24 \%)$ & $25(50 \%)$ & $6(12 \%)$ & $7(14 \%)$ & $50(100 \%)$ \\
\hline \multirow{4}{*}{$\begin{array}{l}\text { Trouble } \\
\text { shooting } \\
\text { computer } \\
\text { problems }\end{array}$} & Not confident & 0 & $1(2 \%)$ & $3(6 \%)$ & $1(2 \%)$ & $5(10 \%)$ \\
\hline & Do not know & $2(4 \%)$ & $4(8 \%)$ & $1(2 \%)$ & $1(2 \%)$ & $5(10 \%)$ \\
\hline & Moderately confident & $4(8 \%)$ & $12(24 \%)$ & $2(4 \%)$ & $3(6 \%)$ & $21(26 \%)$ \\
\hline & Totally confident & $6(12 \%))$ & $8(16 \%)$ & 0 & $2(4 \%)$ & $16(32 \%)$ \\
\hline \multicolumn{2}{|l|}{ Total } & $12(24 \%)$ & $25(50 \%)$ & $6(12 \%)$ & $7(14 \%)$ & $50(100 \%)$ \\
\hline
\end{tabular}

Source: primary data.

As shown in Table 5.3, when cross tabulation was done between the four areas of CSE and the four categorizations of times respondents had spent after training in computer, it was found out that for knowledge of using computer, the respondents who were totally confident registered the highest score of 31 . When this was broken down, $16(32 \%)$ had spent $1-3$ years after training in computer, $9(16 \%)$ had spent less than one year after training, $4(8 \%)$ had spent over 7 years after training, and $2(4 \%)$ had spent between four and six years after training. For using computer terminology, the respondents who were totally and moderately confident registered the same highest score of 20 . To break down the score for 'totally confident', 9 (18\%) had spent 1-3 years after computer training, $6(12 \%)$ had spent less than 1 year, $3(6 \%)$ had spent over 7 years and $2(4 \%)$ had spent $4-6$ years after computer 
training. For advanced skills in computer, the respondents who were totally confident registered the highest score of 30 . To break this down, $16(32 \%)$ had spent 1-3 years after computer training, 9 (18\%) had spent less than 1 year, $2(4 \%)$ had spent $4-6$ years and $3(6 \%)$ had spent 7 and above years after computer training. Finally, for trouble shooting computer problems, respondents who were moderately confident scored the highest score of 21 , which was 5 points above that of totally confident. To break this down, 12 (24\%) had spent 1-3 years after computer training, $4(8 \%)$ had spent less than 1 year, $2(4 \%)$ had spent 4-6 years and $3(6 \%)$ had spent 7 and above years. Putting these scores together, they nullify the Hypothesis that CSE is positively related to time spent after computer training. In other words, it is not clear that the more time respondents spent after training the more they gained confidence in its use; because significantly high scores were recorded for those that had spent either less than 1 year or 1-3 years.

\section{Hypothesis 4:}

\section{Internet Self Efficacy (ISE) is positively related to time spent after internet training.}

From Table 5.4, 24\% of the respondents had spent less than 1 year after training in Internet, $50 \%$ had spent $1-3$ years after training, $12 \%$ had spent $4-6$ years after training and $14 \%$ of them had spent over 7 years after training in Internet. These trends are similar to those of CSE, which means respondents learnt the Internet at about the same time with learning to use the computer.

Table 5.4: Cross tabulation of ISE and time spent after computer training

\begin{tabular}{|c|c|c|c|c|c|c|}
\hline \multicolumn{2}{|l|}{ Type of Scores } & \multicolumn{4}{|c|}{ Time spent } & \multirow{3}{*}{$\begin{array}{l}\text { Total } \\
4(8 \%)\end{array}$} \\
\hline & & \multirow{2}{*}{$\begin{array}{l}<1 \text { year } \\
0\end{array}$} & \multirow{2}{*}{$\begin{array}{l}1-3 \text { years } \\
1(2 \%)\end{array}$} & \multirow{2}{*}{$\begin{array}{l}4-6 \text { years } \\
3(6 \%)\end{array}$} & \multirow{2}{*}{$\begin{array}{l}>7 \text { years } \\
0\end{array}$} & \\
\hline Internet & Not at all confident & & & & & \\
\hline terminology & Not confident & $2(4 \%)$ & $1(2 \%)$ & 0 & $3(6 \%)$ & $6(12 \%)$ \\
\hline & Do not know & $2(4 \%)$ & $10(10 \%)$ & $2(4 \%)$ & 0 & $14(28 \%)$ \\
\hline & Moderately confident & $6(12 \%)$ & $11(22 \%)$ & $1(2 \%)$ & $4(8 \%)$ & $22(44 \%)$ \\
\hline & Totally confident & $2(4 \%)$ & $2(4 \%)$ & 0 & 0 & $4(8 \%)$ \\
\hline \multicolumn{2}{|l|}{ Total } & $12(24 \%)$ & $25(50 \%)$ & $6(12 \%)$ & $7(14 \%)$ & $50(100 \%)$ \\
\hline \multirow{5}{*}{$\begin{array}{l}\text { Knowledge on } \\
\text { using internet }\end{array}$} & Not at all confident & 0 & $1(2 \%)$ & 0 & 0 & $1(2 \%)$ \\
\hline & Not confident & $1(2 \%)$ & $6(12 \%)$ & $2(4 \%)$ & $1(2 \%)$ & $10(20 \%)$ \\
\hline & Do not know & $1(2 \%)$ & $2(4 \%)$ & $3(6 \%)$ & $1(2 \%)$ & $7(14 \%)$ \\
\hline & Moderately confident & $6(12 \%)$ & $10(20 \%)$ & 0 & $2(4 \%)$ & $18(36 \%)$ \\
\hline & Totally confident & $4(8 \%)$ & $6(12 \%)$ & $1(2 \%)$ & $3(6 \%)$ & $14(28 \%)$ \\
\hline \multicolumn{2}{|l|}{ Total } & $12(24 \%)$ & $25(50 \%)$ & $6(12 \%)$ & $7(14 \%)$ & $50(100 \%)$ \\
\hline \multirow{5}{*}{$\begin{array}{l}\text { Advanced } \\
\text { skills in } \\
\text { internet }\end{array}$} & Not at all confident & $1(2 \%)$ & $3(6 \%)$ & $2(4 \%)$ & 0 & $6(12 \%)$ \\
\hline & Not confident & $1(2 \%)$ & $4(8 \%)$ & $1(2 \%)$ & $2(4 \%)$ & $8(16 \%)$ \\
\hline & Do not know & $4(8 \%)$ & $5(10 \%)$ & $1(2 \%)$ & $3(6 \%)$ & $13(26 \%)$ \\
\hline & Moderately confident & $5(10 \%)$ & $12(24 \%)$ & $1(2 \%)$ & $2(4 \%)$ & $20(40 \%)$ \\
\hline & Totally confident & $1(2 \%)$ & $1(2 \%)$ & $1(2 \%)$ & 0 & $3(6 \%)$ \\
\hline \multicolumn{2}{|l|}{ Total } & $12(24 \%)$ & $25(50 \%)$ & $6(12 \%)$ & $7(14 \%)$ & $50(100 \%)$ \\
\hline
\end{tabular}

Source: primary data.

As presented in Table 5.4, when cross tabulation was done between the three areas of ISE and the four categorisations of times respondents had spent after training in Internet, it was found out that for using Internet terminology, the respondents who were moderately confident registered the highest score of 22. To break this down, $6(12 \%)$ had spent less than 1 year after training, $11(22 \%)$ had spent 1-3 years, $1(2 \%)$ had spent $4-6$ years and $4(8 \%)$ had spent 7 and above years. For knowledge of using the Internet, the respondents who were moderately confident again registered the highest score of 18 . 
To break this down, $6(12 \%)$ had spent less than one year after training in Internet use, $10(20 \%)$ had spent 1-3 years after training and $2(4 \%)$ had spent 7 and above years. For advanced skills in Internet use, the respondents who were moderately confident again registered the highest score of 20 . To break this down, $5(10 \%)$ had spent less than 1 year after training in Internet, $12(24 \%)$ had spent 1-3 years, $1(2 \%)$ had spent $4-6$ years and $2(4 \%)$ had spent 7 and above years after training. Putting these scores together, they nullify the Hypothesis that ISE is positively related to time spent after Internet training. In other words, it is not clear that the more time respondents spent after training in Internet the more they gained confidence in its use; because significantly high scores were recorded for those that had spent either less than 1 year or 1-3 years.

Beyond self-efficacy, this study carried out another investigation about the motivation of PWVDs by asking the 50 respondents to mention the benefits they derived from using the different ICTs. This was prompted by the assertion that individuals are more likely to undertake behaviors they believe will result in valued outcomes than those they do not see as having favorable consequences (Compeau \& Higgins, 1995). In other words, outcome expectations should partly explain why PWVDs would persist in adopting different ICTs even when these are characterized by being unsafe, user-unfriendly or unattractive. According to Compeau, Higgins \& Huff (1999), outcome expectations have two dimensions - performance-related outcomes and personal outcomes. The former are those associated with improvements in job performance (efficiency and effectiveness) associated with using computers; and the latter relate to expectations of change in image or status or to expectations of rewards, such as promotions, raises, or praise. This particular study did not break down outcome expectations into such dimensions. Instead, the 50 respondents who had demonstrated strong use of ICTs were interviewed for the benefits they derived from such technologies, and these were grouped into social, financial and technical. The benefits relating to computer are more of a technical nature and they include:

- The computer facilitates editing, formatting and spell-checking; hence enhancing a blind person's independence in task performance.

- The computer helps information sharing between sighted and blind people, especially when given in soft copy.

- It is a source of entertainment (via music and videos stored on the hard disk).

- Helps in building one's esteem - evidence for high capability.

- The computer facilitates proper documentation and information retrieval; hence enhancing storage of important documents.

- Computer improves prospects for employment.

- Compared with Braille, keeping documents in soft copy on the computer makes the volume of work smaller.

- Reading with a screen reader on computer is easier than having to read using ordinary Braille.

- Using a computer cuts down on expenses which would be spent on hiring typing services.

In connection with using the Internet, respondents gave a mixture of social, technical and financial benefits listed as follows:

- Easy communication (through E-mail and chatting).

- Quick access to relevant information.

- Has boosted my academic performance.

- Helps in keeping me up-to-date with news events.

- Can easily create friendship with people around the world using e-mail and social networking sites. 
- The Internet is a source of entertainment.

- Can download some free software applications and updates for both my phone and computer.

- Source of scholarship and employment opportunities.

- The Internet helps me in fundraising.

More than 'receiving and sending out money', which was a financial benefit, most respondents said they derived social benefits from mobile phones, including:

- Easy and quick communication through calls and SMS.

- Have used the phone to make several friends.

- Keeps me up-to-date, especially through SMS from friends and the phone service provider.

- Sometimes the phone acts as a guide because I can call someone to pick me up when I am lost.

- The phone is a source of entertainment.

- The phone helps me to avoid costs I would otherwise incur in transport.

To sum up, it is probable that other users of ICTs could give benefits similar to the above. However, these can specifically help someone to appreciate that PWVDs have defined outcome expectations when using ICTs, which is a good indicator of motivation. Therefore, lack of motivation was not a major constraint in access to ICTs for PWVDs in Uganda.

\subsubsection{Physical constraints towards access of ICTs by PWVDs in Uganda}

According to Van Dijk (2005), physical access is the entry to hardware, operational software, and services of computers, networks, and other digital technologies. This may be done privately at work or school, or with family and friends, or in public places at a particular access point. As presented in Table 5.5, this study registered similar access points when respondents were asked where they accessed computers and the Internet from.

Table 5.5: Places where respondents accessed computers and the Internet

\begin{tabular}{|l|l|l|}
\hline Places & Computer & Internet \\
\hline Workplace & 25 & 14 \\
\hline Home & 16 & 6 \\
\hline Public computer Centre/café & 27 & 19 \\
\hline University or school & 29 & -- \\
\hline Home \& workplace /school & 15 & -- \\
\hline Home, workplace \& café & 5 & 2 \\
\hline Friend's place & 5 & -- \\
\hline Workplace \& public computer centre & 2 & 6 \\
\hline Workplace, home \& friends & -- & 3 \\
\hline Total & 124 & 50 \\
\hline
\end{tabular}

Source: primary data.

For mobile phones, 157 (78\%) of the respondents had personal phones; although 11 of these used public pay phones as well. 22 respondents (11\%) borrowed phones from friends or relatives, and 10 (5\%) used public pay phones only.

But how people access ICTs does not adequately explain the material access constraints. In common among studies on the digital divide, this study found it appropriate to examine the influence of socio- 
economic variables to material access to ICTs. That would probably result into more effective intervention against digital exclusion of a disadvantaged group like PWVDs in Uganda. The factors examined were age, education level, gender, income, location and occupation.

Results show that in terms of age, respondents were in five age brackets: between 15 - 24 years, 25 $34,35-44,45-54$, and 55 years + . Results show that $70 \%$ of the respondents who had access to ICTs were between 15 and 24 years, explained by the fact that most in that age bracket were students with a high likelihood for institutional access. But as shown in Table 5.5, only 14 in the same age bracket had access to the Internet, which was a serious deficiency in the use of the new media. Respondents in the second and third age brackets, 18 and 11 respectively, points to workplaces being more instrumental in providing Internet connection than other situations. All the results are presented in Table 5.6.

Table 5.6: Cross-tab of age and access to ICTs

\begin{tabular}{|l|l|l|l|l|}
\hline Age bracket & Mobile phone & $\begin{array}{l}\text { Personal computer } \\
\text { and mobile phone }\end{array}$ & $\begin{array}{l}\text { Personal computer, mobile } \\
\text { phone, and the internet }\end{array}$ & Totals \\
\hline $15-24$ & 65 & 61 & 14 & 140 \\
\hline $25-34$ & 7 & 10 & 18 & 35 \\
\hline $35-44$ & 3 & 2 & 11 & 16 \\
\hline $45-54$ & 1 & 1 & 6 & 8 \\
\hline 55 and above & - & - & 1 & 1 \\
\hline Grand Total & $\mathbf{7 6}$ & $\mathbf{7 4}$ & $\mathbf{5 0}$ & $\mathbf{2 0 0}$ \\
\hline
\end{tabular}

Source: primary data.

As for occupation, six categories emerged, including 142 students, 10 people in senior management positions, 11 programme/project officers, 22 teachers, 5 support stuffs and 10 respondents who had no occupation. A cross-tabulation revealed that those with managerial occupations had more access to ICTs than the rest. Thus, all the 10 respondents in senior management positions had access to all three ICTs, the same with the 11 programme/project officers, 10 out of the 22 education officers and 2 of the 5 support staff. Only 16 of 142 students accessed three ICTs, and only 1 out of those with no occupation. A summary of all the frequencies is given in the Table 5.7.

Table 5.7: Cross-tab of occupation and access to ICT

\begin{tabular}{|l|l|l|l|l|}
\hline Row labels & $\begin{array}{l}\text { Mobile } \\
\text { phone }\end{array}$ & $\begin{array}{l}\text { Personal computer } \\
\text { and mobile phone }\end{array}$ & $\begin{array}{l}\text { Personal computer, mobile } \\
\text { phone, and the internet }\end{array}$ & Totals \\
\hline Education officer & 8 & 4 & 10 & 22 \\
\hline Have no occupation & 5 & 4 & 1 & 10 \\
\hline $\begin{array}{l}\text { Programme/project } \\
\text { officer }\end{array}$ & - & - & 11 & 11 \\
\hline Senior management & & & 10 & 10 \\
\hline Student & 63 & 63 & 16 & 142 \\
\hline Support staff & & 3 & 2 & 5 \\
\hline Grand Total & $\mathbf{7 6}$ & $\mathbf{7 4}$ & $\mathbf{5 0}$ & $\mathbf{2 0 0}$ \\
\hline
\end{tabular}

Source: primary data.

In terms of gender, $136(68 \%)$ of the respondents were male and $64(32 \%)$ were female. When gender was compared with access to ICTs, findings revealed. 
- Of the 136 males 39 had access to all the three ICTs, 47 to mobile phones, and 50 to both mobile phones and computers.

- Of the 64 females 29 had access to mobile phones, 24 to both mobile phones and computers, and 11 to all the three ICTs.

The study also considered access to ICTs in terms of education level. In this regard, a cross-tabulation between the two variables revealed that uptake of ICTs was greater for respondents with higher education. Thus, all the 5 post-graduates accessed all three ICTs, and 23 of 30 degree holders, 6 of 13 diploma holders, and 11 of the 59 under-graduates, 1 out of 33 UACE students and 4 out of 54 UCE students. All the frequency distributions are given in Table 5.8.

Table 5.8: Cross-tab of level of education and access to ICT

\begin{tabular}{|l|l|l|l|l|}
\hline $\begin{array}{l}\text { ICT Access Vis-à-vis } \\
\text { Education Level }\end{array}$ & Mobile phone & $\begin{array}{l}\text { Personal computer } \\
\text { and mobile phone }\end{array}$ & $\begin{array}{l}\text { Personal computer, mobile } \\
\text { phone, and the internet }\end{array}$ & Totals \\
\hline Post-Graduate & - & - & 5 & 5 \\
\hline Degree & 2 & 5 & 23 & 30 \\
\hline Under-Graduate & 13 & 35 & 11 & 59 \\
\hline Diploma & 1 & 6 & 6 & 13 \\
\hline UACE & 22 & 10 & 1 & 33 \\
\hline UCE & 35 & 15 & 4 & 54 \\
\hline Grade III Teacher & 3 & 2 & - & 5 \\
\hline Secretarial Studies & - & 1 & - & 1 \\
\hline Grand Total & $\mathbf{7 6}$ & $\mathbf{7 4}$ & $\mathbf{5 0}$ & $\mathbf{2 0 0}$ \\
\hline
\end{tabular}

Source: primary data.

In terms of location, the study considered Kampala an urban area while all the other places visited (Gulu, Iganga, Mbarara, Mukono and Soroti) were rural. Classifying Kampala as urban was premised on the fact that all facilities of digital technology were headquartered here, meaning that this is where the best services existed in the country. This classification is in tandem with the literature reviewed in Chapter 2, which showed that ICTs in sub-Saharan Africa were concentrated in urban areas. After considering respondents in terms of urban and rural areas, the results were such that $110(55 \%)$ of them resided in rural areas while 90 (45\%) resided in Kampala. A comparison between location and access to ICTs showed that Kampala had higher access than all the rural areas, save for mobile phones. For instance:

- 32 of the 90 respondents from urban areas had access to all the three ICTs and only 18 of the 110 from rural areas.

- 43 respondents from urban areas had access to both computers and mobile phones, and only 31 from rural areas;

- 15 respondents from urban areas had access to mobile phones, and 61 from rural areas.

Income was also compared with access to ICTs, and the issue under consideration was affordability. In that regard, respondents reported their approximate monthly earnings by which comparison was made with access to ICTs. This showed an upward trend in line with the different income levels. For instance, only 16 respondents with the lowest income bracket, either with incomes below 100,000 Shillings or with no earning whatsoever could afford using all the three ICTs as shown in Table 5.9. 
Table 5.9: Cross-tab of income and access to ICTs

\begin{tabular}{|l|l|l|l|l|}
\hline $\begin{array}{l}\text { Income brackets in } \\
\text { U.Shs }\end{array}$ & $\begin{array}{l}\text { Mobile } \\
\text { phone }\end{array}$ & $\begin{array}{l}\text { Personal computer } \\
\text { and mobile phone }\end{array}$ & $\begin{array}{l}\text { Personal computer, mobile } \\
\text { phone, and the internet }\end{array}$ & Totals \\
\hline $100,000-500,000$ & 6 & 9 & 21 & 36 \\
\hline $600,000-1,000,000$ & 2 & -- & 6 & 8 \\
\hline $1,100,000-1,500,000$ & -- & -- & 4 & 4 \\
\hline $1,600,000-2,000,000$ & -- & -- & 3 & 3 \\
\hline None of the above & 68 & 65 & 16 & 149 \\
\hline Grand Total & $\mathbf{7 6}$ & $\mathbf{7 4}$ & $\mathbf{5 0}$ & $\mathbf{2 0 0}$ \\
\hline
\end{tabular}

Source: primary data.

To conclude this section, all the findings presented here tend to show that the traditional causes of social stratifications are also strongly correlated with the material access to digital technologies. This means that those with higher levels of education have better chances of accessing ICTs than the lowly educated. Similarly, those with higher means of income can afford subscribing for Internet and mobile phone services than those with little or no income. Age, gender and geographical location also depicted a trend similar to what studies on the digital divide had discovered earlier on. Therefore, reducing disparities in socio-economic factors can go a long way in encouraging access to new digital media technologies among PWVDs in a developing country like Uganda. Moreover such a decision does not require substantial addition of funds but just a policy adjustment to include the requirements of PWVDs in universal service, which Uganda implements as the Rural Communication Development Project.

\subsubsection{Digital skills constraints of PWVDs in Uganda}

Skills access is the third stage in the access model. It means someone will have to learn using digital technologies after making a material effort to acquire such technologies. This is so because unlike in the old media where switching on and off is the only skill that matters in most cases, for the new digital media several skills are required and learned in a formal training or through practice. The skills needed to operate the digital media include the ability to retrieve specific sorts of information using a range of tools such as search browsers and online databases; the ability to manipulate or enhance the value of information; and the ability to obtain services that increase the quality of one's life (Clement \& Shade, 1998). These form one of three types of digital skills given by Van Dijk \& Hacker (2003); Van Dijk (2005), including operational skills, information skills and strategic skills. More types of digital skills are discussed in Chapter 2, all of which emphasizing the requirement of a variety of skills in order to use computers and the Internet.

The types of digital skills discussed above do not fully account for those needed in operating a mobile phone; yet this would also require some level of mastery for effective usage. For instance, as observed by Faulkner \& Culwin (2005: pp. 168-169), the mobile phone still has a keyboard designed for dialing numbers which makes text messaging difficult. The standard ISO/IEC 995-8 1994 layout uses 12-15 keys to facilitate text input, which must accommodate 26 letters of the alphabet as well as punctuation and numerical characters. Each key is therefore expected to perform several tasks and it may need more than one key press to achieve the desired character. There are three key-based text entry methods which include the multi-press method, T9 predictive input method and the two-key input method (Ling et al., 2007). Research shows that the T9 predictive input method is the fastest; but that does not necessarily make it the easiest for PWVDs because selecting from the predicted list of words can be quite cumbersome without a good vision. 
On another note, using features such as menu design, display screen, multimedia messaging and the mobile Internet also requires a substantial amount of skill. Just to explain one of these, the display screen of mobile phones is the window for information presentation to users, and it is typically small in size (Ling et al., 2007: p. 149). For that matter, the display screen size and the horizontal depth in menu hierarchy strongly affect the navigation activities and perception of mobile Internet users for complex search tasks.

Finally, touch screen technology, which is now in vogue on many mobile devices such as tablet computers, smart phones and personal digital assistants, is also still largely inaccessible to users with visual disabilities. The inaccessibility is due to interaction techniques that require the user to visually locate objects on the screen (Kane, Bigham \& Wobbrock, 2008). This is especially difficult since most touch screens provide no audio or tactile feedback. But even where audio feedback is provided, learning finger-scan gestures, tapping targets on the screen, flicking gesture and performing an Lshaped gesture (some of the interaction techniques needed to use touch screens) is not a process PWVDs would find simple.

In the present study, the fifty respondents interviewed were asked to point out the challenges they faced in learning to use the three ICTs as a way of gauging their operational skills. It was clear from the findings that many had limited skills in computer and the Internet, which was due to little or no formal training. The challenges were given as follows:

- The training was riddled with abstract and complicated terminologies.

- Had challenges understanding the enunciations of the JAWS screen reader, especially when voicing words from the local languages.

- Inadequate practice due to scarcity of computers.

- Mastery of numerous steps in some packages was required, say JAWS For Windows and Microsoft Excel.

- It was expensive paying for a special computer course.

- Instructors did not know how to train me as a blind person.

- Incorrect fingering of the keyboard because it had very many keys, or very small inscriptions.

- Found it hard to grasp the many keystrokes of the screen reader and other computer packages.

- Too much glaring of the computer screen.

- Could not read some documents, especially in PDF.

When asked about the challenges they faced before getting accustomed to mobile phones, the majority of respondents mentioned issues relating to unusable design features as expressed in the following excerpts:

- Initially I made mistakes in certain functions, say dialing wrong numbers, sending money to wrong contacts and sending blank SMS, due to the complex arrangement of menus.

- Could not write or read SMS on my own.

- Each phone I came across had menus and physical set-up arranged differently from another.

- Found it hard to use mobile Internet.

- Found it hard to load credit on the phone.

- Initially reading the screen of a phone was difficult due to its low resolution.

- Phones had many menus, complicating navigation and orientation; hence missing out on some functions.

- Had problems using a phone with a touch screen, flat buttons or small prints on buttons. 
Beyond the challenges related to operational skills deficiencies, some respondents gave explanations pointing to serious difficulties PWVDs would find with employing information skills as defined by Van Dijk (2005). Some extracts include:

- Before getting used to the web interface a lot of imagination is involved in figuring out how web content is arranged. Initially this meant opening several links before arriving at the one I wanted.

- Surfing is somewhat made difficult by having to go through several links using a host of shortcuts.

- The JAWS screen reader cannot read some of the content on the net, complicating information search and retrieval processes.

- Lapses between commands and feedback are sometimes long, which interrupts my user interface. It means I often experience time-outs or get disoriented during surfing when JAWS goes silent.

- Web sites without headings, frames and links are still a challenge; because sometimes I may not know which part I am at.

- Sometimes JAWS reads instructions that are not visible on the screen, which complicates obtaining assistance from a sighted person in case of trouble-shooting a problem.

\subsubsection{Constraints related to use of ICTs for PWVDs in Uganda}

Usage is the last stage in the access model. At this point, the goal is to use ICT for a particular purpose of information, communication, transaction or entertainment (Van Dijk, 2005). Tracing the use constraints in the current study necessitated employing the concept of 'effective use' (Gurstein, 2003), which refers to the capacity and opportunity to successfully integrate ICTs into the accomplishment of self or collaboratively identified goals. This means access to hardware and software alone is not sufficient to allow users to become productive and satisfied (Bessiere et al., 2002). Instead, for all users to be effective in their tasks, there must be support in many forms, including documentation, tutorials, training, online user assistance, and helpdesk support.

Table 5.10: Years when respondents began using the different ICTs.

\begin{tabular}{|l|l|l|l|}
\hline Year & Personal computer & Phone & Internet \\
\hline 2011 & 9 & 12 & 5 \\
\hline 2010 & 19 & 35 & 16 \\
\hline 2009 & 26 & 42 & 6 \\
\hline 2008 & 24 & 34 & 3 \\
\hline 2007 & 11 & 13 & 7 \\
\hline 2006 & 4 & 11 & 2 \\
\hline 2005 & 7 & 16 & 3 \\
\hline 2004 & 4 & 14 & 2 \\
\hline 2003 & 2 & 2 & 1 \\
\hline 2002 & 7 & 6 & 3 \\
\hline 2001 & 5 & 3 & 0 \\
\hline 1999 & 3 & 3 & 1 \\
\hline 1998 & 2 & 6 & 1 \\
\hline 1996 & 1 & 3 & 0 \\
\hline Totals & 124 & 200 & 50 \\
\hline
\end{tabular}

Source: primary data. 
Three aspects - actual use, usage time, and usage diversity - were employed in analysing the effective use of ICTs. For actual use, focus was first put on when respondents began using the various ICTs. As presented in Table 5.10, the results reveal that 1 and 3 respondents respectively began using a computer and mobile phone in 1996. Between then and 2006 the number of respondents who began using computers were below ten per year. There was an upward trend for mobile phones with usage going beyond ten respondents each year between 2004 and 2010. With the exception of 2010, uptake of the Internet had the least number of respondents per year.

Another bit of actual use involved finding out the common usage challenges faced by respondents in connection with ICTs. For computers, the following were the challenges given:

- Inability to read certain documents, especially in PDF or Power Point.

- getting updates of screen readers and antivirus software is expensive.

- Frequent computer breakdowns, especially in public access points like libraries and community telecentres.

- Working with the latest windows programmes was hard for some respondents.

- The screen reader used by most respondents (JAWS For Windows) made some strange pronounciations, which often made them think they had written certain words wrongly.

Although the above challenges that respondents expressed were related to usability, limited skills was also partly to blame for the limited use of computers. For instance, PWVDs who are computer savvy know that PDF and Power Point files that are received as e-mail attachments can be accessed (read) by simply converting them into HTML documents. It is worth noting that HTML documents are as readable as ordinary MS word documents when using a screen reader. Alternatively, according to Mazrui (2005), when Adobe Reader is launched, it detects whether a screen reader is running, and then it presents a dialog box of configuration options that affect accessibility and sets the default choices to ones that Adobe Reader finds are the most likely to work best. There are three accessibility settings that include "infer reading order from document", "left-to-right, top-to-bottom reading order", and "use reading order in raw print stream". Activating any of these settings enables Adobe Reader to analyse and un tag a PDF file, and add temporary tags to optimize its reading.

Regarding Internet, the major challenges given by respondents cannot be blamed on visual disability per se. These include:

- Limited connectivity, which sometimes makes access to Internet hard.

- Most Internet cafes in Uganda have no screen readers.

- Internet connectivity is sometimes weak, especially during rainy seasons.

- Cannot use most Internet packages because of having not got formal training.

- It is hard entering the search box and input what I want to search for.

- Paying for internet services is expensive.

- I find Internet-based E-mails (yahoo mail and Gmail) not user-friendly.

- I usually lack privacy because someone has to help me through all the Internet tasks.

- The screen reader cannot access some web content due to problems of compatibility.

- Using a screen reader on the Internet requires going through several commands, which is cumbersome.

For mobile phones, the challenges respondents expressed in relation to skill were the same with those for use. These entailed the difficulty of using phones with touch screens, flat buttons or those with small prints on buttons. 
Understanding usage time required asking respondents the intervals at which they used ICTs. The study only captured data regarding mobile phones and the Internet. Thus, it was found out that 157 respondents had full ownership of mobile phones and they used them daily. However, 22 of these expressed buying airtime credit as a challenge, which they offset by using public pay phones. Similarly, 10 respondents, mostly students, did not own mobile phones; and they only used public pay phones once in a while to make important calls.

For the Internet, complications associated with access to computers and Internet connectivity as well as limited digital skills brought out marked differences in how regularly the respondents used this technology. Thus, only $50 \%$ of the respondents interviewed could use the Internet every day, $28 \%$ could use it at least once a week and $22 \%$ only used it once in a long while ( 2 weeks and beyond). Contrary to what was found in the literature reviewed for this dissertation, which showed that using Internet at home was the best alternative for PWVDs, majority of the respondents interviewed (19) said they actually accessed Internet from public computer centres or cafes, followed by 14 who accessed it from their workplaces. Only 6 accessed it from their homes, and another 6 from a combination of workplaces and public computer centres. The remainder -3 accessed Internet from a combination of workplace, home \& friends; and 2 from home, workplace \& café.

Usage diversity can be traced from the variety of tasks for which respondents used the different ICTs. For mobile phones, all the 50 respondents interviewed said they could make and receive phone calls; 47 could send out SMS; 16 could carry out money transactions; 11 could use mobile Internet; 3 could get sports news, photos and screen savers; and 1 could get voicemail. This means few respondents could use mobile phones for anything beyond their traditional functions.

As for computers, out of the fifty respondents interviewed only 24 could use MS Excel in addition to MS Word, 11 added MS Power Point, 2 added a media player and another 2 added MS Access. 1 respondent reported using Win-Braille (an application for digitally transcribing print into Braille) and another one said he used statistical packages such as Epidata, Epi-info and SPSS.

As regards the Internet, the 50 respondents interviewed mentioned tasks such as e-mail (43), searching for literature (38), reading/listening to news (10), social networking on Facebook and Twitter (7), and engaging in entertainment - including downloading music and podcasts, and playing games (7). Some respondents did engage in unique tasks, including two who made calls using Skype, two who made regular software downloads, one who used the Internet for fundraising and one who undertook e-courses. One important point to note here is that the number of respondents who engaged in complex activities on the Internet went on dwindling, which was a clear indicator of the limited digital skills of Ugandans with visual disabilities.

But the suitability and quality of hardware, software and Internet connectivity play a big part in the usage of ICTs. This is part of what was obtained through field notes. For example, use of computers and the Internet should have been high because most respondents were studying and working in institutions with good access to such technologies. However, this was not the case due to numerous challenges. For hardware, many of the secondary schools and universities visited had resource centres and labs fairly equipped with computers; but these were beset with several weaknesses listed below:

i) Resource centres were equipped with old computers - a source of frustrations for users. One student put it quite succinctly that: 
"In order not to lose patience over these slow machines, you set up one and then go for lunch. By the time you return it will just be finishing loading the homepage of a web site you wished to visit."

ii) Computers were also fewer than the users, severely curtailing chances of practice and gaining mastery in use. Many respondents said they found it hard to keep waiting for others to finish before they could take their turn on the machines; so they simply gave up the whole exercise of learning to use the computer.

iii) In some schools students never had free access to resource centres, which was either due to the requirement of seeking permission from higher authorities prior to accessing them or they were always open for a limited time.

As for Internet connection, by the time this study was carried out Uganda was just starting to set up broadband connections in some major towns of the country and key government institutions. Thus most respondents relied on wireless connection from various mobile phone companies, which was on and off for most of the time. As explained by some respondents, this meant waiting till late in the night to read a few e-mails or do some surfing. This was even worse in rural areas where no 'last-mile solutions' had been found. Last-mile solutions are technologies that enable connectivity of Internet users at the periphery to the national data backbone. Some respondents said they tried shifting from one Internet service provider to another in the hope of improving connectivity but ended up getting frustrated even the more.

Regarding software, the challenges respondents gave were around the inability to use ordinary applications such as Microsoft word, spreadsheets and Internet browsers. In addition, many said they could not use computers and mobile phones effectively due to lack of assistive technologies.

\subsubsection{Importance of access to social support for persons with visual disabilities}

The literature reviewed for this dissertation had sufficient evidence showing that access to social support affects the use of ICTs. It was actually found that social support cuts across all the facets of access as elucidated in the cumulative and recursive model of successive kinds of access to digital technologies, and below are results that also show social support affecting motivational, material, skills and use access in somewhat separate ways.

The biggest motivational constraint found was lack of competent users of ICTs to which others could turn. For example, many respondents studied in schools with neither specialist trainers nor fellow students who possessed adequate keyboard skills to help them learn both computer and the Internet, despite having computer labs/resource centres and wireless Internet connections on the school campuses.

For material access, three examples in the study can demonstrate how this relates with social support. Firstly, many respondents studied in institutions with all their computers as donations from NGOs and the World Bank, except where someone had brought their own from home. Secondly, family members were a major source of support in terms of acquiring mobile phones, except where a respondent bought one for him/herself. Thirdly, rather than buying screen readers directly from the known dealers, many respondents looked to blindness organisations to obtain them. 
For digital skills, social support was found relevant in acquiring basic skills in all the three ICTs. For example, friends/colleagues were responsible for enabling 22, 26 and 38 respondents to acquire skills of using mobile phones, computers and the Internet respectively. These numbers translate into $76 \%$ of Internet users, about $21 \%$ of computer users and $11 \%$ of mobile phone users respectively. Table 5.11 presents all the sources of ICT skills that respondents reported.

Table 5.11: Sources of ICT skills for respondents

\begin{tabular}{|l|l|l|l|l|}
\hline Source of ICT Skills & For Mobile Phones & For Computer & For Internet & Total \\
\hline From Training Centre & -- & 71 & 10 & 81 \\
\hline From Friends/colleagues & 22 & 26 & 38 & 86 \\
\hline From Self-Training & 178 & 9 & 2 & 189 \\
\hline From School & -- & 18 & -- & 18 \\
\hline Total & 200 & 124 & 50 & -- \\
\hline
\end{tabular}

Source: primary data.

In terms of usage, the study sought to test out the importance of social support by investigating whether trusting others to help in performing certain Internet tasks was a worthwhile option. In so doing, Respondents were asked to consider such tasks as entering usernames and passwords in case of e-mail, writing search queries in a search box, clicking on relevant links in a web site and troubleshooting some Internet problems. Results show that 18 respondents found that friends and relatives were of great help in providing support in all the tasks given. Further proof that social support was important in the use of ICTs came in the literature reviewed for this dissertation, where some Internet non-users were described as net evaders (those who exploit workarounds that allow them to use the Internet by proxy through family members). From what was found out by this study, it can be argued that net evaders are actually not non-users but Internet users of another category.

\subsection{Discussion}

Although explicitly developed for gaining insights into the reasons why people do not use ICTs, the cumulative and recursive model of successive kinds of access to digital technologies developed by Van Dijk (2005) offers a suitable approach for exploring the constraints to digital inclusion of PWVDs. For example, this study found out that only $64 \%$ and $25 \%$ of the respondents could use computers and the Internet respectively, which were pretty small percentages when one considers the fact that the respondents were carefully sampled from a population (of largely students and workers) with a high likelihood of wanting to reap the benefits of the new media.

Judging from the scenario coming out of this study, using material access alone - the traditional basis for digital exclusion - would have probably been inadequate in uncovering all the constraints found among PWVDs in Uganda. For instance, there was compelling evidence that respondents had sufficient access to computers and Internet connection in their study and/or work institutions but many hardly made effective use of them. Indeed the majority of respondents cited lack of formal training, rather than lack of material access, as the most pressing challenge for non-use of the two ICTs. With respect to mobile phones, since using them did not require lots of prior training, all the 200 respondents reported using them in one way or another.

But there is enough literature supporting the existence of constraints in the four facets of access. For motivational constraints for instance, these were well articulated by Bandura (1999), who argued that 
people regulate their motivation and actions anticipatorily by judgment of their capabilities, goal aspirations, outcome expectations and perceived environmental opportunity structures and impediments. The concepts of Outcome Expectations and Self Efficacy bring out this understanding very well. For outcome expectations, the assertion is that individuals are more likely to undertake behaviors they believe will result in valued outcomes than those they do not see as having favorable consequences (Compeau \& Higgins, 1995). On the other hand, self-efficacy refers to a person's belief in his/her capability to perform certain behaviors, and this affects choices about which behaviors to undertake, the effort and persistence exerted in the face of obstacles to the performance of those behaviors, and ultimately the mastery of those behaviors (Compeau \& Higgins, 1995).

From the numerous benefits that respondents gave for using the different ICTs, it came out clearly that Outcome Expectations were big motivators for PWVDs to adopt ICTs. But the relationship between CSE and ISE vis-à-vis motivation of PWVDs towards use of ICTs was neither strong nor weak. The reason for such an anomaly could have been the sample of participants chosen for the two studies. In prior studies, participants for CSE or ISE were chosen from a group of people who had just undergone or were about to undergo some training in a computer or Internet-related course. For instance, Compeau \& Higgins (1995) used study participants who had just completed a two-day training course covering Lotus 1-2-3. Another study by Eastin \& LaRose (2000) involved 171 participants who were undergraduate students from an introductory communications class. In this particular situation, participants were not linked by any common factor apart from all having some kind of visual disability. They were not recently from a uniform computer or Internet training or about to attend one; and their computer and Internet experiences were disparate since they stayed in different parts of the country.

The digital skills constraints faced by PWVDs depend on the specialty attached to their learning. This is aptly explained by Goggin \& Newell (2003), that: "Every speech, Braille or large print method for getting information from computers requires the user to learn an extra skill above and beyond the skills sighted people need. Blind people must know more to get the same work done."

Mobile phones present even a bigger challenge as expressed by respondents about the ever-changing design of such technologies. Many viewed the advent of touch screen technology with skepticism, while others could simply not cope with the new phone designs laden with a myriad of features. Indeed according to Kane, Bigham \& Wobbrock (2008), the common challenges users with visual disabilities would find with touch screens include the inability to locate objects on the screen or accidentally activating incorrect features such as unintentional deletion of files.

But all the 200 respondents could use mobile phones, which is a useful finding in regard to the diffusion of digital technology among PWVDs in two ways. First, it is possible the designers of mobile phones have reduced the burden of operational skills acquisition so much that self-training and seeking help from friends are now viable options for learning to use them. Secondly, users have a variety of functions to use with a high degree of satisfaction, which renders mobile phones more relevant for day-to-day use than computers. However, mobile computing and mobile Internet remain big challenges for PWVDs in Uganda; because the latter registered only 11 respondents as its users.

Turning to usage constraints, studies in the field of Human-Computer Interaction are so far the only ones that have fully explored the problems relating to the use of various ICTs. One of these was carried out by Ceaparu et al. (2004), with 111 participants, which discovered that problematic situations happen most frequently with applications such as web browsing, e-mail and word 
processing, and these often stem from the users' lack of knowledge, poor training, or unwillingness to read instructions. Problems can also emanate from flaws in computer hardware, software or networking, or troubling interactions among components supplied by diverse manufacturers, or even malicious actions (say sending out viruses) by other users.

Further evidence of constraints related to use of ICTs can be found in the web use project by Eszter Hargittai (2002), who found out how little members of the general user population lack the basics of surfing the web. For instance, a few people barely know what a Back button is, and thus have a hard time moving from screen to screen. More so, many people rarely use search engines, and they solely rely on functions of their browsers or Internet Service Providers. This is coupled with having a hard time entering valid search terms, occasioned by spelling mistakes or entering multiple term queries without any spaces.

But visually disabled people are arguably the marginalized group most drastically affected by the Information Technology industry because of the visual bias of so many ICT products (Chaudhry \& Shipp, 2005). This is one aspect that makes the ICT problems of PWVDs unique. Indeed a specific study evaluating the usability of e-mail applications by blind users noted that these were more likely to avoid something when they know it will cause them accessibility problems, such as the problems often presented by dynamic web content (Wentz \& Lazar, 2011). Another study done by Lazar, Allen, Kleinman \& Malarkey (2007) with 100 blind participants found that the top challenges for blind users of the web include the following:

- Page layout causing confusing screen reader feedback;

- Conflict between screen reader and application;

- Poorly designed/unlabeled forms;

- No alt text for pictures; and

- 3-way tie between misleading links, inaccessible PDF and a screen reader crash.

As already demonstrated in Section 5.4.5, access to social support is vital for PWVDs aspiring to use or in the habit of using ICTs. Relating this to the access model, it is the contention of this study that this be included as the fifth strand of the model, affecting all the other strands. Incontrovertible evidence was found in both the literature and field study supporting this assertion. Below is a detailed discussion:

Starting with motivational access, it is known that social support can transform people from technology want-nots to those with the urge to seek it. For instance, social influence can affect motivation decisively, where influential users can affect the attitude formation of others or induce certain behaviours (Brandtweiner, Donat \& Kerschbaum, 2010). Also, according to Anandarajan, Igbaria \& Anakwe (2002), social pressure (a kind of social influence) can affect the attitudes and behavior of individuals in varying degrees in different societies depending on the culture. Individuals from a collectivistic culture may use microcomputers not because of their potential usefulness but because of the perceived social pressure from their supervisors and peers. On the other hand, people from individualistic cultures promote self-reliance and thus have little concern for status and formality; they often bypass their superiors to perform their tasks.

With material access, there exists no prior evidence showing its relationship with social support. This is however proven to exist in Uganda, going by the findings of the current study. Many respondents obtained computers and assistive technologies as donations from NGOs and blindness institutions 
(some kind of social support). But the same respondents reported the inability to put such technologies to effective use, which renders this kind of social support not so worthy. Perhaps providing computers and Internet through a well-designed digital literacy programme would have come with good arrangements for the relevant formal training. This confirms what Brandtweiner, Donat \&Kerschbaum (2010) said about social support. They said this cannot guarantee use of the Internet as it is not always available and it can be stressful for both the helper and help-seeker.

With skills access, it is well known that digital literacy can often be compensated by social support, given either in the form of emotional support during learning or in the form of technical support (Brandtweiner, Donat \& Kerschbaum, 2010). To confirm this, the present study recorded that $76 \%$ of the respondents had relied on friends/colleagues to learn using the Internet.

The relationship between use access and social support stems from the fact that the visual bias of digital technologies makes it inevitable that PWVDs must, more often than not, seek assistance from others in order to perform certain ICT-based tasks. For example, in the event that PWVDs fail to navigate through the complexities commonly associated with the world wide web, which is often due to lack of assistive technologies or poorly designed web sites, it becomes vital to trust others to assist them. In addition, according to the explanation given by one respondent, screen readers have so far been designed to work with computers and mobile phones in a normal operational state. In other words, they will be the first to fall silent whenever something interrupts the normal functionality of the operation platforms on which they are installed; therefore these would not give the required feedback to a user with visual disability in case of a malfunction. This makes it pretty hard to fix a simple technical problem by a person with a visual disability.

In order to close the gap between users and non-users of digital technology, Warschauer (2003) suggested combining the strength of the Internet with other forms of interaction, especially with regard to a marginalized group like PWVDs. This may be through making use of ICTs to promote social capital and vice versa, which can be done at three different levels:

i) Micro level - the relations with friends, relatives, neighbours and colleagues who provide companionship, emotional support, goods and services, information, a sense of belonging, and opportunities for community development.

ii) Meso level - corresponding to the voluntary associations and political organisations that allow people opportunities to form alliances, create joint accomplishments, and collectively defend their interests.

iii) Macro level - corresponding to the effectiveness of governmental institutions and transparent and trustworthy relationships that exist between government and citizens.

In relation to the above explanation, the study found out that at the micro level, $80 \%$ of the respondents suffered severe exclusion from activities in their local communities by virtue of having visual disabilities. Some of the activities in which community restriction was experienced include: participation in agriculture and business, doing community work (attending meetings and music competitions), participation in sports (athletics, cycling, football and swimming), taking up leadership positions, pursuing computer studies, and taking part in domestic work.

Although the numbers that pointed out restriction from computer studies were small, just $9 \%$, analysing the other activities where restriction was experienced can reveal an unsettling negative trend towards access and use of ICTs. How, for example, would someone obtain permission to take up computer lessons away from home in a situation of social exclusion? This question comes from the 
fact that most activities in which restriction was experienced required considerable movement, say to a garden, school or trading centre, which is similar to going to a nearby training centre to learn computer. Furthermore, social support would be required in form of guidance and assistance during task completion.

At the meso level is where we find the work of NGOs like UNAB, Sight savers International Uganda and others mentioned as givers of ICT-related support. However, much of the support was given on voluntary basis, where sustainability was highly questionable.

At the macro level is where a mechanism for social support could be developed as part of the overall rollout of the plan to enable every citizen of the country get access to ICT services. Probably due to the general marginalization of PWVDs, it was uncommon for them to take part in some electronic activities such as e-commerce, e-governance and e-learning. Therefore, social support would be a vital ingredient in overcoming this marginalization through emotional support by those charged with offering technical assistance.

However, due to resource constraints, this study had a number of weaknesses, which may cast doubt on the accuracy of some findings. It is common for studies about skills and usage of digital technology to employ time diaries in their investigations; but here reliance was largely on selfreporting. Time diaries minimize the reporting burden on respondents by allowing them to record their time-use immediately after it occurs, instead of attempting to remember an aggregate amount of information at a later date (Bessiere et al., 2002). On the other hand, self-reporting requires respondents to recall answers from memory, which can often lead to inflated or incorrect answers.

The second weakness of this study is the little involvement of non-users of ICTs. Although reasons for non-use were obtained from the respondents who did not use computers and the Internet, the datacollection instruments were not specifically designed to give ample coverage to the experiences of people who were purely excluded from using all digital technologies. The instruments should have probably been designed with a section that identifies typical non-users of ICTs.

\subsection{Conclusion}

The study in this chapter has been able to demonstrate that constraints in material, skills and use access are responsible for the low uptake of ICTs by PWVDs in Uganda. This implies that the constraints observed in this study should be an eye opener for policy makers working towards including this group of people in the digital revolution of any given community. Constraints relating to material access came out most clearly, even confirming that PWVDs are prone to the common causes of digital exclusion (age, education levels, gender, income differentials, geographical location and occupation) as had been investigated by scholars in the realm of the digital divide prior to this study. Thus, the findings showed that opportunities for access to ICTs by this social group were more for males than females, residence in urban areas than in rural areas, having more education than having less education, earning income than not earning, and being in employment rather than out of it.

However, the respondents in this study never showed any direct constraints relating to motivational access; so this should not attract much emphasis. Conversely, skills access should be given more attention because, unlike the other three facets of access, it requires some special training to be 
attained by Persons with Visual Disabilities. This means it can only become available to PWVDs if there is a deliberate investment earmarked for its acquisition.

On the side of use access, although the findings of this study did not bring out home access clearly as the best alternative for PWVDs to use computers and the Internet, this is again what was inferred from the literature reviewed for the dissertation. This is also an expensive option because it reduces opportunities for equipment sharing and it attracts high costs for procuring assistive technologies in form of screen readers and screen magnifiers.

The addition of social support makes the study even more relevant. Since social support combines technical assistance with emotional support, this can be a good measure for mitigating the challenges faced by different population segments in acquiring digital skills and using the latest digital equipment in public points of access. Probably more than any other social group, PWVDs would benefit immensely from the availability of social support because it caters for their unique needs. Often PWVDs require both technical assistance and emotional support in order to surmount the challenges associated with learning and using ICTs. Therefore, because governments of developing countries are usually known to lack resources for offering universal access at a personal level, they should consider including social support as one of the vital components of business centres, schools and public libraries in order to meaningfully cater for the digital access of any social group with challenges similar to those of Persons with Visual Disabilities. 


\section{Chapter 6 The contribution of policy to digital inclusion of persons with visual disabilities in Uganda}

\subsection{Introduction}

This chapter explores the research question 'how has the universal access policy in Uganda ensured access to ICTs for persons with visual disabilities?' It uses critical disability theory to focus on Ugandan laws and policies on ICTs, but also draws on the international situation because Internet standards and communication policies are international in nature due to the unique cross-border character of digital networks. Information presented in the chapter is drawn from interviews with key officials in Uganda and analysis of documents and regulations concerning the distribution and use of ICTs.

The research reveals that in the Ugandan context the laws and policies put in place to regulate the use and distribution of ICTs do not adequately address the challenges faced by PWVDs because they do not identify them as a specific group. Instead they mention them as part of a collective identity of Persons with Disabilities or disadvantaged groups. On the other hand, international instruments such as the UN Convention on the Rights of Persons with Disabilities (CRPD) does reflect the ICT needs of PWDs in Articles 3, 4, 9, 21, 26 and 32. The CRPD has been ratified by Uganda; so by fulfilling the obligations to this convention, the ICT needs of those with visual disabilities would largely be met. So far this is not the case because domestication of all the relevant provisions of the CRPD into the Ugandan laws and policies has not taken place yet.

Following these introductory remarks, this chapter proceeds to give an overview of the theoretical approach used to answer the research question and then presents the methodology. This is followed by the results section which contains the findings from both key informant interviews and document analysis. The chapter ends with conclusions on the Uganda ICT policy environment as it relates to Persons with Visual Disabilities.

\subsection{Theoretical approach}

This study sets out to investigate the role of universal access policy in enhancing digital inclusion for PWVDs in Uganda. This is approached through application of critical disability theory, which argues that disability is not a question of medicine or health, nor is it just an issue of sensitivity and compassion; rather, it is a question of politics and power[lessness] over achieving a state of genuine inclusiveness (Pothier \& Devlin, 2006). Critical disability theory also criticizes the materialist account of disability history as being overly simplistic because it downplays the role of culture and other "nonstructural' factors in the oppression/everyday lives of disabled people, and for ignoring impairment and recent debates around embodiment (Barnes \& Mercer, 2004). 
The above argumentations are in direct opposition to both the medical and social models of disability, which dominated the discourse on disability policy throughout the second half of the twentieth century. The two models defined disability, determined which professions could serve persons with disabilities, and helped shape the self-identities of those with disabilities. There is a more detailed account on disability models and their relationship with restriction to access and use of ICTs in Chapter 1.

Departing from the social model of disability, this study argues that any attempt at researching the digital needs and challenges of PWDs should avoid lumping them together because, unlike other disadvantaged groups, they belong to disparate sub-groups which require different interventions. There are examples in history that advanced similar arguments for effective delivery of services to PWDs. For instance, Gordon and Rosenblum (2001) cited the United States National Center for Health Statistics that listed specific categories of physical impairment in the early 1990s for purposes of identifying disability and the consequent eligibility for services and support. The categories it came up with included visual impairment, hearing impairment, speech impairment, absence of extremities, paralysis of extremities, and deformities or orthopedic impairment. Tusler (2005) was even more explicit about the relationship between disability and ICTs by arguing that although disability, as an inclusive term, is valuable when describing the social condition of persons with disabilities; "impairment" is a better term for explaining specific access needs. In so doing, he posited that there were five general impairments that should be taken into account when designing accessible products and services: mobility and dexterity; deafness and hearing loss; blindness and low vision; perceptual and cognitive limitations; speech and language difficulties. The set comprising 'blindness and low vision' is what this study refers to as PWVDs.

Building on the findings in Chapter 5 that investigated digital inclusion impediments from the point of motivational, material, skills and use constraints to digital technology experienced by Ugandans with visual disabilities, this study seeks to examine whether the universal access policy has promoted or impeded the inclusion of PWVDs in the digital revolution of Uganda. Policy is part of what constitute the last (societal) level of restriction to digital inclusion for PWVDs as shown in the ICF model.

Basing on critical disability theory therefore, the study sets out to answer the following questions:

i) How do the principles of affordability and availability in Universal Access cater for the digital needs of persons with visual disabilities in Uganda?

ii) How has lack of accessibility in universal access affected the digital inclusion of Persons with Visual Disabilities in Uganda?

iii) How do qualities of the new digital media affect how Persons with Visual Disabilities benefit from universal access in Uganda?

\subsection{Methodology}

\subsubsection{Study design}

Answering the questions in this chapter necessitated using the qualitative approach of research. In fact, as elaborated in the overall study design in Chapter 3, this study is part of the second phase of the research project; but it only focuses on issues relating to policy.

The qualitative approach is best suited to making critical arguments. According to Walsham (2005), a critical stance demands highlighting what is wrong with the world rather than what is right. It tends to focus on issues such as asymmetries of power, alienation, disadvantaged groups or structural inequity. Society perceives PWDs as a disadvantaged group, and understanding their digital inclusion would 
follow this line of argument. However, rather than focusing on PWDs in general, this investigation seeks to identify gaps in the laws and policies on ICTs in Uganda in relation to PWVDs specifically. This necessitated using in-depth interviews and document analysis.

\subsubsection{Data collection methods}

As already mentioned above, two research methods were used to collect data for this study. These included the following:

i) Interviews. Two in-depth interviews were conducted - one with three officials from the National Information Technology Authority - Uganda (NITA-U) and another with an official from the Uganda Communications Commission (UCC) (see Appendix 6). The purpose was to get a deep understanding of various issues pertaining to ICTs in the country from a policy standpoint. Interviewing officials from both organisations was found appropriate because one of the NITA-U objects is "to promote access to and utilisation of information technology by the special interest groups" (NITA-U Act, 2009). PWVDs are, by implication, one of the special interest groups. So how the authority and the commission had handled their issues was of paramount importance.

ii) Document analysis. Several documents (the laws and policies on ICTs in Uganda, international instruments relating to disability and ICTs, and legislation on disability anti-discrimination from some developed countries) were analysed for provisions relating to universal access to ICTs. The purpose was to compare the situation of PWVDs in Uganda and what pertains in developed countries for the same group of people. Furthermore, reading the laws and policies of Uganda on ICTs would help to corroborate information obtained from the interviews.

\subsection{Presentation and interpretation of findings}

\subsubsection{How the principles of affordability and availability of universal access cater for the digital needs of persons with visual disabilities in Uganda}

A situation where everyone is afforded the means to access the available ICT services is often referred to as universal access. As already discussed in Chapter 2, availability and affordability of ICTs is what originally defined universal access, which have remained part of its core principles up to this day. However, when it comes to PWDs, Goggin \& Newell (2000) observed that there is a persistent (or even dominant) viewpoint that the appropriate approach to disability is "remedial" rather than "inclusive." An understanding of disability is still not regarded as something that should be considered from the outset and made integral to the shaping of existing and new technologies. Instead, disability is an issue policy-makers would only prefer to deal with post-hoc under the pressure of general legislation that outlaws discrimination.

Although the Ugandan policy framework on universal access - consisting of the Uganda Communications Act (1997), the National Information Technology Authority - Uganda Act (2009), the Rural Communications Development Fund Policy (2003-2008), the Rural Communications Development Fund Policy (2010/11-2014/15), the Telecommunications Policy (2011) and the Information Technology Policy for Uganda (2010) - may not bear an outright accusation that it gives a post-hoc attention to disability under the general legislation that outlaws discrimination, this research found out that it still has many gaps in addressing the specific needs of PWVDs. Yet to wear off the status of being a special group, benefiting from affordability and availability of ICTs as provided for in universal access requires that PWVDs are availed opportunity to use the same communication products and services that everyone else uses - and not to be restricted to specialized 
ICTs that are sophisticated, rare to find and more costly. However, offsetting the cost of ICTs in favour of PWVDs is not always possible because, as O'Brien (2005) put it, the market for assistive technologies is smaller and the costs for development are shared by fewer people.

Another reason for PWVDs not to benefit much from the universal access principles of affordability and availability is the inherent weakness of policy not to separate technological from social access to ICTs. Technological access refers to the physical availability of suitable equipment, including computers of adequate speed and equipped with appropriate software for a given activity (Kling, 1999). As discussed in Chapter 2, software suitable for PWVDs includes assistive technology without which they will be excluded from using computers. Social access refers to know-how, a mix of professional knowledge, economic resources, and technical skills to use technologies in ways that enhance professional practices and social life (Kling, 1999). Chapter 2 carries an elaborate discussion of how lack of digital skills can breed exclusion of different groups, and respondents in chapter 5 expressed that many were excluded from using ICTs because of having no access to specialised training.

To delve deeper into Universal Access in Uganda, the official from UCC who was interviewed for this study revealed that there is a $2 \%$ levy on communication services (calls and SMSs), which goes to UCC and part of it is channeled into the Rural Communication Development Fund (RCDF) to cater for under-served areas and people in the country. In the same vein, the NITA-U officials who were interviewed for the same study explained that government, using the prevailing ICT policy framework, had undertaken the following projects to ensure availability of ICTs to all:

i) National Data Transmission Backbone Infrastructure (NBI) Project, which involves the laying of Fiber Optic Cable in major towns to ensure that high bandwidth data connection is available in all major towns at a reasonable rate.

ii) Electronic Government Infrastructure, which is designed to reduce the cost of doing business in government, improving communications between government agencies, and reducing the need for officials to commute for meetings.

iii) District Business Information Centers (DBICs) project, which aims at promoting affordable and timely access to ICTs in rural Uganda; to enhance the exchange of information and experience among government officials and their communities through Internet, Desktop Services, Telephones, Fax, Printing, photocopying and other Business Information services. By the time of this study sites for six DBICs had been established as one step towards extending Computer usage to the rural Communities; with the eventual target of rolling them out into all the districts of the country.

In addition to the above projects, government of Uganda had set up a Telecommunications Policy (2011) to ensure optimum utilization of communications services after recognizing the catalytic role this plays in national development. Focusing on the following areas, the policy recognizes that developments in communication technology will see the convergence between voice, data, video and text:

- The provision of a robust, cost-effective, broadband Telecommunications infrastructure countrywide.

- Promotion of public private partnerships in the development of telecommunications infrastructure and services.

- Promotion of the utilization of telecommunications infrastructure and services by the public by making them affordable. 
- Establish E-Government to promote good governance and improve efficiency in public administration.

Closely linked with the above is the Rural Communication Development Fund (RCDF) Project, which was set up and administered since 2003 as a Universal Service Fund for communications in accordance with the Rural Communications Development Fund Policy (2003-2008) and the Uganda Communications Act of 1997. The RCDF was undertaken by the UCC and aims to affect communications interventions for underserved areas and people of Uganda. Specific objectives of the first phase of the RCDF implementation (2003 - 2008) included the following:

- Access to basic communications services within a reasonable distance to all people in Uganda

- Leverage investment into rural communications development

- Promote ICT usage in Uganda

Table 6.1: ICT related achievements of the first phase of the RCDF

\begin{tabular}{|l|l|}
\hline Achievements & Figures \\
\hline Fixed telephone lines & 327,114 \\
\hline Mobile telephone lines & $12,828,264$ \\
\hline Public pay Phones & 94,896 \\
\hline Internet Users & $4,000,000$ \\
\hline Bandwidth mbps (uplink) & $3,433 \mathrm{mbps}$ \\
\hline Internet cafes & 105 \\
\hline ICT training centres & 65 \\
\hline District Web Portals & 78 \\
\hline School ICT laboratories & 208 \\
\hline Internet Points of Presence at rural locations & 76 \\
\hline Community tele-centres & 13 \\
\hline ICT health facilities & 96 \\
\hline
\end{tabular}

Source: Uganda Communications Updates, March 2011.

The second phase of the RCDF project, basing on the Rural Communications Development Fund Policy (2010/11-2014/15), began in 2010 with three broad objectives of:

- Expanding coverage of the first RCDF interventions in order to attain the World Summit of Information Society (WSIS) target for access to basic information and communications services.

- Provision of Broadband connectivity, especially with respect to education institutions and government service delivery plans.

- Support for local digital content development, essential for the entrenchment and consolidation of the information society in Uganda.

On implementation of the affordability principle of Universal access, the RCDF policy (2010/112014/15) gave the following costs for using mobile phones in Uganda. The average cost for first-time connection to a mobile network by December 2009 stood at Uganda Shillings 3,000 (USD 1.5) excluding the cost of a phone handset; and the cost of a local mobile phone call was at an average of Uganda Shillings 351 (USD 0.17) per minute. These put communication by mobile phones beyond the reach of an average Ugandan.

Specific initiatives aimed at making ICTs affordable by reducing cost, Under the RCDF Project, include: 
- Internet Points of Presence (PoPs), which are wireless connectivity networks in a radius of about 5-10 kilometres within which people can access the Internet at lower costs, high speeds and with types of services that are comparable to those in the capital, Kampala.

- Internet Cafes, which provide public access to affordable internet and ICT training services to people in the districts.

- District Web Portals www.district name.go.ug, which provide information such as: District overview and profile, health, agriculture, education, government and politics, investment and trade, tourism, profile of district leaders and contacts, government programmes, environment, SMS, infrastructure and news. The portal also provides a translation into the common language used in a particular district.

- Public pay phones for basic communications/calls at affordable rates.

- GSM Network Expansion Project, which aims at expanding voice networks to sub-counties with no network coverage.

- School ICT laboratories, which are supports to Ministry of Education and Sports to increase access and usage of ICTs in schools.

- Health ICT facilities, which provide support to Ministry of Health to enhance usage of ICTs in health services delivery in the country.

It is also worth noting that from 2006 Uganda opened its communication sector to full competition with a new licensing regime that is technology neutral. This is a further effort to ensure availability of information and communications services. According to guidelines issued by the Ugandan Ministry of Information and Communications Technology, service providers are free to decide which technology to use in providing services. Licensees can provide either data or voice services (or both). Furthermore, those wishing to operate their own infrastructure facilities are free to do so. As a result, the new technologies through which the Internet and mobile telephony are accessed include GSM (Global System for Mobile Communications), DCS (Digital Cellular System), CDMA (Code Division Multiple Access), UMTS (Universal Mobile Telephone System), Wifi (Wireless Fidelity) and WiMAX (World Wide Interoperability for Microwave Access). In addition there is VSATs (Very Small Aperture Terminals) International Data Gateways, Radio and Microwave Links, and an Optical Fiber cable which connects to International data Gateways such as Seacom, TEAMS and Eassy through Kenya.

When asked how all the above initiatives benefited PWVDs, all the responses given were less than satisfactory. For instance, the UCC official said all secondary schools in Uganda with a special needs unit (catering for students with disabilities) were supposed to be provided with computers in the second phase of the RCDF Project. But the same official admitted that there was no evidence that any project applied for by private investors under the Public-Private-Partnerships during the first phase of the RCDF, actually went to a disabled people's organization (DPO) or specifically targeted their needs. Whether correct or not, the UCC official advanced two reasons for this anomaly:

1. That usage of computers was not widespread in the country by the time UCC implemented the first phase of the RCDF project, which involved Public-Private-Partnership projects.

2. The RCDF policy was not favorable to DPOs, especially where projects required lots of capital from private developers that such organisations did not have.

The researcher sought further evidence to support the above reasons, which uncovered information that the criteria for funds disbursement to individual projects as spelt out in the RCDF policy (2010/11-2014/15) was such that projects from DPOs would get favourable rating on only 1 out of 8 
parameters, which was on social inclusion (how well a project caters for socially disadvantaged interests such as gender, youth, disabled and elderly). A project for PWVDs would score lowest on the parameter on the cost for implementation because attracting a high score would depend on how low this is; yet projects targeting that group of people are characteristically expensive due to the cost for procuring assistive technologies and special training.

On the other hand, when the officials of NITA-U were asked the same question about how PWVDs benefited from RCDF and the other initiatives, they said the policy establishing NITA-U caters for everyone's needs, including those of disadvantaged groups. But the same officials acknowledged that all disadvantaged groups, including PWVDs, had not been adequately catered for in DBICs; but they said the planning unit would set up special facilities for them following a consultancy to determine their needs. This could be regarded to have been a fair comment, but only if the consultancy would recommend procuring screen readers, screen magnifiers and providing special computer training for PWVDs.

Analysing how Ugandan laws and policies on universal access cater for the availability needs of PWVDs, the first provision was found in objective (f) of the National Information and Technology Authority -Uganda Act (2009), which states that: "To promote access to and utilization of information technology by special interest groups". On a similar note, strategy 11 of the IT Human Resource Development priority in the Information Technology Policy for Uganda (2010) states thus: "Ensure equal opportunity in basic IT training at all levels taking into consideration special interest groups namely; women, youth and PWDs." The spirit of these provisions is echoed in objective 4 of the Telecommunications policy (2011), which states thus: to promote the delivery of high level information and service needs to all sectors of society, especially the marginalized sections of society (rural or poor communities, women and Persons with Disabilities). However, all these promise little since they do not mention PWVDs in categorical terms.

On another note, the two RCDF policies define the 'underserved areas and people' as including all those communities that are not able to have access to information and communications services either due to geographical isolation, poverty or any social exclusion factors such as gender, disability or age. Unfortunately, the two RCDF policies failed to recognize that the measures for ensuring access to information and communications services are not the same for all the underserved areas and people; thereby lumping together PWDs, the youth, abject poor, women, the elderly and people in rural areas. Furthermore, despite objective 11 of the RCDF policy (2003-2008) mentioning under-served communities, its implementation strategies stop at gender mainstreaming and neglect including other disadvantaged groups. At this point it becomes difficult to imagine the two policies providing even more specific measures to cater for Persons with Visual Disabilities.

Section 4 of the Uganda Communications Act of 1997 carries 28 functions of the UCC, out of which only two have some association to the needs of Persons with Disabilities. Section 4(y) talks of collaborating with educational institutions in order to promote specialized education in the field of communication; and section 4(n) is more specific, spelling out promotion of research into the development and use of new communications techniques and technologies [including those which promote accessibility of hearing impaired people to communication services]. But these two functions do not give PWVDs any specific mention; although these also have specific communication needs. This research will treat such as a gap that should be addressed in relation to digital inclusion. 


\subsubsection{How lack of accessibility in universal access affects the digital inclusion of persons with visual disabilities in Uganda}

The presence or absence of accessibility in universal access is another factor that influences how much PWVDs can benefit from the new digital media. Goggin \& Newell (2000: p. 127) affirmed this assertion by contending that in order for the development of genuinely inclusive universal service, attention must be given to the accessibility dimension as much as that of geographical availability of universal service. The attention Goggin \& Newell are seeking is best served by policy-makers who were originally responsible for affordability and availability of telephone.

Whentz, Jaeger \& Lazar (2011) made seeking accessibility through policy even more feasible by saying there was nothing about technology that makes it inherently accessible or inaccessible. Rather it is the choices made by those developing and implementing the technology that determine whether this will ultimately be accessible or not. To explain their assertion further they pointed out that most of today's technologies are digital, meaning that they are made up of zeroes and ones, and there is nothing inherently visual or auditory about zeroes and ones.

Further proof that accessibility is the responsibility of technology developers and implementers comes from the fact that for a technology to be accessible it needs to be usable in an equal manner by all users regardless of specific senses or abilities (Whentz, Jaeger \& Lazar, 2011). It should also be compatible with assistive technologies such as refreshable Braille displays, narrators, scanners, voiceactivated technologies and screen magnifiers. These are two options for achieving accessibility, where the former is all embracing and the latter points to the varying disabilities and a range of other factors related to personality, environment, support and the nature of technologies themselves. But accessibility of ICTs can also be decided by policy, which becomes the third option. Indeed, according to Stephanidis \& Emiliani (1999), policy measures, reactive approaches, and proactive strategies are the three collaborative efforts that have been pursued over the years to cater for the accessibility needs of individuals with varying abilities.

Examining accessibility in universal access from a Ugandan perspective, this research found out that the country has not had any influence on reactive and proactive strategies of accessibility because it is largely a consumer and not a manufacturer of ICTs. Only hardware refurbishment is done on a very small scale and is private sector-led (Information Technology Policy for Uganda, 2010). Uganda's history on policy measures is also quite short-lived - starting with the Communications Act of 1997. Therefore, while examining all the three accessibility options below, there is heavy reliance on what pertains in other countries and comparing them with the practices in Uganda. But of course care is taken to ensure that the examples given have specific relevance to Persons with Visual Disabilities.

Reactive approaches aim at adapting ICT products and services so as to build into them the required accessibility features to match the abilities of individual users. The problem of this approach is that the resulting changes are derived from a posteriori adaptations (Stephanidis \& Emiliani, 1999). Adaptability takes two forms - enabling ICTs to be reconfigured, and making ICTs compatible with third-party agents that may be installed by a specific user. Reactive approaches have been the traditional way technologies such as voice browsers, screen readers (with speech or refreshable braille display outputs) and screen magnifiers have been developed, without which PWVDs would have been unable to use personal computers, mobile phones and ultimately the Internet in all its forms. 
Proactive strategies, for example universal design, are a response to the pitfalls inherent in reactive approaches, resulting in generic solutions to the problem of accessibility. These strategies entail a purposeful effort to build accessibility features into a product as early as possible, from its conception to design and release (Stephanidis \& Emiliani, 1999). Such approaches aim to deliver products that can be tailored for use by the widest end-user population possible.

Indeed the promoters of proactive strategies to accessibility advance a polemic argument that the creation of features that make products useful for PWDs and those experiencing functional limitations, should normally make them convenient for everyone else (Tusler, 2005; Shneiderman, 1999; Goggin \& Newell, 2007). Examples abound of technologies designed for PWVDs but end up benefiting others as well, such as remote controls that can be operated without looking at them (appropriate for people who are blind) will be appealing to anyone who likes watching movies in the dark; a cell phone with a large visual display and enough contrast for a user with low vision can be helpful to someone in dim light to read the information; an Automatic Teller Machine (ATM) which uses voice prompts, large prints, simple fonts, high contrast, labels with icons or graphics, and progress displays to make it easier to use for a user with vision loss can be useful for a semi-literate or elderly person.

However, Shneiderman (1999) raised a caution by some technology experts he prefered to label as skeptics, who argued that forcing designers to accommodate low-end technology, low-ability citizens, and low-skilled users (called dumbing down) will result in a lowest common denominator system that will be less useful to most users. Another caution, known as the innovation restriction scenario, is that attempts to accommodate low-end technology, ability or skill will constrain innovation for the high end. The two cautions amount to a damning indictment on society for not appreciating good technology designs, which makes implementation of universal access problematic. Indeed an extended list of frequently-cited reasons for not providing accessible technologies was given by Whentz, Jaeger \& Lazar (2011), and these include:

- Increase costs of the technology;

- Lengthen time of development;

- Only serve a small market;

- Necessitate special design requirements;

- Result in low-tech and uncool products;

- Sacrifice aesthetics;

- Create difficulties in supporting accessible products;

- Never meet the needs of each different disability; and/or,

- Make the product worse for all other users.

Majority of the above reasons are no more than expressions of the deep-seated prejudices against the beneficiaries of accessible technologies, especially Persons with Visual Disabilities. For example, increased costs cannot be an issue when the technology being developed is targeted at mainstream users of ICTs. Nonetheless, a claim that accessibility never meets the needs of each different disability holds a lot of truth because what helps a user with a hearing disability will not necessarily help a user with a visual or learning disability (Jaeger, 2006). Furthermore, sighting a small market as reason for not incorporating accessibility into some technologies is justifiable because, when divided by their distinct disabilities, each group of PWDs has unique functional limitations and accessibility needs. These individual groups are sometimes too small to have much influence over the types of products and services that companies seek to mass market (National Council on Disability, 2006). It is also 
worth reiterating that PWDs cannot significantly impact competitive trends because, on average, they earn lower incomes than the general public (Fox, 2011).

Addressing accessibility through policy measures takes two forms - legislation and standardization both of which provide the frameworks within which commonly held practices or assumptions are put in place; and together they create regulatory systems (Stienstra, 2006). Legislation is the most formal policy measure, because it provides the weight and resources of government to implement the agreed practices. On the other hand, standards are measurements against which products are tested, safety procedures are put in place, or appropriate practices are determined. There are two standard bodies notable for advancing accessibility of digital technologies: the World Wide Web Consortium (W3C) with its guidelines for ensuring accessibility of the web; and the International Organization for Standardization with guidelines for designing software that should ensure effective interaction between users with disabilities and the software (ISO/TS 16071, Ergonomics of human-system interaction - Guidance on accessibility for human-computer interfaces).

Adam \& Kreps (2006b) gave a revealing account of the standardization of the World Wide Web and how the $\mathrm{W} 3 \mathrm{C}$ also became responsible for ensuring accessibility of the web. Development of Hypertext Mark-up Language (HTML) and Cascading Style Sheets (CSS) was the most relevant effort for achieving both. HTML was a tool first created by Tim Berners-Lee to assist in data sharing between the computers at the CERN laboratories in Switzerland and it was later taken up by the W3C, a body established in 1994 by Berners-Lee himself to try to marshal the phenomenal growth of the web. HTML 3 was the first version to be published, which contained a wide range of new visual formatting properties. Later CSS was the technology through which visual formatting was exclusively achieved in HTML 4 and XHTML 1.0 - newer versions published in the late 1990s.

Most noteworthy in this account is that the $\mathrm{W} 3 \mathrm{C}$ wrested control of the web from the likes of Microsoft and Netscape who wanted to define HTML for their own entrepreneurial proprietary purposes, locating it instead within a non-proprietary, non-profit-making global standards body (Kreps, 2008). Kreps (2008) likened this to the British Standard Whitworth System which, in fixing a set of standards for the threads of screw bolts, wrested control of the workplace from the artisans who used to handcraft each screw and bolt for each new machine, and passed that control to the capitalist entrepreneurs who could now, for the first time, simply buy a packet of standard screws.

The Web Accessibility Initiative (WAI) was undertaken by the W3C around the same time HTML was being developed, and it published its Web Content Accessibility Guidelines (WCAG1.0) in 1999. In December 2008 the WAI published WCAG2.0 and, just like the earlier version, was supported by the Authoring Tool Accessibility Guidelines (ATAG) and User Agency Accessibility Guidelines (UAAG). It is these standards for those making web sites, the software tools many use to make them, and the browsers through which they are accessed, that have been increasingly applied by organisations around the world, and have been accepted by governments in numerous countries, as the de facto global standards for web accessibility (Adam and Kreps, 2006b: p. 207). In a way these guidelines can be credited for reducing the inaccessibility of web content, the user interface, and the web authoring tools for the ultimate benefit of PWDs, especially those with vision loss.

The specific benefits for PWVDs from the W3C guidelines come from noting that the web as a whole is a graphical environment, which has to be translated into an alternative representation when used with non-graphical browsers and technologies such as screen readers (Marincu \& McMullin, 2004). This is achievable through the general recommendation of 'providing alternative content' within HTML. Examples of this include providing alternative text for images and applets; avoiding scrolling 
text created with the MARQUEE element; avoiding blinking text created with the BLINK element; and providing a NOFRAMES section for web sites that use frames.

With particular reference to Uganda, officials of NITA-U gave a commitment that developing the government web portals would be done following the W3C standards. Indeed this study found out that the Uganda Government Website Standards document (November 2007) was interspersed with references to the WCAG, ATAG and the UAAG. However, the same document does not provide for user-testing, which is an effective way to ensure accessibility, at least for PWVDs who rely on textbased assistive technologies to navigate the web.

On the side of legislation, by the 1980s disability movements in different parts of the world had begun advocating for recognition by society of disability discrimination and inequality, and they sought basic or general legislation to symbolize this change, as well as to provide a framework for enacting rights, legal redress, and social change (Goggin \& Newell, 2007). Several laws resulted from that advocacy, such as the Americans with Disabilities Act (1990), a revision in 1998 of section 508 of the 1973 U.S. Rehabilitation Act, and section 255 of the U.S. Telecommunications Act (1996); for the UK the Disability Discrimination Act (1995); the Australian Disability Discrimination Act (1992); and the Canadian Provincial Ontarians with Disabilities Act (2002). Uganda followed in the same footsteps to enact the Persons with Disabilities Act (2006); although with no provisions on accessibility of ICTs. However, it is worth reiterating that Uganda ratified the United Nations Convention on the Rights of Persons with Disabilities (CRPD 2006) and its optional protocol on 25th September 2008, thereby making it obligatory to domesticate its provisions into the laws and policies of the country.

The CRPD carries several articles addressing accessibility of ICTs. For instance, article 2 gives an inclusive definition of communication in which accessible ICTs and multimedia are categorically mentioned. These are components from which PWVDs, among other disabilities, should certainly derive clear benefits. Article 3 (f) identifies accessibility as one of the eight principles of this convention. Article 4.1 (f), (g) and (h) carry even more explicit provisions on accessible ICTs as part of the general obligations of the state by making research and development of universally designed goods, services, equipment and facilities, including ICTs and assistive technologies, a specific undertaking. Article 9 mentions the right of PWDs to access information and communication, including ICTs, on an equal basis with others both in urban and rural areas. Hence this article requires all content, communication, hardware, software and interfaces to be accessible. Specifically, 9.2 (g) states that PWDs should be given access to new information and communications technologies and systems, including the Internet; and 9.2 (h) talks of promoting the design, development, production and distribution of accessible information and communications technologies and systems at an early stage, so that they become accessible at minimum cost.

Article 21 obligates states to take appropriate measures to ensure that PWDs can seek, receive and impart information and ideas on an equal basis with others and through all forms of communication of their choice. More importantly, it urges private entities that provide information services to the general public, especially through the Internet, to do so in accessible and usable formats for persons with disabilities. This certainly includes PWVDs, who constantly require modifications to the way they engage in computer mediated communication. Another unique opportunity for Uganda, which is not a manufacturer of ICTs, is in article 32 (b). This recognises the differences in development among states, and it therefore promotes international co-operation in regard to facilitating and supporting capacity building, co-operation in research and access to scientific and technical knowledge, and sharing of accessible and assistive technologies as well as technology transfers. 
When universal access is related with accessibility, this study found out that the three approaches for achieving the latter are riddled with a number of pitfalls that would prevent the digital inclusion of Persons with Visual Disabilities. The first pitfall is the cost implication found in both proactive and reactive approaches. For reactive approaches, adaptations are difficult to implement and maintain because they are programming-intensive. Minor changes in product configuration, or the user interface, may result in substantial resources being invested to re-build the accessibility features (Stephanidis \& Emiliani, 1999). On the other hand, proactive strategies are too costly in the short term for the benefits they offer. It was, for example, reported that Apple dismantled its World Wide Disability Solutions Group in 1998, which had existed for thirteen years, due to financial constraints. This resulted into a saving of 1 million dollars a year (O'Brien, 2005). Before it was pulled to pieces, this Group had been an internal assemblage of experts focused on accessibility, resulting in Apple being hailed by assistive technology experts as the computer of choice.

The second pitfall is the radically changing technological environment, which makes reactive approaches unviable over the long-term. By the time a particular accessibility problem has been addressed, technology has advanced to a point where the same or a similar problem re-occurs (Stephanidis \& Emiliani, 1999). There are two examples in the history of accessibility that illustrate this amply. The first was the invention of Command Line Interface screen readers around 1988, which gave people with vision loss the opportunity to use computers with MS DOS and subsequently the possibility of entry to many jobs in the employment market. The introduction of the Graphical User Interface later on rendered such screen readers dysfunctional, requiring protestations of blind activists in the U.S. before the situation could be rectified by Microsoft and IBM. The two companies provided hooks (or background functions in the operating systems) that screen readers could access directly (O'Brien, 2005). The second example is of Nokia phones with the Symbian Operating system, the first to allow for the installation of third party access software, starting to disappear from the market due to their manufacturer announcing a switch to Windows 7 platform that did not support screen readers (Burton, 2011). This rendered the new Nokia phones incompatible with Mobile Speak and Talks, along with their screen magnifier counterparts, which came on the scene just in 2003 and 2004 respectively. These were by far the most successful phone-based assistive technologies on the market at that time.

The third pitfall, which results from reactive approaches to accessibility, is a scenario that breeds some form of inequality between disabled and non-disabled users of the Internet. Whentz, Jaeger \& Lazar (2011) cite two examples where web sites and interfaces created to serve PWVDs are often far inferior in content and functionality compared to the standard version of the same sites and interfaces. The first example is of some organisations that maintain text-only versions of their web sites, which are not as regularly updated as their primary web pages. The second example is made up of Internetbased e-mails such as Yahoo Mail Classic, Outlook Web Access 2007 Light and the "basic HTML" version of Gmail. All these are recommended for users of assistive technologies (screen readers and screen magnifiers); yet their interfaces do not have the same features as the standard versions of those web-based e-mail interfaces. This is simply a demonstration that users who are blind or have low vision should always settle for less than the latest e-mail features because technology experts are either unable or take long to sort out problems associated with accessibility.

The fourth pitfall, which relates to policy measures, is about the lengthy processes through which standards are developed and these constrain the capacity of PWDs and their organisations to contribute to such processes. Persons with disabilities, including those with vision loss, who live with 
low incomes and have few resources to buy or use sophisticated information technologies, or who feel alienated in a highly technological environment, may be less able to contribute to discussions of accessibility (Stienstra, 2006). This is aggravated by DPOs lacking enough human, financial, knowledge and time resources to engage in standards development discussions.

The fifth pitfall is the voluntary nature of standards, which provides limited opportunity for full inclusion of the needs of PWDs in the development of information technologies (Stienstra, 2006). Specific to the $\mathrm{W} 3 \mathrm{C}$ guidelines, these provide that web sites must be designed keeping in mind the precept of "write once, read everywhere", which can be achieved by designing web content to meet appropriate guidelines and technical standards for interoperability (Marincu \& McMullin, 2004). However, these guidelines carry no punitive sanctions, which leave many private web developers with the freedom to design web sites that are often inaccessible for users of assistive technologies. Worse still, web accessibility guidelines allow for automatic software checkers (such as A-Prompt, Web Exact and LIFT), which are often inadequate or inaccurate in validating adherence to accessibility standards. Adam \& Kreps (2006a) describe three specific ways in which these may not detect problems of inaccessibility on web sites, which include alt tags on images either being non-existent or unhelpful, lack of proper headings and subheadings, and poorly coded forms. User testing is promoted by many studies as the final step needed to ensure accessibility (Kreps, 2008), , but web masters often ignore a human check for such problems with the argument that users of screen readers and voice browsers, particularly PWVDs, do not constitute a significant population segment and the extra work involved in manual checking is not necessary.

Putting all the above weaknesses into consideration, it is quite appreciable that policy-makers and technology developers are yet to fully incorporate the principle of accessibility into universal access. This is so partly because of the broadness in the variety of disabilities that must be catered for, and partly due to the unwillingness of policy-makers to consider disability in its broadest sense when it comes to accessibility. But lack of accessibility is more problematic to PWVDs than people with other disabilities who use or aspire to use the new digital media technologies.

\subsubsection{The qualities of the new digital media and their effects on how PWVDs benefit from universal access in Uganda}

So far the results that have been presented in this chapter show how universal access is seriously tempered by lack of affordability, availability and accessibility of ICTs at least for Persons with Visual Disabilities. More so, Chapter 5 of this dissertation has demonstrated that the process of appropriation of a new technology is only complete with a particular, satisfactory use of that technology. However, even with all the three principles in place, the new digital media has a number of qualities that may still prevent PWVDs from enjoying universal access to the full. This section of the chapter examines such qualities in relation to the implementation of universal access in Uganda.

Jan van Dijk (2005: pp. 96-102) listed eight properties of new digital media which support or impede usage. These properties include interactivity, integration, selectivity, complexity, expense, network effects, multifaceted and multifunctional. For PWVDs, like any other disadvantaged group, the way universal access addresses the likely inequality emanating from such properties can be a source of digital inclusion or exclusion. In an attempt to understand how these properties impact the use of ICTs by PWVDs, this study made a comprehensive literature review and put a specific question to the NITA-U officials to point out existing gaps in the Ugandan laws and policies for ensuring affordability of ICTs for all, including PWVDs. Findings from the two undertakings are given below with each property discussed separately. 
i) Complexity. It is far more difficult to operate a computer or to have an Internet session than to operate a radio, television, telephone, or even a video recorder. As it has been explained clearly in Chapter 5, the complexity of the computer and the Internet is more of a challenge for PWVDs, who are expected to work with technology that is highly visual while using non-visual techniques of information retrieval. Therefore, these are likely to be excluded as the new digital media technologies become even more complex.

ii) Interactivity. This makes use of the new media more attractive, stimulating, involving and participatory; but it is also more demanding than the old media as it requires many cognitive resources. For PWVDs, the point of exclusion comes when digital and IP-based products have touch screens, soft-buttons, or graphical interfaces that are difficult or impossible to identify (National Council on Disability, 2006). In addition to not being able to feel the location of each button, if the button is dynamic -its function changes each time it is pressed - a person who cannot see it will be unable to ascertain what it controls at any one given time.

iii) Integration. For the new media it is possible to combine sound, speech or text with moving images or numerical data to become multimedia. For PWVDs, because information presented in each medium (audio, visual and text) conveys only part of the message, this makes it not fully accessible to them. Some of the accessibility barriers include the difficulty to use or understand fully the visual images such as charts, photographs and video; mouse movements or clicks often lacking keyboard equivalents; the use of bit-mapped text which cannot be read by screen readers; and font sizes or background colours built into computer software, which may make it unusable by people with low vision (National Council on Disability, 1998).

iv) Expense. This relates to the high cost of acquiring and updating peripherals (hardware and software) for computers and network connections, which make the new media more costly than the old. For PWVDs, besides the obvious peripherals like printers and scanners, they are expected to procure expensive screen readers and screen magnifiers from time to time for the effective use of the new digital media technologies. For Uganda specifically, the NITA-U officials pointed out that the country lacks a tax regime policy on software licenses. The zeroimport duty on computer equipment introduced in 2004, which was hailed as one of the best measures for enhancing the usage of ICTs, does not extend into software licensing; yet this would benefit users of assistive technology the most because their software licenses often cost more than computers and mobile phones.

v) Selectivity, where senders and receivers in human-computer interaction and in computermediated communication are allowed to be much more selective in choosing options from menus, applications, and addresses than in the old media. This breeds inequality of use of the new media depending on the different people's capabilities. Persons with Visual Disabilities rely on shortcuts and hotkeys to access most of the applications in the new media, and will find it hard to make informed choices where these are not clearly catered for in the menus and applications of the new digital media technologies.

vi) Network effects. With the new media, people feel forced to get connected if they are not to be excluded from social life. Furthermore, people tend to be able to get help from people similar to themselves, so that low usage levels within a group tend to be somewhat self-perpetuating (Kling, 1999). These two assumptions are true for e-mail because it tends to sustain ongoing dialogues and relationships; hence enabling the creation of social networks. For PWDs in 
general, the Internet opens the door to a world of new ideas and values. It heightens the possibility that these will come into contact with people who do not share their view of the world and that the communication will take place in a context that is not dominated by their 'tragedy' (Seymour and Lupton, 2004). However, the new digital media is a source of exclusion for those who cannot afford regular Internet and mobile phone subscriptions that enable communication via e-mail. This is in addition to the inability to create offline networks, which is particularly common among Ugandans with Visual Disabilities.

As a gap in the Ugandan provision of universal service, the NITA-U officials said there were still high interconnectivity charges between Network Providers, making it expensive to call across different mobile telephone networks. This is also true for Internet service providers, which threatens social interaction for people who switch from one network to another but remain in contact with friends on their previous networks. Uganda is also blighted by poor electrification, especially in rural areas, which limits access to computer and phone recharging; and it also indirectly hampers the widening of personal networks.

vii) The new digital media is multifaceted. This obviously increases usage options for those with various computer and internet types. However, this also increases the chances of exclusion as the available devices and applications may be unequally divided among people. As a gap in the Ugandan ICT legal regime, there was so far no legislation on electronic waste management and recycling at the time of this study, which would give people access to cheaper computers. Despite a government imposing zero-import levy on computer equipment, acquisition of ICTs remains relatively costly for most Ugandans. A good mechanism for electronic waste management and recycling would therefore offer a good alternative for the use of digital media. Closely related is the lack of disposal mechanisms for ICT equipment in Uganda, such as the donation of used computers to schools. To relate this to PWVDs, the computer donations referred to in Chapter 5 as received from NGOs are simply part of an ad hoc measure with no clear sustainability strategy provided for in the Ugandan ICT policy framework.

viii) Multifunctionality. This enables the new digital media (computers, mobile phones and the Internet) to offer such functions as information, communication, transaction, work, education, and entertainment in both simple and complex forms. This is quite different from the old media, where a specific medium (say newspaper) would be geared to offering a specific function. Whereas multifunctionality is a property that makes the new media appear to offer something for everyone, it can be a source of exclusion for PWVDs due to skill deficiencies and accessibility challenges.

Specific to Uganda, the NITA-U officials who were interviewed for this study disclosed that the country lacks a fund to facilitate research into software development. This is particularly detrimental to PWVDs, who have to rely on screen readers made in Western countries with no local language variations. Even software developers, as recommended by the IT policy of Uganda, cannot improve screen readers (such as NVDA and Gnopernicus) available via the open source. It is also worth pointing out that Uganda lacks a certification and accreditation framework to enforcement of compliance to ICT standards. Again according to the NITA-U officials, the National Information Technology Authority - Uganda was in the process of developing the Accreditation and Certification Framework, whose purpose was for certifying and Accreditation of ICT Service Providers, ICT Products, ICT Training Institutions and ICT 
Professionals to ensure compliance to Industry Service Standards and/or internationally recognised best practices.

\subsubsection{Discussion}

This chapter has focused on examining whether the universal access principles of affordability and availability cater for the needs of PWVDs so that they achieve full inclusion in the digital revolution of Uganda. This study has found out that they do not; and solving this problem requires that policy makers put emphasis on the positive elements in both the medical and social models of disability and discard the negative elements. This thinking stems from the fact that none of the two models can singly provide practical guidance in sorting out the inherent problems in universal access vis-à-vis disability. In other words, the cornerstone of critical disability theory in enabling full inclusion of PWVDs into the digital world targets changes in both the environment and the body, rather than emphasizing changes in either of the two. Shakespeare \& Watson (2002) reinforce this assertion by saying that people are disabled by both social barriers and by their bodies.

Putting the above into a proper universal access perspective, instead of recommending public access points (cyber cafes, public libraries, community centres and computer labs in schools) as the most feasible means for enabling disadvantaged groups to use computers and the Internet, which results into all public access points offering standardized equipment organized in a fairly standard way, policy should be directed to giving PWVDs the alternative of home access because these require specialized technologies that are often not available at the public access points. In addition, as was explained in Chapter 5, physically getting to the public access points also requires some effort as PWVDs would often not make it on their own. This means seeking the services of a sighted guide.

The study has also focused on lack of accessibility in the universal access policy as an additional impediment in the inclusion of PWVDs into the digital world. Accessibility is often ignored because of the collective identity of PWDS, which masks the experiential differences found in the various subgroups that make up this group. For instance, Chapter 5 of this dissertation revealed that whereas majority of the respondents (PWVDs) worked and studied in institutions with computers and Internet connectivity, many were unable to use those technologies because of lacking the relevant digital skills. Probably the situation would have been different for people with physical disabilities because these often do not need a special training in order to use ICTs.

Indeed examples abound of PWVDs, far more than other disabilities, coming out to challenge the way ICTs are designed. The first was with activists in the state of Massachusetts who argued that state agencies were at risk of breaking the law (Section 508 of the US Rehabilitation Act) for purchasing Windows to be used within state government offices (Goggin \& Newell, 2003b). Microsoft had introduced Windows with a graphical-user interface that did not work with the Command Line Interface screen readers used by people with vision loss to voice text. Section 508 (as amended in 1998) requires federal agencies to ensure that the electronic and information technology they develop, procure, maintain or use allows federal employees with disabilities to have access and use of information and data that is comparable to that which federal employees without disabilities get, unless such requirement imposes an undue burden. After lengthy negotiations, the U.S. government used its purchasing power to force companies such as Microsoft to make information technology accessible, or else miss out on lucrative government contracts. Consequently, Microsoft agreed to make its Windows 95 more accessible, especially for screen reader users. 
The second example can be traced from a study carried out on 1000 web sites by the Disability Rights Commission (DRC) of the UK in 2004, which found out that 81 percent of them fail to satisfy the most basic of web accessibility (DRC, 2004). Specific to PWVDs, the web sites had characteristics that made it very difficult, if not impossible, for them to make use of the services they provided. This is because they were not designed to allow easy interface with screen readers and screen magnifiers. Yet the Disability Discrimination Act (1995) of Britain makes it unlawful to discriminate against disabled people by refusing them service, providing service on worse terms, or providing a lower standard of service (Adam and Kreps, 2006: p. 221). Under the terms of the Disability Discrimination Act (1995), the owner of a public facing web site, public or private sector, is a service provider and must therefore comply with the law.

The third example relates to the Americans with Disabilities Act (1990). When reviewing literature for this study, the researcher discovered that groups advocating for blindness issues, believing that the Americans with Disabilities Act (especially Title III) pertains to web sites, were the ones that filed most of the legal cases under reference. For example, in November 1999 a number of blind people in the U.S. used the Americans with Disabilities Act to file a law suit against America Online (AOL), forcing it to adopt accessibility measures in its online and Internet services (Goggin \& Newell, 2003a). Another example, cited in Whentz, Jaeger \& Lazar (2011), was a settlement between the National Federation of the Blind and a commercial web site, target.com, in 2007. The web site was noted to be inaccessible to individuals with visual disabilities.

The fourth example is from the Australian Disability Discrimination Act (1992), which was successfully tested in June 1999 when Bruce Maguire, a blind Sydney resident, made a formal complaint to the Australian Human Rights and Equal Opportunity Commission that the Sydney Organizing Committee for the Olympic Games (SOCOG) website was inaccessible to blind users. An initial reaction on the part of SOCOG was to suggest to Maguire that he enlist a sighted person to assist him (Goggin and Newell, 2003a). But then the commission determined in August 2000 that SOCOG had discriminated against Maguire on the basis of his disability by not providing an accessible web site, something that it could have easily done, despite its protestations. In the face of such willful obstruction, the commission awarded Maguire $\$ 20,000$ in damages.

The final part of this study examined the eight properties of the new digital media and how they affect the inclusion of PWVDs into the Ugandan digital revolution. As already pointed out, the eight properties are sources of inequality and any universal access policy should put them into consideration in order to give all people opportunity to benefit from the new digital media in a meaningful way. Such an argument is raised in the context that these properties cannot be divorced from ICTs; they will instead continue growing stronger with time as more innovations are pushed on to the consumer market. For example, the complexity, integration and multifunctionality of computers and mobile phones will keep on increasing as these get better in serving specific users. Likewise, the expense related to acquiring and using the latest digital equipment will continue growing for those who need better and faster processing ability of computers and mobile phones while excluding those who cannot afford such equipment. Persons with Visual Disabilities should not be one of the groups to continue suffering exclusion on grounds of complexity, expense and multifunctionality of ICTs.

However, there is a worrying trend that some assistive technology developers, in order to comply with the principles of universal access, have begun manufacturing simpler versions of their proprietary products and urge users to install them on computers and mobile phones free of charge while encouraging them to purchase add-ons from their web sites. For example, the Nokia Screen Reader is 
a simpler version of Mobile Speak - both of which are products of Code Factory. Likewise, WindowEyes, a product of GW Micro, has a free downloadable version. The simpler versions of most assistive technologies only offer basic functionality, which might exacerbate exclusion of some PWVDs who can still not afford the cost of add-ons and/or lack the technical expertise necessary for the successful download and installation on their computers and mobile phones.

\subsection{Conclusions}

A major conclusion from the findings of this chapter is that Uganda has not yet given ample consideration to the digital needs of PWVDs in its implementation of the universal access policy. This is so in all the three principles of affordability, availability and accessibility. In terms of affordability, it was noted that the average cost for first-time connection to a mobile phone network and the Internet plus the cost of placing a local mobile phone call and the monthly subscription to an Internet service provider were relatively high and beyond the reach of most Ugandans. The majority of Ugandans with visual disabilities can be classified as unemployed; therefore lucking enough income with which to meet such obligations. This leads to their exclusion from the digital world. More so, the zero-import duty on computer equipment, which was instituted in 2004, did not cover software licenses; yet that is what would have made licenses for assistive technologies affordable for Persons with Visual Disabilities. On the side of availability, the several projects listed in Section 4.1 of this chapter had no provisions (screen readers and screen magnifiers) for PWVDs as a special group. In terms of accessibility, it was found out that both the reactive and proactive approaches were hard to implement in Uganda - a country that is largely not a producer of Information and Communication Technologies. Besides, the ICT sector in Uganda was still young by the time of this study - with most of its infrastructure either not in place or was just starting to get established. The laws, policies and standards for ICTs were also quite recent, which would affect buttressing accessibility as a standard practice within the country's ICT sector.

Nonetheless, the above conclusion does not offer sufficient justification for the non-provision of facilities suitable for PWVDs. This is so for several reasons. First, this study found no evidence that organisations of PWVDs were sufficiently consulted before putting in place the Ugandan laws and policies on ICTs, especially the two RCDF policies. The second reason is that the addition of facilities for PWVDs on the infrastructure needed to set up Internet and telecommunications services would not significantly increase the cost of ICTs for the general public, especially if the country does all the procurements at the same time. This is so because, despite their facilities being quite expensive, PWVDs do not constitute a big population.

Another conclusion is that beside the affordability, availability and accessibility principles, the qualities of the new digital media introduce a new set of challenges that policy makers must address in order to enable all people to benefit from universal access. Using the example of PWVDs, this chapter has demonstrated how digital exclusion can emanate from the complexity and expences associated with the new media. All the other qualities also affect use of the new media, and they must be put into consideration before universal access becomes a reality for everyone. 


\section{Chapter 7 Conclusions and recommendations}

\subsection{Introduction}

This dissertation set out to achieve the objective of examining the barriers to digital inclusion of PWVDs in Uganda. Being an LDC, Uganda was thought to offer an opportunity for transfer of knowledge obtained there to other countries at similar development levels. To achieve this goal the researcher found answers to three main research questions as presented in Chapter 1. In line with those questions, the findings are presented respectively in Chapters 4, 5 and 6 on technological, human and policy barriers to the digital inclusion of PWVDs in Uganda. However, merely enlisting the barriers to the digital inclusion of PWVDs would add little to the existing body of knowledge around access to ICTs. Therefore, the three research chapters, through the process of answering the research questions, make a number of academic contributions some of which are briefly explained as follows.

In a bid to investigate the barriers to the adoption of screen readers and screen magnifiers by PWVDs, Chapter 4 makes a contribution towards better understanding of the concept of assistive technology. Although assistive technology is a term used widely (in rehabilitation, medical care, transportation, ICTs and so on), in this dissertation it was restricted to only one of these areas. By restricting this concept to ICTs, the researcher was able to categorize screen readers and screen magnifiers according to quality, which is a useful guide for anybody wishing to adopt them into their daily use of computers, mobile phones and the Internet for information access and communication purposes. Screen readers and screen magnifiers were categorized into proprietary, integrated, freeware and Open Source Software, which subsequently denotes the kind of quality expected from their use.

Even policy makers can use the concept of assistive technology to determine the hardware and software needs of PWVDs and how they can be solved in any given community. Assistive technologies facilitate the full integration of PWVDs in the community which, in terms of ICTs, demands knowing whether these are bought as part of the mainstream equipment or purchased alongside the other equipment. With this knowledge, a policy maker may recommend provision of assistive technology through price reduction measures such as subsidies and tax exemptions or simply restrict procurement to certain products that can be used by all without incurring extra costs. The latter is, for example, easily achievable through purchase of Apple computers that come with relevant assistive technologies already installed on their platforms.

Chapter 5 uses the cumulative and recursive model of successive kinds of access to digital technologies by van Dijk (2005) to understand the multidimensional restrictions of access to ICTs among Persons With Visual Disabilities. This model brings out a hierarchy of decision-making that is typical with human beings, which helps in understanding any constraints in the access of ICTs. The addition of social support, which is a concept explicated as influencing all the other four strands of access in this model, is the most important contribution of this research. Although scholars had made 
various references to social support before, this research found out that it is particularly useful for PWVDs willing to learn and use ICTs effectively because of their need for emotional support from others and close observation/supervision in the course of learning and using ICTs.

Throughout the dissertation there is extensive reference to the concept of digital inclusion/exclusion. Digital exclusion refers to a lack of access to and use of information and communication technology resources (Macdonald \& Clayton, 2012). This concept helps in tracking a specific form of social exclusion and it demands specific measures to be put in place for its resolution. That differs from the general concept of social exclusion that relates to poverty and deprivation in the economic sense. Furthermore, by researching the digital exclusion of PWVDs, this is one specific contribution towards understanding them as a distinctive social group; although it shares certain vulnerabilities with other social groups categorized as Persons with Disabilities or disadvantaged groups.

By examining the principles of affordability, availability and accessibility in the universal access policy, Chapter 6 of this dissertation attempts to show that the digital needs of each disability should be treated separately from those of another if all PWDs are to be accorded equal participation in the information society. Critical disability theory is used to question the efficacy of some elements of both the medical and social models (see Section 1.5) of disability in solving the digital needs of PWVDs in Uganda. For policy-makers, this means putting emphasis on the positives in both the medical and social models of disability and discarding the negative elements, which would eventually lead to the construction of the integrative model of disability that is referred to in Section 1.5 of this dissertation. The major difference between the two models currently in use is that the medical model favours individualization of disability while the social model favours collectivity. Although both models have played a significant role in shaping policy for more than half a century, this dissertation endeavours to contribute to shifting from the status quo by discussing the negative elements of the two models.

Starting with the medical model, although this supports the individualization of disability, which is the biggest argument of this dissertation, its weakness is that the growth of human service industries and the politicization of disability by the disabled people's movement have resulted in the commodification of disability-related rehabilitation as a commercial enterprise (Albrecht, 1992). Disability is a business by which professionals connive with assistive technology experts to keep PWDs in perpetual dependence to their services. As a consequence, medicalization attaches expert approval to the existence of disability, which particularly affects PWVDs because they are usually forced into paying for screen readers and screen magnifiers expensively. Persons with Visual Disabilities, especially in some developed countries, obviate this challenge by relying on welfare schemes and their employment. Thus, those who are unemployed or do not get welfare benefits can easily be excluded from using ICTs. The Ugandan situation is such that PWVDs have no welfare schemes from which to obtain benefits to pay for screen readers and screen magnifiers, and only a few get such technologies from NGOs that focus on blindness issues; leaving most of them excluded from using ICTs altogether.

Secondly, Tusler argues that when designing electronic and information technology products, probably as a result of the medicalization of disability, people often work from stereotypical and inaccurate beliefs about persons with disabilities (Tusler, 2005). They try to "help the handicapped" by alleviating the problems they imagine persons with disabilities encounter. Unfortunately, such products often miss the mark because their designs are based on unexamined assumptions. Direct 
input of people with varying disabilities into design processes would be the best way forward for attaining maximum benefit.

The last negative element of the medical model of disability is the use of physical appearance as the basis for identifying type and severity of disability. Consequently, as the visible identifier of disability, the external body is the most potent catalyst for discriminatory attitudes and practices (Seymour \& Lupton, 2004). But there are people who have disabilities with few or vague visual markers, such as hearing loss, speech impediments, low vision, mild learning difficulties, asthma and epilepsy. Such people may choose to pass as normal as a way of avoiding the stigma attached to disability (Pothier \& Devlin, 2006; Lingsom, 2008). In the world of digital technologies this does not mitigate exclusion as people are still denied the support they need during social interaction. For example, although a person with low vision may choose not to ask for a screen magnifier as a way of hiding disability to the employer, it is still likely to leave this person with job performance deficiencies that would have been avoided when given the right technology.

On the side of the social model of disability, the first negative element is its proclivity towards a collective identity for persons with disabilities. Indeed Corker (1999) argued that collectivity should not be allowed to obscure real differences between disabled people, which may be about gender, race, sexuality and class; nor should it be used to deny the individuality of disabled people, in the tradition of objectifying disability through terminology such as 'the disabled'. In the realm of ICTs, which is the focus of this dissertation, the individuality of the different groups of PWDs is paramount in isolating and dealing with their problems, which makes subsuming PWDs into a collective identity, advocated by the social model of disability, counterproductive.

Secondly, the collectivity element inherent in the social model of disability carries the danger of masking the experiential differences found in the various sub-categories of PWDs. Indeed there are examples in history where lumping PWDs together ended up in disability misrepresentation. The first was by Abberley (1990), who criticized the Office of Population Censuses and Surveys (OPCS) for investigating the functional limitation of disabled people without regard to the different social and environmental contexts of their lives. A more recent example was with the fourth report in the NTIA (National Telecommunications and Information Administration) series, which included a special section examining access and use of computers and the Internet by PWDs for the first time (NTIA, 2000). However, it had a weakness of insufficiently acknowledging the heterogeneity of PWDs; thereby denying them ample coverage in highlighting their digital needs in respect of the various subcategories that make up this social group in the U.S. for example, one of the questions it posed was whether someone had trouble walking, and the answer-options to choose from included: using a white cane, crutches, walker, wheelchair, electric scooter, or similar aid for getting around. All the mobility aids, except the white cane used by PWVDs, could easily be associated with physical disability. It is doubtful whether the conclusion from that particular inquest was not flawed because PWVDs do not use white canes to alleviate difficulties of walking; rather they employ them for detecting obstacles they might find along their tracks.

Another problem with the social model lies in separating disability from impairment. The history of this model shows that in 1974 a small but influential organization of disabled activists known as the Union of the Physically Impaired Against Segregation (UPIAS) redefined disability as social oppression by drawing a distinction between impairment and disability - the former being in common with the traditional medical approach to disability and the latter referring to the society's failure to accommodate disabled people's needs (Barnes, 2005; Woodin, 2012). Redefining disability was 
appropriate at that time but making physical impairment the only yardstick for understanding the challenges of PWDs turned out to be wrong in the long run. For instance, when such organisations as the British Council of Disabled People (BCDP) and Disabled Peoples International (DPI) began recruiting people with sensory and cognitive impairments into the new thinking later on, where they put emphasis on removing barriers in the physical world, the resultant improvement in infrastructural accessibility did not resonate well with sensory impairments whose challenges did not necessarily manifest through physical barriers. For example, it is very clear that many deaf people see impairment and disability in terms of language and communication, rather than impairment as the physical fact of hearing loss (Corker, 1999). Similarly, some people with vision loss do not describe disability in terms of lack of beeper crossings, but as a lack of access to non-verbal communication. Using physical barriers to define disability is even more problematic in today's world that is dominated by ICTs that should have specific accessibility provisions for the different disabilities.

Finally, the social model of disability is accused of paying little attention to culture; yet this is a huge source of obscurity for some disabilities. Shakespeare (1994) argued that the representation and exploration of human experience is incomplete as long as disability is either missing from or misrepresented in all the forms that cultural representation takes. In the Ugandan context, existing laws and policies relating to ICTs mention PWDs in general terms; hence subtly excluding some groups, say those with visual and hearing disabilities, who have problems that tend to take on a more specialized form.

\subsection{Conclusions}

\subsubsection{Conclusions on the adoption of screen readers and screen magnifiers by PWVDs in Uganda}

As derived from what was found in Chapter 4 of this dissertation, adoption of screen readers and screen magnifiers seem to offer the utmost solution to the technological barriers PWVDs find with ICTs; because so far these facilitate their effective use of computers, mobile phones and the Internet. The following conclusions emphasize this fact in the case of Uganda:

i) Appreciating the need for screen readers and screen magnifiers in mainstream society is hard; but these make the difference between users and non-users of ICTs among PWVDs. However, this research has demonstrated that in Uganda the adoption of these technologies is limited in both variety and usage. In terms of variety, this research has revealed that only 4 types of screen readers ( 2 for computers and 2 for mobile phones) were found in use; and only 2 types of screen magnifiers for computers and none for mobile phones were in use. This contrasts sharply with the fact that there are many assistive technologies around the world (See Tables 4.1 and 4.2 for examples).

ii) This research has found out that PWVDs would benefit more from internet-enabled phones than computers when it comes to Internet connectivity. This conclusion is derived from the finding that there was a higher rate of usage of mobile phones than computers among the respondents. This could be tugged to the fact that acquisition of mobile phones is relatively cheaper and more user-friendly when compared to computers. But that will only be possible if designers of web sites in Uganda take into consideration that there are users of mobile devices accessing their web sites. 
iii) Screen readers are restrictive on the type of operating system on which to install them, which is a big constraint for Persons with Visual Disabilities. For instance, although Voice Over comes freely as part of the Apple computer, this is not so common in Uganda. Further, PWVDs would benefit more from the free downloads of screen readers such as Nokia Screen Reader and Thunder Speech Reader if there were no restrictions on the operating systems on which to install them. Even finding home-grown solutions to the development of screen readers becomes problematic when their use is restricted.

iv) Screen magnifiers have not gained widespread usage in Uganda, despite the high number of low vision people within the country. A sizable number of the respondents from the blindness community who were interviewed for the study on adoption of assistive technologies said they were with low vision, which should have been a good reason for them to partake of the freely available options for screen magnification as part of the Windows operating system. This means efforts should be directed towards promoting the use of screen magnifiers for the benefit of many who cannot use ICTs due to weak and/or deteriorating sight.

v) As Uganda pushes for Open Source Software in its endeavor to enhance the development of ICTs, it is vital to join those that have started working on this for screen readers. It is highly probable that this will help in developing a variety of screen readers that can pronounce words in the local languages more correctly, unlike the English-oriented screen readers developed in the UK and the U.S.

vi) The current trend in digital technology is tending towards a paradigm shift, which is similar to the one during the early 1990s where PWVDs were threatened with stoppage in their use of computers because Microsoft had shifted the windows operating system from a text to a graphical user interface. The latter was in total disregard of accessibility for users with visual disabilities. The current trend favours a shift away from keyboard use to touch screen and voicecommand technologies in tablet computers and smart phones. nonetheless, there is hope that development of screen readers capable of providing interoperability between humans and ICTs (computers and mobile phones) via touch screen technology is already underway and so far Voice Over is the best example in that direction.

\subsubsection{Conclusions on the human constraints for PWVDs in accessing ICTs}

Beyond the barriers associated with screen readers and screen magnifiers, it was found out that Ugandan PWVDs face several barriers of a human nature in acquiring and using ICTs. This can be derived from the following conclusions:

i) Rather than physical access, lack of skills was cited as the biggest challenge in accessing digital technologies by PWVDs. This conclusion was derived from the fact that 75 percent of the respondents who took part in the research were incapable of using the Internet, and they cited lack of training as the reason. Ugandans with visual disabilities find acquiring digital skills a problem because it requires a specialized training, which the researcher found out was quite limited.

ii) This research was inconclusive on whether motivational access was a major barrier in the access of ICTs by Ugandan PWVDs; because neither CSE nor ISE brought out clear indicators of whether or not the confidence levels of respondents in using ICTs were affected by type of training in using computers and the Internet or the time taken after acquiring digital skills. 
However, the complexities associated with ICTs would easily lower people's motivation towards accessing ICTs; but this cannot be a problem for PWVDs alone.

iii) It was discovered through this research that social support was a vital ingredient in accessing ICTs by PWVDs. This was found to have an impact at all the four levels of access spelt out in the cumulative and recursive model of successive kinds of access to digital technologies by Van Dijk (2005). It is even a more useful finding for a developing country like Uganda where scarcity of resources is high and can therefore impede the general usage of ICTs. More so for PWVDs, there is a high likelihood that accessible software solutions may increasingly become available via the Internet in the near future, which makes social support the most viable alternative for downloading and learning how to use such solutions. On the contrary, PWVDs will be unable to make use of accessible software solutions if social support is not deliberately made available to them.

\subsubsection{Conclusions on the universal access policy to the digital inclusion of PWVDs in Uganda}

After a careful review of the Ugandan laws and policies on ICTs, and comparing them with what pertains elsewhere around the world, a number of conclusions emerge. These include the following:

i) Ugandan laws and policies on ICTs have little or nothing specific to offer to Persons with Visual Disabilities. For instance, PWVDs are subsumed among other vulnerable groups, which renders them incapable of obtaining any meaningful services at public access points for computers and the Internet. This is so because, as Chapter 6 of this dissertation has elucidated, they have specific needs in terms of ICTs that generalities in laws and policies cannot cure effectively.

ii) Using the disability label to categorise some human beings is not productive in delivering Universal Access. It would instead be better categorizing human beings based on their functional limitations in using hands, eyes or ears. That would offer a more effective solution in ICTs since the accomplishment of input and output functions require specific capabilities in digital technologies. At least human beings have so far managed to transform digital technology suiting only three senses - sight, hearing and touch. Based on these, Uganda can provide solutions for everybody regardless of ability if disability is given a more comprehensive definition.

\subsection{Recommendations}

Basing on the findings and conclusions drawn from the study, the following recommendations are put forward for implementing various findings in the dissertation and for further research.

\subsubsection{Recommendations on technology}

It is important to create awareness on the need for assistive technologies that PWVDs can use on computers, mobile phones and related Internet services. In the case of Uganda this will be in line with policy strategy 7 in the IT promotion and awareness priority of the Information Technology Policy for Uganda (2010). In that regard government can take the following measures:

- Organise demonstration events and public outreaches on existing assistive technologies;

- Conduct media outreach activities such as advertisements and public announcements that highlight accessible computer and mobile phone products as well as accessible Internet and phone services; 
- Build partnerships with leading universities in information technology around the country to develop universally designed products;

- Organise conferences and debates around accessibility and showcasing innovative developments, best practices and working models.

- Facilitate technology transfer and sharing.

\subsubsection{Recommendations to alleviate human and policy barriers to the digital inclusion of PWVDs}

The recommendations below should enhance regulation, standardization and monitoring of the ICT industry to ensure it renders services relevant for all including PWVDs.

i) Make a deliberate effort to implement social support as part of the services rendered by helpdesks and after-sale services relating to ICTs. This will help people that require emotional support on top of technical assistance to be to be brought into the digital world.

ii) Formulate and/or amend laws and policies to promote accessibility of ICTs (computers and mobile phones) and related services. This will be more effective if these are aligned to relevant provisions in the CRPD.

iii) Include accessible service delivery as part of the terms of operators' license agreements or introduce other measures to ensure that affordable and accessible ICTs (computers, mobile phones and their accessories) are provided to PWVDs.

iv) Make available funding from the universal service fund to ensure PWVDs obtain accessible Internet and mobile phone services. This can entail subsidizing the cost of mobile phone handsets, special monthly service packages and provision of assistive technologies.

v) Agencies in charge of public procurement, such as Public Procurement and Disposal of Assets (PPDA) authority and consumer welfare organisations in the case of Uganda, should include accessibility of ICTs and related services as a condition for public procurement. This is provided for in section 508 of the U.S. Rehabilitation Act, which has made the employment of PWDs in public institutions somewhat easy because they are given the same computer equipment and services as their non-disabled counterparts in the United States.

vi) Set aside funds for development of low cost assistive technologies for computers and mobile phones. Effort should be made to ensure these are also adapted to some dominant local languages.

vii) Establish systems for assessing and benchmarking accessibility.

viii) Hold consultations with PWVDs and their organisations to seek their inputs on policy formulation and business practices. This will help in eliminating some of the gaps that are specific to certain disabilities, say Persons with Visual Disabilities.

ix) Promote web site accessibility within the ICT industry and ensure that all government web sites are accessible to Persons with Visual Disabilities.

x) Undertake periodic surveys to gather data on the use of ICTs by persons with various disabilities in Uganda. That will help the country to track the level of disadvantage for this social group from time to time.

xi) In a bid to bring ICTs to the under-served communities, it is vital for certain institutions, schools and NGOs with a disability bias to be identified so that financial and technical support is channeled to them to offer PWDs with digital technology facilities.

xii) Business enterprises could be identified to offer specialized services to PWDs alongside their usual ICT-related work. For instance, a seller of mobile phones and/or computers could be facilitated with the right knowledge to become a vender of related assistive technologies for PWVDs, rather than setting up special service centres. 
xiii) Identify and adopt standards on accessibility of mobile phones and the Internet, which have been developed by international standards bodies such as ITU, ISO and the $\mathrm{W} 3 \mathrm{C}$. this is more practical if their implementation in Uganda follows some guidelines developed for the various service providers.

xiv) Set up a string of web sites that can offer specialized services to PWVDs around the country. Some of the pertinent services could include collection of a host of reading materials for PWVDs; guidance to where newly blinded people can get counselling and retraining in mobility orientation; information about schools that offer quality education for children with visual disabilities; and advice on appropriate ICTs for the various sub-categories of PWVDs.

xv) Agencies involved in public information dissemination can take steps to ensure that all public information and documents are easily available in accessible formats. This should include formats accessible for mobile phones, text formats compatible with screen readers and screen magnifiers, and daisy content for loading on e-book readers.

xvi) Identify a group of experts among PWVDs who can advise government and relevant business enterprises on accessibility. The ICTs where accessibility for PWVDs is crucial include mobile telephony, the Internet and basic computer equipment. With the necessary accessibility in place, PWVDs could live more-or-less independently and reduce on costs for hiring guides and sighted readers.

\subsubsection{Recommendations for further research}

This research has focused on the digital exclusion of Persons with Visual Disabilities. This is a single group of people that cannot represent the situation in the country for all disadvantaged populations. While Uganda aspires to transform itself into a digital country, there is need for periodic surveys on the various correlates for digital exclusion for various population segments as it is done in other countries like the U.S. and the U.K.

There is need for further research into why the use of screen magnifiers is not widespread; yet people with low vision constitute majority of PWVDs in Uganda. It is worth reiterating that access to screen magnifiers is largely cheaper than access to screen readers; because many of the former are in-built in several operating systems of computers and mobile phones while others are bundled together with screen readers.

Analyzing the difficulties people with various disabilities face in the use of ICTs was beyond the scope of this research. However, this would be vital for a future study to find out which of the major disabilities is most affected by inaccessible ICTs. So far a number of researchers have alluded to how some people cope with their disability limitations more than others in using ICTs but no specific study has not been undertaken to establish why.

It is imperative to establish why there is a persistent practice among researchers and policy makers to lump PWDs together. This is so even when it is clear that these constitute a heterogeneous group to which there is no single solution to their digital needs. Some writers have even gone ahead to discover that there are demographic variables, say income, age and education, which tend to affect all PWDs in a similar way; but there is no clear reason for this. Further research in this area could expose types of discrimination hitherto unexplored in academic research. 


\section{List of references}

Abberley, P. (1990). Handicapped by numbers: A Critique of the OPCS Disability Surveys. Bristol: Bristol Polytechnic.

Adam, A. and Kreps, D. (2006a). Web Accessibility: A Digital Divide for Disabled People? In Trauth, E., Howcroft, D., Butler, T., Fitzgerald, D. and DeGross, J. (eds.): IFIP (International Federation for Information Processing), volume 208, Social Inclusion: Societal and Organisational Implications for Information Systems, (Boston: Springer), pp. 217 - 228.

Adam, A. and Kreps, D. (2006b). Enabling or Disabling Technologies? A critical approach to web accessibility. Information Technology and People, 19 (3): pp. 203-218.

African Peer Review Mechanism - National Commission for Uganda (2008). Country SelfAssessment Report. Government of Uganda.

Ahern, K.J. (1999). Ten Tips for Reflexive Bracketing. Qualitative Health Research, 9 (3): pp. 407411.

Albrecht, G. (1992). The Disability Business: rehabilitation in America. Newbury Park, CA, Sage.

Anandarajan, M., Igbaria, M. and Anakwe, U.P. (2002). IT acceptance in a less-developed country: a motivational factor perspective. International Journal of Information Management, 22 (1): pp. $47-65$.

Balka, E. (1997). Viewing the World Through a Gendered Lens. Paper prepared for Universal Access Workshop: Developing a Canadian Access Strategy: Universal Access to Essential Network Services.

Ballabio, E. and Whitehouse, D. (1999). Aging and disability in the information society: a European perspective on research and technological development. Technology and Disability, 10: pp. 3-10.

Bandura, A. (1989). Social Cognitive Theory. In Vasta, R. (Ed.), Annals of Child Development, 6: pp. $1-60$.

Bandura, A. (1999). A Social Cognitive Theory of Personality. In L. Pervin and O. John (Eds.), Handbook of Personality (2nd ed., pp. 154-196).

Barnes, C. (2005). Disability: Western Theories. Encyclopedia of Living Sciences (ELS): John Wiley \& Sons Ltd. Retrieved on July $10^{\text {th }} 2012$ from www.els.net

Barnes, C. and Mercer, G. (eds) (2004). Theorising and Researching Disability from a Social Model Perspective, in 'Implementing the Social Model of Disability: Theory and Research'. The Disability Press: Leeds, pp. 1-17.

Barzilai-Nahon, K. (2006). Gaps and Bits: Conceptualizing Measurements for Digital Divide/s. The Information Society, 22: pp. 269-278.

Bessiere, K., Ceaparu, I., Lazar, J., Robinson, J. and Shneiderman, B. (2002). Understanding Computer User Frustration: Measuring and Modeling the Disruption from Poor Designs. HCIL (Human-Computer Interaction Lab) Technical Report no. 18, University of Maryland.

Bird, J. and Plumpton, S. (2008). Affordable Access Technology. NB Magazine, Royal National Institute for the Blind, UK. Retrieved on September 12, 2009 from www.rnib.org.uk/xpedio/groups/

Blubaugh, M. (2011). Tips for Buying a Computer and Optimizing Its Display for Computer Users with Low Vision. AccessWorld, 12 (5). Retrieved on January 15, 2012 from the American foundation of the Blind (AFB) web site: www.afb.org/aw/

Bonfadelli, H. (2002). The Internet and Knowledge Gaps: A Theoretical and Empirical Investigation. European Journal of Communication, 17 (1): pp. 65-84. 
Bowe, F.G. (2007). Universal service and the disability community: The need for ubiquitous broadband deployment. Retrieved on May 10, 2013 from the Benton Foundation web site: http://www.benton.org/node/6105/

Braman, S. (2012). Internationalization of the Internet by design: The first decade. Global Media and Communication, 8 (1): pp. 27-45.

Brannen, J. (2005). Mixing Methods: The Entry of Qualitative and Quantitative Approaches into the Research Process, International Journal of Social Research Methodology, 8 (3): pp. 173-184.

Brandtweiner, R., Donat, E. and Kerschbaum, J. (2010). How to become a sophisticated user: a twodimensional approach to e-literacy. New Media and Society, 12 (5): pp. 813-833.

Bryman, A. (2006). Integrating Quantitative and Qualitative Research: How Is It Done? Qualitative Research, 6: pp. 97-113.

Bryman, A. (2008). Why do Researchers Integrate/Combine/Mesh/Blend Mix/Merge/Fuse Quantitative and Qualitative Research? In Bergman, M.M. (Ed.): Advances in Mixed Methods Research: Theories and Applications. Sage Publications Ltd. Pp. 87-100.

Burgelman, J.C. (2000). Regulating Access in the Information Society: The Need for Rethinking Public and Universal Service. New Media \& Society, 2 (1): pp. 51-66.

Caldwell, B., Cooper, M., Reid, L.G. \& Vanderheiden, G. (2008). Web Content Accessibility Guidelines (WCAG) 2.0. Retrieved on December 10, 2011 from http://www.w3.org/TR/2008/REC-WCAG20-20081211/

Campbell, S.W. (2007). Perceptions of Mobile Phone Use in Public Settings: A Cross-Cultural Comparison. International Journal of Communication, 1: pp. 738-757.

Candela, A.R. (2006). Legends and Pioneers of Blindness Assistive Technology, Part 3. AccessWorld, 7 (6). Retrieved on October 10, 2010 from the American Foundation of the Blind (AFB) web site: www.afb.org/aw/

Carveth, R. and Kretchmer, S.B. (2002). Policy Options to Combat the Digital Divide in Western Europe. Informing Science, 5 (3): pp. 116-123.

Castro, F.G., Kellison, J.G., Boyd, S.J. and Kopak, A. (2010). A Methodology for Conducting Integrative Mixed Methods Research and Data Analyses. Journal of Mixed Methods Research, 4 (4): pp. 342-360.

Ceaparu, I., Lazar, J., Bessiere, K., Robinson J. and Shneiderman, B. (2004). Determining Causes and Severity of End-User Frustration. International Journal of Human-Computer Interaction, 17 (3): pp. 333-356.

Centre for Universal Design (2008). "Nokia Helps Lead IT Industry to Customers with Disabilities". College of Design, North Carolina State University

Chaudhry, V. and Shipp, T. (2005). Rethinking the Digital Divide in Relation to Visual Disabilities in India and the United States: Towards a Paradigm of 'Information Inequity'. Disabilities Studies Quarterly, 25 (2).

Chua, S.L., Chen, D.T. and Wong, A.F.L. (1999). Computer anxiety and its correlates: a metaanalysis. Computers in Human Behaviour, 15: pp. 609-623.

Clement, A. and Shade, L. (1998). The Access Rainbow: Conceptualising Universal Access to the Information/Communication Infrastructure. Working Paper no. 10, Information Policy Programme, Faculty of Information Studies, University of Toronto.

Coleman, J. S. (1988). Social Capital in the Creation of Human Capital. The American Journal of Sociology, 94 (Supplement: S95-S120).

Collins, K.M.T. and O'cathain, A. (2009). Ten points about mixed methods research to be considered by the novice researcher. International Journal of Multiple Research Approaches, 3: pp. 2-7. 
Compaine, B. (2000). Re-Examining the Digital Divide. Internet and Telecoms Convergence Consortium, MIT.

Compeau, D. R. and Higgins C. A. (1995). Application of Social Cognitive Theory to Training for Computer Skills. Information Systems Research, 6 (2): pp. 118-143.

Compeau, D. R., Higgins C. A. and Huff, S. (1999). Social Cognitive Theory and Individual Reactions to Computing Technology: A Longitudinal Study. MIS Quarterly, 23 (2): pp. 145-158.

Constitution of the Republic of Uganda (1995).

Cooper, J. (2006). The digital divide: the special case of gender. Journal of Computer Assisted Learning, 22 (5): pp. 320-334.

Corker, M. (1999). Differences, Conflations and Foundations: The limits to 'accurate' theoretical representation of disabled people's experience? Disability and Society, 14 (5): pp. 627-642.

Creswell, J.W. and Plano Clark, V.L. (2007). Designing and Conducting Mixed Methods. Sage Publications, Thousand Oaks, London.

Creswell, J.W. and Tashakkori, A. (2007). Editorial: Exploring the Nature of Research Questions in Mixed Methods Research. Journal of Mixed Methods Research, 1 (3): pp. 207-211.

Crump, B. and McIlroy, A. (2003). The digital divide: Why the "don't-want-tos" won't compute: Lessons from a New Zealand ICT Project. First Monday, 8 (12). Retrieved on August $15^{\text {th }} 2012$ from http://www.firstmonday.org/issues/issue8_12/crump/index.html

Davison, R., Vogel, D., Harris, R. and Jones, N. (2000). Technology Leapfrogging in Developing Countries - An Inevitable Luxury? The Electronic Journal on Information Systems in Developing Countries, 1 (5): pp. 1-10.

De Haan, J. (2004). A Multifaceted Dynamic Model of the Digital Divide. IT\&Society, 1 (7): pp. 6688.

Desai, V. and Potter, R. B. (2009). Doing Development Research. Sage Publications Ltd., London.

Dewan, S. and Riggins, F. J. (2005). The Digital Divide: Current and Future Research Directions. Journal of Association for Information Systems, 6 (2): pp. 298-337.

DiMaggio, P. and Bonikowski, B. (2008). Make Money Surfing the Web? The Impact of Internet Use on the Earnings of U.S. Workers. American Sociological Review, 73 (2): pp. 227-250.

DiMaggio, P. and Hargittai, E. (2001). From the 'Digital Divide' to 'Digital Inequality': Studying Internet Use as Penetration Increases. Working Paper \#15, Center for Arts and Cultural Policy Studies, Princeton University.

DiMaggio, P., Hargittai, E., Newman, W.R. and Robinson, J.P. (2001). Social Implications of the Internet. Sociology Annual Review, 27: pp. 307-336.

DiMaggio, P., Hargittai, E., Celeste, C. and Shafer, S. (2004). From Unequal Access to Differentiated Use: A Literature Review and Agenda for Research on Digital Inequality. Report prepared for the Russel Sage Foundation, New York.

Dobransky, K. and Hargittai, E. (2006). The Disability Divide in Internet Access and Use. Information, Communication and Society, 9 (3): pp. 313 - 334.

DRC (2004). "The Web: Access and Inclusion for Disabled People" Disability Rights Commission, London. Retrieved on October 10, 2010 from http://www.drc-gb.org/library/webaccessibility/asp

Eastin, M.S. and LaRose, R. (2000). Internet Self-Efficacy and the Psychology of the Digital Divide. Journal of Computer Mediated Communication (JCMC), 6 (1). Retrieved on August 5, 2011 from jcmc.indiana.edu/vol6/issue1/eastin.html

Epstein, D., Nisbet, E.C. and Gillespie, T. (2011). 'Who's Responsible for the Digital Divide? Public Perceptions and Policy Implications.' The Information Society, 27 (2): pp. 92-104. 
Faulkner, X. and Culwin, F. (2005). When fingers do the talking: a study of text messaging. Interacting with Computers, 17: pp. 167-185.

Fox, S. (2004). Older Americans and the Internet. Pew Internet \& American Life Project, Washington DC. Retrieved on May14, 2012 from www.pewinternet.org

Fox, S. (2011). Americans living with disability and their technology profile. Pew Research Center's Internet and American Life Project, Washington, D.C. Retrieved on May 10, 2013 from http://pewinternet.org/Reports/2011/Disability.aspx

Frank, K. A., Zhao Y. and Borman, C. (2004). Social Capital and the Diffusion of Innovations within Organisations: the case of computer technology in schools. Sociology of Education, 77 (2): pp. 148-171.

Freeman, R.B. (2002). The Labour Market in the New Information Economy. Centre for Economic Performance, London School of Economics and Political Science.

Fuchs, C. and Horak, E. (2008). Africa and the digital divide. Telematics and Informatics, 25: pp. 99116.

Gebremichael, M.D. and Jackson, J.W. (2006). Bridging the gap in Sub-Saharan Africa: A holistic look at information poverty and the region's digital divide. Government Information Quarterly, 23: pp. 267-280.

Gillwald, A., Milek, A. and Stork, C. (2010). Towards Evidence-based ICT Policy and Regulation: Gender Assessment of ICT Access and Usage in Africa. Policy Paper no. 5.

Goggin, G. and Newell, C. (2000). An End to Disabling Policies? Toward Enlightened Universal Service. The Information Society, 16 (2): pp. 127-133.

Goggin, G. and Newell, C.J. (2003a). Digital Disability: The Social Construction of Disability in New Media. Rowman and Littlefield, Lanham, MD and Oxford

Goggin, G. and Newell, C.J. (2003b). "Communicating Disabilities: what's the matter with Internet Studies?" Paper presented at ANZCA conference. Available at: www.bond.edu.au/hss/communication/ANZCA/papers/GGogginCNewellPaper.pdf

Goggin, G. and Newell, C. (2007). The Business of Digital Disability. The Information Society, 23 (3): pp. 159-168.

Gordon, B.O. and Rosenblum, K.E. (2001). Bringing Disability into the Sociological Frame: A comparison of disability with race, sex, and sexual orientation statuses. Disability \& Society, 16 (1): pp. 5-19.

Granovetter, M.S. (1973). The Strength of Weak Ties. The American Journal of Sociology, 78 (6): pp. $1360-1380$.

Granovetter, M. (1983). The Strength of Weak Ties: A Network Theory Revisited. Sociological Theory, 1: pp. 201-233.

Greene, J.C., Caracelli, V.J., and Graham, W.F. (1989). Toward a Conceptual Framework for MixedMethod Evaluation Designs. Educational Evaluation and Policy Analysis, 11: pp. 255-274.

Groenewald, T. (2004). A Phenomenological Research Design Illustrated. International Journal of Qualitative Methods, 3 (1): pp. 42-55.

Gunkel, D.J. (2003). Second Thoughts: toward a Critique of the Digital Divide. New Media and Society, 5 (4): pp. 499-522.

Guo, B., Bricout, J.C. and Huang, J. (2005). "A Common Open Space or a Digital Divide? A Social Model Perspective on the Online Disability Community in China". Disability and Society, 20 (1): pp. 49-66.

Gurstein, M. (2003). Effective use: A community informatics strategy beyond the digital divide. First Monday, 8 (12). Retrieved on March 12, 2012 from: http://frodo.lib.uic.edu/ojsjournals/ index.php/fm/article/view/1107/1027 
Hargittai, E. (2002). The Second-Level Digital Divide: differences in people's online skills. First Monday: Peer-Reviewed Journal on the Internet, 7 (4). Retrieved on March 7, 2012 from http://firstmonday.org/issues/issue7_4/hargittai/index.html

Hargittai, E. (2002). Beyond Logs and Surveys: In-Depth Measures of People's Web Use Skills. Journal of the American Society forInformation Science and Technology, 53 (14): pp. 12391244.

Hargittai, E. (2003). The Digital Divide and What To Do about It. In Jones, C.D. (Ed.), New Economy Handbook. Academic Press, San Diego, CA. Retrieved on May $10^{\text {th }} 2012$ from www.eszter.com/research/pubs/hargittai-digitaldivide.pdf

Hargittai, E. (2008). The Digital Reproduction of Inequality, in Grusky, D. (Ed.): Social Stratification. Boulder, CO: Westview Press: pp. 936-944.

Hassani, S.N. (2006). Locating digital divides at home, work, and everywhere else. Poetics, 34: pp. 250-272.

Helbig, N., Gil-Garcia, J.R. and Ferro, E. (2009). Understanding the complexity of electronic government: Implications from the digital divide literature. Government Information Quarterly, 26 (1): pp. 89-97.

Herring, S.C. (1999). The Rhetorical Dynamics of Gender Harassment On-Line. The Information Society, 15: pp. 151-167.

Hoffman, D.L. and Novak, T.P. (1998). "Bridging the Racial Divide on the Internet". Science, 280: pp. 390-391.

Hoffman, D.L., Novak, T.P. and Schlosser, A.E. (2000). The Evolution of the Digital Divide: How Gaps in Internet Access May Impact Electronic Commerce. Journal of Computer Mediated Communication (JCMC), 5 (3). Retrieved on August 13, 2012 from: http://jcmc.indiana.edu/index.html

Howard, P.E.N., Rainie, L. and Jones, S. (2001). Days and Nights on the Internet: The Impact of a Diffusing Technology. American Behavioral Scientist, 45 (3): pp. 382-404.

Hovitz, R. (2003). Module 6 - ICT Applications. Paper presented at UNDESA-UNITAR "EGovernment for Development" Seminar: Rome, 23-28 June 2003.

Hsieh, J.J.P., Rai, A. and Keil, M. (2008). Understanding Digital Inequality: Comparing Continued Use Behavioral Models of the Socio-Economically Advantaged and Disadvantaged. MIS Quarterly, 32 (1): pp. 97-126.

Huffman, L. and Burton, D. (2007). Expanding the View: A Review of Mobile Magnifier and ZOOMS Screen Magnifiers for Cell Phones. Access World, 8 (4). Retrieved on June 102011 from the American Foundation of the Blind (AFB) WEB site: www.afb.org/aw/

ITU and UNCTAD (2007). World Information Society Report: Beyond WSIS. Retrieved on October 20th from http://www.itu.int/wisr

ITU Telecommunication Development Bureau (2003). Gauging ICT potential around the world. Geneva: ITU publications. http://www.itu.int/ITU-D/ict/dai/material/DAI

Jaeger, P.T. (2006). Telecommunications policy and individuals with disabilities: Issues of accessibility and social inclusion in the policy and research agenda. Telecommunications Policy, 30: pp. 112-124.

Jaeger, P.T. (2012). Disability and the Internet: Confronting a Digital Divide. Boulder, Colo.: Lynne Rienner. 
Johnson, R.B. and Onwuegbuzie, A.J. (2004). Mixed Methods Research: A Research Paradigm Whose Time Has Come. Educational Researcher, 33 (7): pp. 14-26.

Jung, J.Y., Liu, J.L. and Kim, Y.C. (2001). Internet Connectedness and Inequality: Beyond the "Divide". Communication Research, 28 (4): pp. 507-535.

Kane, S.K., Bigham, J.P. and Wobbrock, J.O. (2008). Slide Rule: Making Mobile Touch Screens Accessible to Blind People Using Multi-Touch Interaction Techniques. Retrieved on November $10^{\text {th }} 2009$ from http://www.codefactory.es/

Kasusse, M. (2005). Bridging the digital divide in Sub-Saharan Africa: The rural challenge in Uganda. The International Information \& Library Review, 37 (3): pp. 147-158.

Kaye, S. (2000). Computer and Internet use among PWDs. Disability Statistics Report (13). Washington, DC: U.S. Department of Education, National Institute on Disability Rehabilitation Research.

Kennedy,T., Wellman, B. and Klement, C. (2003). Gendering the Digital Divide. IT\&Society, 1 (5): pp. 149-172.

Kim, T. and Doh, S. (2006). Analysis of the Digital Divide between Disabled and Non-Disabled People in South Korea. The Asia Pacific Journal of Public Administration, 28 (2): pp. 231-261.

Kling, R. (1999). Can the"Next-Generation Internet" Effectively Support "Ordinary Citizens"? The Information Society, 15: pp. 57-63.

Kreps, D. (2008). How the web continues to fail persons with disabilities. Paper 11 presented at the ALT-C 2008 Research Proceedings 113.

Krueger, A.B. (1993). How Computers Have Changed the Wage Structure: Evidence from Microdata, 1984-1989. The Quarterly Journal of Economics, 108 (1): pp. 33-60.

Lazar, J., Allen A., Kleinman, J. and Malarkey, C. (2007). What Frustrates Screen Reader Users on the Web: A Study of 100 Blind Users. International Journal of Human-Computer Interaction, 22 (3): pp. 247-269.

Leavitt, M. O., \& Shneiderman, B. (2006). Research-based web design \& usability guidelines. U.S. Department of Health and Human Services. Retrieved on June 10, 2010 from http://www.usability.gov/pdfs/guidelines.html.

Leech, N.L. and Onwuegbuzie, A.J. (2007). An Array of Data Analysis Tools: A Call for Data Analysis Triangulation. School Psychology Quarterly, 22 (4): pp. 557-584.

Leech, N.L. and Onwuegbuzie, A.J. (2009). A Typology of Mixed Method Research Designs. Quality and Quantity, 43: pp. 265-275.

Lenhart, A. and Horrigan, J.B. (2003). Re-Visualizing the Digital Divide as a Digital Spectrum. IT\&Society, 1 (5): pp. 23-39.

Lenhart, A. Horrigan, J., Rainie,L., Allen, K., Boyce, A., Madden, M. and O'Grady, E. (2003). The Ever-Shifting Internet Population: A new look at Internet access and the digital divide. The Pew Internet and American Life Project. Retrieved on March 10, 2012 from http://www.pewinternet.org/

Liem, A., Swierenga, S. J. and Gheerawo, R. (2010). Moving Towards an All-Encompassing Universal Design Approach in ICT. Journal of Usability Studies, 5 (4): pp. 129-131.

Ling, C., Hwang, W. and Salvendy, G. (2007). A survey of what customers want in a cell phone design. Behaviour and Information Technology, 26 (2): pp. 149-163.

Lingsom, S. (2008). Invisible Impairments: Dilemmas of Concealment and Disclosure. Scandinavian Journal of Disability Research, 10 (1): pp. 2-16.

Losh, S.C. (2004). Gender, Educational and Occupational Digital Gaps 1983-2002. Social Science Computer Review, 22 (2): pp. 152-166. 
Loy, B. and Batiste, L. C. (2008). Universal Design and Assistive Technology in the Workplace. A publication of Job Accommodation Network (JAN). Retrieved on January 13, 2010 from: www.jan.wvu.edu/media/udatfact.doc

Macdonald, S.J. and Clayton, J. (2012). Back to the future, disability and the digital divide. Disability and Society, iFirst article: pp. 1-17.

Mantzoukas, S. (2005). The Inclusion of Bias in Reflective and Reflexive Research: A necessary prerequisite for securing validity. Journal of Research in Nursing, 10 (3): pp. 279-295.

Marincu, C. and McMullin, B. (2004). A comparative assessment of web accessibility and technical standards conformance in four EU states. First Monday, 9 (7). Retrieved on August 10th 2012 from http://firstmonday.org/htbin/cgiwrap/bin/ojs/index.php/fm/article/viewArticle/1160/1080

Martin, S.P. (2003). Is the Digital Divide Really Closing? A Critique of Inequality Measurement in A Nation Online. IT\&Society, 1 (4): pp. 1-13.

Mazrui, J. (2005). What's in a PDF? The Challenges of the Popular Portable Document Format. AccessWorld, 6 (6). Retrieved from the American Foundation of the Blind (AFB) WEB site: www.afb.org/aw/

Microsoft TechNet (2012). Accessibility for Persons with disabilities. Retrieved on March 25, 2012 from technet.microsoft.com/en-us/library/cc939037.aspx

Milner, H.V. (2003). The Digital Divide: The Role of Political Institutions in Technology Diffusion. Paper presented at the annual meeting of the American Political Science Association, Philadelphia, August 28-31.

Ministry of Information and Communications Technology (January 2011). Telecommunications Policy. Republic of Uganda, Kampala.

Morgan, D.L. (2007). Paradigms Lost and Pragmatism Regained: Methodological Implications of Combining Qualitative and Quantitative Methods. Journal of Mixed Methods Research, 1 (1): pp. 48-76.

Morris, A., Brading, H. and Goodman, J. (2007). Internet use and non-use: views of older users. Univ Access Inf Soc, 6: pp. 43-57.

Morris, B. (2006). The Symbian OS Architecture Sourcebook: Design and Evolution of a Mobile Phone OS. John Wiley \& Sons, London.

Mossberger, K., Tolbert, C.J. and Gilbert, M. (2006). Race, Place and Information Technology. Urban Affairs Review, 41 (5): pp. 583-620.

National Council on Disability (1998). Access to Multimedia Technology by People with Sensory Disabilities. National Council on Disability, Washington, DC. Accessed on January 2nd 2013 from http://www.ncd.gov

National Council on Disability (2000). Federal Policy Barriers to Assistive Technology. National Council on Disability, Washington, DC. Accessed on January 2nd 2013 from http://www.ncd.gov

National Council on Disability (2004). Design for Inclusion: Creating a New Marketplace. National Council on Disability, Washington, DC. Accessed on January 2nd 2013 from http://www.ncd.gov

National Council on Disability (2006). The Need for Federal Legislation and Regulation Prohibiting Telecommunications and Information Services Discrimination. National Council on Disability, Washington, DC. Retrieved on May 10, 2013 from http://www.ncd.gov

National Information Technology Authority Act - Uganda (2009).

National Telecommunications and Information Administration (NTIA) (1995). Falling Through the Net: A Survey of the "Have Nots" in Rural and Urban America. July. 
NTIA (1998). Falling Through the Net II: New Data on the Digital Divide. July.

NTIA (1999). Falling Through the Net: Defining the Digital Divide. November.

NTIA (2000). Falling Through the Net: Toward Digital Inclusion. October.

NTIA (2002). A Nation Online: How Americans are Expanding Their Use of the Internet. February.

NTIA (2004). A Nation Online: Entering the Broadband Age. September.

Norris, P. (2001). Civic Engagement, Information Poverty, and the Internet Worldwide. Cambridge University Press, New York.

O'Brien, E. (2005). The Evolution of Screen Reader Technologies: A case study. Topics in HCI: The Evolution of Ideas and Products. Retrieved on August 3, 2011 from ldt.stanford.edu/ emobrien/377_paper.doc

OECD (2001). Understanding the Digital Divide. OECD Publications, Paris.

Oliver, M. (1990). The Individual and Social Models of Disability. Paper presented at Joint Workshop of the Living Options Group and the Research Unit of the Royal College of Physicians on People with Established Locomotor Disabilities in Hospitals: July 23, 1990.

Onwuegbuzie, A.J. and Johnson, R.B. (2006). The Validity Issue in Mixed Research. Research in the Schools, 13 (1): pp. 48-63.

Palys, T. (2008). Purposive Sampling. In Given, L.M. (Ed.) The Sage Encyclopedia of Qualitative Research Methods. Thousand Oaks, 2: pp. 697-698.

Patton, M.Q. (1990). Qualitative evaluation and research methods. Beverly Hills, CA: Sage.

Persons with Disabilities Act (2006).

Pothier, D. and Devlin, R. (2006). Critical Disability Theory: Essays in Philosophy, Politics, Policy and Law. Vancouver, Canada: UBC Press.

Putnam, R., D. (1995). “Bowling Alone: America's Declining Social Capital”. Journal of Democracy, pp. 65-78.

Rempel, J. (2012). The Bigger Picture: A Comparative Review of Magnifier for Windows 7 and Zoom for Mac OS. AccessWorld, 13 (2). Retrieved from the American Foundation of the Blind (AFB) WEB site: www.afb.org/aw/

Report of the Digital Opportunity Task Force (DOT Force) (May 2001). Retrieved on February 5, 2013 from: www.g7.utoronto.ca/summit/2001genoa/dotforce1.html

Republic of Uganda (February 2010). Information Technology Policy for Uganda. Ministry of Information and Communications Technology, Kampala.

Republic of Uganda (November 2007). Uganda Government Website Standards. Ministry of Information and Communications Technology, Kampala.

Rice, R.E. and Katz, J.E. (2003). Comparing Internet and mobile phone usage: digital divides of usage, adoption and dropouts. Telecommunications Policy, 27: pp. 597-623.

Robinson, L. (2008) How to be Engaging. An address to Enviro 08 Convention, Melbourne.

Rogers, E. M. (5 $5^{\text {th }}$ Ed.) (2003). Diffusion of Innovations. Simon and Schuster inc: New York.

Rogers, E.M. and Malhotra, S. (2000). Computer as Communication: the Rise of Digital Democracy, in: Hacker, Kenneth \& Jan van Dijk (eds) Digital Democracy. Issues of Theory and Practice. Sage, London, Thousand Oaks, New Dehli, pp. 10-29.

Sandelowski,M. (2001). Real Qualitative Researchers Do Not Count: The Use of Numbers in Qualitative Research. Research in Nursing and Health, 24: pp. 230-240.

Seelman, K.D. (2005). Universal Design and Orphan Technologies: Do We Need Both? Disability Studies Quarterly, 25 (3). Retrieved on August 8, 2012 from www.dsq-sds.org 
Selwyn, N. (2004). Reconsidering Political and Popular Understandings of the Digital Divide. New Media \& Society, 6 (3): pp. 341-362.

Sen, A. K. (1999). Development as freedom. New York: Knopf Press.

Seymour, W. and Lupton, D. (2004). Holding the line online: exploring wired relationships for persons with disabilities. Disability and Society, 19 (4): pp. 291-305.

Shakespeare, T. (1994). Cultural Representation of Disabled People: Dustbins for Disavowal? Disability and Society, 9 (3) pp. 283-299.

Shneiderman, B. (1999). Universal Usability: Pushing Human-Computer Interaction to Empower Every Citizen. HCIL (Human-Computer Interaction Laboratory) Technical Report No. 99-17. Retrieved on July $10^{\text {th }} 2012$ from http://www.cs.umd.edu/hcil

Smart, J.F. (2009). The Power of Models of Disability. Journal of Rehabilitation, 75 (2): pp. 3-11.

Smith, S.M. (2001). An examination of the computer self-efficacy and computer-related task performance relationship. Retrieved on November 11, 2011 from the Organisational Systems Research Association web site: http://www.osra.org/2001/smith.pdf

Sourbati, M. (2009). 'It could be useful, but not for me at the moment': Older people, internet access and e-public service provision. New Media \& Society, 11 (7): pp. 1083-1100.

Soderstrom, S. and Ytterhus B. (2010). The use and non-use of assistive technologies from the world of information and communication technology by visually impaired young people: a walk on the tightrope of peer inclusion. Disability and Society, 25 (3): pp. $303-315$.

Stephanidis, C. and Emiliani, P.L. (1999). 'Connecting' to the Information Society: a European perspective. Technology and Disability Journal, 10 (1): pp. 21-44.

Stevenson, S. (2007). Public libraries, public access computing, FOSS and CI: There are alternatives to private philanthropy. First Monday, 12 (5). Accessed on April 12, 2013 from URL: http://firstmonday.org/issues/issue12_5/stevenson/index.html

Steyaert, J. (2002). Inequality and the digital divide: Myths and realities. In Hick, S. and McNutt, J. (Eds.), Advocacy, activism and the Internet, pp. 199-221.

Stienstra, D. (2006). The critical space between: Access, inclusion and standards in information technologies. Information, Communication and Society, 9 (3): pp. 335-354.

Stienstra, D. Watzke, J. and Birch, G.E. (2007). A Three-Way Dance: The Global Public Good and Accessibility in Information Technologies. The Information Society: An International Journal, 23 (3): pp. 149-158.

Strang, D. and Meyer, J.W. (1993). Institutional Conditions for Diffusion. Theory and Society, 22 (4): pp. 487-511.

Tashakkori, A. and Creswell, J.W. (2007). Differring Perspectives on Mixed Methods Research. Journal of Mixd Methods Research, 1 (4): pp. 303-308.

Tashakkori, A. and Teddlie, C. (2008). Quality of Inferences in Mixed Methods Research:Calling for an Integrative Framework. In Bergman, M.M. (Ed.): Advances in Mixed Methods Research: Theories and Applications. Sage Publications Ltd. Pp. 101-119.

Teddlie, C. and Yu, F. (2007). Mixed Methods Sampling: A Typology With Examples. Journal of Mixed Methods Research, 1 (1): pp. 77-100.

Teddlie, C. and Tashakkori, A. (2006). A General Typology of Research Designs Featuring Mixed Methods. Research in the Schools, 13 (1): pp. 12-

Teddlie, C. and Tashakkori, A. (2012). Common 'Core' Characteristics of Mixed Methods Research: A Review of Critical Issues and Call for Greater Convergence. American Behavioral Scientist, 56 (6): pp. 774-788.

The Republic of Uganda (2003). National Information and Communication Technology Policy. Ministry of Works, Housing and Communications: Kampala. 
Tichenor, P.J., Donohue, G.A. and Olien, C.N. (1970). 'Mass Media Flow and Differential Growth in Knowledge'. Public Opinion Quarterly, 34: pp. 159-170.

Tobias, J. (2003). Universal Design: Is It Really about Design? Information Technology and Disabilities Journal. Retrieved on April 142013 from http:// people.rit.edu/easi/itd/itdv09n2/ tobias.htm

Tongia, R. (2006). Connectivity and the Digital Divide - Technology, Policy and Design tradeoffs for Developing Regions. Department of Engineering and Public Policy, Carnegie Institute of Technology: paper 125. Retrieved on April 15, 2012 from http://repository.cmu.edu/epp/125

Tusler, A. (2005). How to Make Technology Work: A Study of Best Practices in United States Electronic and Information Technology Companies. Disability Studies Quarterly, 25 (2). Retrieved on August 5, 2012 from www.dsq-sds.org

Tusubira, F.F., Kaggwa, I. and Ongora, J. (2005). "Uganda." In Towards an e-Index: Household and Individual ICT Access and Usage Across 10 African Countries. Gillward Alison, (ed.) The Link Centre, Wits University school of Public and Development Management.

Uganda Bureau of Statistics (2006), The Uganda National Household Survey (UNHS) 2005/06: Uganda Bureau of Statistics, Kampala.

Uganda Bureau of Statistics (2010), The Uganda National Household Survey (UNHS) 2009/10: Uganda Bureau of Statistics, Kampala.

Uganda Communications Commission (December 2009). RCDF Policy 2010/11-2014/15. Uganda Communications Commission, Kampala.

Uganda Communications Commission (October 2011). Access to ICTs by Persons with Disabilities in the Education Sector in Uganda. The Research and Development Unit, Department of Competition and Corporate Affairs, Kampala.

Uganda Communications Act (1997). Chapter 106 of the laws of Uganda.

United Nations (2006). United Nations Convention on the Rights of persons with disabilities. Retrieved on $10^{\text {th }}$ September 2011 from http://www2.ohchr.org/english/law/disabilitiesconvention.htm

UN Millennium Project (2005). Innovation: Applying Knowledge in Development. Task Force on Science, Technology, and Innovation, Earthscan, London.

Valente, T. W. (1996). Social Network Thresholds in the Diffusion of Innovations. Social Networks, 18 (1) pp. 69-89.

Van Deursen, A. and Van Dijk, J. (2011). Internet Skills and the Digital Divide. New Media \& Society, 13 (6): pp. 893-911.

Van Dijk, J. (2000). Widening Information Gaps and Policies of Prevention. In Van Dijk, J. and Hacker, K.L. (Eds.) Digital Democracy: Issues of Theory and Practice. Sage Publications, Thousand Oaks, London, pp. 166-183.

Van Dijk, J. and Hacker, K. (2003). The Digital Divide as a Dynamic and Complex Phenomenon. The Information Society, 19: pp. 315-326.

Van Dijk, Jan A.G.M. (2005). The Deepening Divide: Inequality in the Information Society. Sage Publications, Thousand Oaks, CA.

Van Dijk, J.A.G.M. (2006). Digital divide research, achievements and shortcomings. Poetics, 34: pp. 221-235.

Van Dijk, J.A.G.M. (2006). The Network Society: Social Aspects of New Media (2 ${ }^{\text {nd }}$ Ed.). Sage Publications, Thousand Oaks, London.

Vanderheiden, G. C. and Vanderheiden C. R. (1991). A Brief Introduction to the Major Disability Groups and Some Specific Barriers to Accessibility They Encounter. Trace Research and 
Development Centre: University of Wisconsin-Madison. Retrieved on July 15, 2011 from http://trace.wisc.edu

Verschuren, P. and Doorewaard, H. (2005). Designing a Research Project. Lemma: Utrecht.

Vicente, M.R. and Lopez, A.J. (2010). A Multidimensional Analysis of the Disability Digital Divide:

Some Evidence for Internet Use. The Information Society, 26(1): pp. 48-64.

Waddell, C. D. (1999). The Growing Digital Divide in Access for Persons with disabilities: Overcoming Barriers to Participation in the Digital Economy. US Department of Commerce: Washington DC. Retrieved on June $1^{\text {st }} 2011$ from www.icdri.org

Walsham, G. (2005). Learning about being critical. Information Systems Journal, 15: pp. 111-117.

Watling, S. (2011). Digital exclusion: coming out from behind closed doors. Disability and Society, 26 (4): pp. 491-495.

Warschauer, M. (2003). Technology and social inclusion: Rethinking the digital divide, MIT Press, Cambridge, MA.

Wasserman, I.M. and Richmond-Abbot, M. (2005). Gender and the Internet: Causes of Variation in Access, Level and Scope of Use. Social Science Quarterly, 86 (1): pp. 254-270.

Wei, K.K., Teo, H.H., Chan, H.C. and Tan, B.C.Y. (2011). Conceptualizing and Testing a Social Cognitive Model of the Digital Divide. Information Systems Research, 22 (1): pp. 170-187.

Wejnert, B. (2002). Integrating Models of Diffusion of Innovations: A Conceptual Framework. Annual Review of Sociology, 8: pp. 297-326.

Wheeler, D. A. (April 2007). Why Open Source Software / Free Software? Look At The Numbers! Retrieved on November 22, 2010 from http://www.dwheeler.com/contactme.html

Wentz, B. and Lazar, J. (2011). Usability Evaluation of Email Applications by Blind Users. Journal of Usability Studies, 6 (2): pp. 75-89.

Whentz, B., Jaeger, P.T. and Lazar, J. (2011). Retrofitting accessibility: The legal inequality of afterthe-fact online access for PWDs in the United State. First Monday, 16 (11). Retrieved on May 3, 2013: http:/firstmonday.org/htbin/cgiwrap/bin/ojs/index.php/fm/article/viewArticle/ 3666/3077

Woodin, S.L. (2012). Disability: Western Theories. Encyclopedia of Living Sciences (ELS): John Wiley \& Sons Ltd. Retrieved on July $15^{\text {th }} 2012$ from www.els.net

World Health Organization (2001). International Classification of Functioning, Disability and Health. Geneva, World Health Organization.

World Health Organization (2012). Visual impairment and blindness: Fact Sheet N`282. Retrieved on March 10, 2013 from http://www.who.int/mediacentre/factsheets/fs282/en/

Wyatt, S. (2003). Non-Users Also Matter: The construction of users and non-users of the internet. In N. Oudshoorn and T. Pinch (Eds.) How Users Matter: The Co-construction of users and Technology, Cambridge, MA: MIT Press, pp. 67 - 79.

Yanchar, S.C. and Williams, D.D. (2006). Reconsidering the Compatibility Dissertation and Eclecticism: Five Proposed Guidelines for Method Use. Educational Researcher, 35 (9): pp. 3 12.

Yoshikawa, H., Weisner, T.S., Kalil, A. And Way, N. (2008). Mixing Qualitative and Quantitative Research in Developmental Science: Uses and Methodological Choices. The American Psychological Association, 44 (2): pp. 344-354.

Zickuhr, K. and Smith, A. (2012). Digital Differences. Pew Research Center's Internet and American Life Project, Washington, D.C. 


\section{Summary in Dutch}

Informatie- en communicatietechnologieën (ICT) hebben voor een revolutie gezorgd in de manier waarop mensen met elkaar communiceren. ICT biedt ook gehandicapten nieuwe mogelijkheden tot communiceren die met traditionele communicatiemethoden niet mogelijk waren. Maar als ICT niet speciaal ontworpen is voor gehandicapten, dan kan het juist ook een obstakel vormen. Voor gehandicapten in ontwikkelingslanden is dit obstakel tweeledig, aangezien het, naast het ontwerp, alle nadelen heeft die inherent zijn aan de derde wereld, zoals problemen met toegang tot het internet. Omdat gehandicapten een complexe en heterogene groep vormen, zijn ook de mogelijkheden en obstakels eveneens divers en heterogeen. Daarom richt dit proefschrift zich op het ICT gebruik door één specifieke groep, te weten de visueel gehandicapten in Oeganda.

Het doel van dit proefschrift is bij te dragen aan inzicht in mechanismen van digitale uitsluiting. Deze term verwijst naar een gebrek aan toegang tot en gebruik van ICT-middelen. Hiertoe worden de obstakels voor digitale insluiting van visueel gehandicapten onderzocht, omdat er geen eenduidige oplossing bestaat voor de digitale uitsluiting van alle gehandicapten. Een apparaat met internettoegang en touchscreen bijvoorbeeld is wellicht een wonder voor een gebruiker met een gehoorbeperking, maar een nachtmerrie voor een gebruiker met een visuele handicap (Jaeger, 2012). Zo wordt er ondertiteling aangeboden aan mensen met gehoorbeperkingen zodat zij ten volste van digitale televisie kunnen genieten, maar mensen met een visuele handicap hebben audiobeschrijvingen van beelden nodig.

De obstakels voor de insluiting van visueel gehandicapten in de digitale revolutie van Oeganda zijn geanalyseerd op drie niveaus: handicap, persoonlijk en sociaal. Restrictie op het niveau van handicap richt zich op hulpmiddelen die het gebruik bevorderen, in deze thesis ook wel "assistive" technologieën, of hulpmiddelen genoemd. Bij restrictie op persoonlijk niveau werd rekening gehouden met de intrinsieke eigenschappen van visueel gehandicapten waardoor zij geen toegang hebben tot ICT. Op sociaal niveau richtte het onderzoek zich op overheidsregels en -beleid en internationale instrumenten waardoor toegang tot en gebruik van ICT door visueel gehandicapten bemoeilijkt worden. Voor elk van de drie beperkingsniveaus werd de dynamiek van in- en uitsluiting vanuit een specifiek theoretisch kader geanalyseerd. Op het niveau van handicap werd de innovatietheorie van Rogers toegepast, die veronderstelt dat een innovatie via bepaalde communicatiekanalen na verloop van tijd zich verspreidt onder leden van een sociaal systeem (Rogers, 2003). De innovatietheorie van Rogers gaat uit van vijf factoren die van invloed zijn op de acceptatiesnelheid van een innovatie, waaronder de waargenomen eigenschappen van de innovatie, het soort innovatiebesluit, de aard van communicatiekanalen via welke de innovatie zich verspreidt, de aard van het sociale systeem waarin de innovatie zich verspreidt, en de mate waarin "change agents" de verspreiding van de innovatie bevorderen. Al deze vijf factoren zijn geanalyseerd om de obstakels te begrijpen die de verspreiding van assistieve technologieën (schermlezers en schermvergroters) onder visueel gehandicapten in Oeganda 
in de weg staan. Op het persoonlijke niveau werd het cumulatieve en recursieve model van opeenvolgende soorten toegang tot digitale technologieën (Jan van Dijk, 2005) toegepast om verschillende typen beperkingen voor toegang tot ICT door visueel gehandicapten te onderzoeken. Dit model gaat ervan uit dat vier opeenvolgende en accumulatieve soorten toegang - motivatie, materiaal, digitale vaardigheden en gebruik - de stappen vormen die individuele gebruikers moeten nemen in het totale proces van toe-eigening van digitale technologie (Van Dijk, 2005). Tijdens het onderzoek werd duidelijk dat ook het bestaan van maatschappelijke ondersteuning, waarop ook werd gezinspeeld in het ICF-model als onderdeel van omgevingsfactoren, een belangrijke beperking voor toegang vormt en betrekking heeft op alle bovenstaande vier soorten toegang. Op het sociale niveau werd in dit onderzoek de 'critical disability'-theorie toegepast om de rol te weerspreken die de medische en sociale modellen van handicap spelen bij het ontwikkelen van beleid voor de digitale insluiting van visueel gehandicapten. Dit onderzoek richtte zich op de beoordeling of het Universele Toegangsbeleid dat in Oeganda wordt toegepast visueel gehandicapten alles biedt wat zij nodig hebben voor toegang tot en gebruik van ICT.

Dit onderzoek is methodologisch op een 'Mixed Methods Research'-benadering gestoeld. Dit is een categorie van onderzoek waarbij de onderzoeker kwantitatieve en kwalitatieve onderzoekstechnieken, methoden, benaderingen, concepten of talen combineert in één onderzoek (Johnson \& Onwuegbuzie, 2004: p. 17). Er zijn dan ook twee kwantitatieve enquêtes gehouden, gevolgd door kwalitatieve onderzoeken die werden verricht om bepaalde informatie uit de enquêtes te bevestigen en/of uit te leggen. Dit kwam erop neer dat er twee keer veldwerk is verricht in Oeganda - in 2010 en 2011 - waarbij 100 respectievelijk 200 respondenten (ICT gebruikers met een visuele beperking) zijn geënquêteerd en deels geïnterviewd. Daarnaast zijn sleutelinformanten ondervraagd over de rol van ICTdienstverleners (computervaardigheidstrainers, managers/eigenaren van internetcafés, verkopers van ICT-producten, en personeel van service centres van enkele telefoonbedrijven) tijdens het eerste veldwerk; en beleidsexperts (overheidsfunctionarissen op ICT-afdelingen) tijdens het tweede veldwerk.

De conclusies van dit onderzoek kunnen worden samengevat op basis van de drie empirische hoofdstukken van dit proefschrift. De conclusie van het eerste empirische hoofdstuk, waarin de toepassing van assistieve technologieën (hulpmiddelen) werd onderzocht, is dat de mate van blindheid weinig invloed had op de toepassing van deze technologieën door Oegandezen met visuele beperkingen. Slechts twee ondervraagden maakten gebruik van schermvergroters op hun computer en geen van de ondervraagden maakten gebruik van schermvergroters op hun mobiele telefoon; daarentegen stonden 49 van de 100 ondervraagden geregistreerd als slechtziend. Verder vormde betaalbaarheid geen reden voor de meeste ondervraagden om geen gebruik te maken van assistieve technologieën. Daarentegen manifesteert zich wel zeer duidelijk wat Rogers (2003) de 'KAP (Knowledge, Attitude en Practice) gap' noemt, in het feit dat veel ondervraagden niet wisten waar zij deze assistieve technologieën konden kopen. Ook waren velen niet op de hoogte van de verschillende goedkopere opties - geïntegreerde, opensource of freeware - voor het verkrijgen van dergelijke technologieën. 
In het tweede hoofdstuk, waarin de persoonlijke beperkingen voor insluiting van visueel gehandicapten in Oeganda wat betreft digitale technologie werden onderzocht, is de belangrijkste conclusie dat beperkingen in materiaal, vaardigheden en gebruikerstoegang verantwoordelijk waren voor het feit dat visueel gehandicapten weinig gebruik maken van ICT. Een gebrek aan fysieke toegang tot computers en aansluiting op het internet, een gebrek aan digitale vaardigheden en minder mogelijkheden om het gebruik van assistieve technologieën te delen waren van invloed op hoe visueel gehandicapten ICT onderdeel laten uitmaken van hun dagelijkse activiteiten. Bij geen van de ondervraagden in dit onderzoek was er echter sprake van directe beperkingen die te maken hebben met persoonlijke motivatie; allen maakten kenbaar van ICT gebruik te willen maken als zij toegang konden krijgen tot ICT.

In het derde empirische hoofdstuk, waarin onderzocht werd hoe het universele toegangsbeleid in Oeganda ervoor moet zorgen dat visueel gehandicapten toegang krijgen tot ICT, werd geconcludeerd dat Oeganda bij de uitvoering van dat beleid nog onvoldoende aandacht heeft gegeven aan de digitale behoeften van visueel gehandicapten. Dit gold voor alle drie de beginselen van Universele Toegang - betaalbaarheid, beschikbaarheid en toegankelijkheid. Wat betaalbaarheid betreft werd opgemerkt dat de gemiddelde kosten voor een eerste verbinding met een mobiel netwerk en het internet plus de kosten voor lokaal mobiel bellen en een maandelijks abonnement van een internetaanbieder relatief hoog waren en daarmee buiten het bereik lagen van de meeste Oegandezen. De meerderheid van de visueel gehandicapten is werkloos en heeft daarom niet genoeg inkomen om aan dergelijke verplichtingen te voldoen. Bovendien heeft het basisrecht op computerapparatuur, dat is ingevoerd in 2004, geen betrekking op software-licenties; terwijl dat de licenties voor assistieve technologieën betaalbaar zou hebben gemaakt voor visueel gehandicapten. Wat beschikbaarheid betreft hadden de verschillende projecten die door het Rural Communication Development Fund zijn uitgevoerd geen voorzieningen (schermlezers en schermvergroters) voor visueel gehandicapten als speciale groep. Wat toegankelijkheid betreft bleek dat zowel de reactieve als proactieve methodes moeilijk uitvoerbaar waren in Oeganda, omdat het land zelf geen producent van informatie- en communicatietechnologieën is. Bovendien was ten tijde van dit onderzoek de Oegandese ICT-sector nog jong en was de meeste infrastructuur nog niet geïnstalleerd of was nog maar net een begin gemaakt met de installatie hiervan. 


\section{About the author}

Abdul Busuulwa was born with congenital blindness on March 26, 1970 in Namagunga village Uganda. I am the fourth born in a family of five. At the age of four years my mother died, which incident led me into the direct care of my grandmother, the mother of my mother, who took me to school and did for me everything else needed from a parent. About twenty years later, when I was entering the second year at Makerere University, my grandmother also died and it was my elder brother (Ali Lwanga) who took over the responsibility of caring for me. I am currently married with two children - a boy (Abdulswabur Busuulwa) of five years old and a girl (Usrah Nansereko) of two years.

My academic journey began at Bishop Willis Demonstration School for primary, then Iganga Secondary School for both Ordinary level and Advanced level of education. After that I went to Makerere University for a Bachelor of Arts with Mass Communication, then to the Institute of Teacher Education Kyambogo for a Post-Graduate Diploma in Community Based Rehabilitation and to Uganda Management Institute for a Masters of Management Studies (Human Resource Management). One important fact regarding this academic ascent is that I obtained sponsorship from both the government of Uganda and private scholarship institutions throughout the different levels of study, which underscores my character as a hardworking person amid the serious challenges of penury. While at Uganda National Association of the Blind (UNAB) in 2001 I studied for a certificate in computer literacy for the blind. This was probably the first point at which I got introduced to direct use of ICTs.

Before joining the University of Twente for doctoral studies, I spent eight years doing social development work with disabled people's organizations such as UNAB and National Union of Disabled Persons of Uganda (NUDIPU), which sent me to the most rural places of Uganda to train and organize persons with disabilities into viable organizations for purposes of advocating for their rights and engaging in economic empowerment ventures. From my academic pursuits and working experience I gained various skills in writing grant applications, writing conference reports, drafting and editing publications, and training persons with disabilities in Organizational Development skills and advocacy at national and district levels. I have also engaged in several research undertakings, the most recent of which include an Assessment of the Impact of Affirmative Action on the Quality of Life of Persons with Disabilities in Uganda (2009) for National Union of Disabled Persons of Uganda, a retrospective assessment of violence against children with disabilities in Uganda (2009) for African Child Policy Forum - Addis Ababa; and a case study on the Inclusion and Participation of Disabled Persons in Democratic Governance and Decision-Making Structures and Processes in Uganda (2012) for International Institute for Democracy and Electoral Assistance - Stockholm. 


\section{Appendix 1: Questionnaire for respondents with visual disabilities}

\section{Introduction}

I am undertaking a research leading to the award of a $\mathrm{PhD}$ of Sustainable Development (ICT for the Blind) of University of Twente - Netherlands.

My research topic is: Barriers to the Adoption of Screen Readers and Screen Magnifiers by Persons with Visual Disabilities in Uganda

All categories of PWVDs face a lot of challenges in accessing and using Information and Communication Technologies (ICTs), which prompted me to carry out research on how to spread user-friendly ICT products and ensure that PWVDs get to utilize them independent of assistants or guides. This brings in the aspect of universal design, which asserts that all products should be designed in such a way that they are usable by a majority of people irrespective of age, disability or social status.

As a person with visual disability in Uganda, I feel you are one of those who can explain to me the correct experience with ICTs on a daily basis. I therefore kindly request you to respond to the questions below in a frank and exhaustive manner. The information you provide will help me understand the trend the spread of ICT for blind people is taking in Uganda, the factors that influence this spread and what should be done to make the situation better.

Your responses will be treated with the highest degree of confidentiality and used only for purposes of this study. In order to ensure anonymity, you need not disclose your name.

Thank you very much for giving me your precious time and co-operation. I greatly appreciate your help in furthering this research endeavour.

Abdul Busuulwa

Researcher / PhD Candidate

University of Twente, Netherlands 


\section{SECTION A:}

\section{Personal Bio data}

1) Sex: a) Female

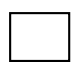

b) male

2) Age bracket in terms of years:
a) $15-24$
b) $25-34$
c) $35-44$
d) 4554
e) 55 - above

3) Your degree of blindness.
a) Totally blind
b) Low vision
c) Functional vision

4) Your highest education level:
a) Uganda Certificate of Education
b) Uganda Advanced Certificate of Education
c) Diploma
d) Degree
e. Any other (Please specify)

5) State your current occupation and the institution you work/study in:

6) In which of the locations below is your work/study institution?
(a) Urban
(b) Rural

7) I believe you consider yourself a member of UNAB. If so, mention some of the norms or practices that bind you to UNAB. 


\section{SECTION B:}

\section{Experience with Computer-Based ICTs}

8) Do you use a computer in your work/studies?
(a) Yes
(b) No

9) For what kind of work/study assignments do you find the computer indispensable?

10) If no to question 8 above, what are your reasons?

11) As a person with visual disability, do you use any special software in order to access the computer?
(a) Yes

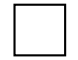
(b) No

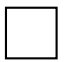

12) If yes, choose the kind of special software you use on your computer from the list below:
a) SuperNova
b) JAWS for Windows
c) Magic
d) ZoomText
e) Any other (Please specify)

13) If no to question 11 above, what are your reasons?
a) Despite my sight deficiency, I can still use a computer without a special software
b) Although I would like to use the special software, I find it too expensive to afford
c) I did not know of any special software until now
d) I cannot install a special software on the computer I use because it is not mine
e) Any other reason (please specify) 
14) What contribution has the special software you selected in question 12 above made to your daily performance of tasks?

a) It has quickened my doing of assignments

b) It has enhanced my degree of independence

c) I produce quality work with no or fewer mistakes

d) Any other (please specify)

15) For how long have you been using the special software you selected?
a) Less than one year
b) 1 to 3 years
c) 4 to 6 years
d) 7 and above years

16) How did you acquire that special software?
a) I got it from the institution I work/study in
b) I bought it from a licensed distributor
c) I got sponsorship from a donor-agency
d) I got the software from a blindness institution
e) Any other (Please specify)

17) How did you know of the existence of such software?
a) Through a friend
b) It was part of my institution's policy
c) Through a promotion exercise
d) Through the media
e) Any other (please specify)

18) Where did you learn to use the special software from?
a) From an ordinary computer training institution
b) From the donor agency which gave me the software
c) From a special training organised by the distributor
d) From a special training organised by the blindness institution
e) Any other (please specify)

19) What computer-related challenges did you encounter in your work/studies before acquiring the special software?
a) Always needed assistance from others in order to use the computer
b) Was unable to use the computer at all
c) Delays in accomplishing tasks
d) Used to produced work with lots of mistakes
e) Any other challenge (please specify) 
20) I believe there are many blind people who still have challenges of accessing and/or using the computer. Suggest ways through which they can overcome these: 


\section{SECTION C:}

\section{Experience with Mobile Phones}

21) Have you been using a mobile phone in your life?
(a) Yes
(b) No

22) If yes, for what tasks do you use the mobile phone?

23) If no to question 21 above, state your reasons:

24) Have you ever used any kind of special software on your mobile phone?
(a) Yes
$\square$
(b) No

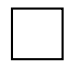

25) If yes, select the type you have used from the list below
a) Talks
b) Mobile Speak
c) ZOOMS
d) Mobile Magnifier
e) Any other (please specify)

26) If no to question 24 above, state the reasons for not using a special software:
a) I found the special software too expensive to afford
b) I did not know of any such software until now
c) I did not see the need for using such software on my mobile phone
d) Any other reason (please specify).

27) If you use a special software, what improvement has it made to your mobile phone?
a) It has made me perform phone-based tasks faster
b) It has enhanced my degree of independence in performing phone-based tasks
c) I no longer make mistakes in any phone-based task
d) Any other (please specify)

28) For how long have you used the special software on your mobile phone?
a) Less than one year
b) 1 to 3 years
c) 4 to 6 years
d) 7 and above years 
29) How did you acquire that special software?
a) I bought it from a licensed distributor
b) I got it from a blindness institution
c) I bought it from an ordinary seller of mobile phones
d) Any other (Please specify)

30) How did you know of the existence of such software?
a) Through a friend
b) Through a promotion exercise
c) Through the media
d) From a blindness institution
e) Any other (please specify)

31) Who taught you how to use the special software?
a) An ordinary mobile phone seller as part of the after-sale service
b) The blindness institution which gave/told me about the software
c) The distributor organised a special training
d) Any other (please specify)

32) What challenges did you encounter with your mobile phone before acquiring the special software?
a) Always needed the support of a sighted guide to perform phone-based tasks
b) Usually performed phone-based tasks with lots of mistakes
c) I could not use the mobile phone at all
d) Any others (please specify)

33) I believe there are many blind people who still have challenges using a mobile phone. Suggest ways through which such challenges can be overcome. 


\section{SECTION D:}

\section{Experience with the Internet}

34) Have you ever used the internet?
(a) Yes
(b) No

35) If yes, where do you access the internet from?
a) From an internet café/computer lab
b) At home
c) At the office
d) Any other (please specify)

36) If no to question 35 above, what could be the possible reasons?

37) If at all you have been using the internet, what tasks do you perform with it?

38) I believe you visit some websites in the course of using the internet. Mention any challenges you have found with such web sites.
a) My special software could not work with it
b) It was hard searching for what I wanted
c) Hyperlinks were not available on the various pages I would wish to view.
d) Any other challenge (please specify)

39) What would you suggest to improve the web site(s) you visited?

\section{Thank You!}




\section{Appendix 2: Interview guide for ICT service providers}

\section{Introduction}

I am undertaking a research leading to the award of a $\mathrm{PhD}$ of Sustainable Development (ICT for the Blind) of University of Twente - Netherlands.

My research topic is: Barriers to the Adoption of Screen Readers and Screen Magnifiers by Persons with Visual Disabilities in Uganda.

Persons with Visual Disabilities face a lot of challenges in accessing and utilisation of Information and Communication Technologies (ICTs), which prompted me to carry out a research on how to spread user-friendly ICT products that PWVDs can use independently. This brings in the aspect of universal design, which asserts that all products should be designed in such a way that they are usable by a majority of people irrespective of age, disability or ability.

Your involvement in this research stems from the fact that you offer one of the key services to the public, PWVDs inclusive, and ICTs are the component of your service I would like to focus on. You could be an owner/manager of an internet café, a worker in a mobile phone service station, ICT trainer or an importer of certain ICT products. I therefore feel you can, using your general experience with ICTs, assist me to understand the appropriateness of ICTs in Uganda for Persons with Visual Disabilities. In that regard, I kindly request you to respond to the questions below in a frank and exhaustive manner. Your responses will be treated with the highest degree of confidentiality and used only for this study. You need not to disclose your name.

Thank you very much for giving me your precious time and co-operation!

Abdul Busuulwa

Researcher / PhD Candidate

University of Twente, Netherlands 


\section{Interview Guide for Informants}

1) Name of your organisation.

2) State the kind of ICT-related service you render to the public.

3) In which kind of location is your work station?
(a) Urban

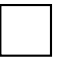
(b) Rural

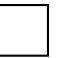

4) As a service provider, what is your role in spreading ICTs around the country? (Let the interviewee explain in accordance with the service he/she renders).

5) In the course of your work, do you serve clients with visual disability?
(a) Yes
(b) No

6) If yes, for how long have you been serving such clients?
a. Less than one year
b. 1 to 3 years
c. 4 to 6 years
d. 7 and above years

7) By way of estimation, how many clients with visual disability have benefited from your service? (Ask for some records backing up the claim)

8) If no to question 5 above, what could be the possible reasons?

9) What consideration have you put in place to ensure that your service is accessible to a user with visual disability? 
10) How did you know of such a consideration you have mentioned above?
a) Through a friend
b) I derived it from my own knowledge of ICTs
c) I had ever seen the modification I have mentioned work elsewhere
d) I read/heard about it in the media
e) Any other (please specify)

11) How did you make the clients with visual disability benefit from your consideration?
a) I taught them myself
b) I requested for a special training from a blindness organisation
c) I simply told them about what I put in place and they were able to cope on their own
d) Probe for any other alternatives (noting them in the space below).

12) What challenges did you register from clients with visual disability as regards ICTs in your service before making any special consideration for them?

13) How did any of the challenges you mentioned above affect your service?
a) Reduction of clientele
b) I realised no effect on my clientele
c) Any other effect (please explain)

14) Considering the present with the past, explain the change in the cost of offering special considerations in your service:

15) Government has put in place incentives for ensuring that ICTs becomes part and parcel of national development priorities. Do you know of any?
(a) Yes
(b) No

16) If yes, mention those you know--showing their relevance to your service.

17) I believe you have heard of PWVDs who have had challenges of accessing your service. Suggest ways through which these can be overcome: 


\section{Appendix 3: Letter for Abdul}

\section{UNIVERSITY OF TWENTE}

To whom it may concern

FACULTY OF MANAGEMENT AND GOVERNANCE

Twente Centre for Studies in Technology and Sustainable Development (CSTM)

YOUR REF

OUR REF: CSTM 050-11-j1

DATE: $\quad 25$ August 2011

PHONE +31(0)53-4893533

FAX +31(0)53-4894850

EMAIL: j.c.lovett@utwente.nl

\section{SUBJECT:}

This letter is to confirm that Abdul Busuulwa, born 26 March 1970, is conducting research for his $\mathrm{PhD}$ studies at CSTM, School of Management and Governance, University of Twente, The Netherlands on: "Appropriate information and communication technology for blind people in Uganda"

I would be very grateful if you could give him every assistance in pursuance of his studies.

With many thanks for your help.

Yours faithfully

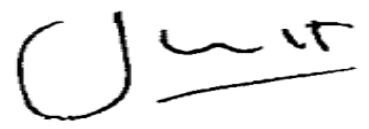

Jon Lovett

Professor of Technology and Sustainable Development, CSTM - Twente Centre for Studies in Technology and Sustainable Development

P.O. Box 217, 7500 AE Enschede

The Netherlands www.utwente.nlimb/ostm

University of Twente (UT) is registered at the Dutch Chamber of Commerce under Cr. 501395360000 


\section{Appendix 4: Survey questionnaire for respondents with visual disabilities}

\section{Please tick or fill in the most appropriate answer(s)}

\section{SECTION A:}

\section{Personal Bio data}

1. Gender: a) Female

b) male

2. Age bracket in terms of years:
a) $15-24$
b) $25-34$
c) $35-44$
d) $45-54$
e) 55 and above

3. Your education level:
a) Uganda Certificate of Education
b) Uganda Advanced Certificate of Education
c) Diploma
d) Degree
e) Any other (Please specify)

4. State the occupation category your current designation lies:
a) Senior Management
b) Programme/Project Officer
c) Education Officer
d) Student
e) Have no occupation

5. State the institution you work/study in.

6. Select your income bracket from the following:
a) UShs $100,000-500,000$
b) UShs $600,000-1,000,000$
c) UShs $1,100,000-1,500,000$
d) UShs $1,600,000-2,000,000$
e) None of the above

7. Are there activities you would wish to participate in but are restricted by your local community by virtue of your disability?

(a) Yes (b) No

8. If yes, mention some of them. 


\section{SECTION B:}

\section{Experience with ICTs}

9. Tick any of the following ICTs in which you have skills:
a) Personal computer
b) Mobile phone
c) The internet

10. State the year when you started using the ICT you selected above.

11. In case you are not literate in any of the ICTs above, what could be your reasons?

12. In case you are computer or internet-literate, explain how UNAB assisted you in acquiring such ICT skills.

13. If you did not acquire ICT skills from UNAB, mention any other organisation/association and explain how it assisted you to get such skills.

14. Where do you usually access the personal computer?
a) at place of work
b) at home
c) at a public computer centre/café
d) Any other (Please specify)

15. Where do you usually access the internet?
(a) At place of work/study
(b) At a public computer centre/internet café
(c) Any other (Please specify)

16. Where do you usually access the mobile phone for communication
(a) personal
(b) borrow from a friend/colleague/relative
(c) Use public pay phone
(d) Any other (please specify)

17. Explain how affordable you find using any of the ICTs you selected in question 11 for communication. 


\section{Appendix 5: Interview protocol for respondents conversant with ICTs}

\section{Please provide the appropriate answer(s) as exhaustively as you can}

\section{SECTION A:}

Experience with a Personal Computer

1) Through what way did you learn using a computer?

a. through training at a Computer training centre

b. I taught myself using the manual

c. I learnt with help from a friend/colleague

d. Any other (please specify)

2) What Challenges did you face when learning computer?

3) How did you overcome the challenges you mentioned above?

4) State any challenges you still find with using a computer.

5) State the computer packages you are conversant with.

6) What benefits do you associate with using the computer?

7) I believe you know of some blind people still facing challenges with the computer. What do you suggest in order to overcome such challenges? 


\section{SECTION B:}

\section{Experience with Mobile Phones}

8) Through what ways did you learn using a mobile phone?

a. Through a mobile phone seller as part of after-sale service

b. I learnt it myself using the manual

c. I learn through help from a friend/colleague of mine

d. Any other (please specify)

9) What communication activities do you regularly do with a mobile phone?

10) What challenges did you experience in learning to use the mobile phone?

11) How did you overcome the challenges you mentioned above?

12) What Challenges do you still face communicating with the mobile phone?

13) What benefits do you associate with communicating using a mobile phone?

14) I believe you know some blind people who face challenges with using mobile phones. Suggest ways through which they can overcome them. 


\section{SECTION C:}

\section{Experience with the Internet}

15) Through what way did you learn using the internet?

a. through training at a Computer training centre

b. I taught myself

c. I learnt with help from a friend/colleague

d. Any other (please specify)

16) What activities do you undertake using the internet?

17) How regularly do you use the internet?
a. everyday
b. once a week
c. once in a long while (two weeks and beyond).

18) What challenges did you experience when learning the internet?

19) How did you overcome the challenges you mentioned above?

20) What Challenges do you still face with the internet?

21) What benefits do you associate with using the internet?

22) As someone with visual impairment, explain how you go about such intricacies as entering a user name, password, etc. 


\section{SECTION D:}

Computer and Internet Self-Efficacy

23) Computer Self-Efficacy Scale

The following statements are intended to gauge your confidence levels in using a computer. Please indicate your response by ticking in the box that corresponds with your confidence level from the five alternatives provided against each statement in the table below. The first box is 'Not at all confident', the second is 'not confident', the third is 'do not know', the fourth is 'moderately confident' and the fifth is 'totally confident'.

I feel confident:

\begin{tabular}{|l|l|l|l|l|l|l|}
\hline No. & \multicolumn{1}{|c|}{ Statement } & 1 & 2 & 3 & 4 & 5 \\
\hline 1 & Working on a personal computer & & & & & \\
\hline 2 & Getting software up and running & & & \\
\hline 3 & $\begin{array}{l}\text { Entering and saving data (numbers and words) into a } \\
\text { file }\end{array}$ & & & & \\
\hline 4 & Exiting from the programme (software) & & & & & \\
\hline 5 & Calling up a data file to view on the monitor screen & & & & & \\
\hline 6 & $\begin{array}{l}\text { Understanding terms/words relating to computer } \\
\text { hardware }\end{array}$ & & & & \\
\hline 7 & $\begin{array}{l}\text { Understanding terms/words relating to computer } \\
\text { software }\end{array}$ & & & & \\
\hline 8 & Learning to use a variety of programmes (software) & & & & & \\
\hline 9 & Using a printer to make hard copies of my work & & & & & \\
\hline 10 & Copying a disc & & & & & \\
\hline 11 & Copying an individual file function of computer hardware & & & & & \\
\hline 12 & Adding and deleting information from a data file & & & & & \\
\hline 13 & Using the computer to write a letter or essay & & & & \\
\hline 14 & $\begin{array}{l}\text { Describing the funcs } \\
\text { (keyboard, monitor, disc drives) }\end{array}$ & $\begin{array}{l}\text { Understanding the three stages of data processing- } \\
\text { (input, processing and output) }\end{array}$ & & & & \\
\hline 15 & Getting help for problems in the computer system & & & & & \\
\hline 16 & Storing software correctly & & & & & \\
\hline 17 & Using the computer to organize information & & & & \\
\hline 18 & Getting rid of files when they are no longer needed & & & & & \\
\hline 19 & Organising and managing files & & & & \\
\hline 20 & & & & & & \\
\hline
\end{tabular}


24) Internet Self-Efficacy Scale

The following statements are intended to gauge your confidence levels in using the internet. Please indicate your response by ticking in the box that corresponds with your confidence level from the five alternatives provided against each statement in the table below. The first box is 'Not at all confident', the second is 'not confident', the third is 'do not know', the fourth is 'moderately confident' and the fifth is 'totally confident'.

I feel confident:

\begin{tabular}{|c|c|c|c|c|c|c|}
\hline No. & Statement & 1 & 2 & 3 & 4 & 5 \\
\hline 1 & Understanding terms relating to Internet hardware. & & & & & \\
\hline 2 & Understanding terms relating to Internet software. & & & & & \\
\hline 3 & Describing functions of Internet hardware. & & & & & \\
\hline 4 & Navigating through the world wide web by myself. & & & & & \\
\hline 5 & Using the internet to search for any kind of information. & & & & & \\
\hline 6 & Obtaining entertainment on the internet. & & & & & \\
\hline 7 & Trouble shooting Internet problems. & & & & & \\
\hline 8 & Explaining why a task would not run on the Internet. & & & & & \\
\hline 9 & Learning advanced skills within a specific Internet program. & & & & & \\
\hline 10 & Asking for help from a friend via the internet. & & & & & \\
\hline
\end{tabular}




\section{Appendix 6: Interview guide for knowledge experts}

1) What is the name of your organisation?

2) State your designation in that organisation.

3) What strategies and/or projects has Government of Uganda put in place to promote the use of ICTs (computer, telephone and the internet) by vulnerable groups such as people with visual impairment?

4) What mechanisms does Uganda use to fund Universal Access ventures?

5) What are the means through which people apply for funds from the RCDF so as to start an Internet connection or telecommunications project?

6) What sort of projects has the RCDF supported so far?

7) What evidence exists that persons with disabilities have ever applied for funds from the RCDF?

8) If none has ever applied for funds from the RCDF, what might have been the reason?

9) What modalities have been put in place to correct this anomaly?

10) What do laws and policies on ICTs provide for ensuring that web content is accessible to all, including people with visual impairment?

11) What international standards does Uganda follow to ensure accessibility of telecommunication services?

12) What internet connectivity challenges does Uganda still face today?

13) What gaps in legislation do you think still exist in order to make ICTs (Computer, Telephone and the internet) affordable for all?

14) Several services can now be obtained via SMS. What safeguards has Uganda put in place to ensure that such services are affordable to all Ugandans?

Thank you! 